\title{
Untersuchung der Differenzierungskapazität von Osteoblasten und Osteoblastensubpopulationen in vitro und ihre Beeinflussung durch verschiedene Wuchsfaktoren
}

\author{
Dissertation \\ Zur Erlangung des Doktorgrades \\ der Mathematisch-Naturwissenschaftlichen Fakultäten \\ der Georg-August-Universität zu Göttingen
}

\author{
vorgelegt von \\ María Laura Ponce \\ aus
}

Buenos Aires / Argentinien

Göttingen 2005 
D7

Referent: Prof. Dr. R. Hardeland

Korreferent: Prof. Dr. F.W. Schürmann

Tag der mündlichen Prüfung: 28. 06. 2005 
Die Natur ist schlau. Sie setzt durch, was sie will. Und warum? Weil sie gerissen ist!

Bertolt Brecht

Für meine Eltern 
I. Einleitung . . . . . . . . . . . . . . . 1

I.1. Das Skelett als biomechanische Struktur ～. . . . . . . . . . . . . .

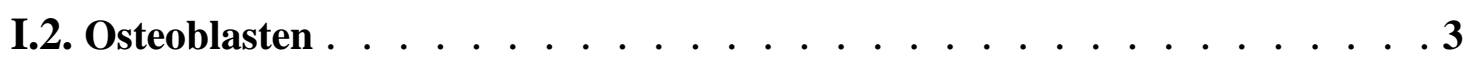

I.2.1 Zentrale Rolle des Osteoblasten in der lokalen Knochenresorption $\quad 3$

I.2.2. Die Osteoblasten-Familie 4

I.2.3. Osteoblasten und mesenchymale Stammzellen 6

I.2.4. Osteoblastäre Differenzierung in Kultur 8

I.3. Biochemie der Knochenmatrix . . . . . . . . . . . . . . . . . 9

I.4. Bedeutung des pHOB-Systems als Osteoblastendifferenzierungsmodell . . 10

I.5. Plastizität zwischen Osteoblasten und Adipozyten . . . . . . . . . 11

$\begin{array}{ll}\text { I.5.1. Basis der Transdifferenzierung } & 11\end{array}$

I.5.2. Marker zur Charakterisierung der Transdifferenzierung zu Adipozyten

$\begin{array}{lr}\text { I.5.2.1. PPAR } \gamma 2 & 12\end{array}$

$\begin{array}{ll}\text { I.5.2.2. Lipoproteinlipase } & 13\end{array}$

$\begin{array}{ll}\text { I.5.3. Differenzierungsfaktoren } & 15\end{array}$

$\begin{array}{lr}\text { I.5.3.1. Vitamin C } & 15\end{array}$

$\begin{array}{ll}\text { I.5.3.2. Vitamin } D_{3} & 15\end{array}$

I.5.3.3. $\beta$-Glycerophosphat 16

$\begin{array}{ll}\text { I.5.3.4. Glukokortikoide } & 16\end{array}$

$\begin{array}{ll}\text { I.5.3.5. „Transforming Growth Factor }-\beta 1^{“} & 17\end{array}$

I.5.3.6. Bone Morphogenetic Proteins (BMPs) 18

$\begin{array}{ll}\text { I.5.3.7. IBMX (3-Isobutyl-1-Methylxanthin) } & 18\end{array}$

I.6. Bedeutung der Transdifferenzierung für den pathologischen Knochenverlust . . . . . . . . . . . . . . . . . . . 19

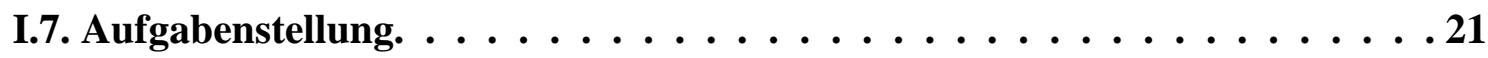


II. Material und Methoden. . . . . . . . . . . . . . 23

II.1 Material . . . . . . . . . . . . . . . . . 23

II.1.1 Zellmaterial $\ldots \ldots \ldots \ldots \ldots \ldots \ldots \ldots$

II.1.1.1 Primäre humane Osteoblasten (pHOB) 23

II.1.1.2. Humane immortalisierten Osteoblastenzellinie (AHTO) 23

II.1.2. Basismedien, Zusätze, Chemikalien und Kits . . . . . . . . . . 24

II.1.3. Medien und Lösungen $\quad 25$

$\begin{array}{ll}\text { II.1.4 Antikörper } & 28\end{array}$

$\begin{array}{ll}\text { II.1.5 Geräte } & 28\end{array}$

II.1.6. Zellkulturgefäße und Hilfsmittel 29

II.2. Methoden der Zellkultur . . . . . . . . . . . . . . . . 30

II.2.1. Anlegen einer Primärkultur aus humanen Knochen 30

II.2.2. Ablösung durch Trypsinierung

$\begin{array}{ll}\text { II.2.3. Passagierungsmethoden } & 31\end{array}$

II.2.4. Einfrieren von Knochenzellen $\quad 32$

II.2.5. Auftauen von Knochenzellen $\quad 32$

II.2.6. Vitalitätstest mit Trypanblau $\quad 32$

II.3. Durchflußzytometrie (FACS) . . . . . . . . . . . . . . . 32

II.3.1. Vorbereitung von Zellen auf eine FACS Analyse 34

II.3.1.1. Proteinnachweise $\quad 34$

II.3.1.2. Autofluoreszenzansatz 35

II.3.1.3. Hintergrundansatz 35

II.3.2. FACS-Zellanalyse $\quad 35$

II.3.3. Grenzwertbestimmung $\quad 35$

$\begin{array}{ll}\text { II.3.4. Auswertung } & 38\end{array}$

II.4. Magnetische Zellsortierung (MACS) . . . . . . . . . . . . . 38

II.4.1. Markierung der pHOB-Zellen für die magnetische Zellsortierung 38 
II.4.2. Magnetische Zellsortierung

II.5 Fluoreszenzaktivierte Zellsortierung (FACS Sorting) . . . . . . . . . 43

II.5.1 Markierung der pHOB-Zellen für die FACS Sorting 45

II.6. Nachweis osteoblastencharakteristischer Marker. . . . . . . . . . . . 46

II.6.1. Enzymaktivität der Alkalische Phosphatase 46

II.6.1.1. Assay zum Nachweis der AP-Aktivität im Zellpellet 46

II.6.1.2. Zytochemische Färbung zur Nachweis der AP-Aktivität 46

$\begin{array}{ll}\text { II.6.2. Kollagen-I Sekretion } & 47\end{array}$

$\begin{array}{ll}\text { II.6.3. Osteokalzinsekretion } & 47\end{array}$

II.6.4. Mineralisationsnachweis (Alizarinrot-Färbung) 47

II.7. Histologischer Nachweis von Adipozytendifferenzierungsmarkern . . . . . 48

$\begin{array}{ll}\text { II.7.1. Oil Red O-Färbung } & 48\end{array}$

II.8. Molekularbiologische Methoden zur Bestimmung der Genexpression . . . 49

$\begin{array}{ll}\text { II.8.1. Isolierung von RNA } & 49\end{array}$

II.8.2. Photometrische Bestimmung der RNA 49

II.8.3. Reverse Transkriptase-PCR (RT-PCR)-Synthese von cDNA 49

II.8.4. Polymerase-Kettenreaktion (PCR) $\quad 50$

II.8.4.1. Semi-quantitative PCR $\quad 51$

II.8.4.2. Herstellung interner Standards (Mimics) 51

II.8.4.3. Semiquantitative PCR 53

II.8.4.4. Nachweis der Produkte 53

II.8.5. „Housekeeping“-Gen $\quad 54$

II.8.6. Primersequenzen und Amplifizierungsprogramme 54

II.9. Direkte Immunogoldzytochemie / Elektronenmikroskopie . . . . . . . . . 56

II.9.1. Fixierung und Einbettung der Zellen für die

Elektronenmikroskopie

II.9.2. Anfertigung von Ultradünnschnitten für die 
Elektronenmikroskopie $\quad 56$

II.9.3. Herstellung von kolloidalem Gold $\quad 57$

II.9.3.1. Kolloidales Gold mit einem Durchmesser von 8 nm $\quad 57$

II.9.3.2. Kolloidales Gold mit einem Durchmesser von 16 nm $\quad 57$

II.9.4. Antikörper-Gold-Kopplung $\quad 57$

II.9.5. Inkubationsbedingungen für den Proteinnachweis 58

II.9.5.1. Einzelmarkierungen $\quad 58$

II.9.5.2. Doppelmarkierung

II.9.6. Kontrastierung $\quad 59$

$\begin{array}{ll}\text { II.9.7. Kontrollen } & 60\end{array}$

II.10. Stimulationsversuche . . . . . . . . . . . . . . 61

II.10.1. Induktion der Adipogenese in der immortalisierten

Osteoblastenzellinie AHTO und in pHOB Zellen 61

II.10.2. Stimulation von pHOB Zellen mit BMP-2 61

II.10.3. Untersuchung der Plastizität AP-negativer Subpopulationen von pHOB Zellen $\quad 62$

II.10.4. Langzeitstimulation von pHOB Zellen mit TGF- $\beta 1$ und BMP-2 63

II.10.5. Stimulation der pHOB Zellen für die Immunogoldzyto chemische/ Elektronenmikroskopische Analyse $\quad 64$

II.11. Statistische Methoden . . . . . . . . . . . . . . . . . . . 64

III. Ergebnisse . . . . . . . . . . . . . . . . . . . . . . . . .

III.1. Untersuchung zur Induktion der Adipogenese unter IBMX plus

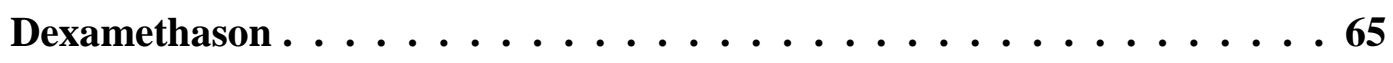

III.1.1. Induktion der Adipogenese in pHOB Zellen 65

III.1.1.1. Histologische und zytochemische Analyse 65

III.1.1.2. Wirkung auf die Genexpression $\quad 67$ 
III.1.2. Untersuchungen zur Induktion der Adipogenese an der immortalisierten Osteoblastenzellinie AHTO

III.1.2.1. Histologische und zytochemische Analyse

III.1.2.2. Wirkung auf die Genexpression

III.2. Untersuchung zur Expression adipozytärer und osteoblastärer Marker in pHOB Zellen unter Stimulation mit BMP-2 . . . . . . . . . . . . 72

III.3. Untersuchung der Plastizität homogener Subpopulationen von pHOB Zellen . . . . . . . . . . . . . . . . . . 74

III.3.1. Magnetische Zellsortierung AP-negativer Zellen

III.3.2. Untersuchung des Differenzierungspotential AP-negativer Zellen 78

III.3.2.1. Histologische und zytochemische Analyse 78

III.3.2.2. Quantifizierung der AP-Enzymaktivität 81

III.3.2.3. Kollagen I Sekretion in den AP-negativen Zellen 82

III.3.2.4. Osteokalzinsekretion in den AP-negativen Zellen

III.3.2.5. Genexpression adipozytärer Marker in den

AP-negativen Zellen

III.4. Untersuchung der Genexpression adipozytärer Marker in den mittels

FACS Sorting isolierten AP-Subpopulationen aus pHOB Zellen . . . . . 85

III.4.1. Isolierung von AP Subpopulationen mittels FACS Sorting

III.4.2. Basale Genexpression adipozytärer Marker in den AP

Subpopulationen

III.5. Langzeitwirkung von TGF $\beta-1$ und BMP-2 auf die Adipogenese und die Osteogenese in pHOB Zellen . . . . . . . . . . . . . . . 90

III.6. Ultrastrukturalle elektronmikroskopische Lokalisation adipozytärer und osteoblastärer Marker auf Einzellzellniveau in pHOB Zellen . . . . . . . 92 
IV. Diskussion . . . . . . . . . . . . . . . 94

IV.1. Untersuchung zur Induktion der Adipogenese . . . . . . . . . . . 94

IV.1.1. Induktion der Adipogenese in primären humanen

Osteoblasten

IV.1.2. Induktion der Adipogenese in der AHTO Zellinie

IV.2. Effekt von BMP-2 auf die adipozytären Marker in primären humanen Osteoblasten . . . . . . . . . . . . . . . 97

IV.3. Untersuchung der Plastizität in Subpopulationen primärer humaner Osteoblasten . . . . . . . . . . . . . 99

IV.3.1. Expression osteoblastärer Marker in den AP-negativen Zellen

IV.3.2. Genexpression adipozytärer Marker in den AP-negativen Zellen

IV.4. Basale Genexpression adipozytärer Marker in den mittels FACS Sorting isolierten AP-Subpopulationen . . . . . . . 105

IV.5. Langzeitwirkung von BMP-2 und TGF- $\beta 1$ auf die Adipogenese und die Osteogenese in primären humanen Osteoblasten . . . . 106

IV.6. Ultrastrukturalle elektronenmikroskopische Lokalisation adipozytärer und osteoblastärer Marker auf Einzellzellniveau in primären humanen Osteoblasten . . . . . . 107

IV. 7. Ausblick . . . . . . . . . . . . . . . . 110

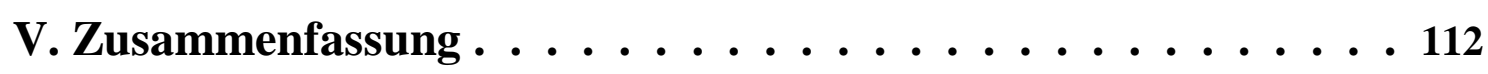

VI. Literaturverzeichnis . . . . . . . . . . . . . . 115 


\begin{tabular}{|c|c|}
\hline Abb. & Abbildung \\
\hline AHTO & ,adult human trabecular osteoblastic cells“ \\
\hline Ak. & Antikörper \\
\hline AP & alkalische Phosphatase \\
\hline BAP & bone alkaline phosphatase \\
\hline BGP & Osteokalzin (bone GLA protein) \\
\hline BMP & "Bone Morphogenetic Protein" \\
\hline BSA & Bovines Serumalbumin \\
\hline CBFA-1 & “core binding factor alpha 1" (Runx 2) \\
\hline cDNA & komplementäre DNA \\
\hline $\mathrm{C} / \mathrm{EBP}$ & „CCAT enhancer-binding protein““ \\
\hline CICP & Carboxiterminale Propeptid \\
\hline $\mathrm{CMF}$ & Calcium und Magnesium frei \\
\hline DMEM & Dulbeccos Minimal Essential Modifikation (Medium) \\
\hline DMSO & Dimethylsulfat \\
\hline EDTA & Ethylendiamintetraacetat \\
\hline ELISA & „enzyme linked immunosorbent assay“ \\
\hline ETOH & Ethanol \\
\hline FA & Formaldehyd \\
\hline FACS & Durchflußzytometrie („fluorescence activated cell analyser“) \\
\hline FCS & Fetales Kälberserum („fetal calf serum“) \\
\hline FITC & Fluoresceinisothiocyanat \\
\hline FL1 & Fluoreszenz 1 \\
\hline FSC & forward scatter (Vorwärtsstreulicht) \\
\hline $\mathrm{g}$ & Vielfaches der Fallbeschleunigung (x 9,8 m/ $\left.\mathrm{sec}^{2}\right)$ \\
\hline GLA & Gamma-Carboxyglutaminsäurerest \\
\hline h & Stunde(n) \\
\hline $\mathrm{HOB}$ & humanen Osteoblasten \\
\hline HOS & human osteosarcoma (humanes Osteosarkom) \\
\hline IBMX & 3-Isobutyl-1-Methylxanthin \\
\hline Koll I & Kollagen I \\
\hline LPL & Lipoproteinlipase \\
\hline MACS & magnetische Zellsortierung (magnetic cell sorting) \\
\hline $\min$ & Minute \\
\hline M-MLV & Moloney-mouse leukemia virus (Moloney Mäusenleukämievirus) \\
\hline mRNA & messenger RNA \\
\hline $\mathrm{OC}$ & Osteokalzin (bone GLA protein) \\
\hline OD & optische Dichte \\
\hline OPG & Osteoprotegerin \\
\hline OPG-L & Osteoprotegerin-Ligand \\
\hline
\end{tabular}




$\begin{array}{ll}\text { OSX } & \text { Osterix } \\ \text { PCR } & \text { Polymerase-Kettenreaktion (,polymerase chain reaction“) } \\ \text { pHOB } & \text { primäre humane Osteoblasten (,primary human osteoblasts“) } \\ \text { PBS } & \text { phosphatgepufferte Salzlösung (,phosphate buffered saline“) } \\ \text { Pen } & \text { Penizillin } \\ \text { PPAR } & \text { "peroxisome proliferator activated receptor” } \\ \text { PTH } & \text { Parathormon } \\ \text { RANK } & \text { Receptor activator of NF-kappa B } \\ \text { RT } & \text { Raumtemperatur } \\ \text { RT-PCR } & \text { Reverse Transkription- PCR } \\ \text { Smad } & \text { Mothers-against-decantaplegic-related proteins } \\ \text { SSC } & \text { Seitwärtsstreulicht (,sideward scatter“) } \\ \text { Strep } & \text { Streptomyzin } \\ \text { SV } & \text { Säulenvolumen } \\ \text { Tab. } & \text { Tabelle } \\ \text { TBS } & \text { Tris Borat Salzlösung } \\ \text { TG-13 } & \text { Thyreoglobulin 13 } \\ \text { TGF } & \text { Transforming growth factor } \\ \text { TNF } & \text { Tumor necrosis factor } \\ \text { TZD } & \text { Thiazolidinedione } \\ & \end{array}$




\section{Einleitung}

Das Skelett ist ein effizientes System, das ständig Signale empfängt und integriert. Durch die zeitlebens ablaufende Funktion dieses Systems wird die Anpassung an geänderte funktionelle Bedingungen sowie die lebenslange mechanische Stabilität des Skeletts gewährleistet. Trotz seiner Festigkeit stellt der Knochen überraschenderweise ein sehr dynamisches Gewebe dar, welches von ständiger Auflösung und Neubildung (Knochenremodeling) geprägt ist.

Dabei handelt es sich um einen komplexen Prozess, der zum einen von endokrinen, parakrinen und autokrinen Faktoren, zum anderen von der direkten Interaktion zwischen Osteoblasten und Osteoklasten abhängig ist. Durch das fein abgestimmte Zusammenspiel von Aufbau- und Abbauvorgängen erfolgt ein lebenslang anhaltender Knochenumbau. Einen Eindruck über die Faktoren, die zur physiologischen Homöostase dieses Systems (Harada \& Rodan, 2003) beitragen, vermittelt die Abbildung 1.

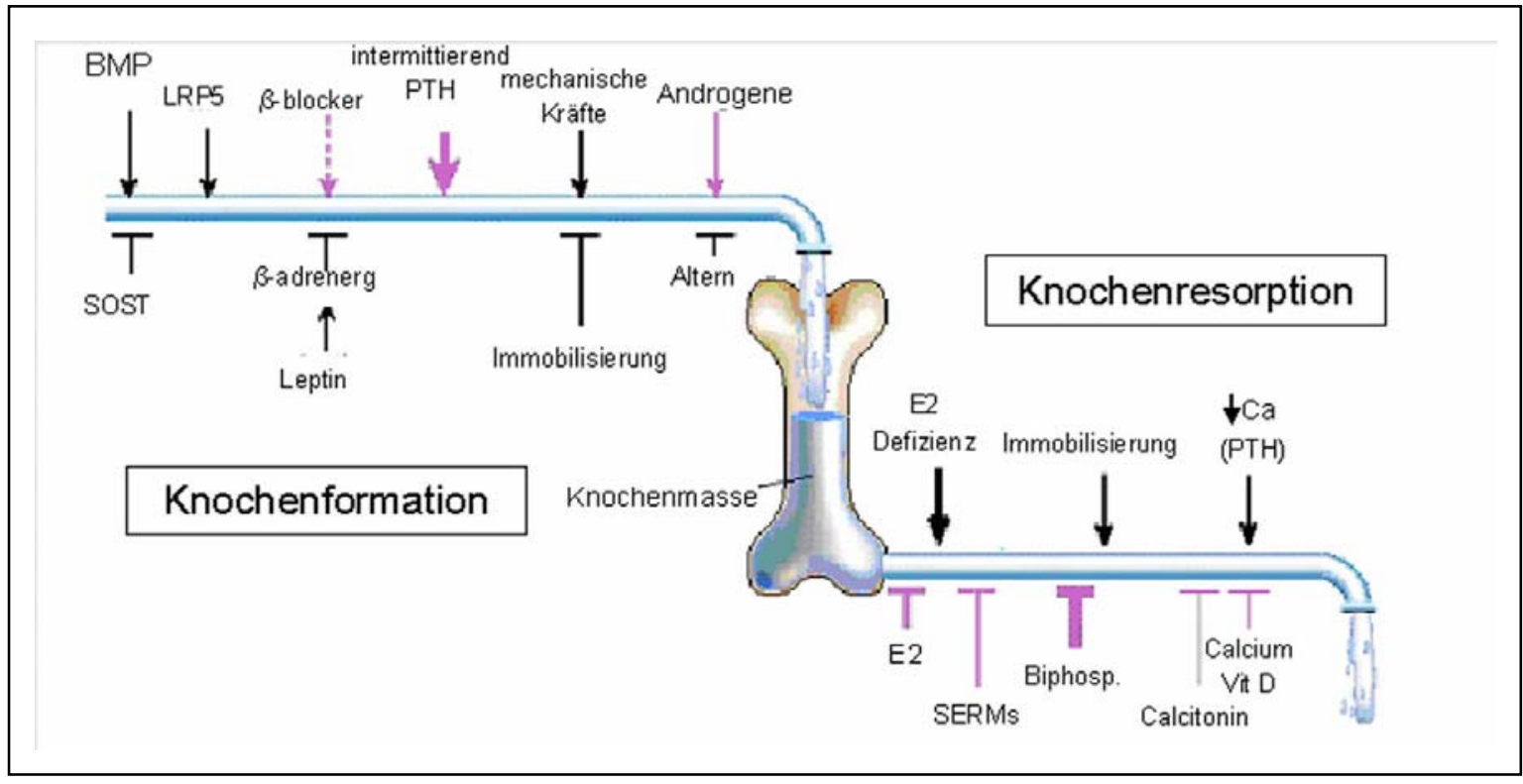

Abb. 1: Schematische Darstellung (modifiziert nach Harada \& Rodan, 2003) des Skeletts als "servo"System. Die physiologischen (schwarz) und pharmakologischen (lila) Stimulatoren und Inhibitoren werden empfangen und integriert. Der relative Einfluss wird durch die Dicke der Pfeile dargestellt. Durchgezogene Pfeile repräsentieren aktuelle nachgewiesene und gestrichelte Linien eventuelle Einflüsse. Abkürzungen: BMP: "bone morphogenetic protein", SOST: "sclerostin", LRP5: "low-densitiy lipoprotein (LDL)-receptor-related protein 5", PTH: Parathormon, Vit. D: 1,25-(OH)2-D3; E2: Östrogen, SERM: selective Östrogen-Rezeptor Modulator, Biphosp.: Biphosphonate.

\section{I.1. Das Skelett als biomechanische Struktur}

Von dem Standpunkt der Biomechanik aus kann das Skelett als eine biomechanisch regulierte Struktur ("mechanostat theory" von Frost, 1987) betrachtet werden, deren Kraft von der inneren Festigkeit und Architektur des Baumaterials (mineralisiertes Gewebe) abhängt (Ferretti et al. 
2003). Von diesem Standpunkt aus betrachtet existiert ein biomechanisches Feedback dieses Systems, das durch die Modulation des Knochenumbaus, d.h. die Qualität und Architektur des Baumaterials, die Knochenfestigkeit optimiert.

In der Abbildung 2 wird der Knochen als biomechanische regulierte Struktur dargestellt, in der das Knochenremodeling auf ein koordiniertes Zusammenspiel zwischen Osteoblasten, Osteozyten und Osteoklasten zurückzuführen ist.

Die Kooperation zwischen diesen Zelltypen ist die Basis für die biomechanische Anpassung des Knochengewebes, wobei folgende Hinweise für eine Hauptrolle der Osteozyten als mechanosensorielle Zellen sprechen (Aarden et al. 1994; Knothe Tate et al. 2004): 1) Die Osteozyten repräsentieren den überwiegenden Teil der Zellen der Osteoblasten-Familie im Knochen und sind in der mineralisierten Knochenmatrix regelmäßig verteilt. 2) Osteozyten kommunizieren über Psedudopodien via „gap junction“ miteinander, mit Osteoblasten und auch mit den Zellen auf der Knochenoberfläche („,bone lining cells“). 3) Dieses Netzwerk spielt durch den Kontakt zwischen Membran und mineralisierter Knochenmatrix eine wichtige Rolle in der Ionen-Homöostase.

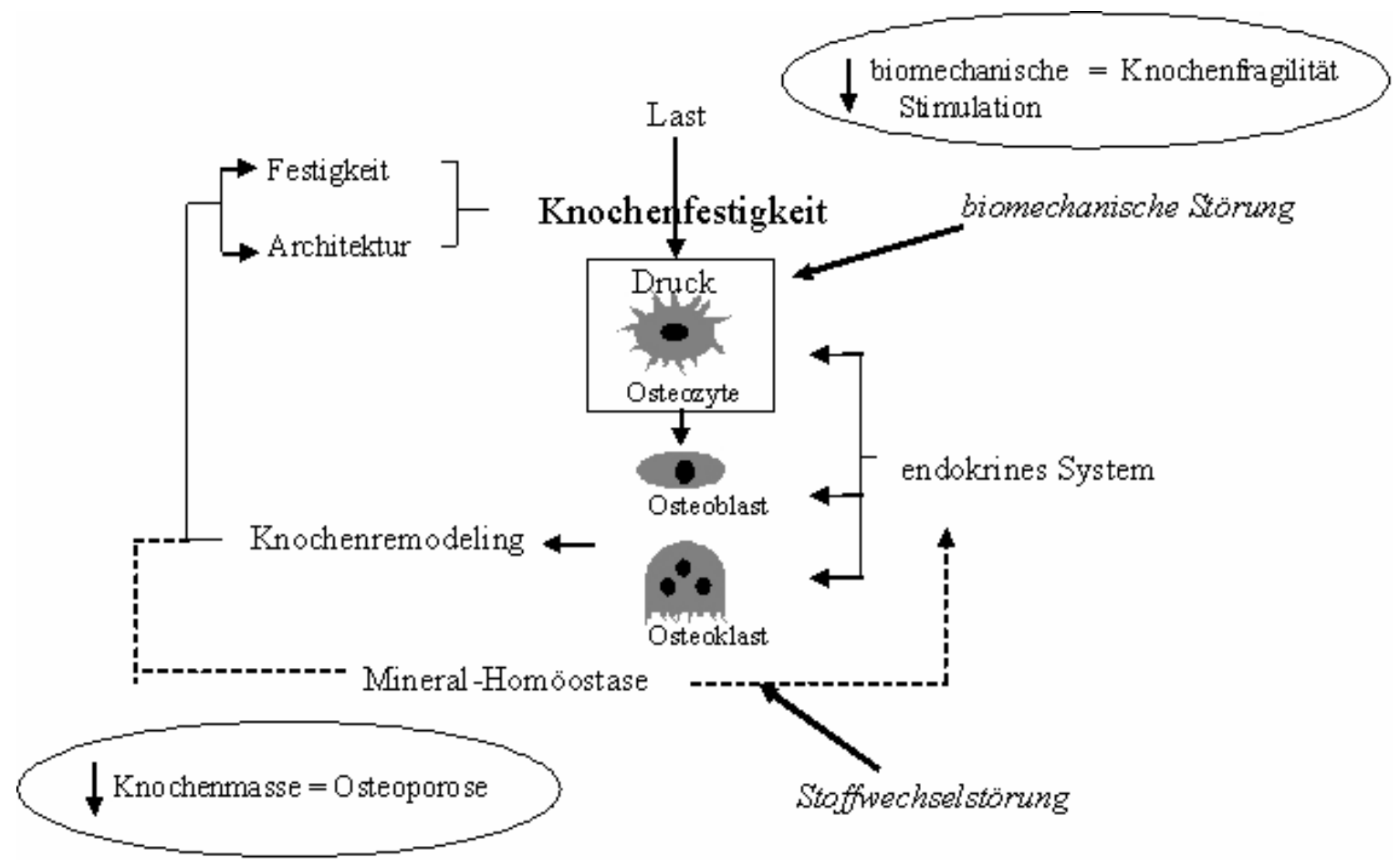

Abb. 2: Schematische Darstellung des Knochens als biomechanische regulierte Struktur (modifiziert von Ferretti et al. 2003).

In diesem Zusammenhang ist ein pathologischer Knochenverlust eine Folge von Störungen dieses Systems, wie beispielsweise bei: 1) metabolischen Erkrankungen (Stoffwechselstörung), 
2) Immobilisierung (biomechanische Störung) und 3) Störung von zellbiologischen Mechanismen (verminderte Osteoblastendifferenzierung).

\section{I.2. Osteoblasten}

\section{I.2.1 Zentrale Rolle des Osteoblasten in der lokalen Knochenresorption}

In den letzten Jahren wurden Faktoren identifiziert, die eine zentrale Rolle in der lokalen Regulation der Knochenresorption spielen und gleichzeitig für eine enge funktionelle Abhängigkeit zwischen Osteoblasten und Osteoklasten sprechen (Abb.3).

Hierbei wurden zwei Faktoren identifiziert, die von Osteoblasten synthetisiert werden: Osteoprotegerin (OPG) und Osteoprotegerin-Ligand (OPG-L). Die Regulation der Verhältnisse OPG/ OPG-L in der Knochenmark-Mikroumgebung, das von verschiedenen Zytokinen und Hormonen reguliert wird sowie der Kontakt zwischen Osteoklasten und Osteoblasten scheint eine entscheidende Rolle in der Regulation der Knochenresorption zu haben.

Diese Faktoren gehören zur TNF Superfamilie und sollen unterschiedliche Effekte auf die Osteoklasten Funktion bzw. Formation haben. OPG ist ein inhibitorischer Faktor der Osteoklastogenese und OPG-L ein Osteoklasten Differenzierungsfaktor. Sowohl OPG als auch OPG-L werden von Osteoblasten als löslicher oder membrangebundener Faktor exprimiert.

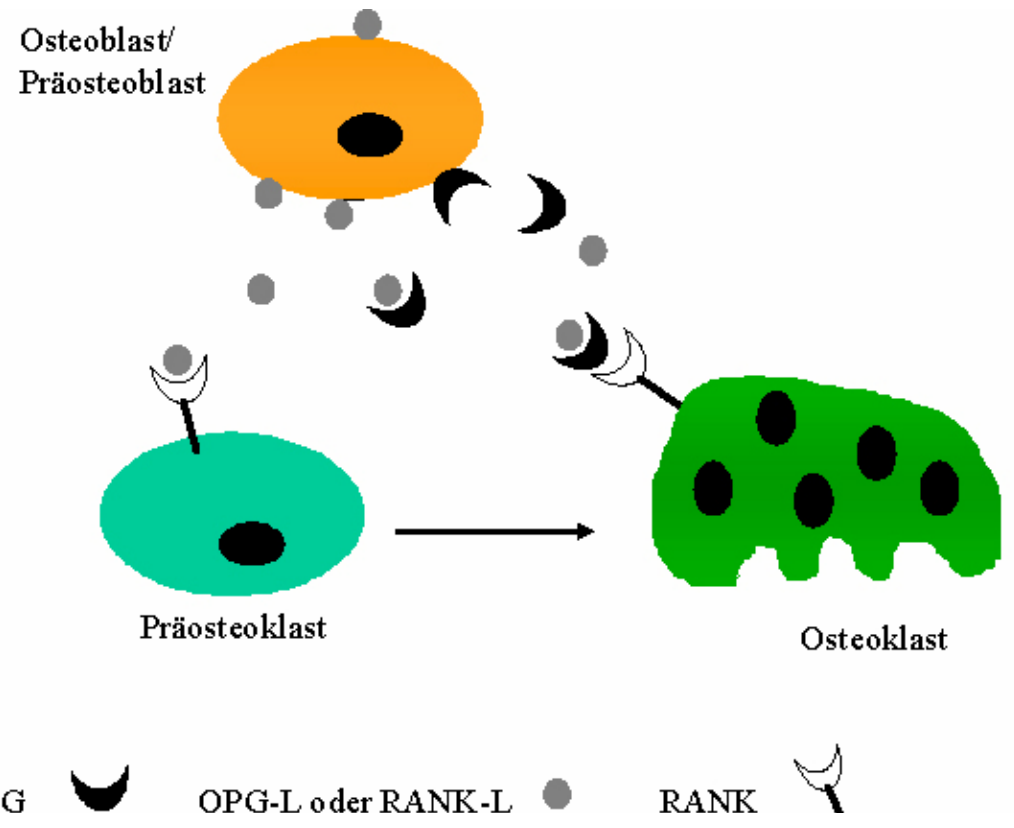

Abb. 3: Zusammenspiel von OPG, RANK-L und RANK bei der Aktivierung von Osteoklasten 
Der membrangebundene Faktor OPG-L (auch TRANCE (TNF-related activation-induced cytokine), RANK-L (receptor activator of NF-kappa B ligand) oder ODF (Osteoclast differentiation factor) benannt) interagiert mit RANK-Rezeptoren von Osteoklastenprogenitorzellen durch direkten Zellkontakt und induziert die Differenzierung von Osteoklasten. OPG als Osteoklasten inhibierender Faktor ist in der Lage, die beiden OPG-L Formen zu antagonisieren, indem es die Bindung von OPG-L an seinen RANK-Rezeptor auf den Osteoklastenprogenitorzelle verhindert. Auf diese Weise kann OPG die Wirkung von OPG-L inaktivieren und so durch Verminderung der Knochenresorption die Knochenmasse erhalten (Lacey et al. 1998; Simonet et al. 1997).

\section{I.2.2. Die Osteoblasten-Familie}

Während der Embryogenese entsteht der Knochen durch zwei unabhängige Ossifikationsprozesse: indirekte- und direkte-Ossifikation. In beiden Prozessen sind die Osteoblasten für die Synthese eines Großteils des Osteoids (unmineralisierte Knochenmatrix) und somit für den Knochenaufbau hauptverantwortlich. Osteoblasten entstehen aus Osteoprogenitorzellen, die sich aus undifferenzierten mesenchymalen Zellen des Knochenmarks entwickeln.

Die Osteoblasten-Familie (Abb.4) umfasst verschiedene Differenzierungsstufen: 1) reife Osteoblasten 2) Osteozyten und 3), ,bone lining cells“.

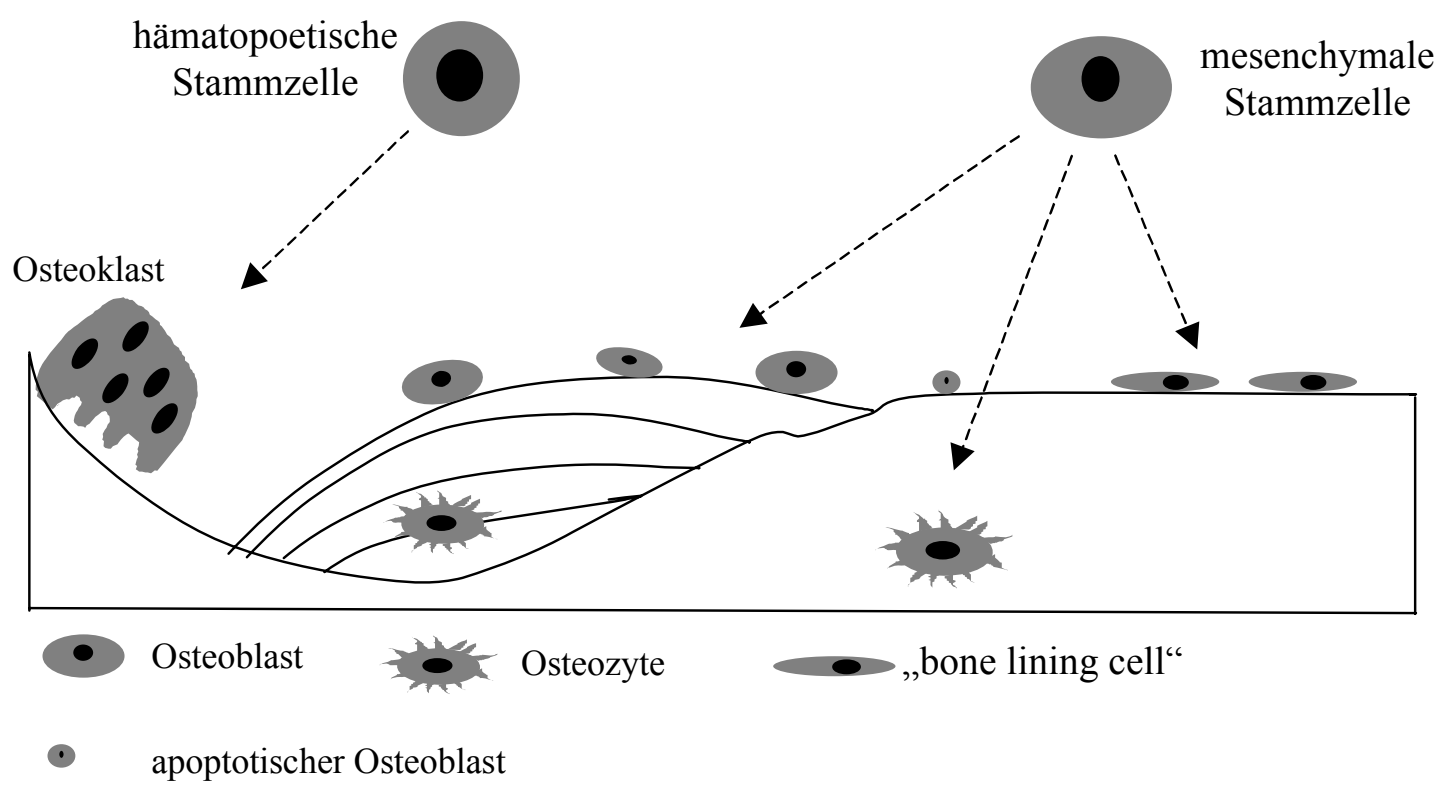

Abb. 4: Die Osteoblasten-Familie in der Knochenmatrix (modifiziert von Chan \& Duque, 2002) 
1) Nach phänotypischen Kriterien werden die reifen Osteoblasten in polygonale, basophile Zellen mit einem gut entwickelten Golgi Apparat bzw. endoplasmatischen Retikulum eingeordnet. Reife Osteoblasten werden durch die Synthese von Knochenmatrixproteinen wie z.B. Kollagen-I, Osteonectin, Osteopontin, Osteokalzin und die alkalische Phosphatase charakterisiert. Sie besitzen Rezeptoren für PTH (Parathormon) und EGF („epidermal growth faktor"). In vitro Versuche haben gezeigt, dass die Variation der Genexpression dieser molekularen Marker vom Reifestadium abhängig ist (Aubin et al. 1995).

Neben der Osteoidproduktion wirkt der Osteoblast durch die Bildung von Matrixvesikeln als Initiator des Mineralisationsprozesses (Anderson \& Reynolds, 1973).

2) Die Osteozyten repräsentieren den überwiegenden Teil der Zellen der Osteoblasten-Familie im Knochen. Osteozyten stammen von Osteoblasten ab, die Knochenmatrix produziert haben und sich in diese einmauern. Während des Differenzierungsprozesses zu Osteozyten verlieren die Osteoblasten einen großen Anteil ihrer Zellorganellen und entwickeln gleichzeitig Pseudopodien, die an der Ausscheidung von Matrixvesikeln beteiligt sind. Durch die Pseudopodien kommunizieren Osteozyten miteinander und bilden ein Syncytium oder Netzwerk. Junge Osteozyten besitzen osteoblastenähnliche Strukturen, einen prominenten Golgi Apparat bzw. endoplasmatisches Retikulum sowie reichlich freie Ribosomen, alles Zellorganellen, die für die schnelle Produktion von Proteoglykanen und Kollagen benötigt werden. Die Pseudopodien reifer Osteozyten orientieren sich eher nach der vaskulären Seite als nach der mineralisierten Seite des Knochengewebes (Aarden et al. 1994, Knothe Tate et al. 2004).

Spezifische Marker für Osteozyten wie z.B. Enzyme oder Matrixproteine sind zur heutigen Zeit nicht bekannt. Ein osteozytenspezifischer monoklonaler Antikörper gegen Hühnerkalvarienosteoblasten wurde von Nijweide \& Mulder (1985) entwickelt, der an ein unbekanntes Zelloberflächenantigen bindet.

3) Die „bone lining cells“ sind flache Zellen, die direkt auf den inaktiven (nichtremodelierenden) Knochenoberflächen liegen. Elektronenmikroskopische Studien zeigen folgende Eigenschaften: langestrecktes Zytoplasma (10 $\mu \mathrm{m}$ x $1 \mathrm{um}$ ), flaches nukleares Profil, wenige Zellorganellen und interzelluläre Komunikation via „gap junction“ (Miller 1987). Ihre Funktion ist nicht definiert, es wird eine Rolle in der Ernährung der Osteozyten (Miller et al. 1980) und in der Ionen Homöostase diskutiert (Talmage et al. 1970). Diese Zellen könnten an der Aktivierung des Knochenumbaus durch die Rekrutierung von Osteoklasten beteiligt sein (Parfitt, 1994). 


\section{I.2.3. Osteoblasten und mesenchymale Stammzellen}

Osteoblasten entstehen aus Osteoprogenitorzellen, die sich aus undifferenzierten mesenchymalen Zellen entwickeln. Diese mesenchymalen Stammzellen, die zur Regeneration zahlreicher Gewebe beitragen, gehören zu dem Knochenstromasystem, das sich in den Kavitäten des adulten Knochenmarks befindet (Bianco \& Robey, 2000). Diese Knochenstromazellen werden in der Literatur als „mesenchymal stem cell“ (MSC) oder adulte Stammzellen benannt (Abb.5).

Die ersten Vorarbeiten zur Identifizierung und in vitro Kultivierung humaner mesenchymaler Stammzellen (hMCS) gehen auf Friedenstein in den 1970er Jahren zurück. Das osteogenische Potential dieser Zellen wurde durch die Fähigkeit, Knochenbildung extraskeletal zu induzieren, demonstriert (Friedenstein et al. 1987).

Pluripotente mesenchymale

Stammzelle

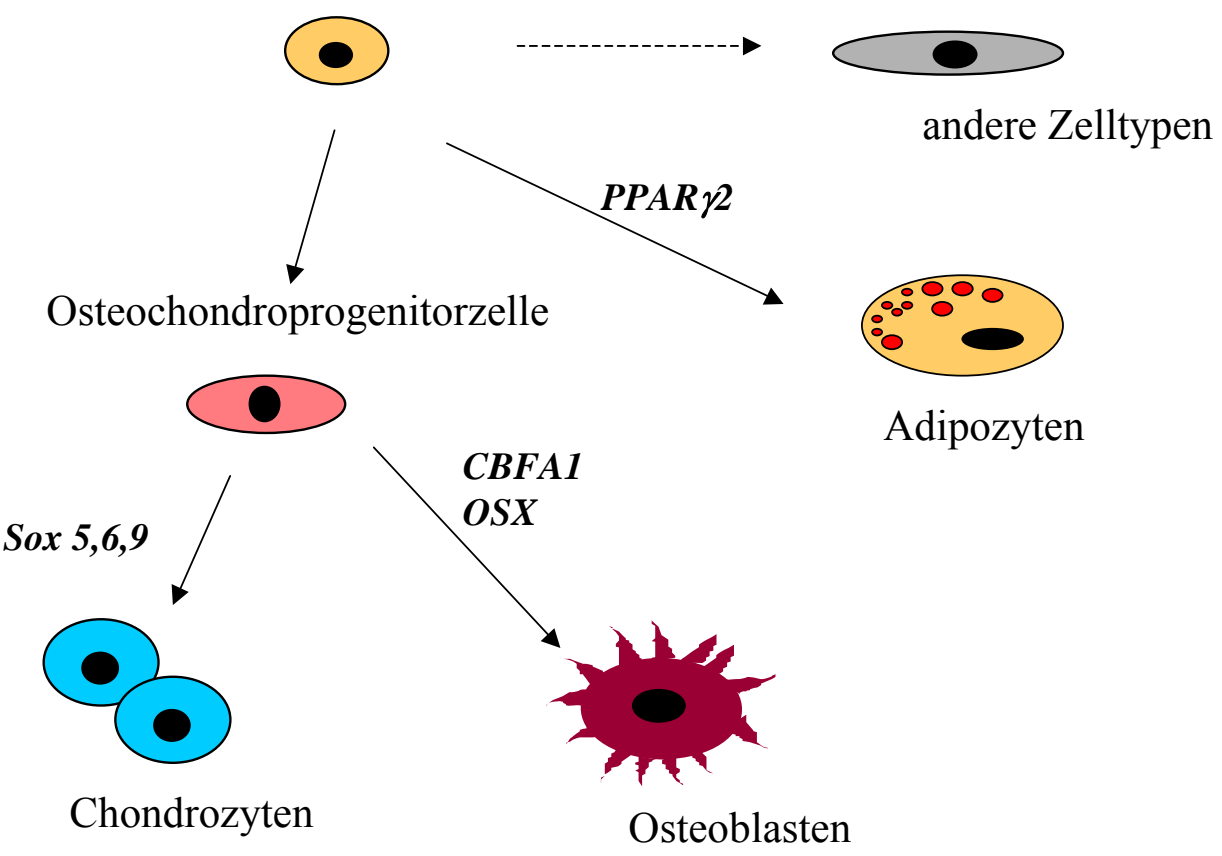

Abb. 5: Differenzierungspotential von hMSCs (Stromazellen) des Knochenmarks.

Seitdem wurden heterogene Populationen von Knochenstromazellen isoliert, die unter geeigneten in vitro-Kulturbedingungen osteoblastär differenzierten (Beresford, 1989; Bennett et al. 1991; Owen, 1985; Haynesworth et al. 1992; Cheng et al. 1994; Rickard et al. 1996; Fromigue et al. 1997; Pittenger et al. 1999). Die Gemeinsamkeit der genannten Arbeitsgruppen liegt in der Hypothese der Existenz von multipotenten hMSC, die sich unter geeigneten Kulturbedingungen in Fibroblasten, Osteoblasten, Chondroblasten, Myozyten und Adipozyten 
differenzieren können. Hierbei wurden in den letzten Jahren gewebespezifische Transkriptionsfaktoren identifiziert, die die Differenzierung der hMSC in den verschiedenen Zelltypen regulieren (Abb.5). Durch genetische Studien an Mäusen konnten essentielle Transkriptionsfaktoren identifiziert werden, welche die Osteogenese (CBFA1/Runx2 und Osterix) und die Adipogenese (PPAR 2 2) regulieren. Einer dieser Faktoren wird Runx 2 (Ducy et al. 1997), früher CBFA1 („,core-binding-factor-alpha-1“) genannt, ein nukleärer-Transkriptionsfaktor, und Osterix (OSX) (Nakashima et al. 2002), ein „zink-finger-containing protein“. Tatsächlich zeigten „knockout-Mäuse“, bei denen entweder Runx 2 oder OSX fehlte, keine mineralisierte Knochenmatrix bzw. keine Osteoblasten 


\section{I.2.4. Osteoblastäre Differenzierung in Kultur}

Die osteoblastäre Differenzierung ist ein komplexer Prozeß, der eine Phase der Zellproliferation beinhaltet, gefolgt von einer koordinierten Expression knochencharakteristischer Proteine. Diese sequentielle Entwicklung, in der Abbildung 6 dargestellt, kann also durch drei Phasen charakterisiert werden: 1. schnelle Proliferation, 2. Matrixmaturation und 3. Mineralisation.

Dieses Osteoblastendifferenzierungsmodell, auch Owen-Modell genannt, resultierte aus intensiven Untersuchungen an einem Rattenkalvarienzellsystem (Owen et al. 1990). Das Prinzip der sequentiellen Differenzierung konnte sowohl in Hühnerkalvarienosteoblasten (Gerstenfeld et al. 1987), normalen Mäuseosteoblasten (Quarles et al. 1992), als auch in verschiedenen in vivo-Systemen bestätigt werden (Mundlos 1994).

Derartige Untersuchungen bezüglich der Expression von Wachstums- und Differenzierungsparametern wurden auch an primären humanen Osteoblasten (pHOB) (Siggelkow et al. 1999) durchgeführt. Hierbei gelang es prinzipiell den Differenzierungsablauf von Rattenkalvarienzellen (Owen et al. 1990) zu reproduzieren, bis auf einige Abweichungen, z.B. eine Verzögerung der Matrixmaturation, welche durch die Art der Kultivierung (Standardbedingungen, Zeitverlauf) oder Speziesunterschiede bedingt sein könnte.

\section{Proliferation Matrixmaturation Mineralisation}

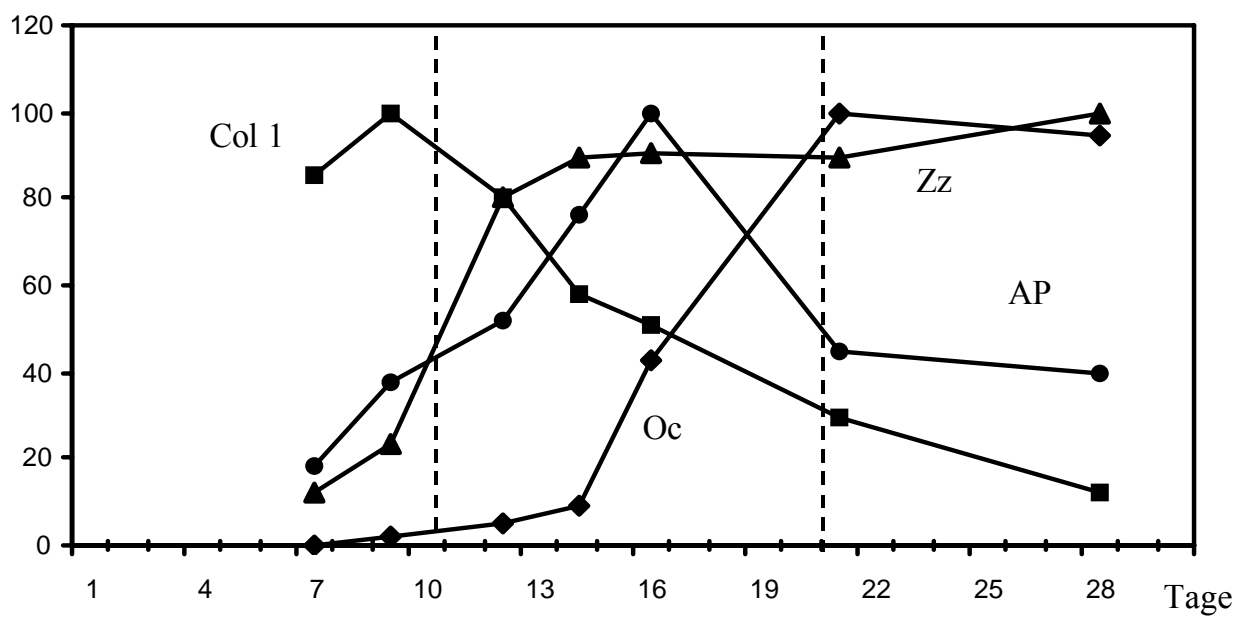

Abb. 6: Sequentieller Ablauf der Differenzierung in Kulturen von primären Rattenosteoblasten anhand von Proliferation und Genexpression osteoblasten-charakteristischer Proteine nach Owen (Owen et al. 1990). AP: alkalische Phosphatase, Col I: Kollagen I, Oc: Osteokalzin, Zz: Zellzahl.

Während der Proliferationsphase erfolgt eine sequentielle Expression von Genen, die mit dem Zellzyklus und Wachstum (Histone, c-myc und c-fos) assoziiert sind. Diese Phase der 
Osteoblastendifferenzierung wird auch durch die Expression von extrazellulären

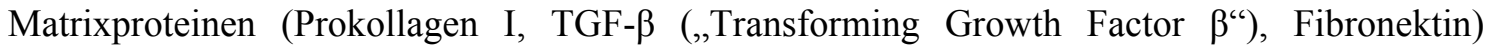
charakterisiert. Der Proliferationsphase folgt eine zweite Phase der Matrixmaturation, charakterisiert durch eine maximale Expression der alkalischen Phosphatase (AP). Zu Beginn der Mineralisation werden Gene für Proteine wie Osteokalzin, Knochensialoprotein und Osteopontin exprimiert, die als Marker reifer Osteoblasten dienen.

\section{I.3. Biochemie der Knochenmatrix}

Das Osteoid oder unmineralisierte Knochenmatrix besteht aus Kollagenproteinen, unter denen Kollagen-I (ca. 90\%) dominiert. Die restlichen 10\% bestehen aus nichtkollagenen Proteinen, die zum Teil am Mineralisationsproze $\beta$ beteiligt sind. Mineralisierte Knochenmatrix enthält zwischen 70 bis $90 \%$ Mineral in der Form von Hydroxylapatit Kristallen $\left(\mathrm{Ca}_{10}\left(\mathrm{PO}_{4}\right)_{6}(\mathrm{OH})_{2}\right)$ (Young 2003).

Zur Charakterisierung des Osteoblastenphänotyps dienen bestimmte knochenassoziierte Proteine, die von Osteoblasten in vitro exprimiert werden: Kollagen-I, alkalische Phosphatase und Osteokalzin.

Die Knochenmatrix besteht zu 90\% aus Kollagen-I, ein komplexes Molekül bestehend aus einer Triplehelix, die aus zwei Pro- $\alpha_{1}(\mathrm{I})$-Ketten und einer Pro- $\alpha_{2}(\mathrm{I})$-Kette aufgebaut ist. Die $\alpha$-Ketten besitzen eine charakteristische Aminosäurensequenz mit einem sich fortlaufend wiederholenden Triplet (Gly-X-Y), in dem auf Glycin immer ein Prolin folgt. Die Prokollagen-I Moleküle werden extrazellulär am aminoterminalen (NICP) Ende und am carboxyterminalen (CICP) Ende durch spezifische Peptidasen abgespalten. Die abgespaltenen NICP- und CICP-Propeptide werden ins Blut transportiert und können als Marker der Osteoblasten Aktivität bzw. Knochenbildung verwendet werden. Da Kollagen-I und seine Propeptide stöchiometrisch produziert werden, kann die Bestimmung der Propeptide zur Quantifizierung der Kollagen-I Sekretion verwendet werden.

Neben einer strukturalen Rolle in der Knochenmatrix wirkt Kollagen-I auf verschiedene intrazelluläre Osteoblastenfunktionen: 1. Apoptose, 2. Zellproliferation und 3) Differentiation (Young, 2003).

Genetische Evidenzen bei Menschen weisen auf einen Zusammenhang zwischen Polymorphismus in der regulatorischen Region von Kollagen-I und eine verminderte Knochenmasse (McGuigan et al. 2001) hin.

AP ist ein glycosyliertes Metalloenzym, welches überwiegend an der äußeren Osteoblastenmembran über Phosphatidylinositol-Glykan gebunden ist (Moss et al. 1992). Die 
genaue Funktion für die Knochenbildung ist nicht bekannt, aber folgende Hinweise sprechen für eine Rolle des Enzyms in dem Mineralisationsprozess bzw. Knochenbildung: 1) Die AP ist in der Lage, organische Phosphatester zu spalten, und könnte so für eine ausreichende Konzentration anorganischen Phosphates sorgen (Robison, 1923). 2) In den Matrixvesikeln mineralisierender Gewebe wurden besonders hohe AP-Konzentrationen nachgewiesen (Ali et al. 1970; Miao \& Scutt, 2002). 3) Primäre Osteoblastenkulturen, die aus Mäusen gewonnen wurden, denen das AP-Gen fehlt (,knockout mice“), waren nicht in der Lage zu mineralisieren (Wennberg et al. 2000). Die fehlende Mineralisation bei diesem „knockout-Modell“ wird vermutlich durch die erhöhte Konzentration anorganischen Pyrophosphates (PPi) um die Matrixvesikeln herum verursacht (Anderson et al. 2004). Hierbei wirkt das PPi, welches normalerweise von AP in Monophosphationen gespalten wird, als Inhibitor der Hydroxylapatit Kristallen.

Für die Charakterisierung der Osteoblasten steht Osteokalzin nicht nur als charakteristischer sondern als spezifischer Marker im Mittelpunkt. Osteokalzin ist ein kalziumbindendes Protein (5.2-5.9 kD) und repräsentiert den überwiegenden Anteil (10-20\%) der nichtkollagenen Knochenmatrixproteine bzw. 1,5\% der gesamten Knochenproteine (Hauschka et al. 1975).

Die genaue Funktion dieses Proteins im Knochenstoffwechsel ist noch nicht vollständig geklärt. Mäuse, denen zwei von drei Osteokalzingenen fehlten, zeigten eine Zunahme der Knochenmasse, während die Knochenresorption und Mineralisation nicht beeinflußt wurden (Ducy et al. 1996).

Osteokalzin wird postranslational modifiziert und als gammacarboxyliertes Protein exprimiert. Hierbei zeigten in vivo-Studien eine signifikante Korrelation zwischen carboxylierter Form und Knochenqualität (Sugiyama et al. 2001). Da die Carboxylierung von Osteokalzin Vitamin-K abhängig ist, könnte dieses Vitamin eine wichtige Rolle in der Prävention von Knochenfrakturen spielen. Die Osteokalzinsekretion und -genexpression bei pHOB Zellen wird stark durch 1,25(OH) ${ }_{2} \mathrm{D}_{3}$ stimuliert (Beresford et al. 1984; Siggelkow et al. 1999). Da Osteokalzin als Marker fortgeschrittener differenzierter Osteoblasten gilt, wird somit eine Zunahme der Osteokalzinsekretion als eine weitere Differenzierung interpretiert.

\section{I.4. Bedeutung des pHOB-Systems als Osteoblastendifferenzierungsmodell}

Die Kenntnisse über molekulare Mechanismen metabolischer Knochenerkrankungen und Pathogenese resultieren zu einem großen Anteil aus Daten von Tiermodellen sowie in vitroExperimenten mit Osteosarkomzellinien bzw. Knochenzellkulturen verschiedener Spezies.

Im Folgenden werden die Gründe, die für die Verwendung von primären humanen Osteoblastenkulturen (pHOB) sprechen, dargestellt. 1) Die schlechte Übertragbarkeit von 
Befunden anderer Spezies auf das humane System. 2) Viele Daten von fetalen, neonatalen oder transformierten Zelltypen weichen deutlich von denen adulter humaner Zellen ab.

Primäre humane osteoblastenähnliche Zellkulturen können durch verschiedene Methoden etabliert werden (Beresford et al. 1984; Marie et al. 1989a; Robey, 1995; Nöth et al. 2002). Allerdings werden mittels der verschiedenen Methoden unterschiedlich differenzierte osteoblastenähnliche Zellen aus dem Knochenmaterial gewonnen.

In dieser Arbeit wurde zur Isolierung von pHOB Zellen die Technik der sogenannten Explantkultur verwendet (Auf'm Kolk et al. 1985; Beresford et al. 1984; Gundle \& Beresford 1995; Nuttall et al. 1998). Bei dieser Explant-Technik, lösen sich die Osteoblasten aktiv aus mechanisch zerkleinerten trabekulären Knochenfragmenten ab. Hierbei werden die Knochenfragmente nicht enzymatisch behandelt.

Dieses pHOB System ist prinzipiell in der Lage, die komplette Differenzierung bis zur Mineralisation zu durchlaufen (Siggelkow et al. 1999). Es erscheint somit als humanes Modell für die Untersuchung der Differenzierungsmechanismen geeignet zu sein.

\section{I.5. Plastizität zwischen Osteoblasten und Adipozyten}

\section{I.5.1. Basis der Transdifferenzierung}

Die Tatsache, daß klonale mesenchymale Stammzellen (MSCs) isoliert aus dem Knochenmark verschiedener Spezies einschließlich des Menschens (Pittenger et al. 1999; Ahdjoudj et al. 2001) sich in Osteoblasten, Adipozyten, Chondrozyten und Myoblasten differenzieren können, spricht für eine Multipotentialität der einzelnen Zellen (Abb.5).

Zahlreiche in vitro Untersuchungen bzw. Modelle weisen darauf hin, daß eine besondere Plastizität zwischen Osteogenese und Adipogenese besteht (Beresford et al. 1992; Houghton et al. 1998; Park et al. 1999; Thomas et al. 1999; Gimble \& Nuttall 2004; Ahdjoudj et al. 2004) und das beide Entwicklungsprozesse durch verschiedene Faktoren beeinflusst werden können.

Der Ausdruck Transdifferenzierung, in einem Zelldifferenzierungskontext, bezeichnet einen phänotypischen Wechsel von einem terminal differenzierten Zelltyp (z.B. Osteoblasten, die Osteokalzin synthetisieren) zu einem anderen (z.B. Adipozyten mit Lipidvakuolen).

In Studien an verschiedenen Human-Osteoblasten Kulturmodellen konnte eine Transdifferenzierung von Osteoblasten zu Adipozyten unter Einfluß geeigneter Faktoren gezeigt werden. Von Nutall et al. (1998) gelang zum erstenmal, einen Transdifferenzierungsprozeß von pHOB Zellen, die aus trabekulären Knochenfragmenten isoliert wurden, nachzuweisen. Dabei waren sogar Klone von Osteoblasten, die Osteokalzin synthetisieren konnten, in der Lage, sich zum Adipozyten zu differenzieren. Der adipozytäre Phänotyp wurde unter Stimulation mit Dexamethason und IBMX (3-Isobutyl-1-Methylxanthin) induziert und ging mit einer sinkenden 
Osteokalzinsekretion einher. Nöth et al. (2002) zeigten, daß Kollagenase vorbehandelte pHOB Zellen sowohl zu Adipozyten als auch zu Chondroblasten differenzieren können. Song \& Tuan (2004) berichteten über eine solche Transdifferenzierung bei Osteokalzin-positiven Osteoblasten, die aus dem humanen Knochenmark isoliert wurden.

Eine Umdifferenzierung zwischen Osteogenese und Adipogenese wurde für klonierte humane Knochenmarkadipozyten nachgewiesen (Park et al. 1999). Dabei waren reife Adipozyten zu einer Dedifferenzierung in der Lage und wiesen osteoblastencharakteristische Marker wie APAktivität und Osteokalzinsekretion unter Stimulation mit $1,25(\mathrm{OH})_{2} \mathrm{D}_{3}$ auf.

\section{I.5.2. Marker zur Charakterisierung der Transdifferenzierung zu Adipozyten}

Ein adipozytärer Phänotyp kann durch strukturelle und funktionale Kriterien definiert werden. Reife Adipozyten können histologisch durch ihre zytoplasmatischen Lipidvakuolen um den Zellkern identifiziert werden. Durch die Färbung mit Oil-red O erscheinen diese Lipidvakuolen rot im Lichtmikroskop. Da dieser Nachweis jedoch nur ein hoch differenziertes Stadium darstellt, verwendet man zusätzlich Marker um frühere Differenzierungsstufen des Adipozyten zu charakterisieren. Die Marker, die in dieser Arbeit bestimmt und analysiert wurden, sollen im folgenden Abschnitt kurz beschrieben werden.

\section{I.5.2.1. PPAR $\gamma 2$ (,peroxisome proliferator activated receptor gamma 2“)}

PPARs (,peroxisome proliferator activated receptor“) sind eine wichtige Subfamilie (PPAR- $\alpha$,$\beta,-\gamma$ und $-\delta$ ), die zur Steroid-Thyroid-Vitamin D-nuklear Rezeptorsuperfamilie gehört. Diese ligandaktivierten bzw. an DNA-bindenden Transkriptionsfaktoren sind an der Lipid- bzw. Glukosehomöostase, Zellproliferationskontrolle und Differenzierung beteiligt und werden ubiquitär exprimiert. Wie andere nuklearen Hormonrezeptoren besitzen sie gut konservierte Domänstrukturen: 1) eine N-terminal Region mit einer potentiellen Transaktivationsfunktion und 2) eine DNA-binding Domäne mit zwei ,zink-finger-containing proteins“ (Rosen \& Spiegelman 2001).

Von dieser ganzen Subfamilie gilt PPAR $\gamma$ als der wichtigste Transkriptionsfaktor, der für die Adipozytendifferenzierung erforderlich ist (Spiegelman \& Flier 1996). Die Aktivierung von $\operatorname{PPAR} \gamma$, die in der frühen Phase des Adipozytendifferenzierungsprogramms stattfindet, führt zur Induktion zahlreicher Gene, die für Enzyme kodieren, welche bei dem Lipid-Anabolismus involviert sind, wie beispielsweise Lipoproteinlipase (LPL) und ,adipocyte fatty acid binding protein“ (aP2) (Kersten et al. 2000).

Klonierung des humanen PPAR $\gamma$ belegen die Existenz von zwei Isoformen, PPAR $\gamma 1$ und $-\gamma 2$, die sich an ihren N-Termini unterscheiden. Diese beiden ,splice“-Varianten unterscheiden sich auch in ihrer Funktion. 
Eine essentielle Rolle von PPAR $\gamma 2$ bei der Induktion der Adipogenese konnte erstmals von Tontonoz et al. (1994) durch die Transfektion von einer Fibroblastenzellinie (NIH 3T3) gezeigt werden. Unter bestimmten Faktoren konnte bei dem mit dem PPAR $\gamma 2$-Gen transfizierten Fibroblasten eine Adipogenese induziert werden (Tontonoz et al. 1994). Durch mRNA Analyse an Fettgewebe von übergewichtigen Patienten zeigte sich eine erhöhte Expression von PPAR $\gamma 2$ (Vidal-Puig et al. 1997). Bei diesen Patienten konnte auch eine positive Korrelation zwischen PPAR $\gamma 2$ / PPAR $\gamma 1$ und „body mass index“ (BMI) aufgezeigt werden.

Seitdem zeigen zahlreiche in vivo und in vitro Studien, daß die PPAR $\gamma 2$-Aktivierung die Adipogenese stimuliert und gleichzeitig die Osteoblastogenese inhibiert (Ahdjoudj et al. 2001, Lecka-Czernik et al. 1999, Akune et al. 2001; Halvorsen et al. 2001). PPAR 22 ist auch die Isoform, deren Genexpression bei der Transdifferenzierung von pHOB Zellen zu Adipozyten hochreguliert wird und somit als früher Transdifferenzierungsmarker der pHOB Zellen verwendet werden kann (Nuttal et al. 1998).

An der Aktivierung von PPAR $\gamma$ sind unterschiedliche Liganden (endogene und pharmakologische) verschiedener Affinität beteiligt. Ein echter endogener Ligand, der mit hoher Affinnität binden kann ist bisher nicht bekannt. Es existieren jedoch synthetische Agonisten, z.B Thiazolidinedione (TZDs), die als Pharmaka in der Behandlung des Diabetes mellitus Typ 2 bzw. in der Reduzierung der Insulinresistenz wirken. Tatsächlich zeigten in vitro Untersuchungen an Osteoblasten, daß die Aktivierung von PPAR $\gamma$ durch TZDs die Adipogenese stimulierte und gleichzeitig die Expression des Osteoblasten-spezifischen Transkriptionsfaktor CBFA1/ Runx 2 und Osteokalzin hemmte (Gimble et al. 1996; Lecka-Czernik et al. 1999; Lecka-Czernik et al. 2002). Auch in vivo (Mausmodell) stimulierte die Behandlung mit TZDs die Adipogenese im Knochenmark (Tornvig et al. 2001).

\section{I.5.2.2. Lipoproteinlipase (LPL)}

Das Enzym Lipoproteinlipase (LPL) spielt durch folgende Funktionen eine entscheidende Rolle im Lipoprotein Stoffwechsel: durch die Hydrolisierung von Triglyceriden in Lipoproteinpartikel und einfache Fettsäuren, durch ihre Rolle als Mediator in der Interaktion zwischen Lipoproteinen und Zellmembran bzw. Rezeptoren.

LPL wird während des frühen Adipozytendifferenzierungsprozesses exprimiert und gilt somit als Marker der adipozytären Phänotypen. Zahlreiche in vitro Studien konzentrierten sich auf die Regulation der LPL-Promotoraktivität sowie auf die Identifizierung von Transkriptionsfaktoren. Schoonjans et al. (1996) identifizierten an den LPL-Promotor Bindungsregionen für den Glukokortikoidrezeptor sowie für PPAR $\gamma 2$, beide Transkriptionsfaktoren, die während des frühen Differenzierungsprozesses zum Adipozyten exprimiert werden. Auch während der Transdifferenzierung von pHOB Zellen zu Adipozyten läßt sich eine Hochregulierung der LPL- 
Genexpression, die nach der Aktivierung von PPAR $\gamma 2$ stattfindet, nachweisen. (Nuttall et al. 1998). Neben dieser direkten Regulation spielen möglicherweise andere indirekte Faktoren eine Rolle in der Aktivierung des LPL-Promotors, wie z.B. Zell-Zell bzw. Zell-Matrix-Interaktionen (Ntambi \& Young-Cheul 2000). 


\section{I.5.3. Differenzierungsfaktoren}

Die Differenzierung von mesenchymalen Zellen zu Osteoblasten und Adipozyten wird von zahlreichen Molekülen einschließlich Hormonen und lokalen Wachstumsfaktoren reguliert. Die Faktoren, mit denen wir gearbeitet haben, sollen kurz beschrieben werden.

\section{I.5.3.1. Vitamin C}

Vitamin C, auch Ascorbinsäure benannt, ist essentiell für die ausreichende Hydroxylierung von Kollagen und somit für die Stabilität der extrazellulären Matrix

Beim Menschen führt ein Mangel an Vitamin C zur Skorbut, eine Krankheit deren Symptome zum ersten Mal von Jaques Cartier in Jahr 1536 beschrieben wurden (Major 1945). In vivo Untersuchungen an Meerschweinchen haben die zentrale Rolle dieses Vitamins für die Knochenentwicklung bestätigt. So konnte von Kipp et al. (1996) eine Korrelation zwischen Vitamin C-Mangel und reduzierter Knochenmasse nachgewiesen werden. In Tieren mit diesem Mangel zeigte sich auch sowohl eine reduzierte Knochenbildung als auch eine verminderte Osteoblasten Differenzierung (Mahmoodian et al. 1996).

Studien an MC3T3-E1-Zellen (murine Preosteoblastenzellinie) zeigten, daß im ein aktiver $\mathrm{Na}^{+}-$ Transport der reduzierten Forms der Ascorbinsäure essentiell für die Osteoblastendifferenzierung ist (Francheschi et al. 1995). Zahlreiche in vitro Untersuchungen an unterschiedlichen Kulturmodellen; z.B. Rattenkalvarienzellen (Owen et al. 1990) und humane Knochenstromazellen (Rickard et al. 1996) zeigten auch einen fördenden Effekt dieses Vitamins auf die osteoblastären Differenzierung.

\section{I.5.3.2. Vitamin $D_{3}$}

Das Vitamin $\mathrm{D}_{3}\left(1,25 \mathrm{OH}_{2} \mathrm{D}_{3}\right)$, auch Calcitriol benannt, ist ein Steroidhormon, das für die Kalzium- und Phosphathomöostase im Körper und somit für eine normale Knochenentwicklung gebraucht wird. Die Haupwirkung von Vitamin $\mathrm{D}_{3}$ auf den Knochen erfolgt durch die Induktion der Matrixproteinproduktion (z.B. Osteokalzin) bzw. die Aktivierung des Mineralisationsprozesses.

Die biologischen Effekte von Vitamin $\mathrm{D}_{3}$ auf die Osteoblasten zeigen sich sowohl im Zellkern als auch auf der Zellmembranebene. So reguliert es die Osteoblastengenexpression durch die Bindung an den Vitamin D Rezeptor, welcher als Transkriptionsfaktor wirkt (Bouillon et al. 1995). Ferner aktiviert Vitamin $D_{3}$ Signaltransduktionswege, steigert die intrazelluläre Kalziumkonzentration und moduliert die Funktion der Ionenkanäle an der Osteoblastenzellmembran (Zanello \& Norman 2003). Hierbei sind die genauen molekulären Mechanismen sowie die physiologische Relevanz dieser nicht genomische Effekte nicht bekannt. In vitro Untersuchungen zeigen, daß diese durch Vitamin $\mathrm{D}_{3}$-induzierten Erregung der 
Ionenströme an den Osteoblastenzellmembran sekretorische Vorgänge hervoruft (Zanello \& Norman 2003).

Die Wirkung von Vitamin $\mathrm{D}_{3}$ auf die Adipogenese wird hingegen unterschiedlich beurteilt. Es existieren Untersuchungen hierzu, in denen sowohl eine antagonisierende Wirkung (Kelly und Gimble 1998), als auch ein stimulierender Effekt (Bellows et al. 1994) auf die Adipogenese beschrieben werden.

\section{I.5.3.3. $\beta$-Glycerophosphat}

Zahlreiche in vitro Studien zeigen, daß die Zugabe von $\beta$-Glycerophosphat, das als Quelle für anorganische Phosphate dient, den Mineralisationsprozeß induziert. Bei Experimenten mit der murinen Preosteoblastenzellinie (MC3T3-E1) konnte die Bildung mineralisierter extrazellulärer Matrix unter Zugabe von $\beta$-Glycerophosphat und Vitamin C über einen Zeitraum von 21 Tagen beobachtet werden (Quarles et al., 1992). Hierbei konnte früh in den Differenzierungsprozeß einen parallelen Anstieg extrazellulärer anorganischen Phosphat und die AP-Aktivität nachgewiesen werden, was darauf hinweist daß $\beta$-Glycerophosphat durch AP hydrolisiert wird. Die Dynamik dieses Prozesses scheint allerdings sehr komplex zu sein. So konnte von Bellows et al. (1991) einen Mineralisationsprozeß blockiert werden, indem die AP-Aktivität innerhalb der ersten 8 Stunden, nicht aber nach 24 Stunden, inhibiert wurde. Von Fratz-Zelman et al. (1998) konnte nachgewiesen werden, daß verschiedene Dosis/ Wirkungszeit von $\beta$ Glycerophosphat auf den Mineralisationsprozeß unterschiedlich wirken. Obwohl das extrazelluläre anorganische Phosphat für die Formation von Hydroxylapatit Kristallen benötigt wird, suggerieren die oben genannten Studien, daß die Freisetzung anorganischer Phosphat einen relevanten Effekt auf die Zellfunktion hat.

\section{I.5.3.4. Glukokortikoide}

Es ist seit langen bekannt, daß die Langzeitbehandlung mit hohen Konzentrationen von Glukokortikoiden häufig zum Knochenverlust führt. Die genaue Pathogenese dieser Erkrankung ist aber sehr komplex und nicht vollständig geklärt.

Durch in vivo Studien an Menschen und Mäusen konnte jedoch die sequentielle Entwicklung dieser Erkrankung in 2 Phasen geteilt werden; 1) eine frühe Phase, in der einen rapiden Knochenschwund stattfindet, der aus eine erhöhte Knochenresorption resultiert und 2) eine spätere Phase, in der einen langsamen Knochenverlust aufgrund einer verminderten Knochenformation nachgewiesen werden konnte (Weinstein 2001).

In vitro Untersuchungen zeigen dagegen, daß Dexamethason, ein synthetisches Glukokortikoid, in der Lage ist die Osteoblastogenese positiv zu beeinflussen. So konnte nachgewiesen werden, daß die kontinuerliche Behandlung mit Dexamethason die Differenzierung von Osteoprogenitorzellen induziert, die sowohl aus humanem (Cheng et al. 1994; Rickard et al. 
1996; Fromigue et al. 1997; Ahdjoudj et al. 2001) als auch aus Ratten (Rickard et al. 1994) Knochenmark isoliert wurden. Die Wirkung auf die Proliferation und auf die Differenzierung von Osteoprogenitorzellen scheint aber abhängig vom Zellwachstum, dem Stadium der Differenzierung, vom Kulturmodell sowie vom Dosis/ Wirkungszeit zu sein (Beresford et al. 1992; Stewart et al. 1999; Atmani et al. 2002; Porter et al. 2003; Jorgensen et al. 2004).

Außerdem zeigte Dexamethason einen stimulierenden Effekt auf die Adipogenese in Knochenmarkzellen (Bennett et al. 1991) und in pHOB Zellen (Nuttall et al. 1998).

\section{I.5.3.5. „Transforming Growth Factor- $\beta 1 “$}

Der „Transforming growth factor- $\beta 1$ “ (TGF- $\beta 1$ ) gehört zusammen mit „,activins“, „bone morphogenetic proteins“ (BMPs) und „growth and differentiation factors“ (GDFs) zur großen TGF- $\beta$-Superfamilie. Alle diese Proteine sind heutzutage bekannt als multifunktionelle Zytokine, die sowohl für die embryonale Entwicklung als auch für die posnatale Homöostase relevant sind. Bekannt ist z.B., daß TGF- $\beta 1-$, ,knockout-Mäuse“ eine anormale Hämatopoese zeigen (Dickson et al. 1995).

Hinweise für die Annahme, daß TGF- $\beta 1$ eine physiologische Bedeutung in der postnatale Knochenbildung hat, sind folgende: Mutationen des humanen TGF- $\beta 1-G e n s$ führen zu dem „Camurati -Engelman“-Syndrom, eine Krankheit, die von pathologischen Knochenveränderungen charakterisiert ist (Kinoshita et al. 2000), und bei Mäusen wurde der altersbedingte Knochenverlust mit einer verminderten Produktion von TGF- $\beta 1$ assoziiert (Gazit et al. 1998).

TGF- $\beta$ ist auch der am häufigsten vorkommende Wachstumsfaktor in der Knochenmatrix. Zahlreiche Untersuchungsmodelle zeigen, daß die TGF- $\beta 1$ Expression in der frühen Phase der osteoblastären Differenzierungsprozesse stattfindet (Joyce et al. 1990; Bolander 1992). In diesem Kontext zeigen in vitro Studien, daß TGF- $\beta 1$ die Matrixproteinsynthese (z.B: Fibronektin, Fibronektinrezeptor, Kollagen, Osteonektin, Osteopontin und Integrinen) stimuliert (Roberts et al. 1988). Untersuchungen an einer multipotenten mesenchymalen Zellinie (Maus) zeigen, daß TGF- $\beta 1$ die osteoblastenspezifische Genexpression induziert und gleichzeitig eine inhibitorische Wirkung auf die Myozytendifferenzierung hat (Lee et al. 2000).

Die Wirkung von allen Proteinen der TGF- $\beta$-Superfamilie erfolgt durch die Bindung an spezifische Rezeptoren, die „serine/threonine“-Kinaseaktivität besitzen. Nach der LigandAktivierung des Rezeptors erfolgt die Phosphorylierung bzw. Translokation spezifischer Proteine einschließlich Smad (,Mothers-against-decantaplegic-related proteins“), die als Mediator zwischen Membran und Zellkern die Genexpression kontrollieren.

Hierbei spielt die spezifische Aktivierung bzw. Interaktion zwischen unterschiedlichen SmadProteinen eine entscheidende Rolle in der positiven bzw. negativen Regulation der 
Genexpression. Untersuchungen von Knochenmarkszellen (Maus) zeigen, daß die Expression von TGF- $\beta 1$ Rezeptoren (Typ-I, II und III) wesentlich höher in Kulturen jüngerer Tiere ist als in denen älterer Tiere (Gazit et al. 1998). Zusätzlich zeigt diese Studie, daß die Neutralisierung von endogenem TGF- $\beta 1$ mit Antikörpern die Proliferation der Zellen beeinträchtigt unabhängig vom Alter der Tiere.

\section{I.5.3.6. Bone Morphogenetic Proteins (BMPs)}

Bone Morphogenetic Proteins (BMPs) wurden ursprünglich 1965 identifiziert durch ihre Fähigkeit, ektopische Knorpel- und Knochenbildung in vivo zu induzieren (Urist 1965). Zurzeit sind mehr als 20 BMP-Isoformen bekannt, deren positiven Einflüsse auf die Knochenbildung (z.B. auf die Förderung des Frakturheilungsprozesses) durch zahlreiche präklinische Studien an verschiedenen Tiermodellen gezeigt wurden (Hogan 1996). BMPs werden vermehrt als inaktive Proteine im Knochengewebe gespeichert und nachdem diese durch spezifischen Proteinase oder niedrige $\mathrm{pH}$ aktiviert werden, rekrutieren sie die für die Knochenbildung benötigten Osteoblasten.

Von der ganzen BMP-Familie gilt BMP-2 als eine der stärksten knocheninduzierenden Isoformen. Untersuchungen von Hirata et al. (2003) konnten zeigen, daß die subkutane Implantation von BMP-2 überexprimierenden Hautfibroblasten zur ektopischen Knochenbildung führt. Zusätzlich konnte durch in vitro als auch in vivo Versuche gezeigt werden, daß BMP-2 eine essentielle Rolle in der Osteoblasten Differenzierung, durch die positive Regulation von osteoblastenspezifischer Gene (CBFA-1, Kollagen-I, alkalische Phosphatase), spielt (Abe et al, 2000; Devlin et al. 2003).

In Übereinstimmung mit den in vivo Beobachtungen zeigen zahlreiche in vitro Untersuchungen an unterschiedlichen Zellkulturmodellen; z.B. humanen Knochenstromazellen (Fromigue et al. 1998; Gori et al. 1999) oder murine Zellinie (MC3T3-E1 und C3H10T1/2) (Spinella-Jaegle et al. 2001), daß BMP-2 einen fördenden Effekt auf die osteoblastären Differenzierung.

Bezüglich der Wirkung von BMP-2 auf die Adipogenese existieren Untersuchungen, die sowohl von einer Hemmung (Gimble et al. 1995; Gori et al. 1999; Thomas et al. 1999; Spinella-Jaegle et al. 2001) als auch von einer Förderung (Ahrens et al. 1993; Chen et al. 1998; Ji et al. 2000; Sottile \& Seuwen 2000; Date et al. 2004) dieses Prozesses in verschiedenen Zellkultursystemen berichten.

\section{I.5.3.7. IBMX (3-Isobutyl-1-Methylxanthin)}

IBMX (3-Isobutyl-1-Methylxanthin) ist ein Hemmer der Phosphodiesterase, die für den Abbau des zyklischem Adenosinmonophosphat (cAMP) verantwortlich ist.

Zahlreiche in vitro Untersuchungen zeigen, daß IBMX zusammen mit Dexamethason und Insulin in der Lage ist, einen Adipozytendifferenzierungsproze $\beta \mathrm{zu}$ initiieren oder $\mathrm{zu}$ 
beschleunigen (Gregoire et al. 1998). Hierbei konnte an pHOB Zellen gezeigt werden, daß IBMX (mit Dexamethason) die PPAR $\gamma 2$ Genexpression hochreguliert und somit einen Transdifferenzierungsprozeß zu Adipozyten induzieren kann (Nuttall et al. 1998; Prichett et al. 2000).

\section{I.6. Bedeutung der Transdifferenzierung für den pathologischen Knochenverlust}

Ein gestörtes Gleichgewicht zwischen Knochenformation und -resorption führt zur Osteoporose. Charakteristisch für diese Pathologie sind sowohl ein Knochenmasseverlust als auch eine Verschlechterung der Knochenmikroarchitektur, beide Faktoren, die das Frakturrisiko wesentlich erhöhen (Abb.2).

In den letzten Jahren gewinnt die Altersosteoporose aufgrund der angestiegenen mittleren Lebenserwartung immer mehr an Bedeutung. Bei dieser Form der Osteoporose handelt es sich um einen Knochenverlust, der hauptsächlich aus einer verminderten Knochenformationsrate resultiert (Marie 2001).

Es ist seit langem bekannt, daß eine Abnahme des Knochenvolumens im Rahmen der Alterosteoporose mit einer Zunahme des Fettgewebes im Knochenmark einhergeht. Hierbei fand sich eine Korrelation zwischen der Zahl bzw. Größe der Adipozyten und dem Knochenverlust in Knochenmarkbiopsien von Patienten mit Osteoporose (Meunier et al. 1971, Justesen et al. 2001). Auch in anderen Situationen wurde über eine solche Korrelation berichtet, z.B. nach Ovarektomie (Martin et al. 1990), Immobilisation (Minaire et al. 1984) und Glukokortikoidbehandlung (Wang et al. 1977).

Zur Erklärung dieses Phänomens wird die Hypothese aufgestellt, daß die Osteoblasten bzw. Osteoprogenitoren in Adipozyten umdifferenziert bzw. transdifferenziert werden (Gimble et al. 1996; Nuttall \& Gimble 2000; Gimble \& Nuttall 2004; Nuttall \& Gimble 2004) (Abb. 7). Hierbei konnte in den letzten Jahren durch zahlreiche Untersuchungen nachgewiesen werden, daß PPAR $\gamma$ (I.5.2.1) eine relevante Rolle in der Regulation der adipozytären und osteoblastären Differenzierung spielt.

Eine Rolle von PPAR $\gamma$ als Inhibierungsfaktor der Osteoblastendifferenzierung konnte sowohl bei primären Osteoblasten (Lecka-Czernik et al. 1999) als auch durch Untersuchungen an PPAR $\gamma$-knockout-Mäusen gezeigt werden (Akune et al. 2001). Homozygote Mäuse (-/-) verstarben; heterozygote (+/-) zeigten dagegen eine verminderte Adipogenese im Knochenmark, die mit einer Abnahme der Knochenmasse bzw. der Osteoblastogenese einherging (Akune et al. 2001). Dieser Effekt konnte auch in vitro bestätigt werden (Akune et al. 2004). 


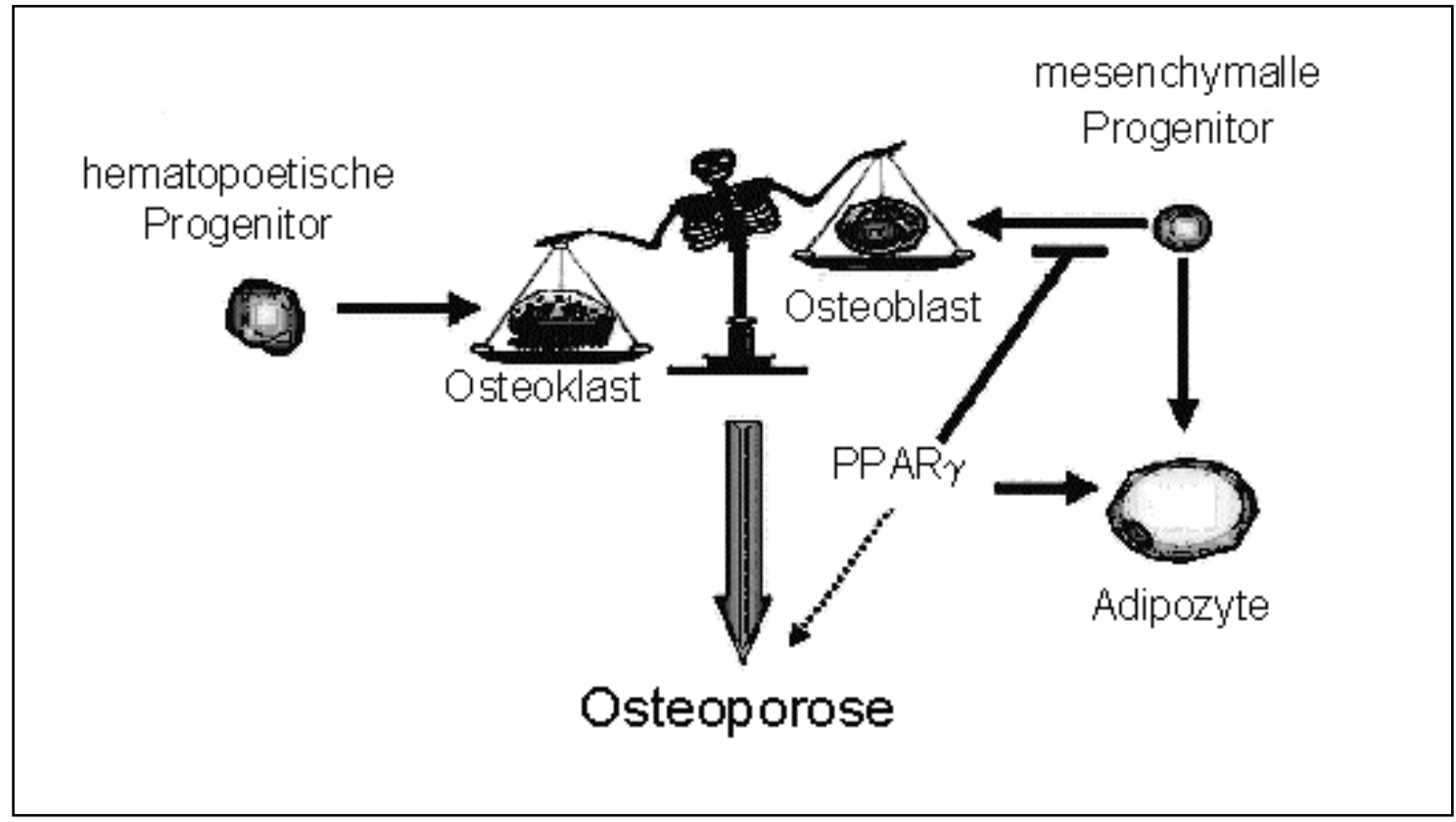

Abb. 7: Modell (modifiziert von Pei \& Tontonoz 2004) für den Einfluss von PPAR $\gamma$ in der Osteogenese. Die Knochenhomöostase wird durch das Gleichgewicht zwischen Knochenaufbau (Osteoblasten) und Knochenabbau (Osteoklasten) erhalten. Ein gestörtes Gleichgewicht zwischen den beiden Prozessen führt zur Osteoporose. Der determinante Faktor (PPAR $\gamma)$ für die Differenzierung von mesenchymalen Progenitoren $\mathrm{zu}$ Adipozyten wurde auch als Inhibierungsfaktor der Osteoblastendifferenzierung beschrieben (Akune et al. 2001).

Genetische Untersuchungen suggerieren eine Assoziation zwischen Knochendichte und PPAR $\gamma$ Polymorphismus bei Menschen (Ogawa et al. 1999). Pharmakologische Untersuchungen zeigen, daß die PPAR $\gamma 2$-Aktivierung durch Rosiglitazon (das stärkste synthetische PPAR $\gamma$-Agonist) zu einem signifikanten Verlust der Knochenmasse führte (Rzonca et al. 2004). 


\section{I.7. Aufgabenstellung}

Diese Arbeit beschäftigt sich mit der Untersuchung der in vitro Regulation der Plastizität bzw. der adipozytären Differenzierungskapazität primärer humaner Osteoblasten (pHOB).

$\mathrm{Da}$ in pHOB Zellen eine Transdifferenzierung zum Adipozyten unter einem definierten Adipogenesemedium nachgewiesen wurde (Nuttall et al. 1998; Prichett et al. 2000), bestand die erste Aufgabe darin, in den in dieser Arbeit verwendeten pHOB Zellen eine vollständige Differenzierung zu Adipozyten zu induzieren. Im Vergleich dazu sollte überprüft werden, ob dieser Transdifferenzierungsproze $ß$ auch in einer immortalisierten humanen Osteoblastenzellinie induziert werden kann.

Aufgrund der bisher existierenden widersprüchlichen Daten über den Effekt von BMP-2 auf die Expression adipozytärer und osteoblastärer Marker war die zweite Aufgabe, die Stimulierbarkeit dieser Marker unter verschiedene BMP-2-Konzentrationen in pHOB Zellen zu untersuchen.

Ein weiterer Schwerpunkt dieser Arbeit war die Untersuchung der Plastizität homogener Subpopulationen von pHOB Zellen. Hierbei sollte das adipozytäre Differenzierungspotential AP-negativer Zellen, die mittels magnetischer Zellsortierung gewonnen wurden (Ponce 2000), untersucht werden. Da die AP-negativen Zellen eine frühe Differenzierungsstufe (Osteoprogenitoren) darstellen, war die dritte Aufgabe, die Entwicklung dieser Zellen unter dem Einfluß von Osteoblastendifferenzierungsfaktoren einschließlich TGF- $\beta 1$ und BMP-2 zu untersuchen.

Die vierte Aufgabe dieser Arbeit war die Etablierung der FACS Sortings Methode zur Isolierung von AP-Subpopulationen aus pHOB Zellen. Dadurch sollten AP-positive und APnegative Subpopulationen aus den gleichen Patienten/ Kulturen gewonnen werden, um ihr adipozytäres Differenzierungspotential zu untersuchen bzw. zu vergleichen.

Die fünfte Aufgabe war die Untersuchung der endgültigen Phase der Differenzierung von Osteoblasten und Adipozyten. Hierbei sollten eventuelle unterschiedliche Langzeitwirkungen von BMP-2 und TGF- $\beta 1$ in pHOB Zellen beurteilt werden.

Schließlich umfaßte die letzte Aufgabe die Untersuchung der Plastizität von pHOB Zellen auf Einzelzellebene. Mittels Immunogoldzytochemie sollte hier die ultrastrukturale elektronen- 
mikroskopische Lokalisation adipozytärer und osteoblastärer Marker auf Einzellzellniveau erreicht werden. 


\section{Material und Methoden}

\section{II.1 Material}

\section{II.1.1 Zellmaterial}

\section{II.1.1.1 Primäre humane Osteoblasten (pHOB)}

Das spongiöse Knochenmaterial für diese Arbeit (Tab. II.1) stammte aus den Abteilungen für Unfallchirurgie (Prof. Dr. Stürmer) und Orthopädie (Prof. Dr. Schulz) des Klinikums Göttingen. Im Rahmen von korrektiven operativen Eingriffen angefallene und nicht mehr benötigte Spongiosa des Beckenkammes bzw. des Femurschaftes diente als Ausgangsmaterial für Primärkulturen. Sämtliche Patienten willigten schriftlich ein, daß das Knochenrestmaterial für experimentelle Untersuchungen verwendet werden durfte.

\begin{tabular}{|l|l|l|l|}
\hline HU & $16 /$ männlich & Spongiosa Beckenkamm & MACS-Versuch \\
\hline RN & $36 /$ männlich & Spongiosa Femurschaft & MACS-Versuch \\
\hline WS & $64 /$ männlich & Spongiosa Femurschaft & MACS-Versuch \\
\hline FK & $22 /$ männlich & Spongiosa distaler Femur & BMP-2 Versuch \\
\hline MB & $26 /$ männlich & Spongiosa distaler Femur & IBMX Versuch \\
\hline GS & $80 /$ männlich & Spongiosa proximaler Femur & FACS / FACS Sort \\
\hline KL & $54 /$ männlich & Spongiosa proximaler Femur & FACS/FACS Sort \\
\hline GH & $72 /$ männlich & Spongiosa proximaler Femur & FACS Sort \\
\hline HC & $54 /$ männlich & Spongiosa proximaler Femur & FACS Sort \\
\hline DJ & $76 /$ männlich & Spongiosa proximaler Femur & FACS Sort \\
\hline KA & $66 /$ männlich & Spongiosa proximaler Femur & FACS Sort \\
\hline KS & $65 /$ männlich & Spongiosa Beckenkamm & Alizarin Rot/ Red Oil \\
\hline
\end{tabular}

Tabelle II.1.: Angaben Knochenmaterial

\section{II.1.1.2. Humane immortalisierten osteoblastenzellinie (AHTO)}

Die in dieser Arbeit verwendete AHTO Zellinie wurde freundlicherweise von Herrn Abderrahim Lomri (Arbeitsgruppe: P.J. Marie, Cell and Molecular Biology of Bone and Cartilage, Lariborisière Hospital, Paris, France) zur Verfügung gestellt. Die AHTO Zellen sind eine Population differenzierter Osteoblasten, isoliert aus humanen trabekulären Knochen eines 65-jährigen gesunden Patienten, die durch die Genom-Insertion des SV-40 (LT) Oncogens immortalisiert wurden. Die AHTO Zellen wurden bezüglich ihrer in vitro Eigenschaften charakterisiert (Lomri et al. 1999). 


\section{II.1.2. Basismedien, Zusätze, Chemikalien und Kits}

\begin{tabular}{|c|c|}
\hline Chemikalien & Hersteller \\
\hline Agarose & Biozym, Hessisch-Oldendorf \\
\hline Albumin, Bovine Fraktion V 35\% (BSA) & Sigma, München \\
\hline $\begin{array}{l}\text { Alkalische Leukozytenphophatase } \\
\text { (ALP) Kit, AS-BI Lösung, FBB Lösung, } \\
\text { Natriumnitril Lösung }\end{array}$ & Sigma Diagnostics, München \\
\hline $\begin{array}{l}\text { AMP (2-Amino-2-methyl-propanol) } \\
\text { 95\% Lösung }(\mathrm{Mg}=89,14)\end{array}$ & Sigma, München \\
\hline Betaglycerophosphat & Sigma, München \\
\hline $\begin{array}{l}\text { BMP-2 (recombinant human) } \\
\text { (Bone Morphogenetic Protein 2) }\end{array}$ & Promocell, Heidelberg \\
\hline Borsäure $\left(\mathrm{H}_{3} \mathrm{BO}_{3}\right)$ & Sigma, München \\
\hline Bromphenolblau & Sigma, München \\
\hline $\mathrm{CaCl}_{2}$, wasserfrei & Merck, Darmstadt \\
\hline 1,25 Dihydroxyvitamin $\mathrm{D}_{3}$ (Calcitriol) & Hofmann La-Roche, Basel, Schweiz \\
\hline Dexamethason & \\
\hline DNA Ladder & Invitrogen, Karlsruhe \\
\hline dNTPs & Boehringer, Mannheim \\
\hline DMSO (Dimethylsulfoxid) & Merck, Darmstadt \\
\hline dT15 (RT-PCR-Primer) & Roche, Mannheim \\
\hline DTT (Dithiothreitol) & Invitrogen, Karlsruhe \\
\hline Dulbeccos MEM (Fertigmedium) & PAA, Colbe \\
\hline $\begin{array}{l}>\text { Dulbecco's mod eagle medium } \\
>\text { with } 0,11 \mathrm{~g} / 1 \mathrm{NaPyr} \text { with Pyridoxine }\end{array}$ & GIBCO Cat.No 41966-026 \\
\hline EDTA (Ethylendiamintetraessigsäure) & Sigma, München \\
\hline EDTA $(0,5 \mathrm{M})$ & Invitrogen, Karlsruhe \\
\hline Ethanol & Merck, Darmstadt \\
\hline Ethidiumbromid & Sigma, München \\
\hline FCS (Fetales Kälberserum) & Biochrom-Seromed, Berlin \\
\hline FCS (heat inactivated-charcoal stripped) & Allgaeu Biotech Service. Görisried \\
\hline Formaldehyd, mind. $37 \%$, säurefrei & Merck, Darmstadt \\
\hline Glycerin $(87 \%) \mathrm{C}_{3} \mathrm{H}_{8} \mathrm{O}_{3}$ & Merck, Darmstadt \\
\hline Glycogen & Roche, Mannheim \\
\hline Harnstoff $\left(\mathrm{H}_{2} \mathrm{~N} \mathrm{CO} \mathrm{NH} \mathrm{NH}_{2}\right)$ & Merck, Darmstadt \\
\hline HCL $37 \%$ & Merck, Darmstadt \\
\hline $\mathrm{K}_{2} \mathrm{H} \mathrm{PO}_{4}$ & Merck, Darmstadt \\
\hline $\mathrm{K} \mathrm{H}_{2} \mathrm{PO}_{4}$ & Merck, Darmstadt \\
\hline
\end{tabular}




\begin{tabular}{|l|l|}
\hline L-Glutamin- Lösung $(200 \mathrm{mM})$ & Gibco BRL, Berlin \\
\hline $\mathrm{MgCl}_{2}$ x $6 \mathrm{H}_{2} \mathrm{O}$ & Merck, Darmstadt \\
\hline $\mathrm{NaCl}$ & Baker, Deventer, Holland \\
\hline $\mathrm{NaN}_{3}$ & Merck, Darmstadt \\
\hline $\mathrm{NaOH}(1 \mathrm{~N})$ & Merck, Darmstadt \\
\hline NOVOCALCIN (ELISA/Osteokalzin) & Metra, Mountain View, USA. \\
\hline Oil Red O (Pulver) & Sigma, München \\
\hline PBS (Fertiglösung) & Gibco BRL, Colbe \\
\hline Penicillin/Streptomycin (Fertiglösung) & Gibco BRL, Colbe \\
\hline PNP (p-Nitrophenol) (gelbes Pulver-RT Lag.) & Sigma, München \\
\hline PNPP (p-Nitrophenylphosphat)(-20 ${ }^{\circ} \mathrm{C}$ Lag.) & Sigma, München \\
\hline Rnase-Inhibitor & Roche, Mannheim \\
\hline Sacharose $\left(\mathrm{C}_{12} \mathrm{H}_{22} \mathrm{O}_{11}\right)$ & Merck, Darmstadt \\
\hline $\begin{array}{l}\text { TGF- } \beta 1 \text { (natural human) } \\
\text { (Transforming Growth Factor } \beta 1)\end{array}$ & Promocell, Heidelberg \\
\hline Tris Base $\left(\mathrm{C}_{4} \mathrm{H}_{11} \mathrm{NO}_{3}\right)$ & Roth, Karlsruhe \\
\hline Trypanblau & Serva, Heidelberg \\
\hline $\begin{array}{l}\text { VitaminC: Ascorbat (L-Ascorbic Acid) } \\
\text { Pulver }\end{array}$ & $\begin{array}{l}\text { VitaminC: Ascorbat (L-Ascorbic } \\
\text { Acid) Pulver }\end{array}$ \\
\hline
\end{tabular}

\section{Enzyme}

\begin{tabular}{|l|l|}
\hline Trypsin-EDTA-Lösung (1x) & Gibco BRL, Colbe \\
\hline $\begin{array}{l}\text { Taq DNA Polymerase. (Cat No 1418432) } \\
\text { (dazu 10x First-Strand Buffer) }\end{array}$ & Roche, Mannheim \\
\hline M-MLV (dazu 5x First-Strand Buffer) & Invitrogen, Karlsruhe \\
\hline
\end{tabular}

\section{II.1.3. Medien und Lösungen}

Von allen frisch angesetzten Medien wurde eine 24-h-Sterilprobe $(5 \mathrm{ml})$ angelegt, die bei $37^{\circ} \mathrm{C}$ und $5 \% \mathrm{CO}_{2}$ im Brutschrank inkubiert wurde. Am folgenden Tag wurde die Probe mikroskopisch auf Kontamination untersucht.

\begin{tabular}{|c|l|l|}
\hline $\begin{array}{c}\text { AP-Assay-Lösungen } \\
\text { Stocklösung A }\end{array}$ & $100 \mathrm{ml}$ & Dest. Wasser \\
(Lagerung: RT) & $20,33 \mathrm{~g}(1 \mathrm{M})$ & $\mathrm{Mg} \mathrm{Cl}_{2} 6 \mathrm{H}_{2} \mathrm{O}$ \\
& \\
Stocklösung B & $0,4 \mathrm{ml}$ & Stocklösung A \\
(Lagerung:dunkel, RT) & $100 \mathrm{ml}$ & Dest. Wasser \\
& $10,1 \mathrm{ml}$ & AMP \\
\hline
\end{tabular}




\begin{tabular}{|c|c|c|}
\hline Reaktionspuffer & $63,14 \mathrm{~g}$ & PNPP \\
\hline (frisch angesetzt) & $30 \mathrm{ml}$ & Stocklösung B \\
\hline$\underline{\text { Standard Stocklösung }(100 \mathrm{x})}$ & $0,139 \mathrm{~g}(0,2 \mathrm{M})$ & PNP \\
\hline \multirow{2}{*}{ (Lagerung:dunkel, RT) } & $5 \mathrm{ml}$ & Dest. Wasser \\
\hline & $20 \mu 1$ & AMP \\
\hline \multicolumn{3}{|l|}{ Extraktionspuffer } \\
\hline \multirow[t]{7}{*}{ Lösung I (bei $4^{\circ} \mathrm{C}, 1$ Monat haltbar) } & $1,74 \mathrm{~g}$ & $\mathrm{~K}_{2} \mathrm{H} \mathrm{PO}_{4}$ \\
\hline & $0,20 \mathrm{~g}$ & $\mathrm{NaN}_{3}$ \\
\hline & $0,56 \mathrm{~g}$ & EDTA \\
\hline & $700 \mathrm{ml}$ & Dest. Wasser \\
\hline & & pH auf 7,5 einstellen.(mit Lösung II) \\
\hline & $115 \mathrm{ml}$ & Glycerin $(87 \%)$ \\
\hline & & mit dest. Wasser auf 1 Liter auffüllen \\
\hline \multirow[t]{2}{*}{ Lösung II } & $1,36 \mathrm{~g}$ & $\mathrm{~K} \mathrm{H}_{2} \mathrm{PO}_{4}$ \\
\hline & $200 \mathrm{ml}$ & Dest. Wasser \\
\hline \multirow{3}{*}{$\begin{array}{l}\text { DNA Ladder } \\
\text { (bei } 4^{\circ} \mathrm{C} \text { lagern) }\end{array}$} & $50 \mu 1$ & DNA Ladder \\
\hline & $450 \mu 1$ & Dest. Wasser \\
\hline & $100 \mu \mathrm{l}$ & Stopp Mix \\
\hline Ethidiumbromid-Stammlösung & $100 \mathrm{mg}$ & Ethidiumbromid \\
\hline$(10 \mathrm{mg} / \mathrm{ml})$ & $10 \mathrm{ml}$ & dest. Wasser \\
\hline \multirow[t]{4}{*}{ Adipogenese-Medium } & $500 \mathrm{ml}$ & DMEM (HOB) / $\quad$ (AHTO) \\
\hline & $50 \mathrm{ml}(10 \%)$ & FCS (charcoal stripped, heat inactivated) \\
\hline & $5 \mathrm{ml}$ & Pen/Strep \\
\hline & $5 \mathrm{ml}(2 \mathrm{mM})$ & L-Glutamin $(200 \mathrm{mM})$ \\
\hline AHTO-Medium & $500 \mathrm{ml}$ & Dulbeccos MEM \\
\hline \multirow[t]{3}{*}{ Standard } & $50 \mathrm{ml}(10 \%)$ & FCS \\
\hline & $5 \mathrm{ml}$ & Pen/Strep \\
\hline & $5 \mathrm{ml}(2 \mathrm{mM})$ & L-Glutamin (200 mM) \\
\hline HOB-Medium & $500 \mathrm{ml}$ & Dulbeccos MEM \\
\hline \multirow[t]{3}{*}{ Standard } & $50 \mathrm{ml}(10 \%)$ & FCS \\
\hline & $5 \mathrm{ml}$ & Pen/Strep \\
\hline & $5 \mathrm{ml}(2 \mathrm{mM})$ & L-Glutamin (200 mM) \\
\hline \multirow[t]{4}{*}{ HOB-BSA-Inkubationsmedium } & $100 \mathrm{ml}$ & Dulbeccos MEM \\
\hline & $286 \mu \mathrm{l}(0,1 \%)$ & BSA $(35 \%)$ \\
\hline & $1 \mathrm{ml}(0,8 \mathrm{mM})$ & $\mathrm{MgSO}_{4}(0,16 \mathrm{M})$ \\
\hline & $1 \mathrm{ml}$ & Pen/Strep \\
\hline Inkubationsmedium mit & $200 \mathrm{ml}$ & Inkubationsmedium \\
\hline $2 \mathrm{mM}$ Betaglycerophosphat & $115,2 \mathrm{mg}$ & ß-glycerophosphat \\
\hline Inkubationsmedium mit & $15 \mathrm{ml}$ & Inkubationsmedium \\
\hline
\end{tabular}




\begin{tabular}{|c|c|c|}
\hline $10^{-8} \mathrm{M}$ Dexamethason & $150 \mu \mathrm{l}$ & Dexamethason $\left(10^{-6} \mathrm{M}\right)$ \\
\hline $\begin{array}{l}\text { Inkubationsmedium mit } \\
4 \times 10^{-8} \mathrm{M} 1,25(\mathrm{OH})_{2} \mathrm{D}_{3}\end{array}$ & $\begin{array}{l}15 \mathrm{ml} \\
1 \mu \mathrm{l}\end{array}$ & $\begin{array}{l}\text { Inkubationsmedium } \\
1,25(\mathrm{OH})_{2} \mathrm{D}_{3} \text {-Stammlösung }\end{array}$ \\
\hline ЕTOH 90\% & $\begin{array}{l}100 \mathrm{ml} \\
1 \mathrm{ml}\end{array}$ & $\begin{array}{l}\text { ETOH }(99 \%) \\
\text { PBS }\end{array}$ \\
\hline $\begin{array}{l}\text { Oil Red O-Lösung ( 0,5\%ige } \\
\text { Stammlösung) }\end{array}$ & $\begin{array}{l}100 \mathrm{ml} \\
0,5 \mathrm{~g}\end{array}$ & \begin{tabular}{|l} 
Isopropylalkohol \\
Oil Red O (Pulver)
\end{tabular} \\
\hline PBS-Lösung & $\begin{array}{l}9,6 \mathrm{~g} \\
\text { ad } 1000 \mathrm{ml} \\
9,6 \mathrm{~g} \text { PBS enthalten : } \\
8 \mathrm{~g} \\
0,2 \mathrm{~g} \\
0,2 \mathrm{~g} \\
1,15 \mathrm{~g}\end{array}$ & $\begin{array}{l}\text { PBS } \\
\text { AMPUWA (dest. Wasser) } \\
\mathrm{NaCl} \\
\mathrm{KCl} \\
\mathrm{KH}_{2} \mathrm{PO}_{4} \\
\mathrm{NaHPO}_{4} \\
\text { Mit } \mathrm{HCl} \text { pH 7,6 einstellen }\end{array}$ \\
\hline PBS $(\mathrm{Ca} 2+, \mathrm{Mg}+), \mathrm{pH} 7,6$ & $\begin{array}{l}1000 \mathrm{ml} \\
0,2 \mathrm{~g}(18 \mathrm{mM}) \\
0,047 \mathrm{~g}(0,2 \mathrm{mM})\end{array}$ & $\begin{array}{l}\text { PBS-Lösung } \\
\mathrm{CaCl}_{2} \text { wasserfrei } \\
\mathrm{MgCl}_{2} \times \mathrm{H}_{2} \mathrm{O}\end{array}$ \\
\hline PBS/BSA $(0,5 \%, 2$ mM EDTA $)$ & $\begin{array}{l}100 \mathrm{ml} \\
1,436 \mathrm{ml} \\
0,2 \mathrm{ml}\end{array}$ & $\begin{array}{l}\text { PBS } \\
\text { BSA (35\%) } \\
\text { EDTA ( } 0,5 \text { M Stocklösung) }\end{array}$ \\
\hline PBS/BSA ( $1 \%, 5$ mM EDTA) & $\begin{array}{l}500 \mathrm{mg}(1 \%) \\
0,5 \mathrm{ml}(5 \mathrm{mM}) \\
\text { ad } 50 \mathrm{ml}\end{array}$ & $\begin{array}{l}\text { BSA } \\
\text { EDTA ( 0,5 M Stocklösung) } \\
\text { PBS }\end{array}$ \\
\hline PBS/Formaldehyd (1\%) & $\begin{array}{l}36 \mathrm{ml} \\
1 \mathrm{ml}(1 \%)\end{array}$ & $\begin{array}{l}\text { PBS } \\
\text { Formaldehyd (37\%) }\end{array}$ \\
\hline Stopp Mix & $\begin{array}{l}21 \mathrm{~g} \\
25 \mathrm{~g} \\
100 \mu \mathrm{l} \\
0,05 \mathrm{~g}\end{array}$ & $\begin{array}{l}\text { Harnstoff } \\
\text { Sacharose } \\
\text { EDTA }(0,5 \mathrm{M}) \\
\text { Bromphenolblau SIGMA } \\
\text { erst mit } 10 \mathrm{ml} \text { AMP lösen dann auf } \\
50 \mathrm{ml} \text { mit AMP auffüllen }\end{array}$ \\
\hline $\begin{array}{l}\text { 10x TBE Puffer } \\
\text { (PCR-Puffer) }\end{array}$ & $\begin{array}{l}108 \mathrm{~g} \\
55 \mathrm{~g} \\
20 \mathrm{ml} \\
400 \mathrm{ml}\end{array}$ & $\begin{array}{l}\text { Tris Base } \\
\text { Borsäure } \\
\text { EDTA }(0,5 \mathrm{M}, \mathrm{pH} 8) \\
\text { rühren lassen (pH ca. 8,46) } \\
\text { dest. Wasser } \\
\text { pH auf 8-8,2 mit 87\% HCl einstellen } \\
\text { mit dest Wasser auf } 1 \text { Liter auffüllen. }\end{array}$ \\
\hline Vitamin C Stammlösung & $125 \mathrm{mg}$ & Vitamin C \\
\hline
\end{tabular}




\begin{tabular}{|l|l|l|}
\hline (frisch ansetzen/ steril filtrieren) & $25 \mathrm{ml}$ & AMPUWA (dest. Wasser) \\
\hline Vitamin $\mathrm{D}_{3}$ Stammlösung & $250 \mu \mathrm{g}$ & $\begin{array}{l}1,25(\mathrm{OH})_{2} \mathrm{D}_{3} \\
\text { Ethanol } 99,9 \%\end{array}$ \\
\hline
\end{tabular}

\section{II.1.4 Antikörper}

\begin{tabular}{|l|l|l|}
\hline Primärantikörper & Spezies & Hersteller \\
\hline $\begin{array}{l}\text { anti-human BAP } \\
\text { Siggelkow et al. 1998; } \\
\text { Heinemann et al. 2000) }\end{array}$ & monoklonal $\left(\operatorname{IgG}_{2 \mathrm{~b}}\right)$, Maus & Metra, Mountain View, USA \\
\hline $\begin{array}{l}\text { Anti-LPL (5D2) } \\
\text { (Peterson et al. 1992; } \\
\text { Chang et al 1998) }\end{array}$ & Monoklonal, Maus & $\begin{array}{l}\text { Dr Brunzell, University of } \\
\text { Washington }\end{array}$ \\
\hline Anti Osteokalzin & polyklonal & BIT, MA, USA \\
\hline Anti-PPAR $($ E-8) & Monoklonal, Maus & Santa Cruz Biotechnology \\
\hline
\end{tabular}

FITC-markierte Antikörper

\begin{tabular}{|l|l|l|}
\hline anti-Maus IgG & polyklonal, Ziege & Sigma, München \\
\hline Anti-Ratte IgG & polyklonal Kanninchen & Dako, Denmark \\
\hline
\end{tabular}

Magnetpartikel-markierter Sekundärantikörper

\begin{tabular}{|l|l|l|}
\hline anti-Maus IgG2a+b & monoklonal, Ratte & $\begin{array}{l}\text { Miltenyi Biotec, Bergisch- } \\
\text { Gladbach }\end{array}$ \\
\hline
\end{tabular}

\section{II.1.5 Geräte}

\begin{tabular}{|l|l|}
\hline Geräte & Hersteller \\
\hline Absaugpumpe & Schütt, Göttingen \\
\hline Brutschrank & Heraeus, Osterode \\
\hline Brutschrank Stericult 2000 Inkubator & Forma Scientific \\
\hline FACScan 81553 & Becton-Dickinson Immunocytochemistry, \\
\hline Fireboy & Tecnomara, Fernwald \\
\hline Kühlzentrifuge Rotixa/K (Rotor 5094A) r=15cm & Hettich, Tuttlingen \\
\hline mini-MACS & Miltenyi Biotec, Bergisch-Gladbach \\
\hline Vario-MACS & Miltenyi Biotec, Bergisch Gladbach \\
\hline Mikroskop CK 2 mit Kamera SC35 & Olympus, Tokyo, Japan \\
\hline Pipettboy Plus & Tecnomara, Fernwald \\
\hline Tischzentrifuge 5415 C; r=7cm & Eppendorf, Hamburg \\
\hline Zentrifuge Hettich Rotixa/A (Rotor 6267) & Hettich, Tuttlingen \\
\hline
\end{tabular}




\section{II.1.6. Zellkulturgefäße und Hilfsmittel}

\begin{tabular}{|l|l|}
\hline Kulturgefäße & Hersteller \\
\hline Greiner-Petrischalen, 94 x $16 \mathrm{~mm}$ & Greiner, Nürtingen \\
\hline Greiner-Petrischalen, 60 x $15 \mathrm{~mm}$ & Greiner, Nürtingen \\
\hline Sarstedt-Petrischalen, 100 x $20 \mathrm{~mm}$ & Nunc, Roskilde, Dänemark \\
\hline Gewebekulturflaschen & Nunc, Roskilde, Dänemark \\
\hline Eppendorfcups: $500 \mu 1$ & Eppendorf GmbH, Hamburg \\
\hline Falcon 2054 Pst 20x75 mm Round Bottom Tube & Becton Dickinson, USA \\
\hline Filme Kodak Ektachrome 64 T (Profesional) & Kodak \\
\hline LR-Gold (hydrophile Kunststoff ) & London Resin Co. Ltd. \\
\hline Sarstedt 15ml-Röhrchen & Sarstedt, USA \\
\hline PPN-Röhrchen 21026, KO, 30x115 mm, 50ml & Greiner, Nürtingen \\
\hline Mikroplatte 651101, V-Form, 96 Well & Becton Dickinson, New Jersey, USA \\
\hline Nalgene Sterilization Filter $\varnothing 0,2 \mu \mathrm{m}, 115 \mathrm{ml}$ & Sybron, Hereford, England \\
\hline Sterilfilter Minisart $\varnothing ~ 0,2 \mu \mathrm{m}, \varnothing 0,45 \mu \mathrm{m}$ & Sartorius, Göttingen \\
\hline Container für flüssigen Stickstoff & Cryoson, Schöllkrippen \\
\hline Cryoröhrchen & Nalgene, Hereford, England \\
\hline Einfriercontainer für Cryoröhrchen & Nalgene, Hereford, England \\
\hline Neubauer-Zählkammer & Neubauer \\
\hline Pasteur-Pipetten & Brand \\
\hline Spritzen 5/10/20 ml & Braun, Melsungen \\
\hline Trennsäule (Vario-MACS) A1 & Miltenyi Biotec, Bergisch Gladbach \\
\hline
\end{tabular}




\section{II.2. Methoden der Zellkultur}

Alle Arbeiten mit Zellkulturen sowie Herstellung der Lösungen wurden unter sterilen Bedingungen (Sterilbank Federal Standard 209b, Ceag Schirp Reinraumtechnik, Bork/Westfalen) durchgeführt. Vor jedem Füttern wurden die Zellkulturen mikroskopisch (Mikroskop CK2 mit Kamera SC 35, Olympus, Tokyo, Japan) auf Kontamination untersucht.

Die Kultivierung der Zellen fand unter kontrollierten Bedingungen, $37^{\circ} \mathrm{C}, 5 \% \mathrm{CO}_{2}$ und $95 \%$ Luftfeuchtigkeit, in einem Brutschrank (Brutschrank Stericult 2000 Inkubator, Forma Scientific) statt.

\section{II.2.1. Anlegen einer Primärkultur aus humanen Knochen}

Primäre Knochenkulturen wurden nach einer früher beschriebenen Methode angelegt (Auf' $m$ Kolk et al. 1985; Beresford et al. 1984; Siggelkow et al. 1998). Die erste Lagerung der Knochenstücke erfolgte im Operationssaal in steriler physiologischer Kochsalzlösung $(0,9 \% \mathrm{NaCl})$. Wenn eine sofortige Weiterverarbeitung direkt nach der Knochenentnahme nicht möglich war, wurde die Kochsalzlösung gegen ein Nährmedium für pHOB Zellen (HOB-Medium) ausgetauscht und dann das Knochenmaterial über Nacht bei $4^{\circ} \mathrm{C}$ gelagert.

Am Aufarbeitungstag wurde zuerst das Knochenmaterial gewaschen und gleichzeitig mit Pinzette und Skalpell der spongiöse Knochen vom kortikalen und anderen Gewebe wie z.B. Fettgewebe getrennt und zerkleinert. Dafür wurden die Knochenfragmente in mehrere mit $10 \mathrm{ml}$ PBS $(\mathrm{Ca} 2+, \mathrm{Mg}+)$ gefüllte Gewebekulturschalen $(10 \mathrm{~cm} \varnothing)$ überführt und wiederholt zerkleinert. Die Anzahl der Waschschritte richtete sich nach dem Blutinhalt des Probenmaterials, je blutiger dieses war, desto mehr waren erforderlich bis das Material komplett weiß erschien.

Je nach vorhandener Knochenmenge wurden bis zu zehn Gewebekulturschalen $(10 \mathrm{~cm} \varnothing)$ mit je $3 \mathrm{ml}$ HOB-Medium gefüllt, wo die Fragmente letzmalig überführt und zerkleinert wurden. Um jedes 0,5-2 mm große Knochenfragment befand sich danach ein Hof von Medium. Diese Primärkulturen wurden anschließend im Brutschrank weiterkultiviert. In der ersten Woche wurden kleine Mengen Medium zugefügt um Verdunstungen auszugleichen. Danach erfolgte zweimal pro Woche ein ganzer Mediumwechsel, wobei abhängig von der Anzahl der aus dem Knochen emigrierten Zellen 4 bis $7 \mathrm{ml}$ vorsichtig, möglichst ohne die Fragmente wegzuspülen, in die Petrischalen pipettiert wurden.

Wenn nach Ablauf von 3-4 Wochen die Knochenstücke von Zellen dicht umwachsen waren, wurden sie zur Ablösung trypsiniert und dann entweder zur Weiterkultivierung passagiert oder in flüssigem Stickstoff $\left(-196^{\circ} \mathrm{C}\right)$ gelagert. 


\section{II.2.2. Ablösung durch Trypsinierung}

Das Medium wurde unter Vakuum abgezogen. Je nach Kulturgefäß wurde mit auf $37^{\circ} \mathrm{C}$ vorgewärmten PBS das FCS aus der Kultur gewaschen. FCS würde sonst im folgenden Schritt die Trypsin-Aktivität hemmen und eine Ablösung der Zellen verhindern. Nach 10 min Inkubation bei RT wurde das PBS abgezogen und zu der jeweiligen Kultur (auf $37^{\circ} \mathrm{C}$ vorgewärmten) Trypsin-EDTA-Lösung (1x) pipettiert. Die Zellen sollten dabei von der Trypsin-Lösung gut bedeckt werden. Das Trypsinieren erfolgte bei $37^{\circ} \mathrm{C}$, Zellen die sich nach 10 min noch nicht vom Boden gelöst hatten, wurden mit kurzen kräftigen Schlägen des Kulturgefäßes gegen eine harte Fläche abgelöst. Das Trypsin wurde durch Zugabe der 4-fachen Menge eines serumhaltigem Mediums gestoppt. Die gesamte Zellsuspension wurde je nach Volumen in das geeignete Röhrchen überführt und abzentrifugiert. Der Überstand wurde verworfen und die Zellen wurden zur Weiterkultivierung mit Medium auf eine bestimmte Konzentration eingestellt.

\section{II.2.3. Passagierungsmethoden}

Eine Passage wurde als eine bestimmte zeitliche Phase des Wachstums von Zellen bezeichnet, welche durch eine Ablösung (z.B.:Trypsinierung) beendet wurde. Wurden z.B. die Zellen einer Primärkultur trypsiniert und passagiert, dann wuchsen diese weiter in der 1. Passage. Diese 1. Passage endete mit der darauffolgenden Trypsinierung. Zellen, die als 1. Passage eingefroren wurden, wurden nach dem Auftauen als 2. Passage weiterkultiviert.

Die Zellen, die nach der Trypsinierung als Zellpellet vorlagen, wurden in Medium resuspendiert, nachdem die Zellkonzentration der Suspension durch Zählung in einer Neubauer-Zählkammer ermittelt worden war. Die Zellen wurden je nach Versuchsplan in einer bestimmten Anzahl/ Napf oder Flasche ausgesät (Tab. II.2)

\begin{tabular}{|c|c|c|}
\hline & AHTO-Zellen & pHOB-Zellen \\
\hline Zelldichte & $1,3 \times 10^{4}$ Zellen $/ \mathrm{cm}^{2}$ & $4 \times 10^{3}$ Zellen $/ \mathrm{cm}^{2}$ \\
\hline Konfluenz & Tag 2 & Tag 10 \\
\hline
\end{tabular}

Tab. II.2: Zelldichte 


\section{II.2.4. Einfrieren von Knochenzellen}

Es besteht die Möglichkeit Zellen in Suspension einzufrieren. Je nach Versuchsablauf wurde das erhaltene Zellpellet in auf $37^{\circ} \mathrm{C}$ vorgewärmten $1,5 \mathrm{ml}$ HOB-Medium (10\% DMSO) resuspendiert. Die Zellsuspension wurde in ein 2-ml-Kryoröhrchen überführt, und dann in einen bei RT gelagerten Einfriercontainer (Nalgene Cryo $1{ }^{\circ} \mathrm{C}$ freezing Container, Sybron, Hereford, England) eingesetzt. Dieser Einfriercontainer wurde sofort über Nacht in eine $-80^{\circ} \mathrm{C}$ Gefriertruhe gestellt. Am nächsten Tag wurde das Röhrchen bis zu seiner weiteren Verwendung in flüssigem Stickstoff (Cryoson ABR-48 (-196 ${ }^{\circ}$ ), Cryoson Deutschland, Schöllkrippen) gelagert.

\section{II.2.5. Auftauen von Knochenzellen}

Das tiefgefrorene Kryoröhrchen wurde aus dem Stickstoffbehälter entnommen und im Wasserbad bei $37^{\circ} \mathrm{C}$ solange erwärmt, bis gerade das letzte Eiskristall gelöst war. Die Zellsuspension wurde zur Neutralisation des zelltoxischen DMSO sofort unter sterilen Bedingungen in ein 15 ml-Röhrchen überführt, das bereits $10 \mathrm{ml}$ Medium enthielt. Anschließend erfolgte eine Zentrifugation in einer Kühlzentrifuge für 10 min (pHOB-Zellen: $370 \mathrm{~g}$ ). Nach Abziehen des Überstandes wurde das Zellpellet in auf $37^{\circ} \mathrm{C}$ vorgewärmten $10 \mathrm{ml}$ Medium resuspendiert und die Zellsuspension auf Zellkulturflaschen zur Weiterkultivierung verteilt. Nach einer Inkubationszeit von mindestens $12 \mathrm{~h}$ im Brutschrank erfolgte ein Mediumwechsel, um auch die letzten Spuren des toxischen DMSO zu entfernen.

\section{II.2.6. Vitalitätstest mit Trypanblau}

Tote Zellen nehmen den Farbstoff Trypanblau auf, lebende dagegen schließen ihn aus und erscheinen im Mikroskop farblos. Zur Färbung der Zellen wurde das Zellpellet in PBS resuspendiert und $20 \mu 1$ dieser Zellsuspension mit $20 \mu 1$ Trypanblau (0,5\%ig) vorsichtig vermischt. Die Zellen wurden sofort in einer Neubauer-Zählkammer gezählt.

\section{II.3. Durchflußzytometrie (FACS)}

Ein Durchflußzytometer erlaubt die gleichzeitige Messung von Fluoreszenz- und Streulichtsignalen an einzelnen Zellen. Relative Zellgröße, Granularität, sowie drei verschiedene Fluoreszenzintensitäten können für mehrere tausend Zellen in weniger als einer Minute ermittelt werden. Grundvoraussetzung zur Messung ist das Vorliegen der Probe als Einzelzellsuspension in einer Konzentration von etwa 0,5 bis 20 Millionen Zellen/ml. 
Zur Analyse wird die in einem Probenröhrchen befindliche Zellsuspension über eine Stahlkapillare durch Überdruck in die aus Quarzglas bestehende Meßküvette eingeführt. Die Zellen passieren, von einem Hüllstrom umgeben, den Analysepunkt. Der Hüllstrom dient dazu, den Probenstrom im Zentrum der Meßküvette zu stabilisieren und so zu verengen, daß die Zellen hintereinander einzeln zum Analysepunkt gelangen. Dieses Prinzip wird als hydrodynamische Fokussierung bezeichnet (Abb. 8).

Der Analysepunkt ist definiert als der Ort, an dem der Lichtstrahl (Laserstrahl) den Flüssigkeitsstrahl kreuzt. Nur Zellen die tatsächlich diesen Punkt treffen, werden korrekt erfaßt, analysiert und klassifiziert. Durch die Interaktion dieser Lichtstrahl mit einer Zelle wird das Licht gestreut. Dieser physikalische Prozess, der als Lichstreuung bezeichnet wird, dient als Maß für bestimmte Zelleneigenschaften.

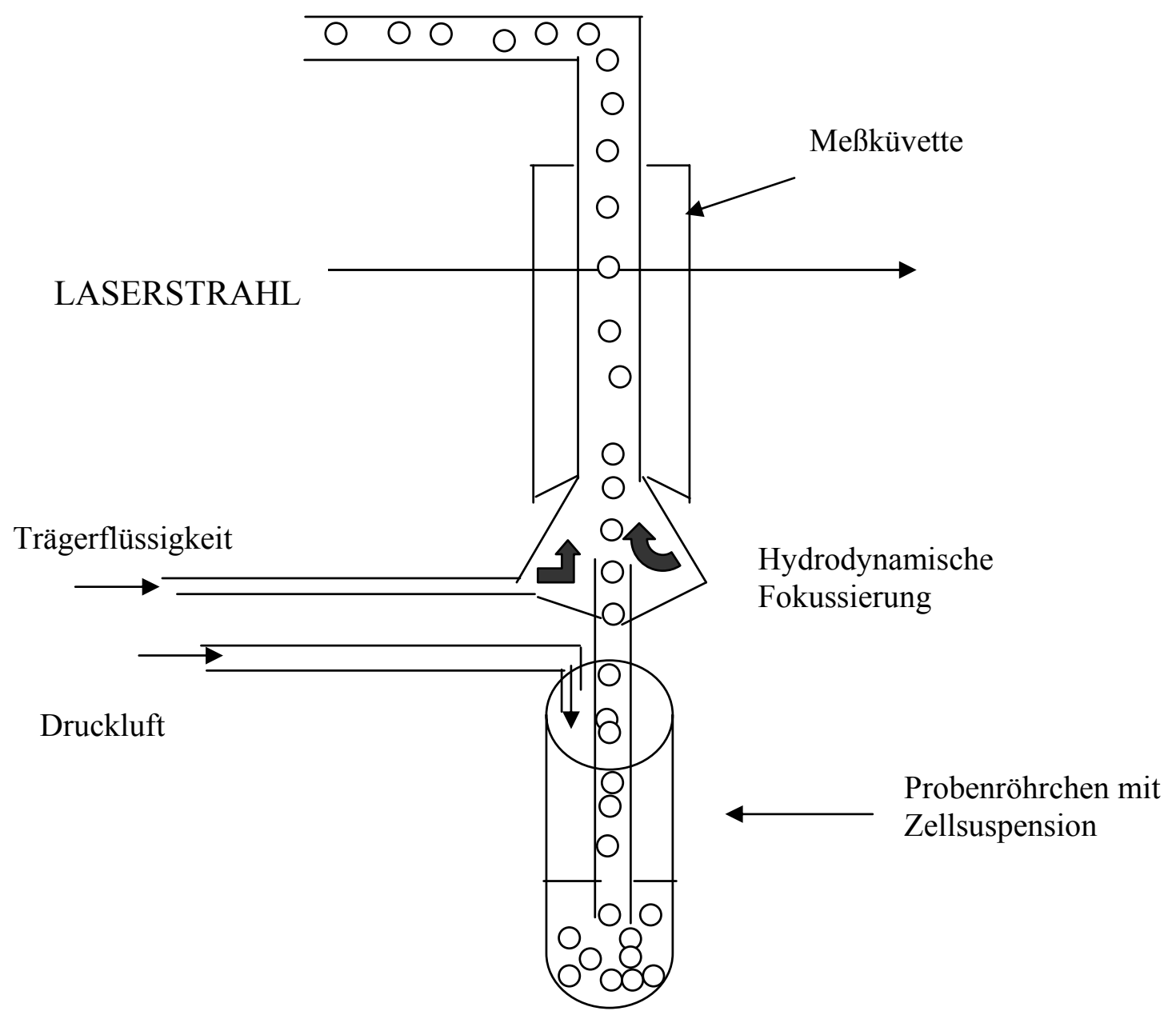

Abb. 8: Schematische Darstellung des FACS Analyse Prinzips.

Der größte Teil des auf eine Zelle treffenden Laserstrahls wird in Vorwärtsrichtung (Forward light scatter, FSC) gestreut. Diese Streuung dient als Maß für die Zellgröße, das bedeutet, kleine 
Zellen streuen weniger Licht. Streulicht im Winkel von $90^{\circ}$, gemessen als Seitwärtsstreulicht (side light scatter, SSC), dient als Maß für die intrazelluläre Granularität.

Trägt eine Zelle Fluoreszenzfarbstoff-konjugierte Antikörper, so absorbieren diese den Laserstrahl, werden angeregt und emitieren daraufhin Licht einer höheren Wellenlänge. Durch diese Fluoreszenzanalyse lassen sich Proteine (Marker), die bei bestimmten Differenzierungsstadien exprimiert werden, nachweisen, und die Zellen, die diesen Phänotyp entsprechen, als „positiv“ klassifiziert.

In dieser Arbeit wurden Fluoresceinisothiocyanat (FITC) konjugierte Antikörper verwendet, die Licht mit einem Emissionsgipfel bei $\lambda=530 \mathrm{~nm}$ (Grünfluoreszenz) emittieren und im Kanal FL1 des FACScan 81533 (Becton Dickinson Immunocytochemistry Systems, Mountain View, CA, USA) gemessen wurden.

\section{II.3.1. Vorbereitung von Zellen auf eine FACS Analyse}

Die FACS Analyse wurde nach einer früher beschriebenen Methode (Siggelkow et al. 1998), die in unserem Labor optimiert wurde, durchgeführt.

Das Medium wurde 24 Stunden vor dem Versuch gewechselt. Am Tag der Analyse wurden die Zellen trypsiniert, das Zellpellet in PBS resuspendiert und zentrifugiert $\left(10 \mathrm{~min}, 4^{\circ} \mathrm{C}, 370 \mathrm{~g}\right)$. Das Zellpellet wurde in PBS resuspendiert und auf eine Konzentration von 1 x 106 Zellen/ ml eingestellt. Von dieser Zellsuspension wurden jeweils $100 \mu$ l, d.h. 100.000 Zellen/ Napf einer 96erNapf-Mikrotiterplatte pipettiert. Je nach untersuchtem Parameter wurden die Ansätze unterschiedlich weiterbehandelt.

\section{II.3.1.1. Proteinnachweise}

Um die Zellen bezüglich charakteristischer Antigene (Proteine) zu untersuchen, wurden sie indirekt immunozytochemisch in zwei sukzessiven Inkubationen markiert.

1. Inkubation: Dazu wurden die Zellen mit einem monoklonalen BAP (human bone alkaline phosphatase, Metra Biosystems Palo Alto, CA, USA) Primärantikörper in der Verdünnung 1:50 inkubiert (20 min, RT, auf Schüttler: 100 UPM). Die Zellen wurden im Anschluß abzentrifugiert (6 min, RT; 329 g; Hettich Rotixa/ A) und zweimal in $160 \mu$ l PBS gewaschen (6 min, 329 g, RT).

2. Inkubation: Dazu wurden die Zellen mit einem FITC-konjugierten Sekundärantikörper in der Verdünnung 1:50 inkubiert (20 min, RT, auf Schüttler 100 UPM, im Dunkeln). Um unspezifische Bindungen an Humanproteine zu vermeiden, wurde der Sekundärantikörper im Verhältnis 4:1 (Antikörper: Humanserum) präabsorbiert. Nach der zweiten Inkubation wurden die Zellen abzentrifugiert und zweimal gewaschen. Jedes Zellpellet wurde für die folgende FACS-Analyse in PBS/ 1\% Formaldehyd aufgenommen und bei $4^{\circ} \mathrm{C}$ bis zur Analyse aufbewahrt. 
Um eventuelle Veränderung bei der Bindung des BAP-Primärantikörpers berücksichtigen zu können, wurden zwei Kontrollen durchgeführt.

Zur Kontrolle der unspezifischen Bindung des BAP-Primärantikörpers wurden die Zellen mit einem monoklonalen Antikörper (TG-13 statt BAP) inkubiert. Da die pHOB-Zellen keine TG13 Antigen exprimieren, wurde diese Kontrolle als Negativ-Kontrolle berücksichtigt.

Zur Kontrolle der intakten Bindung des BAP-Primärantikörpers wurden HOS-58-Zellen (Humane Osteosarkom Zelllinie) mit dem BAP Primärantikörper inkubiert. Da die HOS-58-Zellen BAP-Antigen konstitutiv exprimieren, wurde diese Kontrolle als Positiv-Kontrolle der BAPAntikörper berücksichtigt. Dadurch konnten eventuelle Effekte auf die Qualität der Antikörper kontrolliert werden.

\section{II.3.1.2. Autofluoreszenzansatz}

Zum Test auf Autofluoreszenz wurden die Zellen nur mit PBS inkubiert. Durch diese Kontrolle konnten die Eigenschaften (Größe, Granularität, Autofluoreszenz für die FACS Analyse) der Zellen und eventuelle Effekte, die auf die Reagenzien zurückführen waren, festgestellt werden (Abb. 9). Bis auf die fehlenden Antikörper, waren alle Inkubations- und Waschschritte identisch zum Proteinnachweis.

\section{II.3.1.3. Hintergrundansatz}

Zur Spezifitätskontrolle des FITC-konjugierten Sekundärantikörpers (Abb. 10) wurden die Zellen nur mit dem präabsorbierten Sekundärantikörper inkubiert.. Die erste Inkubation wurde nur mit PBS durchgeführt, alle weiteren Schritte entsprachen denen des Proteinnachweises.

\section{II.3.2. FACS-Zellanalyse}

Die in PBS/ 1\% Formaldehyd aufgenommenen Zellen wurden innerhalb einer Stunde nach Ende der Inkubationen in einem FACScan-Gerät untersucht. Die Auswertung erfolgte mit dem FACScan-Programm Research Software Version 2.1.

\section{II.3.3. Grenzwertbestimmung}

Die Analyse-Fenster des FACScan-Gerätes wurden nach einer früheren Optimierung (Hilmes, 1996) eingerichtet. Zur Analyse wurden die Grenzwerte (Gates) für die Größe (FSC) und Granularität (SSC) mit Hilfe des Autofluoreszenz-Ansatzes festgelegt, um die für die Knochenzellen spezifische Zellwolke einzugrenzen (Abb. 9). Mit dem Hintergrund-Ansatz des FITCkonjugiertAntikörpers wurde der Fluoreszenz-Grenzwert (FL1) ermittelt (Abb. 10). Die positiven Zellen der Analyse mußten mit ihrer Fluoreszenz über diesem Grenzwert liegen. 


\section{Bestimmung der Grenzwerte für Zellgröße und -granularität}

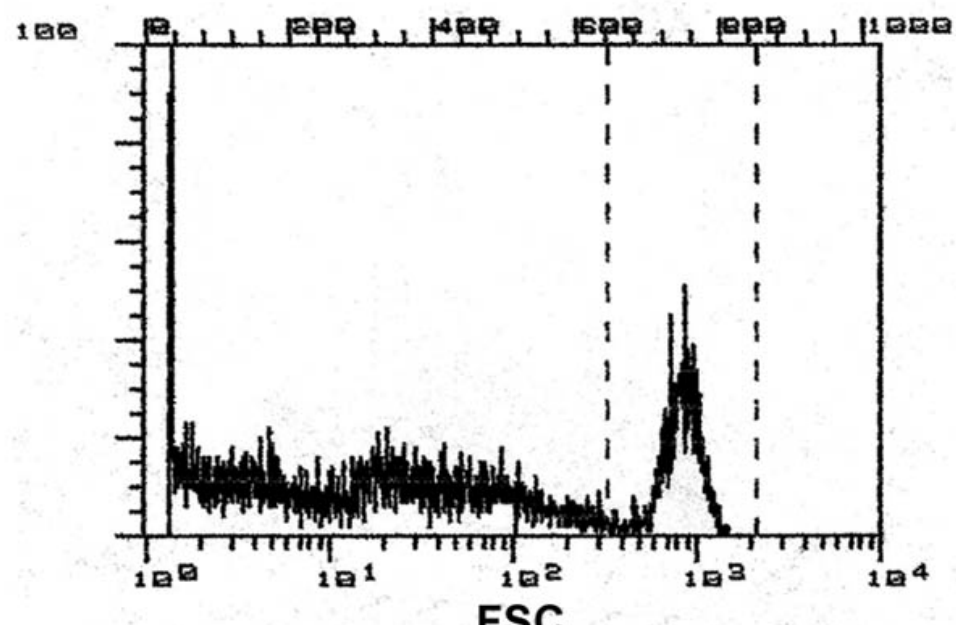

A

$1 \mathrm{ag}$

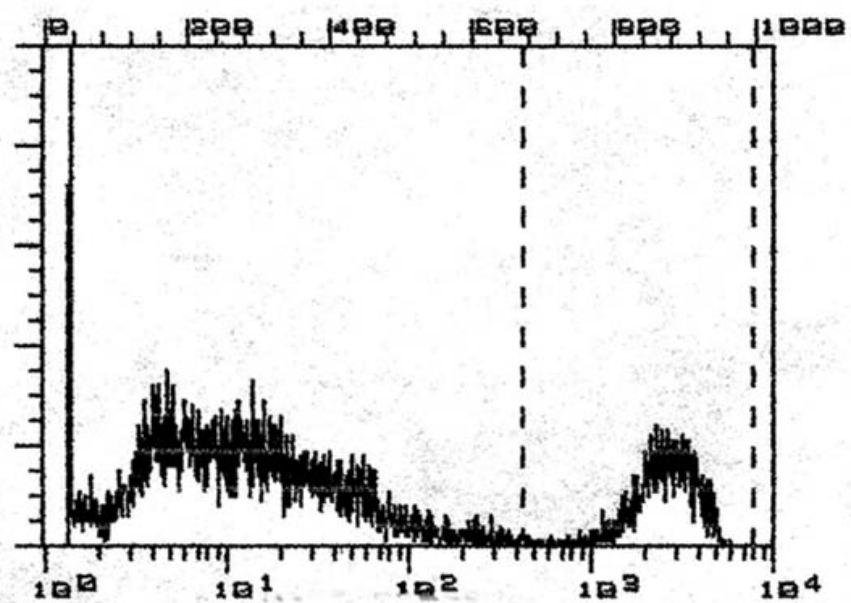

B

C

SSC

D
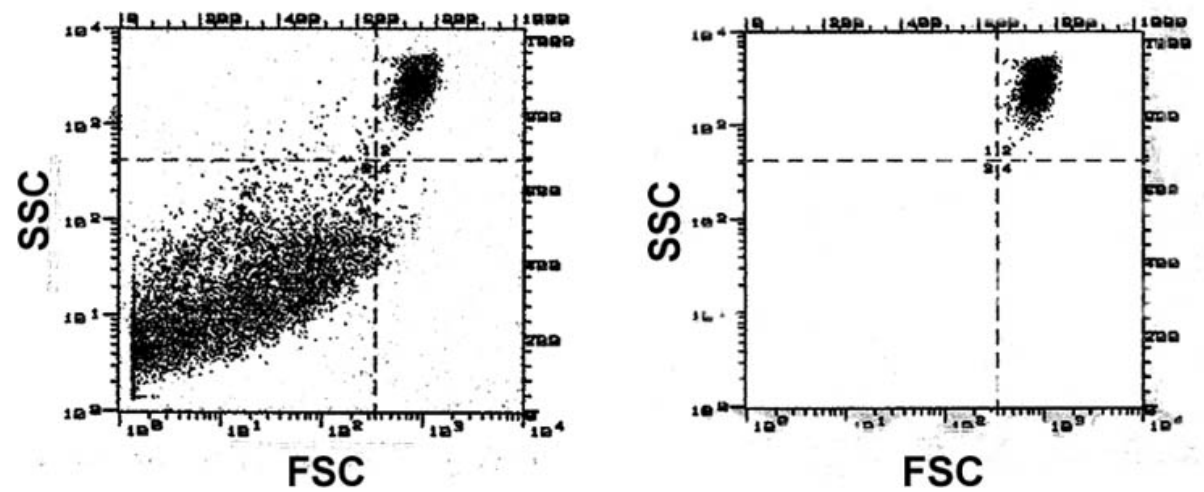

Abb. 9: Beispiel für die Bestimmung der Grenzwerte (Gates) für Zellgröße (FSC) und Zellgranularität (SSC). Für diese Analyse wurden 10.000 Ereignisse des Autofluoreszenz-Ansatzes (ohne Zusatz von Antikörpern) gemessen. In der Histogramm-Darstellung (A, B) wurden anhand von Zellgröße (A) und Granularität (B) die deutlich erkennbaren Peaks von den Zelltrümmern abgegrenzt Die Linien die diese Peaks eingrenzen bezeichnen die entsprechenden Grenzwerte. Die Grenzwerte wurden automatisch in die Dot Plot-Darstellung (C, D) übernommen. Die intakten Zellen wurden als Wolke von den Zelltrümmern abgegrenzt (C). Nach der Aktivierung der Grenzwerte (Gates) erschienen nur die intakten Zellen (D).

FSC: forward scatter (Vorwärtsstreulicht), SSC: sideward scatter (Seitwärtsstreulicht) 


\section{Bestimmung der Grenzwerte für die Hintergrundfluoreszenz}

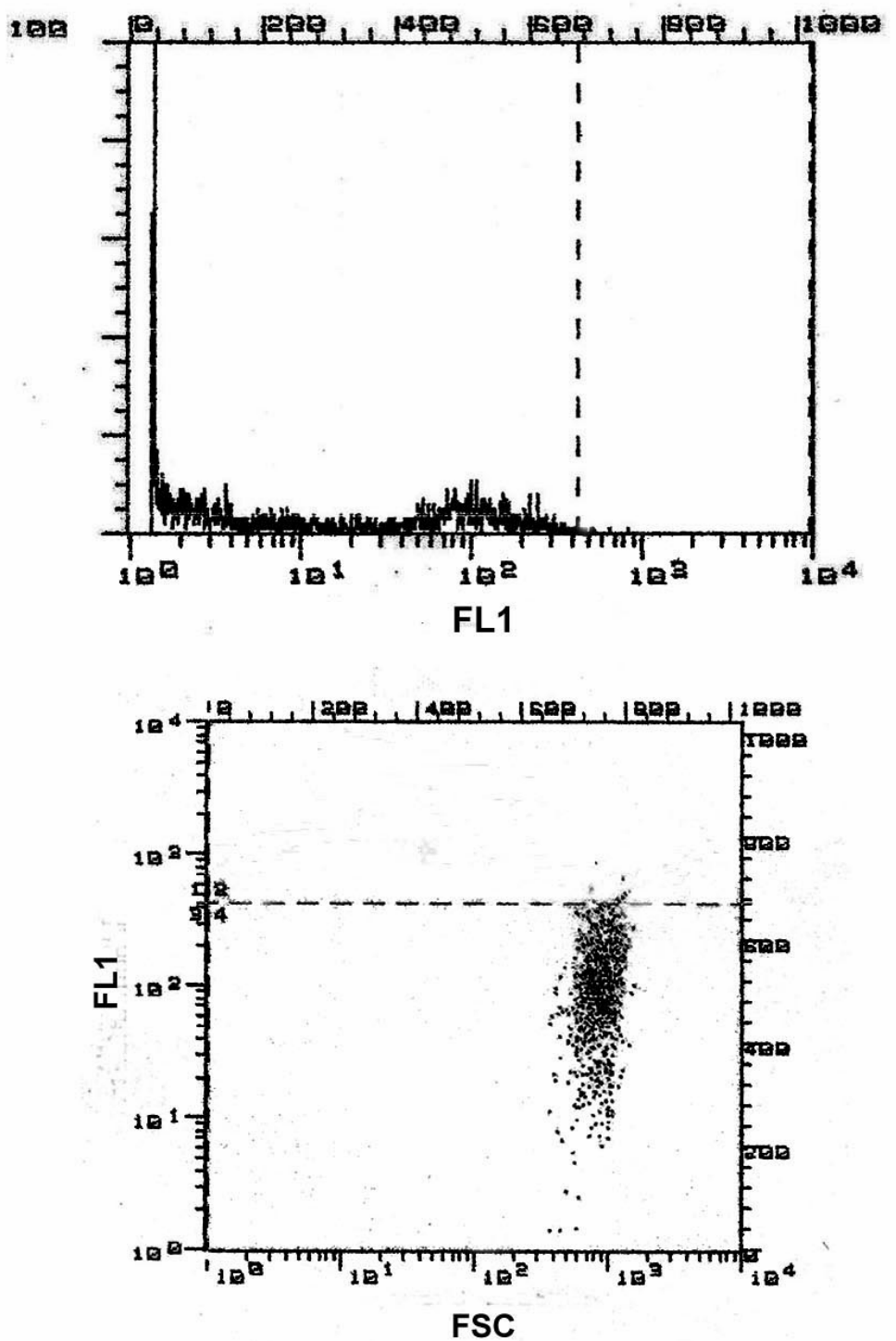

A

B

Abb. 10: Beispiel für die Bestimmung der Grenzwerte (Gates) für die Hintergrundfluoreszenz (FL1). Für diese Analyse wurden 10.000 Ereignisse des Hintergrundfluoreszenz-Ansatzes (nur mit Sekundär- bzw. Tertiärantikörper) gemessen. Um die unspezifische Bindung des FITCkonjugierten Sekundärantikörpers oder Tertiärantikörpers, wurde der Grenzwert ermittelt bis zu dem dieses Antikörper in der Lage ist auch ohne einen Primärantikörper an Zellen zu binden.

In der Histogramm-Darstellung (A) wurden die positiven Zellen zwischen die Linien den Bereich abgegrenzt (rechts) in den die tatsächliche positiven Zellen in der späteren Analyse finden sollen. In der Dot Plot-Darstellung (B) wurden die intakten Zellen die unspezifisch den entsprechenden Antikörper binden als Wolke dargestellt. Die Wolke der tatsächlich positiven intakten Zellen soll über der Linie erscheinen. 


\section{II.3.4. Auswertung}

Nach Festlegung der Grenzwerte konnten diese auf die bereits gemessenen Ereignisse angewendet werden. Alle Ereignisse, die im Bereich der Grenzen für Größe und Granularität lagen, wurden als Zellen erkannt (Abb. 9). Unter diesen Zellen wurden anschließend diejenigen ermittelt, die eine Fluoreszenzintensität (positiv) aufwiesen.

Der prozentuale Anteil positiver Zellen wird wie folgt berechnet:

\begin{tabular}{|c|}
\hline Zahl der positiven Zellen \\
\hline Zahl der intakten Zellen \\
\hline
\end{tabular}

\section{II.4. Magnetische Zellsortierung (MACS)}

Lebendige Zellen lassen sich aufgrund eines bestimmten charakteristischen Membranproteins (Antigen) durch die magnetische Zellsortierung Methode physikalisch trennen. Das erfolgt durch die gleichzeitig indirekte Markierung mit magnetisch- und FITC- gekoppelten Antikörpern (Abb. 11).

Die Sortierung der positiven- und negativen-Zellen wurde mit einem MACS-Gerät (VarioMACS, Miltenyi, Bergisch-Gladbach) durchgeführt (Abb. 12)

Da die sortierten Zellen weiterkultiviert werden sollten, benötigten alle Arbeitsschritte sterile Bedingungen. Für die Versuche wurde eine in unserem Labor optimierte Methode angewandt (Hilmes, 1996).

\section{II.4.1. Markierung der pHOB-Zellen für die magnetische Zellsortierung.}

Das Medium wurde 24 Stunden vor jedem Versuch gewechselt. Am Tag der MACS-Sortierung wurden die Zellen trypsiniert und in PBS gewaschen. Das resultierende Zellpellet wurde auf eine Konzentration von 1 x 106/ ml eingestellt. Von dieser Zellsuspension wurden $3 \mathrm{ml}\left(3 \times 10^{6}\right.$ Zellen) als Markierungsansatz in ein 15-ml-Röhrchen überführt. Parallel wurde zweimal je $1 \mathrm{ml}$ $\left(1 \times 10^{6}\right.$ Zellen) dieser Zellsuspension zu Kontollzwecke in 15-ml-Röhrchen pipettiert.

Insgesamt wurden 3 Ansätze durchgeführt, für die die gleiche Behandlung (wie bei der Markierungansatz) galt aber mit den folgenden Unterschieden:

1. Markierungsansatz: Zellen, die mit dem Primärantikörper (BAP-Ak), Sekundärantikörper (MACS-Microbead-Ak) und Tertiärantikörper (FITC-konjugiert) inkubiert wurden (Abb. 11). 
2. Kontrollen

2.1 Autofluoreszenzansatz: Die Zellen wurden nur mit PBS inkubiert. Durch diese Kontrolle konnten die Eigenschaften (Größe, Granularität, Autofluoreszenz für die FACS Analyse) der Zellen und eventuelle Effekte, die auf die Reagenzien zurückzuführen sind, berücksichtig werden (Abb. 9)

2.2 Hintergrundansatz: Die Zellen wurden nur mit dem Tertiärantikörper (FITC-konjugiert-Ak) inkubiert. Diese Kontrolle diente zum Nachweis der unspezifischen Bindung des Tertiärantikörpers für die FACS Analyse (Abb. 10)

Alle folgenden Inkubationen und Waschschritte wurden in PBS durchgeführt.

Die Zellen des Markierungsansatzes wurden mit einem monoklonalen BAP-Antikörper in der Verdünnung 1:50 inkubiert (20 min, RT, auf Schüttler: 100 UPM). Nach der Inkubation wurden die Zellen zentrifugiert ( $\left.8 \mathrm{~min}, 4^{\circ} \mathrm{C}, 1500 \mathrm{UPM}\right)$, im Ausgangsvolumen resuspendiert und erneut zentrifugiert.

Für die 2. Inkubation wurde die Zellen in $180 \mu 1$ PBS resuspendiert und mit $20 \mu 1$ MACSMicrobead-Ak (20 min, RT, auf Schüttler: 100 UPM) inkubiert.

In dieser Zeit wurde der anti-Ratte FITC-konjugierte (polyclonal Kaninchen, Dako, Dänemark) Tertiärantikörper mit Humanserum (1:4) präabsorbiert (20 min, RT, im Dunkeln) und dann zentrifugiert (10 min, 16000g, RT).

Die inkubierten Zellen wurden zentrifugiert ( $\left.8 \mathrm{~min}, 4^{\circ} \mathrm{C}, 1500 \mathrm{UPM}\right)$ in $3 \mathrm{ml}$ gewaschen, erneut zentrifugiert. Für die 3. Inkubation wurde das Zellpellet in $3 \mathrm{ml}$ aufgenommen und mit dem präabsorbierten FITC-Tertiärantikörper (1:50) (20 min, RT, auf Schüttler, im Dunkeln) inkubiert.

Nach dieser letzten Inkubation wurden die Zellen identisch gewaschen. Die beiden Kontrollansätze wurden nach der Vorbereitung je in $1 \mathrm{ml}$ PBS/ 1\% Formaldehyd aufgenommen, gezählt und bis zur FACS-Analyse im Kühlschrank aufbewahrt.

Die Zellen des Markierungsansatzes wurden in PBS/ 1\% BSA aufgenommen, gezählt und jeweils ein Aliquot (ungetrennte Fraktion; UF: $10^{5}$ Zellen) bis zur FACS-Analyse im Kühlschrank aufbewahrt. 


\section{Markierung Protein-positiver Zellen mit Antikörpern für die magnetische Zellsortierung}

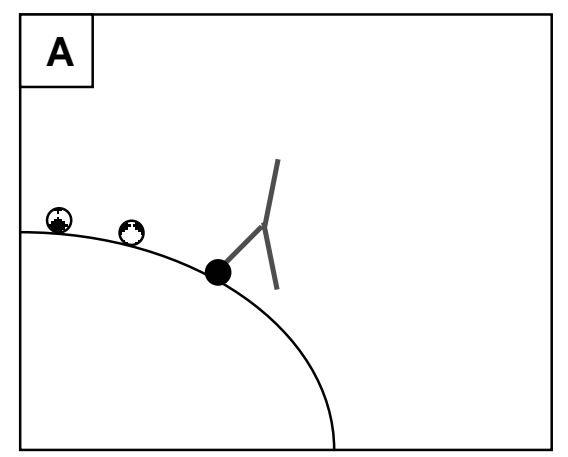

- Protein

z.B.: BAP

1

\section{Primärantikörper}

(anti-Human, Maus)

z.B.: BAP-Ak

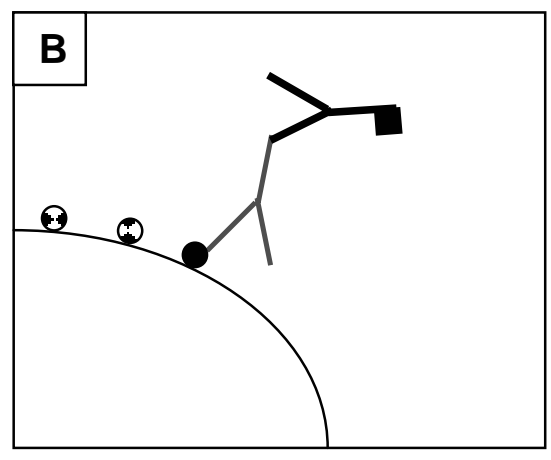

$\gamma$

„Microbead"--markierter

Sekundärantikörper

(anti-Maus, Ratte)
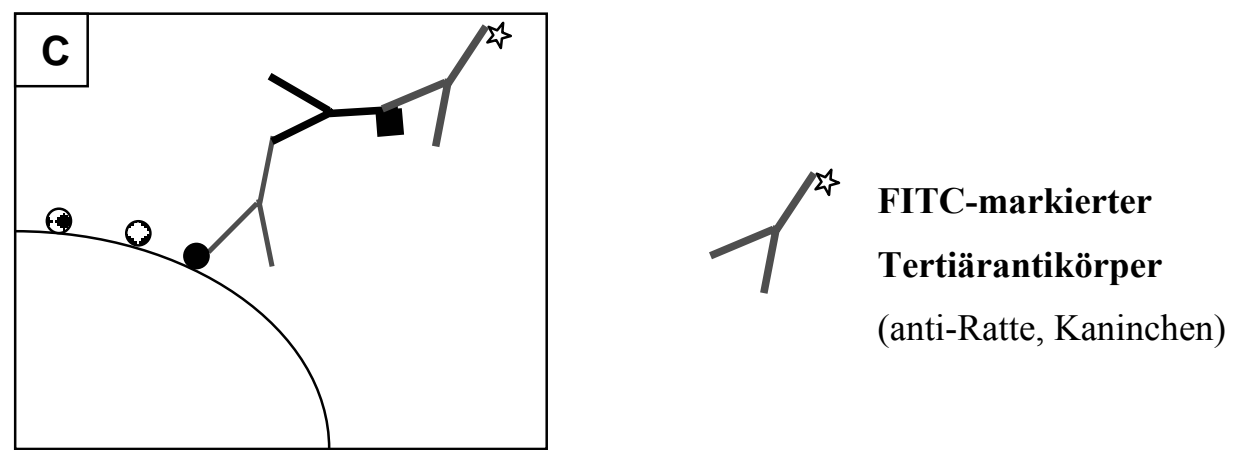

Abb. 11: Markierung Protein-positiver Zellen mit den verschiedenen Antikörpern

A: 1. Inkubation: Der Primärantikörper bindet an das gesuchte Protein (z.B.: BAP) auf der Zelloberfläche.

B: 2. Inkubation: Der „Microbeads“-Sekundärantikörper bindet an den Primärantikörper.

C: 3. Inkubation: Der FITC-markierte Tertiärantikörper bindet an den Sekundärantikörper. 


\section{II.4.2. Magnetische Zellsortierung}

Zur Sortierung der magnetisch-markierten (Abb. 12) Zellen wurde ein MACS-Gerät mit der Trennsäule AS (Säulenvolumen $(\mathrm{SV})=1 \mathrm{ml}$ ) verwendet. Zunächst mußte die Säule für die Trennung vorbereitet werden. Die Säule wurde über einen am Boden befestigten Dreiwegehahn langsam von unten mit 70\% Ethanol gefüllt, ohne daß sich Luftblasen in der Säule bildeten. Die gefüllte Säule wurde zwischen die Magneten des MACS-Gerätes eingesetzt und mit vier Säulenvolumen PBS /1\%BSA /5 mM EDTA von oben gespült. Eine Spritze mit PBS / 1\% BSA wurde über den Dreiwegehahn mit der Säule verbunden. Von oben (zum Kühlen der Säule) flossen durch die Säule 2 SV eisgekühltes PBS/ 1\% BSA. An die Ausflußöffnung des Dreiwegehahns wurde eine Kanüle Größe 17 gesteckt und mit $1 \mathrm{ml}$ PBS/ 1\% BSA aus der Spritze gespült.

Die Zellen des Markierungsansatzes (ohne Aliquot) wurden mit einer Pipette auf die Säule aufgetragen. Aufgrund der magnetischen Wirkung wurden die markierten (positiven) Zellen in der Säule gehalten. Die nicht-markierten (negativen) Zellen flossen durch und konnten als 1. Durchfluß in einem Röhrchen aufgefangen werden (Abb. 12, a). Zum Spülen wurden 4 SV PBS/ 1\% BSA auf die Säule pipettiert und der Durchfluß in demselben Röhrchen aufgefangen. Die Säule wurde erneut mit 2 SV gespült, wobei der Durchfluß in einem 2. Röhrchen aufgefangen wurde. Nach diesen Spülvorgängen wurde die Kanüle entfernt. Eine mit 4 Säulenvolumen PBS/ 1\% BSA gefüllte Spritze wurde über ein Deckelverbindungsstück von oben mit der Säule verbunden. Die Säule wurde mit der aufgesteckten Spritze von Magneten entfernt. Die markierten Zellen wurden mit Hilfe des Spritzeninhaltes aus der Säule gespült (Abb. 12, b).

Zum Regenerieren der Säule wurden nacheinander 20 SV PBS, 20 SV bidestilliertes Wasser und 5 SV Ethanol (95 \%) auf die Säule pipettiert.

Nach der Sortierung wurden Aliquots $\left(10^{5}\right.$ Zellen) von jeder Fraktion (Ungetrennter, Negativer, Positiver) in PBS/ 1\% Formaldehyd fixiert und dann im FACS analysiert. 


\section{Magnetische Zellsortierung Protein-positiver und -negativer Zellen}

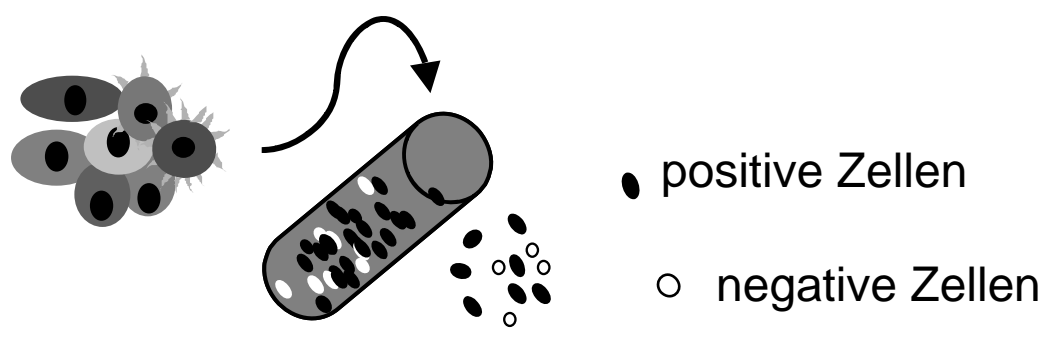

ungetrennte Zellen

a

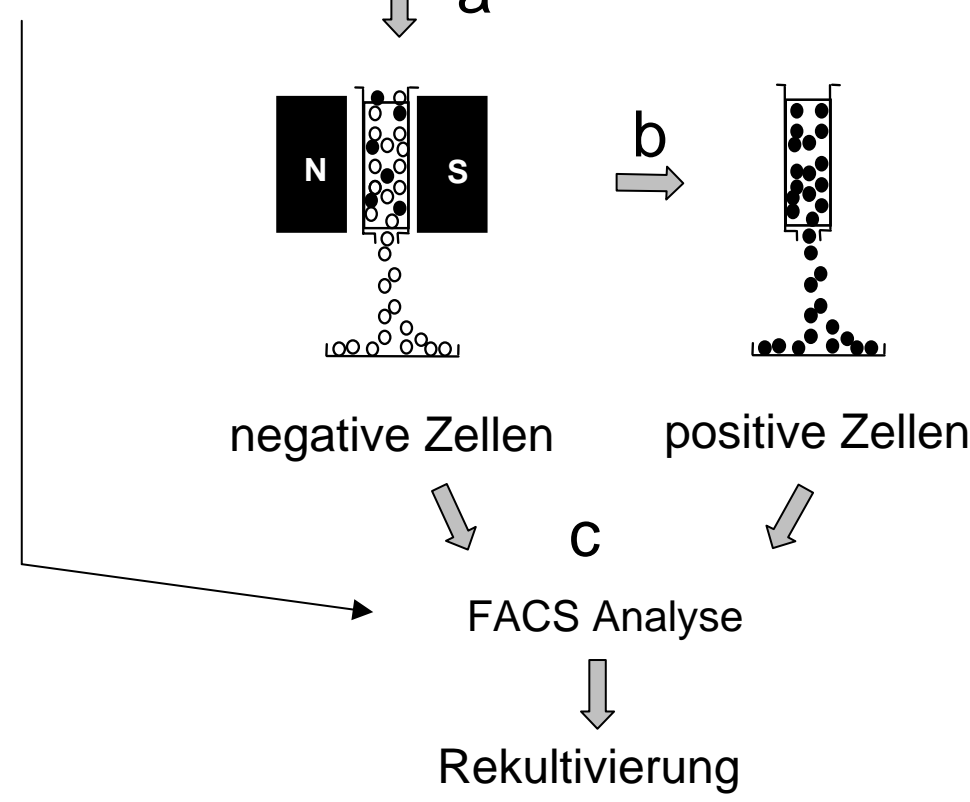

Abb. 12: Magnetische Zellsortierung (MACS) Protein-positiver und negativer Zellen. (Übersicht)

a: die gesamten Zellen werden in die Säule zwischen die Magneten (N und S) eines MACS-Gerätes eingebracht. Während die positiven Zellen (magnetisch-markiert) in der Säule gehalten werden, fließen die Negativen hindurch.

b: Die Säule wird vom Magneten entfernt und die positiven Zellen kommen so bei dem Spülvorgang aus der Säule.

c: Nach der Sortierung (vor der Rekultivierung) werden die ungetrennten, positiven und negativen Fraktionen im FACS analysiert. 


\section{II.5 Fluoreszenzaktivierte Zellsortierung (FACS Sorting)}

Eine Zellsuspension, die mit fluoreszenten Antikörpern gefärbte Zellen enthält, wird mit Druckluft aus dem Probenröhrchen durch einen dünnen Schlauch und ein Metallröhrchen in eine Düse gepresst (Abb. 13). Die Zellen treten aus dem Metallröhrchen in das Zentrum der Düse ein und aus der $70 \mu \mathrm{m}$ weiten Öffnung wieder aus. Von der Seite wird eine isotone Hüllflüssigkeit zugeführt. Die Zellen werden innerhalb der Düse enorm beschleunigt (bis zu $10000 \mathrm{~g}$ ), wodurch sie einer erheblichen Belastung ausgesetzt werden. Die Geschwindigkeit der Zellen beim Austritt aus der Düse beträgt ca. $9 \mathrm{~m} / \mathrm{s}$. Etwa $0,3 \mathrm{~mm}$ unterhalb der Düsenöffnung trifft ein fokussierter Laserstrahl den austretenden Flüssigkeitsstrahl. Die den Laserstrahl passierenden Zellen streuen das Licht in verschiedene Richtungen, zusätzlich senden die zuvor mit fluoreszierenden Antikörpern gekoppelten Zellen Fuoreszenzlicht aus. Das von den Zellen in Richtung des Lasers gestreute Licht wird von einer speziellen Optik in einem relativ engen Winkel erfaßt und mit einem Lichtsensor als sogenanntes Vorwärtsstreulicht gemessen (FSC), das ein Maß für die Zellgröße ist. Das vom Mikroskopobjektiv hinter der Düse aufgefangene Licht ist das sogenannte Seitwärtsstreulicht (SCC) und das emittierte Fluoreszenzlicht der Antikörper-Fluoreszenzkonjugate. Während das Seitwärtsstreulicht ein Maß für die Granularität der Zellen ist, ist das Fluoreszenzlicht für die verwendeten Fluorochrome spezifisch. Es wird durch einen optischen Interferenzfilter nach Wellenlängen getrennt und gelangt auf die hochempfindlichen Lichtsensoren. Die verschiedenen Signale einer Zelle werden durch eine spezielle Elektronik weiterverarbeitet und graphisch dargestellt.

In dieser Arbeit wurde die „Dot-Plot“ Darstellung gewählt, eine zweidimensionale Darstellung zweier Parameter. Jede Zelle wird entsprechend ihrer Werte für Parameter 1 (X-Achse) und Parameter 2 (Y-Achse) zwischen X- und Y-Achse als Punkt eingetragen. Auf dem „Dot-Plot“ lassen sich Flächen (Gates) für die Sortierung markieren. Die betreffenden Zellen werden dann von der Elektronik abgelenkt. Die Zellen fliegen nach der Messung zum Abrißpunkt, wo der Flüssigkeitsstrahl durch einen piezoelektronischen Schwingungsgeber stabilisiert, in Tröpfchen aufbricht (20-200000 Tröpfchen/ sek). Dabei werden die Zellen in einzelne Tröpfchen verpackt. Soll eine Zelle isoliert werden, wird das Tröpfchen kurz vor dem Abreißen vom Strahl mit einer elektrischen Ladung versehen. Es durchfliegt ein elektrostatisches Feld, das von zwei geladenen Metallplatten $(3 \mathrm{kV})$ erzeugt wird, und wird in Richtung des Auffangröhrchens abgelenkt. 


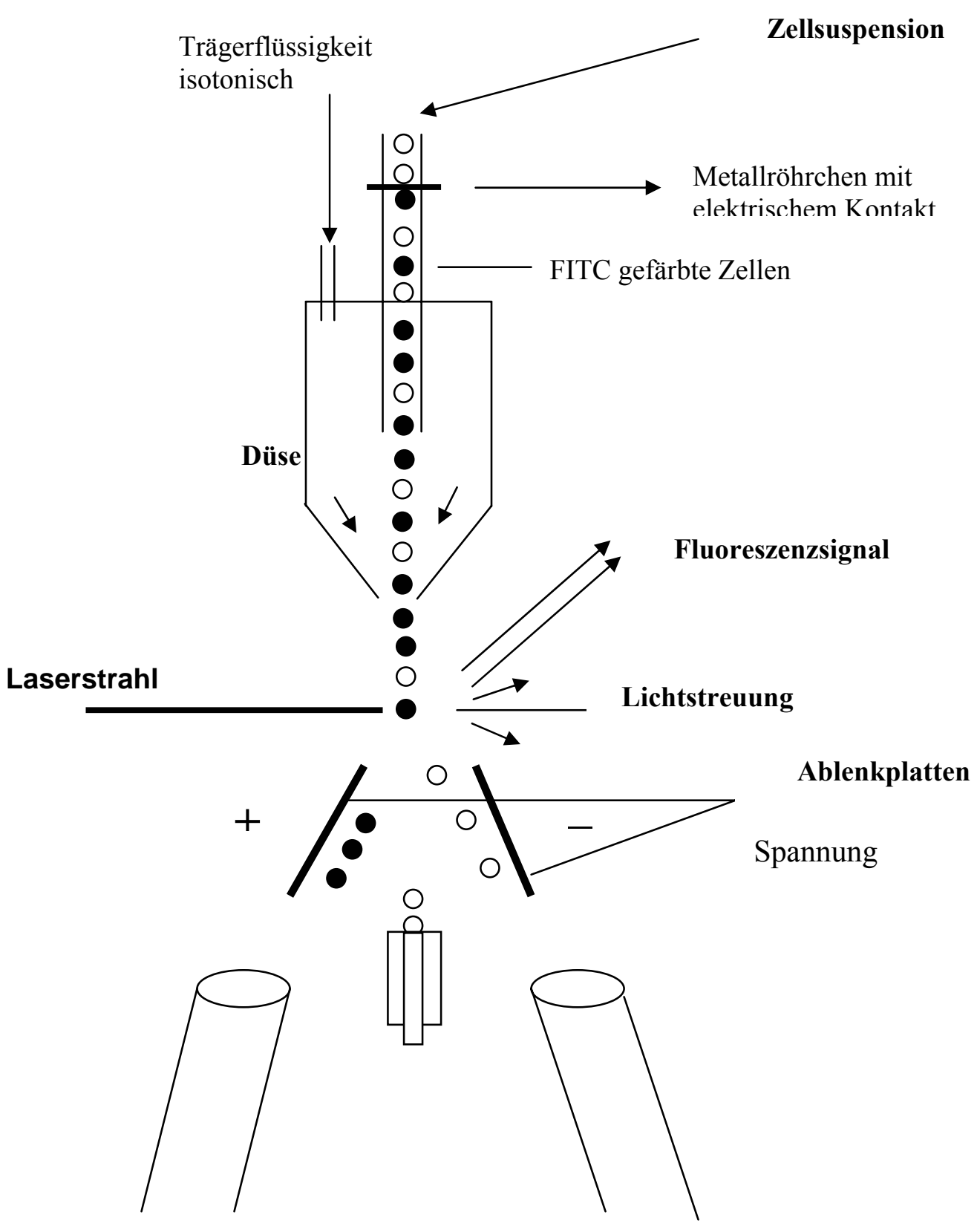

Abb. 13: Schematische Darstellung des FACS Sorting Prinzips

Die zum Teil mit fluoreszierenden Antikörpern markierte Zellsuspension wird mit Druckluft durch eine Düse gepresst, gleichzeitig wird eine Trägerflüssigkeit zugeführt. Unterhalb der Düsenöffnung trifft der Flüssigkeitsstrahl auf einen fokussierten Laserstrahl. Die den Laserstrahl passierenden Zellen streuen das Laserlicht, die markierten Zellen emittieren zusätzlich Fluoreszenzlicht. In Richtung des Laserstrahls wird das Vorwärtsstreulicht gemessen, im rechten Winkel das Seitwärtsstreulicht und die Fluoreszenzen. Am Abrisspunkt bricht der Flüssigkeitsstrahl in Tröpfchen auf. Die Tröpfchen können während des Abreißens vom Flüssigkeitsstrahl mit elektrischer Ladung versehen werden, indem kurzfristig der gesamte Flüssigkeitsstrahl aufgeladen wird. Geladene Tröpfchen mit den gewünschten Zellen werden beim Durchfliegen des elektrischen Feldes zwischen den geladenen Ablenkplatten in die jeweiligen Auffangröhrchen abgelenkt. 


\section{II.5.1 Markierung der pHOB-Zellen für die FACS Sorting}

Wenn es nicht anders beschrieben wurde, erfolgte die Markierung der Zellen für die FACS Sorting grundsätzlich analog der unter den II.4.1 angegebenen Markierung für die MACS Sortierung.

Insgesamt wurden 3 Ansätze durchgeführt, für die die gleiche Behandlung (wie bei der Markierungansatz) galt aber mit dem folgenden Unterschiede:

1. Markierungsansatz: Die Zellen wurden mit dem Primärantikörper (monoklonal, AP-Ak), und Sekundärantikörper (polyklonal, FITC-konjugiert) inkubiert.

2. Kontrollen

2.1 Autofluoreszenzansatz: Die Zellen wurden nur mit PBS inkubiert. Durch diese Kontrolle konnten die Eigenschaften (Größe, Granularität) der Zellen erfasst werden.

2.2 Hintergrundansatz: Die Zellen wurden nur mit dem Sekundärantikörper (FITC-konjugiertAk) inkubiert. Diese Kontrolle diente zum Nachweis der unspezifischen Bindung des Sekundärantikörpers.

Anhand dieser beiden Kontrollen lassen sich die Zellen als „Dot-Plot“ darstellen und lassen sich die Gates für die Sortierung markieren.

Die FACS Sorting wurde von Frau Boguscha Sadowski (Arbeitsgruppe Prof. Dr. Gerald Wulf) aus der Abteilung Hämatologie und Onkologie des Klinikums Göttingen durchgeführt. 


\section{II.6. Nachweis osteoblastencharakteristischer Marker}

\section{II.6.1. Enzymaktivität der Alkalische Phosphatase}

Die AP-Enzymaktivität wurde im Zellpellet (quantitativ) und in fixierten Zellen als zytochemische Färbung (qualitativ) nachgewiesen.

\section{II.6.1.1. Assay zum Nachweis der AP-Aktivität im Zellpellet}

Die Zellschicht entsprechender Näpfe wurde trypsiniert, die Zellzahl bestimmt und der Rest als trockenes Pellet für die Bestimmung der AP-Aktivität bei $-80^{\circ} \mathrm{C}$ gelagert. Am Tag der Bestimmung wurde das Pellet aufgetaut und mit $40 \mu$ l Extraktionspuffer gelöst. Zur Fragmentierung der Zellen wurden die gelösten Proben dreimal eingefroren und aufgetaut und anschließend (10 s) mit einem Ultraschall-Homogenisator beschallt. Die Zellfragmenten wurden 15 min $(15000 \mathrm{~g})$ in der Tischzentrifuge sedimentiert und anschließend die Überstände für die Bestimmung der AP-aktivität weiterverwendet.

Die Bestimmung der AP-Aktivität erfolgte nach der in unserem Labor etablierten Methode. Die Umwandlung (Farbreaktion: gelb) von p-nitrophenylsubstrat (PNPP) zu p-nitrophenol (PNP) durch die in den einzelnen Proben AP diente zur Nachweis der Enzymaktivität $(n=4)$. Die APReaktionspuffer enthielt $8 \mathrm{mM}$ p-nitrophenilphophat in 0,5 AMP-Puffer (2-amino-2methyl.1.propanol) mit $0,2 \mathrm{mM} \mathrm{MgCl} 2$. In jedes Well einer auf Eis gelagerten Microtiterplatte wurden $10 \mu 1$ Probe und $100 \mu 1$ AP-Reaktionspuffer pipettiert und gemischt. Um die enzymatische Reaktion zu starten, wurde die Platte für $10 \mathrm{~min}$ im Wasserbad auf $37^{\circ} \mathrm{C}$ erwärmt.

Die Reaktion wurde mit $50 \mu 11 \mathrm{~N} \mathrm{NaOH}$ pro Napf gestoppt. Innerhalb der nächsten Stunde wurde die Extintion bei $405 \mathrm{~nm}$ gemessen.

Bei jedem Assay wurde eine Standard-Kurve erstellt und die Konzentration der Proben durch Interpolation bestimmt. Die quantitative Messung wurde auf die jeweilige Zellzahl (Zählung des entsprechenden Pellets) bezogen und die Ergebnisse als pmol / minute / $10^{5}$ Zellen dargestellt.

\section{II.6.1.2. Zytochemische Färbung zur Nachweis der AP-Aktivität}

Die AP Enzymaktivität lässt sich als Zytochemische Färbung mit AP-Kit 86-C (SIGMA Diagnostics, Deutschland) nach dem folgenden Prinzip nachweisen.

Farbreaktion $\left\{\begin{array}{l}\text { Naphthol AS-BI Phosphat } \longrightarrow \text { Naphthol AS-BI + Phosphat } \\ \text { Naphthol AS-BI }+ \text { Fast Blue BB Salz } \longrightarrow \text { blaues Pigment }\end{array}\right.$

Die adhärenten Zellen wurden zweimal mit PBS vorsichtig gespült und dann 20 min mit Ethanol (90 \%) fixiert. Nach der Fixierung wurden die Zellen zweimal mit PBS und zweimal 
destilliertem Wasser gespült. Für die Farbreaktion, die möglichst unmittelbar durchgeführt werden sollte, wurde die folgende Reaktionslösung eingesetzt.

- $50 \mu \mathrm{l}$ alkalische FBB-Lösung

- $50 \mu \mathrm{l}$ Natriumnitrit-Lösung

vorsichtig mischen, 2 min stehenlassen

- $2,25 \mathrm{ml}$ destilliertes Wasser

- $50 \mu \mathrm{l}$ alkalische Naphthol AS-BI

gut mischen, sofort verwenden.

Die Zellen wurden mit der Reaktionslösung 15 min im Dunkeln bei RT inkubiert. Die Färbung wurde mit destilliertem Wasser abgestoppt und dann gründlich zweimal gespült. Die Zellen wurden mit PBS oder destillierten $\mathrm{H}_{2} \mathrm{O}$ überschichtet und bei $-20^{\circ} \mathrm{C}$ gelagert. Blau gefärbte Zellen wurden als AP-positiv bzw. die ungefärbte als AP-negativ klassifiziert.

\section{II.6.2. Kollagen-I Sekretion}

Die Kollagen-I Sekretion wurde durch die Kollagen-I C-terminale Propeptid (CICP) Konzentration mittels eines Sandwich Immunoassay (Metra Biosystems, Palo Alto, CA, USA) im Überstand bestimmt. Dafür wurden die Zellüberstände bei $-80^{\circ} \mathrm{C}$ bis zum Tag der Bestimmung gelagert. Die quantitative Messung wurde (Doppelbestimmung) nach dem Herstellerprotokoll durchgeführt.

Das gesamte im Überstand gemessene CICP wurde auf die jeweilige Zellzahl (Zählung des entsprechenden Pellets) bezogen und die Ergebnisse als ng/ $10^{5}$ Zellen/ Tag dargestellt.

\section{II.6.3. Osteokalzinsekretion}

Osteokalzinsekretion wurde mittels eines Sandwich Immunoassay (Metra Biosystems, Palo Alto, CA, USA) im Überstand bestimmt. Dafür wurden die Zellüberstände bei $-80^{\circ} \mathrm{C}$ bis zum Tag der Bestimmung gelagert. Die quantitative Messung wurde (Doppelbestimmung) nach dem Herstellerprotokol durchgeführt.

Das gesamte im Überstand gemessene Osteokalzin wurde auf die jeweiligen Zellzahl (Zählung des entsprechenden Pellets) bezogen und die Ergebnisse als pg/ $10^{5}$ Zellen/ Tag dargestellt.

\section{II.6.4. Mineralisationsnachweis (Alizarinrot-Färbung)}

Die Alizarinrot-Färbung wurde für den Nachweis eines Mineralisationsprozesses verwendet. Die durch diese Methode gefärbten Mineralisationskerne erscheinen rot im Lichtmikroskop. Die adhärenten Zellen wurden mit eiskaltem Ethanol (90 \%) für 1 Stunde (RT) fixiert. Nach der Fixierung wurden die Zellen zweimal mit destilliertem Wasser gespült. Die Zellen wurden mit 
der Alizarinrot Färblösung (40 mM, pH 4,2) inkubiert (RT, Rotation). Nach 10 min erfolgten Waschgänge (5x) mit destilliertem Wasser und nach 15 min (Rotation) mit PBS. Die Zellen wurden mit PBS überschichtet, bei $-20^{\circ} \mathrm{C}$ gelagert und nur zum Fotografieren aufgetaut.

\section{II.7. Histologischer Nachweis von Adipozytendifferenzierungsmarkern}

\section{II.7.1. Oil Red O-Färbung}

Die Oil Red O-Färbung, die spezifisch für Lipidvakuolen ist, wurde für den Nachweis eines eventuellen adipozytären Phänotyps verwendet. Die durch diese Methode gefärbten Lipidvakuolen erscheinen rot im Lichtmikroskop.

Diese Färbung wurde an den Zellen, die vorher für die AP-Enzymaktivität gefärbt waren, durchgeführt. Für die Farbreaktion wurde die Oil Red O Stammlösung (0,5\%) im Verhältnis 3/2 mit destilliertem Wasser versetzt und anschließend filtriert. Diese Oil Red-Gebrauchslösung wurde kurz vor Gebrauch hergestellt. Die Zellen wurden mit der Oil Red-Gebrauchslösung bedeckt. Nach 15 min bei RT wurden die Zellen 3x mit destilliertem Wasser vorsichtig gewaschen. Die Zellen wurden mit PBS überschichtet, bei $-20^{\circ} \mathrm{C}$ gelagert und nur zum Fotografieren aufgetaut. 


\section{II.8. Molekularbiologische Methoden zur Bestimmung der Genexpression}

\section{II.8.1. Isolierung von RNA}

Die Isolierung von RNA aus Zellkulturen erfolgte mit Hilfe des QIAGEN RNeasy Kit

Die folgenden Arbeitsschritte wurden nach dem Herstellerprotokoll durchgeführt:

- Die Zellen mit $350 \mu 1$ RLT-Puffer / 1\% ß-Mercaptoethanol lysieren.

- Das Lysat bei $-80^{\circ} \mathrm{C}$ aufbewahren oder direkt aufgearbeiten.

- Das Lysat auftauen lassen und dann 10 min. bei $37^{\circ} \mathrm{C}$ inkubieren.

- Das Lysat (350 $\mu 1)$ mit gleichem Volumen 70\%igem Ethanol vorsichtig mischen.

- Das Gemisch auf ein RNeasy spin column geben und (15 sek, 13000g, RT) zentrifugieren.

- $700 \mu 1$ RW1 Puffer zugeben und (15 sek, 13000g, RT) zentrifugieren.

- $500 \mu 1$ RPE Puffer mit 100\%igem Ethanol zugeben und (15 sek, 13000g, RT) zentrifugieren.

- Auf das Rneasy spin column erneut $500 \mu \mathrm{l}$ RPE Puffer mit 100\%igem Ethanol und (15 sek, $13000 \mathrm{~g}, \mathrm{RT})$ zugeben, anschließend (2 min, 13000g, RT) zentrifugieren.

- 20-30 $\mu 1$ steriles Wasser zugeben und dann nach $10 \min (2 \mathrm{~min}, 13000 \mathrm{~g}, \mathrm{RT})$ zentrifugieren, um die an der spin column angehafteten RNA zu lösen.

\section{II.8.2. Photometrische Bestimmung der RNA}

Die Konzentrationsbestimmung erfolgt UV spektrophotometrisch bei einer Wellenlänge von $260 \mathrm{~nm}$. Zur Bestimmung des Reinheitsgrades der isolierten Nukleinsäuren wurde zusätzlich die optische Dichte (OD) bei einer Wellenlänge von $280 \mathrm{~nm}$ bestimmt. Der Quotient (Ratio) aus OD $260 \mathrm{~nm} /$ OD $280 \mathrm{~nm}$ sollte zwischen 1,8 und 2,0 liegen.

\section{II.8.3. Reverse Transkriptase-PCR (RT-PCR) - Synthese von cDNA}

Zur weiteren Untersuchung der mRNA-Genexpression muß die mRNA in komplementäre cDNA umgeschrieben werden. Das Verfahren beruht auf der Fähigkeit eines viralen Enzyms (reverse Transkriptase:RT), sich an ein Oligonukleotid (OligodT) anzulagern, an das polyAEnde der mRNA zu binden und DNA-Stränge zu synthetisieren.

Das Enzym des Moloney-Mäuseleukämievirus (M-MLV) bietet den Vorteil, daß sie keine RNAse H und auch keine DNA-Endonukleaseaktivität besitzt. Wäre dies der Fall, käme es zum Abbau des RNA-Stranges sowie zur Degradierung der gewonnenen cDNA, was die gewonnene Produktmenge der Methode deutlich verschlechtern würde. 


\section{Reaktionsansatz für die RT-PCR}

$1 \mu \mathrm{g}$ RNA wird auf ein Volumen von $9 \mu 1$ mit bidest. Wasser eingestellt. Die RNA Probe wird mit folgendem Reaktionsansatz versetzt:

$8 \mu \mathrm{l}$ 5x-Reverse-Transkriptase-Puffer $\left(15 \mathrm{mM} \mathrm{MgCl}_{2}, 375 \mathrm{mM} \mathrm{KCl}, 250 \mathrm{mM}\right.$ MM Tris-

$\mathrm{HCl}(\mathrm{pH} 8,3)$

$4 \mu 1 \quad 0,1$ M DTT

$8 \mu \mathrm{l}$ (je 2 mM dATP, dCTP, dGTP, dTTP)

$8 \mu 1 \quad\left(80\right.$ pmol) poly $(\mathrm{dT})_{15}$ Primer

$2 \mu 1 \quad$ (400 U) M-MLV reverse Transkriptase (RT)

$0,5 \mu \mathrm{l}(20 \mathrm{U})$ RNAse-Inhibitor

$0,5 \mu 1$ bidest. Wasser

Die Reaktionsansätze durchliefen im Thermocycler (Primus 25/96 Thermocycler, MWG Biotech, Ebersberg) folgendes Programm:

1 Stunde bei $38^{\circ} \mathrm{C}$

$10 \min$ bei $72^{\circ} \mathrm{C}$

Die cDNA-Proben wurden bei $-80^{\circ} \mathrm{C}$ gelagert.

\section{II.8.4. Polymerase-Kettenreaktion (PCR)}

Die PCR (polymerase chain reaction) ist ein Verfahren zur selektiven Vervielfältigung der DNA. Diese Methode wurde von Kary B. Mullis entwickelt (Saiki et al. 1985) und ist ihm für diese Leistung im Oktober 1993 der Nobelpreis verliehen worden. Dabei hybridisieren Oligonucleotide, auch Primer genannt, spezifisch an ihre komplementären Sequenzen des gesuchten Gens. Der Genabschnitt, der zwischen den Oligonukleotiden liegt, wird von dem Taq DNA-Polymerase synthetisiert. Die Taq DNA Polymerase wurde ursprünglich aus dem thermophilen Eubacterium Thermus aquaticus BM isoliert. Das Enzym wurde in E. coli cloniert und hochgereinigt, so daß es von unspezifischen Endo- oder Exonuclease frei ist.

Die PCR Reaktion basiert auf drei Einzelschritten, die sich in Länge und Temperatur unterscheiden:

Denaturierung: Die DNA-Doppelstränge werden bei ca. $95^{\circ} \mathrm{C}$ aufgeschmolzen.

Annealing: Hier findet die Hybridisierung $\left(55-65^{\circ} \mathrm{C}\right)$ der Oligonucleotide an komplementäre DNA Sequenzen statt.

Elongation: In dieser Phase findet die eigentliche Polymerisation (bei $72^{\circ} \mathrm{C}$ ) des DNA Stranges statt. Die Taq Polymerase synthetisiert einen komplementären Einzelstrang in 5'-3'-Richtung. 
Dieser Vorgang umfaßt einen Zyklus. In jedem Zyklus verdoppelt sich die Menge der gebildeten Moleküle, so daß zu eine exponentielle Vermehrung der spezifischen Sequenz stattfindet. Bei dieser exponentiellen Vermehrung sollte die Plateauphase nicht erreicht werden, die zu einer Verfälschung der PCR Ergebnisse führen könnte. Diese kritische Phase oder sogenannter Plateaueffekt der PCR Reaktion findet unter anderem aus folgenden Gründen statt: 1) Verbrauch der Ausganssubstanzen wie Primer und dNTPs , 2) Abnahme der Effektivität der Taq-Polymerase bei zu hohen Pyrophosphate, 3) Wettbewerb zwischen PCR-Produkt und Primer.

Die Zyklenzahlen werden abhängig von der Intensität des zu erwartenden Expressionssignals bestimmt und liegen in der Regel zwischen 23-37 Zyklen. Die PCR Bedingungen werden durch Progammieren des Thermocyclers festgelegt.

\title{
II.8.4.1. Semiquantitative PCR
}

Die semiquantitative PCR dient zur Quantifizierung der Expression der spezifischen Transkripte. Die Methode basiert auf dem Prinzip der „kompetitiven PCR“, indem die TargetSequenz und ein interner Standard um dieselben Primer konkurrieren. Als interner Standard wird ein Fragment hergestellt, welches zu jeder PCR-Reaktion eingesetz wird. Dieser Standard wird auch als Mimic bezeichnet, weil er die Bindung des Primers und somit die Amplifikationsverhalten des Targets ,imitiert“. Der Mimic besitzt dieselben Bindungsstellen wie das Target und wird so konstruiert, daß er sich um eine definierte Längendifferenz von der zu amplifiziereden Target-Sequenz unterscheidet. Die Amplifikationsprodukte können aufgrund ihrer unterschiedlichen Größe getrennt voneinander quantifiziert werden.

\section{II.8.4.2. Herstellung interner Standards (Mimics)}

Zur Herstellung der interner Standards wurde der PCR MIMIC TM construction kit (Clontech, CA, USA) verwendet. Zur Synthese des Mimics wurden zwei composite Primer (MWG Biotech, Ebersberg) verwendet, die am 3'-Ende komplementär zu einem neutralen Fragment DNA (in E.coli kloniert) und am 5'-Ende komplementär zur spezifischen Target-Sequenz sind. Es wurde folgender Reaktionsansatz gewählt:

\author{
34,6 $\mu 1$ Aqua bidest (AMPUWA) \\ 3,0 $\mu 1$ neutrales DNA-Fragment ( $=2$ ng DNA) \\ $5,0 \mu 1$ 10x PCR Puffer (10x $=50 \mathrm{mM} \mathrm{KCl}, 100 \mathrm{mM}$ Tris $\left.\mathrm{HCl}, 15 \mathrm{mM} \mathrm{MgCl}_{2},(\mathrm{pH} 8,3)\right)$ \\ 4,0 $\mu$ 1 Desoxynucleotide (je Fraktion 0,2 mM dATP, dCTP, dGTP, dTTP) \\ 1,5 $\mu 1$ (30 pmol) composite-sense-Primer \\ $1,5 \mu 1 \quad(30 \mathrm{pmol})$ composite-antisense-Primer
}


$\underline{0,4 \mu 1}$ (2 U) Taq-DNA-Polymerase

$50,0 \mu 1$

In der primären PCR Amplifikation erfolgte die Bindung der composite Primer an das neutrale DNA Fragment und dieser Komplex wurde dann über 20 Zyklen im folgenden Programm repliziert:

2 min bei $94^{\circ} \mathrm{C}$

45 sek bei $94^{\circ} \mathrm{C}$

45 sek bei $60^{\circ} \mathrm{C}$

90 sek bei $72^{\circ} \mathrm{C}$

Anschließend wurden $16 \mu 1$ des Amplifikationsproduktes mit $4 \mu 1$ Laufpuffer gemischt, auf ein Agarosegel aufgetragen, die Bandengröße kontrolliert, ausgeschnitten und abgewogen. Das PCR-Produkt wurde mittels QIAEX Gel Extraktions Kit genau nach Anleitung aufgearbeitet. 1 $\mu 1$ der DNA aus der Aufreinigung wurde der sekundären PCR Amplifikation mit den spezifischen Primern zugeführt. Hierfür wurde folgender Reaktionsansatz gewählt:

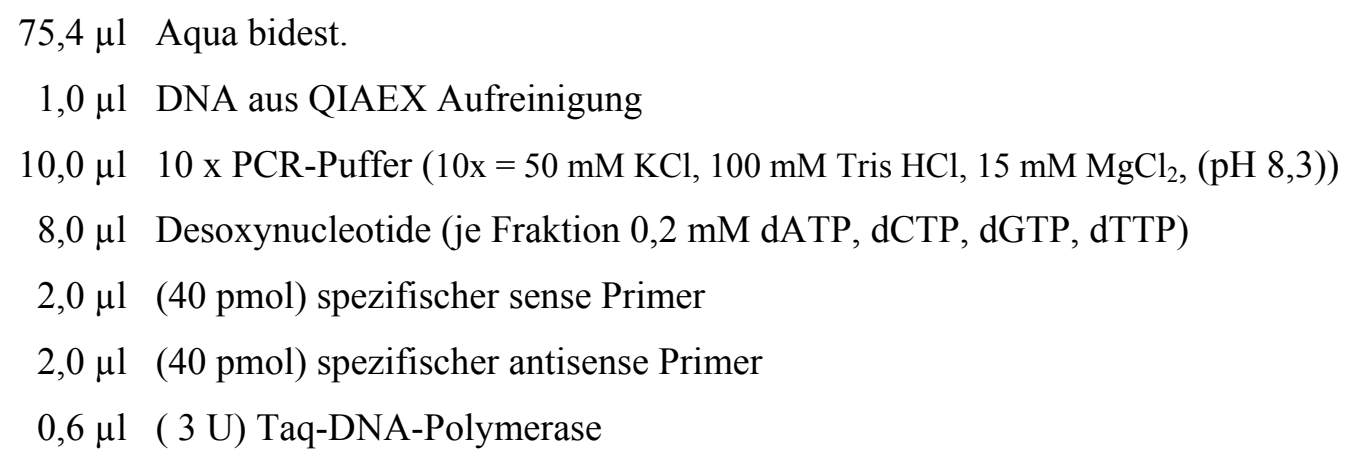

Das PCR Zyklerprogramm gleicht dem der primären PCR mit Ausnahme der Annealingstemperatur, die jetzt primerspezifisch gewählt wird. Anschließend wurden $5 \mu 1$ des sekundären PCR-Produktes mit $5 \mu$ Aqua bidest gemischt und auf ein Agarosegel (Kontrollgel) aufgetragen.

Das PCR-Produkt der sekundären Amplifikation wurde mit QIAQUICK PCR Purification Kit genau nach Anleitung aufgereinigt und in $100 \mu$ bidest. Wasser gelöst. Die Konzentration der Doppelstrang-DNA wurde im Photometer bestimmt und diese Stammlösung auf 100 attomol/ $\mu 1$ eingestellt. Aus dieser Stammlösung wurde eine Verdünnungsreihe (1:10) von 102 bis 10-6 attomol $/ \mu 1$ mit Glycogen $(50 \mu \mathrm{g} / \mathrm{ml})$ hergestellt und bei $-20^{\circ} \mathrm{C}$ gelagert. 


\section{II.8.4.3. Semiquantitative PCR}

Wie bereits beschrieben basiert die semiquantitative PCR auf dem Prinzip der kompetitiven PCR, indem die cDNA-Target und ein interner Standard (Mimic) um dieselben Primer konkurrieren.

Zunächst werden verschiedene Proben mit unterschiedlichen Konzentrationen des Mimics amplifiziert, um so diejenige Konzentration zu ermitteln, in der cDNA-Probe und Mimic übereinstimmen. Je geringer die Expression des spezifischen Gens, umso stärker wird der interne Standard amplifiziert und umgekehrt.

Falls Target-cDNA und Mimic im selben Maße amplifiziert werden, erhält man äquimolare Mengen an Amplifikationsprodukt (Ratio 1).

Nachdem die optimale Mimickonzentration auf diesem Weg in einer Kontrolle ermittelt wurde, wurden alle Proben eines Versuches mit demselben Mimickonzentration koamplifiziert, um Veränderungen in der Genexpression zu quantifizieren.

Ansatz pro Probe

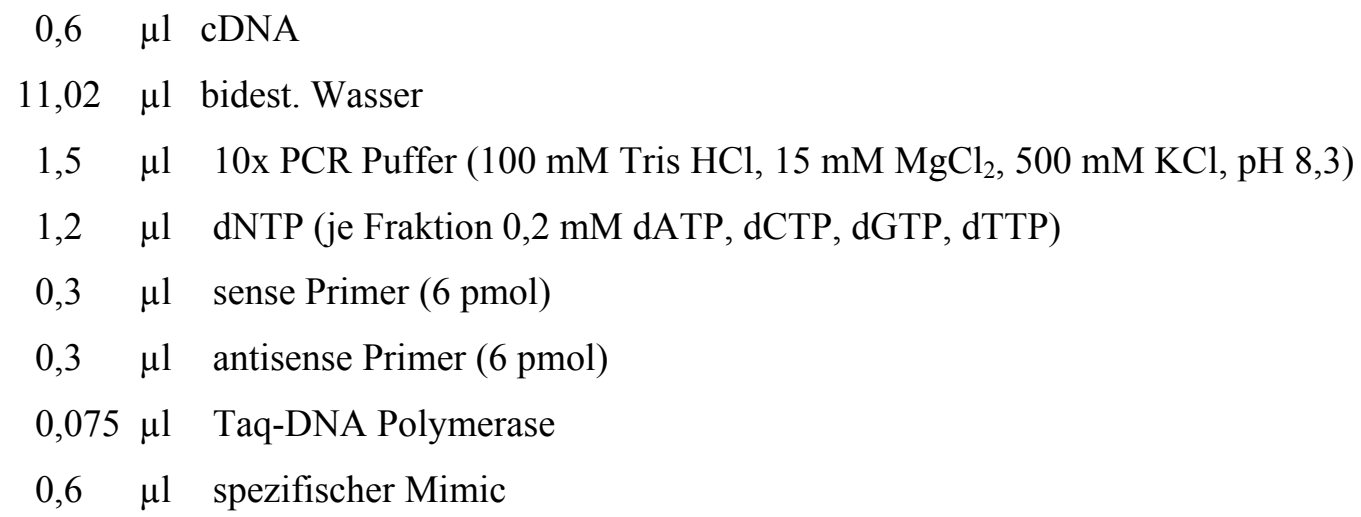

\section{II.8.4.4. Nachweis der Produkte}

Der Nachweis von Reaktionsprodukten erfolgte durch elektrophoretische Auftrennung in 1,5\% (w/v) Agarosegelen. Hierzu wurde 1,87 g Agarose in $125 \mathrm{ml}$ 1xTBE-Puffer für $3 \mathrm{~min}$. in einem Mikrowellengerät erhitzt. Anschließend wurden $5 \mu$ Ethidiumbromid hinzugegeben, Abkühlen bis zu etwa $60^{\circ} \mathrm{C}$ und dann luftblasenfrei in eine Horizontalflachbettkammer mit senkrecht eingestecktem Kamm gegossen. Nach Erstarren des Gels wurde der Kamm entfernt und das Gel in eine Horizontalelektrophoresekammer gelegt. Die Kammer wurde mit 1xTBE-Puffer als Laufpuffer so weit gefüllt, daß das Gel vollständig mit Flüssigkeit bedeckt war. Die zu analysierende Probe $(15 \mu \mathrm{l})$ wurde mit $4,5 \mu \mathrm{l}$ Auftragspuffer versetzt und aufgetragen. Zur Größenbestimmung der Fragmente wird ein 100bp-DNA-Größenmarker eingesetzt. Die Auftrennung erfolgte bei $75-85 \mathrm{~V}$ bis die Bromphenolblaubande des Auftragspuffers eine 
Wanderungsstrecke von etwa $5 \mathrm{~cm}$ im Gel zurückgelegt hatte. Die Visualisierung der DNA wurde unter UV-Anregung der interkalierende Ethidiumbromid in einem UV-Leuchtkasten.

\section{II.8.5. „Housekeeping““-Gen}

Unter dem Begriff „Housekeeping“-Gen versteht man Gene, deren Expression konstitutiv und unabhängig von intra- oder extrazellulären Vorgängen erfolgt. Es wird somit angenommen, daß die Genexpression eines „Housekeeping“-Gens immer konstant bleibt und somit als internes Referenzgen gilt. Seine Transkription wird in jeder Probe bestimmt und dient durch den Abgleich der Daten dazu, Unterschiede, die nicht eine tatsächliche Regulation der mRNA Expression widerspiegeln sondern methodisch bedingt sind, zu eliminieren. Bei dem hier verwendeten Housekeeping-Gen L7 handelt es sich um ein Gen für ein ribosomales Protein.

\section{II.8.6. Primersequenzen und Amplifizierungsprogramme}

Die Primers wurden von der Firma MWG-Biotech, Ebersberg synthetisiert.

\begin{tabular}{|c|c|c|c|c|}
\hline \multirow{2}{*}{$\begin{array}{c}\text { Target } \\
\text { mRNA }\end{array}$} & \multicolumn{2}{|c|}{ Primer Sequenzen $\left(5^{`}-3^{`}\right)$} & PCR-Produkte (bp) \\
\cline { 2 - 5 } & Sense & Antisense & mRNA & Mimic \\
\hline L 7 & AGATGTACAGAACTGAAATTC & ATTTACCAAGAGATCGAGCAA & 378 & 548 \\
\hline LPL & GAGATTTCTCTGTATGGCACC & CTGCAAATGAGACACTTTCTC & 276 & 442 \\
\hline Cbfa-1 & CCACCTCTGACTTCTGCCTC & GACTGGCGGGGTGTAAGTAA & 172 & 340 \\
\hline PPAR $\gamma 2$ & CAGTGGGGATGCTCATAA & CTTTTGGCATACTCTGTGAT & 390 & 542 \\
\hline AP & ACGTGGCTAAGAATGTCATC & CTGGTAGGCGATGTCCTTA & 475 & 569 \\
\hline
\end{tabular}

AP

(humane Sequenz aus Rickard et al. 1996)

(1) 2 min bei $94^{\circ} \mathrm{C}$

(2) 30 sek bei $94^{\circ} \mathrm{C}$

45 sek bei $55^{\circ} \mathrm{C}$

90 sek bei $72^{\circ} \mathrm{C}$

(3) $7 \mathrm{~min}$ bei $72^{\circ} \mathrm{C}$

\section{CBFA-1}

(humane Sequenz aus Pub Med Accession NM 004348)

(1) 2 min bei $95^{\circ} \mathrm{C}$

(2) 30 sek bei $95^{\circ} \mathrm{C}$

30 sek bei $59^{\circ} \mathrm{C}$

1 min bei $72^{\circ} \mathrm{C}$ 
(3) $10 \mathrm{~min}$ bei $72^{\circ} \mathrm{C}$

L7

(humane Sequenz aus Hemmerich et al. 1993)

(1) $2 \mathrm{~min}$ bei $94^{\circ} \mathrm{C}$

(2) $1 \mathrm{~min}$ bei $94^{\circ} \mathrm{C}$

$1 \mathrm{~min}$ bei $54^{\circ} \mathrm{C}$

$1 \mathrm{~min}$ bei $72^{\circ} \mathrm{C}$

(3) $10 \mathrm{~min}$ bei $72^{\circ} \mathrm{C}$

LPL

(humane Sequenz aus Rickard et al. 1996)

(1) $2 \mathrm{~min}$ bei $94^{\circ} \mathrm{C}$

(2) 30 sek bei $94^{\circ} \mathrm{C}$

$2 \mathrm{~min}$ bei $55^{\circ} \mathrm{C}$

2 min bei $72^{\circ} \mathrm{C}$

(3) $10 \min$ bei $72^{\circ} \mathrm{C}$

\section{PPAR $\gamma 2$}

(humane Sequenz aus Thomas et al. 1999)

(1) $2 \mathrm{~min}$ bei $95^{\circ} \mathrm{C}$

(2) 40 sek bei $94^{\circ} \mathrm{C}$

50 sek bei $55^{\circ} \mathrm{C}$

50 sek bei $72^{\circ} \mathrm{C}$

(3) $10 \min$ bei $72^{\circ} \mathrm{C}$ 


\section{II.9. Direkte Immunogoldzytochemie / Elektronenmikroskopie}

\section{II.9.1. Fixierung und Einbettung der Zellen für die Elektronenmikroskopie}

Die primären HOB Zellen wurden trypsiniert und mit PBS gewaschen. Zur Fixierung und Entwässerung wurden die Zellen $\left(\sim 1 \times 10^{6}\right)$ bei $4^{\circ} \mathrm{C}$ mit den folgenden Lösungen $(10 \mathrm{ml})$ versetzt:

- 15 min mit 4\% Paraformaldehyd / 25\% Glutaraldehyd in 0,2 M Hepes (pH 7,4) versetzt.

- 10 min mit 0,2 M Hepes gewaschen

- $45 \mathrm{~min}$ mit $10 \mathrm{mM}$ Ammoniumchlorid in 0,2 M Hepes versetzt.

- 2 x 10 min mit 0,2 M Hepes gewaschen

- 10 min mit 30\% Ethanol

- 10 min mit $50 \%$ Ethanol

- 10 min mit $70 \%$ Ethanol

In $70 \%$ igem Ethanol können die fixierten Zellen bei $4^{\circ} \mathrm{C}$ bis zum nächsten Tag aufbewahrt werden.

Zur Einbettung der entwässerten Zellen wurde der hydrophile Kunststoff LR-Gold (London Resin Co. Ltd.) verwendet. Dies erfolgte in aufsteigender Verdünnungsreihe mit Ethanol (90\%) wie folgt:

- 30 min bei $4^{\circ} \mathrm{C}$ in LR-Gold / Ethanol (1:3)

- 30 min bei $4^{\circ} \mathrm{C}$ in LR-Gold / Ethanol (1:1)

- 30 min bei $4^{\circ} \mathrm{C}$ in LR-Gold / Ethanol (3:1)

- 1 Stunde bei $25^{\circ} \mathrm{C}$ in LR Gold

- Über Nacht bei $-20^{\circ} \mathrm{C}$ in LR-Gold $+0,8 \%$ Benzil (Beschleuniger)

Am nächsten Tag wurden die Zellen mit neuem LR-Gold $+0,8 \%$ Benzil in eine Beemkapsel gebracht und mit einem Deckel luftdicht verschlossen. Durch Belichtung mit einer 1000 W Halogenlampe über einen Zeitraum von 24 Stunden.erfolgte die Polymerisation des Kunststoffes in den Kapseln in einer Kältekammer $\left(-25^{\circ} \mathrm{C}\right)$.

\section{II.9.2. Anfertigung von Ultradünnschnitten für die Elektronenmikroskopie}

Als Objektträger für die Ultradünnschnitte dienten mit Formvar beschichtete Nickelgrids (Storck, Eerbeck, Niederlande). Zu deren Herstellung wurden staubfreie Glasobjektträger in Formvar-Lösung (Serva, Heidelberg) eingetaucht. Die befilmten Objektträger wurden nach ihrer Trocknung vorsichtig schräg in ein mit tridestilliertem Wasser gefülltes Bad eingeführt. Dabei löste sich an der Wasseroberfläche der Film ab, welcher nun mit Nickelgrids belegt und anschließend mit einer Parafilmfolie abgehoben und getrocknet werden konnte. 


\section{II.9.3. Herstellung von kolloidalem Gold}

Zur Darstellung von Doppel- und Dreifachmarkierungen erschien die Verwendung von kolloidalem Gold mit einem Durchmesser von $8 \mathrm{~nm}$ und $16 \mathrm{~nm}$ zur sicheren Unterscheidung der Markierung am geeignetsten.

\section{II.9.3.1. Kolloidales Gold mit einem Durchmesser von 8 nm}

Zur Herstellung von $8 \mathrm{~nm}$ kolloidalem Gold wurden $106 \mathrm{ml}$ von 2,2 mM Natriumcitrat-Lösung in einem silikonisierten Erlenmeyerkolben mit Schliff auf einen beheizbaren Magnetrührer unter Verwendung eines Rücklaufkühlers bis zum Siedepunkt erhitzt und 5 min gekocht. Nun erfolgte die Zugabe von $955 \mu \mathrm{l}$ 1\%iger Tetrachlorgoldsäure $\left(\mathrm{HAuCl}_{4}\right)$ im Schuss mit einer Eppendorfpipette. Anschließend wurde die Goldlösung unter ständigem Rühren 15 min weitergekocht bis sie eine klare, kirschrote Farbe zeigte.

\section{II.9.3.2. Kolloidales Gold mit einem Durchmesser von 16 nm}

$\mathrm{Zu} \mathrm{49,5} \mathrm{ml} \mathrm{destilliertem} \mathrm{Wasser} \mathrm{wurden} \mathrm{1,2} \mathrm{ml}$ 1\%ige Natriumcitrat-Lösung in einem silikonisierten Erlenmeyerkolben mit Schliff hinzupipettiert, bis zum Siedepunkt auf einem beheizbaren Magnetrührer unter Verwendung eines Rücklaufkühlers erhitzt und ca. 5 min gekocht. Dann erfolgte, während ständig gerührt wurde, die Zugabe von $500 \mu 1$ 1\%iger Tetrachlorgoldsäure $\left(\mathrm{HAuCl}_{4}\right)$ im Schuß. Die Goldlösung wurde weitergekocht, bis sie eine klare kirschrote Farbe zeigte.

\section{II.9.4. Antikörper-Gold-Kopplung}

Zur Erzeugung von Antikörper-Gold-Konjugaten war zunächst die Einstellung der kolloidalen Goldlösung auf pH 9,0 mit 0,2 M Kaliumcarbonat-Lösung $\left(\mathrm{K}_{2} \mathrm{CO}_{3}\right)$ notwendig. Außerdem wurden mit destilliertem Wasser $(\mathrm{pH}$ 9,0) Verdünnungen der frisch aufgetauten Antikörperstammlösung von 1:10 und 1:100 hergestellt.

Die bei der Kopplung mit dem kolloidalen Gold eingesetzte Antikörpermenge muss ausreichen, um eine Ummantelung der Goldpartikel zu gewährleisten, welche ausreichenden Schutz z.B. vor Elektrolyten bietet. Andererseits soll der Verbrauch des teuren Antikörpers so gering wie möglich gehalten werden. Um diesen Forderungen gerecht zu werden, wurde mit Hilfe einer Verdünnungsreihe der sogenannte „minimal protecting amount of protein“ bestimmt, also die Proteinmenge, welche gerade ausreicht, um die kolloidalen Goldpartikel sicher zu umhüllen.

Dazu wurde die mit destilliertem Wasser ( $\mathrm{pH} 9,0)$ auf 1:10 verdünnte Antikörperstammlösung aufsteigend in $10 \mu \mathrm{l}$-Schritten von 10-100 $\mu \mathrm{l}$ in eine Mikrotiterplatte pipettiert und jeweils 100 $\mu 1$ der 0,01\%igen Tetrachlorgoldsäure in die Chargen zugegeben. Nachdem die Mikrotiterplatte 
im Photometer 1 min geschüttelt worden war, erhielt jede Charge $100 \mu 1$ einer 10\%igen NaClLösung, welche als Reduktionsmittel diente. War die jeweilige Proteinmenge zu gering, erfolgte ein Farbumschlag von rot nach blau, welcher mit Hilfe eines Testfilters (Extinktion $450 \mathrm{~nm}$ ) im Photometer gemessen und dadurch quantifiziert werde konnte. Die erste Charge, die keinen Farbumschlag zeigte, enthielt ausreichend Protein.

Nach der Bestimmung des ,minimal protecting amount of protein“ erfolgte die definitive Antikörper-Gold-Kopplung. Dazu wurde $1 \mathrm{ml}$ der Goldlösung mit der entsprechenden Menge der 1:10 verdünnte Antikörperstammlösung gekoppelt. Reichten in der Verdünnungsreihe z.B. 3 $\mu 1$ der 1:100 verdünnten Antikörperstammlösung aus, um $100 \mu$ Goldlösung zu koppeln, wurden $3 \mu \mathrm{l}$ der 1:10 verdünnten Antikörperstammlösung $\mathrm{zu} 1 \mathrm{ml}$ Goldlösung in ein silikonisiertes Eppendorfgefäß (2 ml) gegeben und 2 min kräftig geschüttelt.

Um das Gemisch auf einen Anteil von 1\% BSA zu bringen, war der Zusatz von 10\%igem TBSBSA (pH 9,0) in einer Menge, die einem Zehntel der eingesetzten Menge des Antikörper-GoldGemisches entsprach, notwendig. Mit 1\%igem TBS-BSA wurde das Gemisch auf 1,7 ml aufgefüllt und anschließend bei $4^{\circ} \mathrm{C}$ zentrifugiert. Dabei musste hinsichtlich der erforderlichen Zentrifugationskraft und der Zentrifugationsdauer bei den jeweiligen Goldgrößen unterschieden werden.

\begin{tabular}{|c|c|c|}
\hline Goldgröße & Zentrifugationskraft & Zentrifugationsdauer \\
\hline $8 \mathrm{~nm}$ & $15000 \mathrm{~g}$ & $35 \mathrm{~min}$ \\
\hline $16 \mathrm{~nm}$ & $10000 \mathrm{~g}$ & $20 \mathrm{~min}$ \\
\hline
\end{tabular}

Eine erfolgreiche Kopplung des Goldes und der Antikörper ließ sich nach der Zentrifugation daran erkennen, daß am Boden des Röhrchens ein Pellet von ca. 20-25 $\mu 1$ und eine fest mit der Wand verbackene Fahne von ungekoppeltem Gold zu sehen war. Aus dem Zentrum dieses Pellets konnten nur mit Hilfe einer silikonisierten Pipettenspitze $15 \mu 1$ der gekoppelten Antikörper pipettiert und in ein weiteres silikonisiertes Röhrchen überführt werden. Das Antikörper-Gold-Konjugat wurde dann zu gleichen Teilen mit 1\%igem TBS-BSA (pH 9,0) und 1\%igem TBS-BSA ( $\mathrm{pH} 7,4)$ auf 1:10 verdünnt und dadurch auf einen $\mathrm{pH}$ von ca. 8,0 gebracht. Die Lösung konnte nun bei $4{ }^{\circ} \mathrm{C}$ aufbewahrt werden.

\section{II.9.5. Inkubationsbedingungen für den Proteinnachweis}

\section{II.9.5.1. Einzelmarkierungen}

Vor der Doppelmarkierung wurden zunächst die Antikörper einzeln untersucht. Um eine optimale Markierung der untersuchten Epitope zu erhalten, wurden bezüglich der Inkubationsbedingungen verschiedene Varianten erprobt. 
Es wurden folgende Inkubationsschritte getestet:

- Blockierung unspezifischer Bindungsstellen mit BSA

Dazu wurden die Nickelgrids für 5 min mit der Präparatseite auf einen Tropfen 1\%iger TBSBSA -Lösung (pH 7,4) gelegt und anschließend mit TBS (pH 7,4) abgespült.

- Vorverdauung der Schnitte mit Pepsin

Die Schnitte wurden entweder gar nicht oder für 5 oder 10 min mit einem Tropfen von 0,4\%igem Pepsin ( $\mathrm{pH} 2,0)$ und anschließend jeweils 5 min mit TBS (pH 7,4) inkubiert.

- Konzentration der gekoppelten Antikörper

Der gekoppelte Antikörper wurde mit TBS (pH 7,4) auf Konzentrationen von 1:20; 1:40; 1:80 oder 1:100 gebracht und ausgetestet. Anschliessend erfolgte jeweils eine gründliche Spülung mit destilliertem Wasser.

- Inkubationstemperatur

Die Reaktionen erfolgten bei $4^{\circ} \mathrm{C}$ im Kühlschrank oder bei Raumtemperatur.

- Inkubationszeit

Die Inkubationsdauer betrug 1 Stunde oder über Nacht (16 Stunden) in einer feuchten Kammer.

Die Austestung dieser Variablen ergab, daß alle verwendeten Antikörper die besten Ergebnisse hinsichtlich Reaktionsstärke und Spezifizität durch das folgende Protokoll erreichten:

- Inkubation der Schnitte in einer feuchten Kammer bei $4^{\circ} \mathrm{C}$ (über Nacht) mit folgender Antikörper Verdünnung (mit TBS-Puffer): 1:40 für die monoklonalen Antikörper gegen AP, LPL und PPAR $\gamma 2$ und 1:80 (für den polyklonalen Antikörper gegen OC).

- Intensive Spülung mit destilliertem Wasser.

- Kontrastierung

- Beurteilung im Elektronenmikroskop

\section{II.9.5.2. Doppelmarkierung}

Bei den Mehrfachnachweisen wurde die Inkubation der Schnitte mit einem Gemisch der Antikörper durchgeführt. Hierbei haben wir das Protokoll der Einzelnachweise berücksichtigt.

\section{II.9.6. Kontrastierung}

Für die Konstrastierung wurden die Schnitte nach folgendem Schema behandelt.

- 10 min Inkubation auf einem Tropfen von 1\%igem Uranylacetat und anschließend gründliches Abspülen mit destilliertem Wasser. 
- 10 min Inkubation auf einem Tropfen von 1\%igem Bleicitrat und anschließend gründliches Abspülen mit destilliertem Wasser.

Nachdem die Schnitte mindestens eine halbe Stunde getrocknet waren, konnten sie im Elektronenmikroskop (Zeiss EM 109) betrachtet und fotografiert werden.

\section{II.9.7. Kontrollen}

Zur Kontrolle der hergestellten kolloidalen Goldpartikel wurde ein Tropfen der jeweiligen Godlösung auf einem mit Formvar beschichteten Nickelgrid eingetrocknet. Nun konnten im Elektronenmikroskop Größe und Form der Goldpartikel beurteilt werden.

Zur Überprüfung der Antikörper-Gold-Kopplung wurde ein Tropfen auf einem mit Formvar beschichteten Nickelgrid eingetrocknet. Nach der Konstrastierung mit 1\%igem Uranylacetat war eine Beurteilung im Elektronenmikroskop möglich. Bei einer erfolgreichen Kopplung zeigte sich um die Goldkugel ein heller Hof, welcher der Proteinhülle durch den gekoppelten Antikörper enstprach. Ungekoppeltes kolloidales Gold wies hingegen keinen solchen Hof auf.

Die Spezifizität der Immunreaktion wurde kontrolliert, indem Schnitte mit ungekoppelten kolloidales Goldlösungen aller zwei Größen unter den gleichen Reaktionsbedingungen wie die Antikörper-Gold-Konjugate mit Schnitte inkubiert wurden. 


\section{II.10. Stimulationsversuche}

\section{II.10.1. Induktion der Adipogenese in der immortalisierten Osteoblastenzellinie AHTO und in pHOB Zellen}

Dieses Experiment wurde geplant, um die Adipogenese in der immortalisierten Osteoblastenzellinie (AHTO) und in den primären HOB Zellen unter Einfluß von IBMX plus Dexamethason (Dexa) zu untersuchen. Die Zellen wurden bis zur Konfluenz unter Standardbedingungen kultiviert und danach mit IBMX $(100 \mu \mathrm{g} / \mathrm{ml})+$ Dexa $(1 \mu \mathrm{M})$ inkubiert. Während des Stimulationsversuches wurde das Medium alle 2-3 Tage gewechselt und die Faktoren frisch angesetzt. Das Inkubationsmedium enthielt $10 \%$ FCS, das anders als üblicherweise in diesen Versuche mit Kohle filtriert und durch Hitze $\left(30 \mathrm{~min}\right.$ bei $\left.37^{\circ} \mathrm{C}\right)$ inaktiviert wurde. Zur Aufarbeitung wurden die Zellen aus einzelnen Näpfen in $350 \mu 1$ RNA Lysis Puffer/ Napf aufgenommen. Die lysierten Proben wurden für die späteren RT-PCR Analysen bei $-80^{\circ} \mathrm{C}$ asserviert $(\mathrm{n}=4)$. Parallele Kulturen wurden fixiert und anschließend die AP-Aktivität und die Oil Red O Färbung durchgeführt $(n=2)$. Die gefärbten Zellen wurden mit PBS überschichtet, bei $-20^{\circ} \mathrm{C}$ gelagert und nur zum Photographieren aufgetaut. Diese Untersuchungen wurden mit Kulturen (pHOB Zellen) von einem Patient durchgeführt.

\begin{tabular}{|c|c|c|}
\hline & Primären HOB Zellen & AHTO Zellinie \\
\hline bis zur Stimulation & 10 Tage (1.Passage) & 2 Tage \\
& $24^{\text {er }}$ Napf Platte & $12^{\text {er }}$ Napf Platte \\
& $7,6 \times 10^{3}$ Zellen /Napf & $7,6 \times 10^{3}$ Zellen $/$ Napf \\
& HOB Medium & AHTO Medium \\
\hline $\begin{array}{c}\text { Stimulation (IBMX } \\
+ \text { Dexa) }\end{array}$ & 21 Tage & 14 Tage \\
\hline Aufarbeitung & $7 / 14 / 21$ Tage & AHTO-Adip-Inkubationsmedium \\
\hline RT-PCR-Analyse & PPAR $\gamma 2$ & PPAR 2 2, AP, Cbfal \\
\hline Histochemische & AP-Aktivität & AP-Aktivität \\
Analyse & Oil Red O (Lipidvakuolen) & Oil Red O (Lipidvakuolen) \\
\hline
\end{tabular}

\section{II.10.2. Stimulation von pHOB Zellen mit BMP-2}

Die Auswirkung von BMP-2 auf die Osteoblasten- bzw. Adipozytendifferenzierungsmarker wurde in pHOB Zellen untersucht. Die pHOB Zellen wurden in 24er Napf-Platten ausgesät und unter Standardbedingungen (HOB Medium: DMEM/ 10\% FCS) kultiviert. Nach 10 Tagen (1. Passage) wurden die Zellen 1x mit serumfreiem Medium gewaschen und es erfolgte der Wechsel auf Inkubationsmedium (DMEM/ 0,1\% BSA) supplementiert mit verschiedenen BMP- 
2 Dosen $(50,100$ und $200 \mathrm{ng} / \mathrm{ml})$ für 2 und 7 Tage. Alle 2 Tage wurde frisches supplementiertes Medium zugegeben ohne das ganze Medium zu wechseln. Zur Aufarbeitung nach 2 und 7 Tagen wurden die Zellen aus einzelnen Näpfen in $350 \mu$ RNA Lysis Puffer/Napf aufgenommen. Die lysierten Proben wurden für die späteren RT-PCR Analysen bei $-80^{\circ} \mathrm{C}$ asserviert $(\mathrm{n}=4)$. An Tag 2 und 7 wurde an parallelen Kulturen die AP-Aktivität- und die Oil Red O Färbung durchgeführt ( $\mathrm{n}=2$ ). Die gefärbten Zellen wurden mit PBS überschichtet, bei $20^{\circ} \mathrm{C}$ gelagert und nur zum Photographieren aufgetaut. Diese Untersuchungen wurden mit Kulturen von einem Patient durchgeführt.

\section{II.10.3. Untersuchung der Plastizität AP-negativer Subpopulationen von pHOB Zellen}

In der Abbildung 14 sind die wichtigsten Arbeitschritte zur Untersuchung von APSubpopulationen zusammengefasst.

AP-negative Subpopulationen wurden durch MACS aus pHOB Kulturen gewonnen. Nach der Sortierung wurden die Zellen mittels FACS hinsichtlich ihrer AP-Negativität analysiert. Aufgrund ihrer Homogenität wurden nur die AP-negativen Zellen weiterkultiviert.

Die AP-negativen wurden in 24er Napf-Platten ausgesät und unter Standardbedingungen (HOB Medium: DMEM/ 10\% FCS) kultiviert. Nach 2 Wochen (beim Konfluenz) wurden die Zellen 1x mit serumfreiem Medium gewaschen (Konfluenz) und erfolgte eine Stimulation mit OFInkubationsmedium (Betaglycerophosphat $(2 \mathrm{mM})$, Ascorbat $(50 \mu \mathrm{g} / \mathrm{ml}), 1,25(\mathrm{OH})_{2} \mathrm{D}_{3}\left(10^{-8} \mathrm{M}\right)$, Dexamethason $\left(10^{-8} \mathrm{M}\right)$ in DMEM/ 0,1\% BSA) und entweder OF + TGF- $\beta 1(1 \mathrm{ng} / \mathrm{ml})$ oder OF + BMP-2 (50 ng/ ml) für eine Dauer von 2 und 7 Tagen. Das Kontroll-Inkubationsmedium enthielt Ethanol und Citrat Puffer $(<0,01 \%)$. Alle 2 Tage wurde frisches supplementiertes Medium zugegeben ohne das ganze Medium zu wechseln. Während der gesamten Stimulationszeit (7 Tagen) wurde Ascorbat täglich frisch zugegeben.

Zum Nachweis eines Differenzierungsprozesses zu Osteoblasten wurden die Osteokalzinsekretion, die Kollagen I-sekretion, die AP Aktivität und die Zellzahl bestimmt $(n=4)$. Ein Differenzierungsprozeß zu Adipozyten wurde durch die Oil Red O Färbung sowie durch den Nachweis der Genexpression von PPAR $\gamma 2$ und LPL mittels semiquantitativer PCR analysiert.

Zur Aufarbeitung nach 2 und 7 Tagen wurden die Zellen aus einzelnen Näpfen in $350 \mu 1$ RNA Lysis Puffer/Napf aufgenommen. Die lysierten Proben wurden für die späteren RT-PCR Analysen bei $-80^{\circ} \mathrm{C}$ asserviert $(\mathrm{n}=2)$. Am Tag 2 und 7 wurde an parallelen Kulturen die APAktivität- und die Red Oil-Färbung durchgeführt $(n=2)$. Die gefärbten Zellen wurden mit PBS überschichtet, bei $-20^{\circ} \mathrm{C}$ gelagert und nur zum Photographieren aufgetaut. Diese Untersuchungen wurden mit Kulturen von 3 Patienten durchgeführt. 


\section{Zusammenfassung des MACS \\ Sortierungsversuches von HOB Zellen}

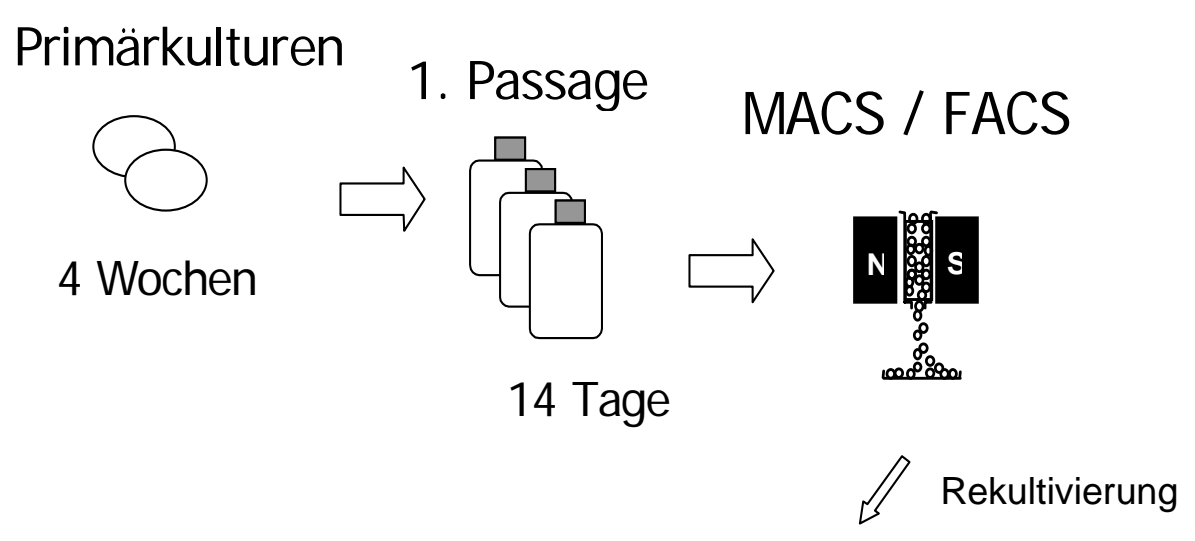

2. Passage

AP-negative- und AP-positive Zellen

14 Tage

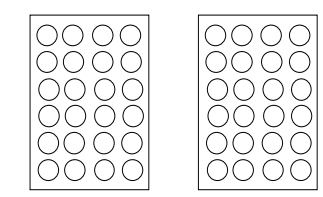

FACS

$\sqrt{ }$

STIMULATION

Abb. 14: Zusammenfassung der wichtigsten Arbeitschritte zur Untersuchung der Differenzierung von AP-Subpopulationen

\section{II.10.4. Langzeitstimulation von pHOB Zellen mit TGF- $\beta 1$ und BMP-2}

Die Auswirkung von TGF- $\beta 1$ und BMP-2 auf die Osteoblasten- bzw. Adipozytendifferenzierungsmarker wurde bei pHOB Zellen über einen Zeitraum von 24 Tagen untersucht. Die pHOB Zellen (1. Passage) wurden in 6er Napf-Platten ausgesät und unter Standardbedingungen (HOB Medium: DMEM/ 10\% FCS) kultiviert. Bei der Konfluenz wurden die Zellen 1x mit 
serumfreiem Medium gewaschen und es erfolgte der Wechsel auf OF-Inkubationsmedium (Betaglycerophosphat $(2 \mathrm{mM})$, Ascorbat $(50 \mu \mathrm{g} / \mathrm{ml}), 1,25(\mathrm{OH})_{2} \mathrm{D}_{3}\left(4 \times 10^{-8} \mathrm{M}\right)$, Dexamethason $\left(10^{-8} \mathrm{M}\right)$ in DMEM/ 0,1\% BSA) mit entweder TGF- $\beta 1(1 \mathrm{ng} / \mathrm{ml})$ oder OF + BMP-2 $(50 \mathrm{ng} / \mathrm{ml})$ supplementiert. Das Kontroll-Inkubationsmedium enthielt Ethanol und Citrat Puffer $(<0,01 \%)$. Während der gesamten Stimulationszeit (24 Tagen) wurde Ascorbat täglich frisch zugegeben. Die anderen Faktoren wurden alle 2 Tagen frisch zugefügt. Alle 7 Tage erfolgte ein Mediumwechsel.

Nach 24 Tagen wurde die Auswirkung dieser Faktoren (zytochemisch) durch den parallelen Nachweis eines Mineralisationsprozesses (Alizarin Rot-Färbung) bzw. Lipidvakuolen (Oil Red O-Färbung) untersucht. Die gefärbten Zellen wurden mit PBS überschichtet, bei $-20^{\circ} \mathrm{C}$ gelagert und nur zum Photographieren aufgetaut. Diese Untersuchungen wurden mit Kulturen von einem Patient durchgeführt.

\section{II.10.5. Stimulation der pHOB Zellen für die Immunogoldzytochemische/ Elektro- nenmikroskopische Analyse}

Die pHOB Zellen (1.Passage) wurden in Zellkulturflaschen $\left(75-\mathrm{cm}^{2}\right)$ unter Standardbedingungen (HOB Medium: DMEM/ 10\% FCS) kultiviert. Beim Konfluenz erfolgte der Wechsel auf OF-Inkubationsmedium (Betaglycerophosphat (2 mM), Ascorbat $(50 \mu \mathrm{g} / \mathrm{ml}), 1,25(\mathrm{OH})_{2} \mathrm{D}_{3}$ $\left(4 \times 10^{-8} \mathrm{M}\right)$, Dexamethason $\left(10^{-8} \mathrm{M}\right)$ in DMEM/ 0,1\% BSA) mit BMP-2 (50 ng/ ml) supplementiert. Während der gesamten Stimulationszeit (7 Tagen) wurde Ascorbat täglich frisch zugegeben. Die anderen Faktoren wurden alle 2 Tagen frisch zugefügt ohne das Medium zu wechseln. Nach 7 Tagen wurden die Zellen trypsiniert, fixiert und eingebettet für die Immunogoldzytochemische/ Elektronenmikroskopische Analyse.

\section{II.11. Statistische Methoden}

Für die Statistik wurde das Programm GraphPad Prism in der Version 3.0 verwendet. Die statistische Auswertung erfolgte durch Anwendung eines Mann-Whitney Tests. 


\section{Ergebnisse}

\section{III.1 Untersuchung zur Induktion der Adipogenese unter IBMX plus Dexamethason}

Von Nuttall et al. (1998) wurde zum ersten Mal in pHOB Zellen die adipogeneseinduzierende Wirkung von 3-isobutyl-1-methylxanthine (IBMX) plus Dexamethason (Dexa) beschrieben. Unter dem Einfluß dieser Faktoren waren differenzierte Osteoblasten, die bereits Osteokalzin synthetisieren konnten, in der Lage einen Transdifferenzierungsprozeß zum Adipozyten zu durchlaufen.

Im folgenden Teil dieser Arbeit wurde zunächst die Wirkung dieser Faktoren an primären HOB Zellen überprüft. Zum Vergleich wurde in der immortalisierten AHTO Zellinie untersucht, ob die Zellen in der Lage sind sich zu Adipozyten zu differenzieren. Die hier verwendeten Kulturbedingungen waren identisch zu den von Nuttall et al. (1998) beschriebenen. Hierfür wurde die Kombination von IBMX $(100 \mu \mathrm{g} / \mathrm{ml})+$ Dexa $(1 \mu \mathrm{M})$ verwendet, eine Kombination, die im folgenden Adipogenesemedium genannt wird. IBMX ist ein Hemmer der Phosphodiesterase, die für den Abbau des zyklischem Adenosinmonophosphat (cAMP) verantwortlich ist.

Das Inkubationsmedium enthielt $10 \%$ FCS, das in diesem Versuch mit Kohle filtriert und durch Hitze inaktiviert wurde. Die Auswirkung auf die Adipogenese wurde sowohl auf mRNA-Ebene als auch histologisch durch zytochemische Färbung nachgewiesen.

\section{III.1.1. Induktion der Adipogenese in pHOB Zellen}

Hier sollte zunächst untersucht werden, inwieweit sich die Ergebnisse von Nuttall et al. (1998) auf unser pHOB Modell übertragen lassen. Dabei wurden die primären HOB Zellen für eine Dauer von 7, 14 und 21 Tagen mit Adipogenesemedium stimuliert, um zu überprüfen, ob eine Induktion der Adipogenese auch in unserem Modell möglich ist.

\section{III.1.1.1. Histologische und zytochemische Analyse}

An den fixierten pHOB Zellen wurde eine Doppelfärbung zum Nachweis der AP-Enzymaktivität, als Osteoblastendifferenzierungsmarker, sowie von Lipidvakuolen (Oil Red O), als Adipozytendifferenzierungsmarker, durchgeführt.

Unter den verschiedenen Kulturbedingungen war die Anheftung der Zellen gut, so daß es keinen Hinweis negativer Auswirkungen der Kulturbedingungen auf Vitalität bzw. Funktion der Zellen gab.

Unter Basalbedingungen waren die Zellen länglich ausgestreckt und homogen in ihrer Zellform. Es konnte bis zum Ende des Versuches am Tag 21 (Abb. 15, III) keine Veränderung der 
Zellform beobachtet werden. Die Zellen zeigten unter diesen Bedingungen weder eine basale AP-Enzymaktivität noch Lipidvakuolen.

Unter Stimulation mit Adipogenesemedium nahmen die Zellen eine flache Form an und waren gegenüber nicht induzierten Zellen sehr inhomogen in Gestalt und Größe. Unter diesen Bedingungen konnte schon nach 7 Tagen die Entstehung von rot gefärbten Lipidvakuolen in einzelnen Zellen beobachtet werden. Nach 14 Tagen nahm sowohl die Anzahl der Zellen mit kleinen Lipidvakuolen als auch die Anzahl der Lipidvakuolen pro Zelle (s. Pfeil in Abb.15) zu. Am Tag 21 bildeten die Zellen wesentlich größere Vakuolen, die wohl durch Fusion der kleineren entstanden sind (s. Pfeil in Abb.15, IV). Durch die Doppelfärbung konnten auch APpositive Zellen (blaue Farbe) nachgewiesen werden (Abb.15, II, IV).
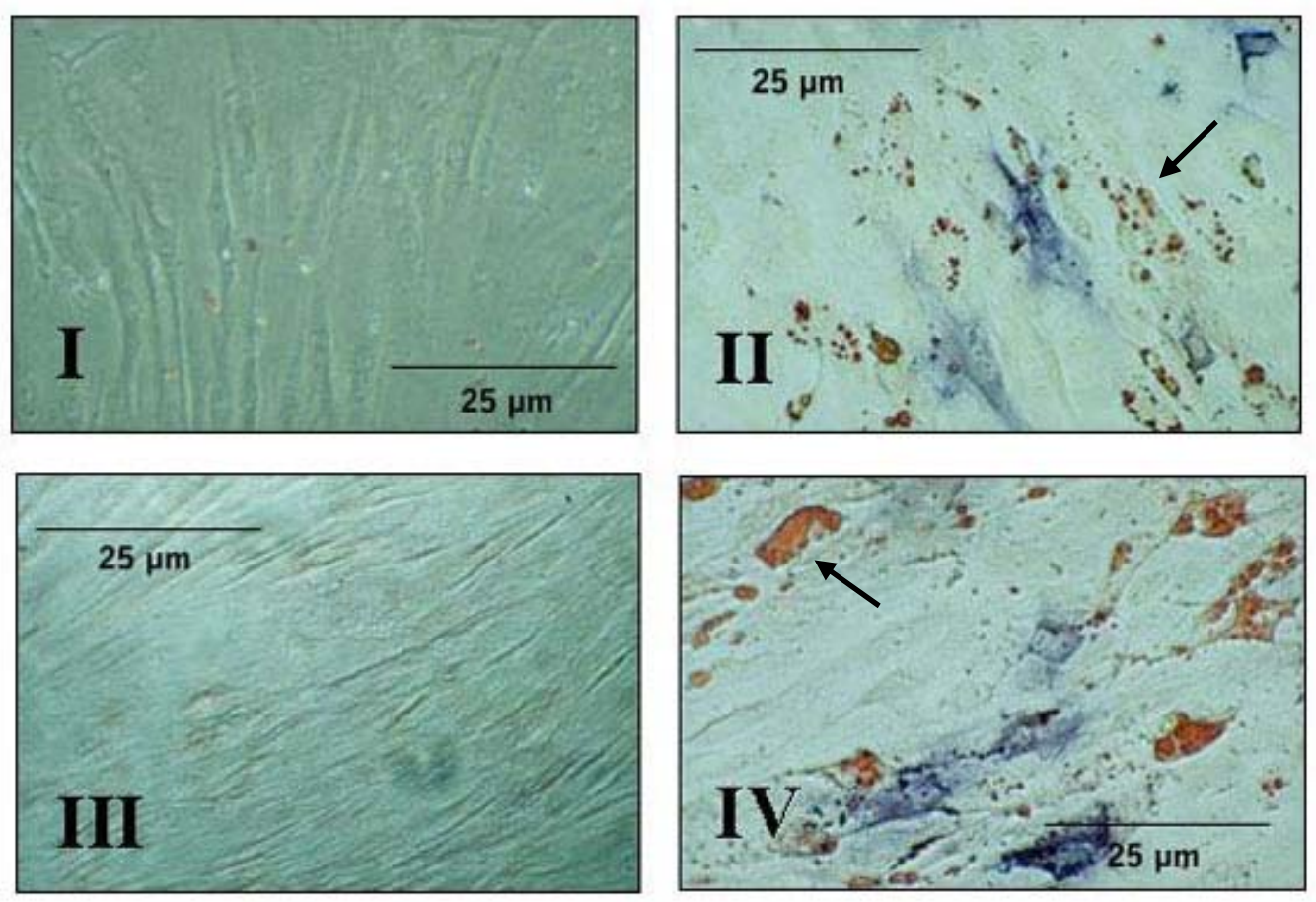

Abb.15: Induktion der Adipogenese in pHOB Zellen unter Stimulation mit IBMX + Dexa. Die Doppelfärbung zum Nachweis der AP-Aktivität (blaue Farbe) und Lipidvakuolen (Oil Red O, rote Farbe) wurde nach 7, 14 und 21 Tagen Stimulationsdauer durchgeführt. Die Pfeile zeigen auf unter Stimulation gebildete Lipidvakuolen (II, IV).

I: Zellen unter Basalbedingungen nach 14 Tagen

II: Zellen unter IBMX + Dexa nach 14 Tagen

III: Zellen unter Basalbedingungen nach 21 Tagen

IV: Zellen unter IBMX + Dexa nach 21 Tagen

Das HOB Adipogenesmedium enthielt $10 \%$ FCS (Kohle-filtriert/inaktiviert) und Ethanol $(<0,01 \%)$

Durch den Nachweis von Lipidvakuolen als späteren Marker eines adipozytären Phänotyps, konnte eine adipogene Wirkung von IBMX + Dexa in pHOB Zellen gezeigt werden. 


\section{III.1.1.2. Wirkung auf die Genexpression}

Zur weiteren Charakterisierung eines adipozytären Phänotyps sollte die mRNA Expression von PPAR $\gamma 2$ untersucht werden. Eine positive Wirkung des Adipogenesemedium in pHOB Zellen zeigte sich durch die Induktion der PPAR 22 Genexpression, als früher Marker der Adipogenese (Abb.16).

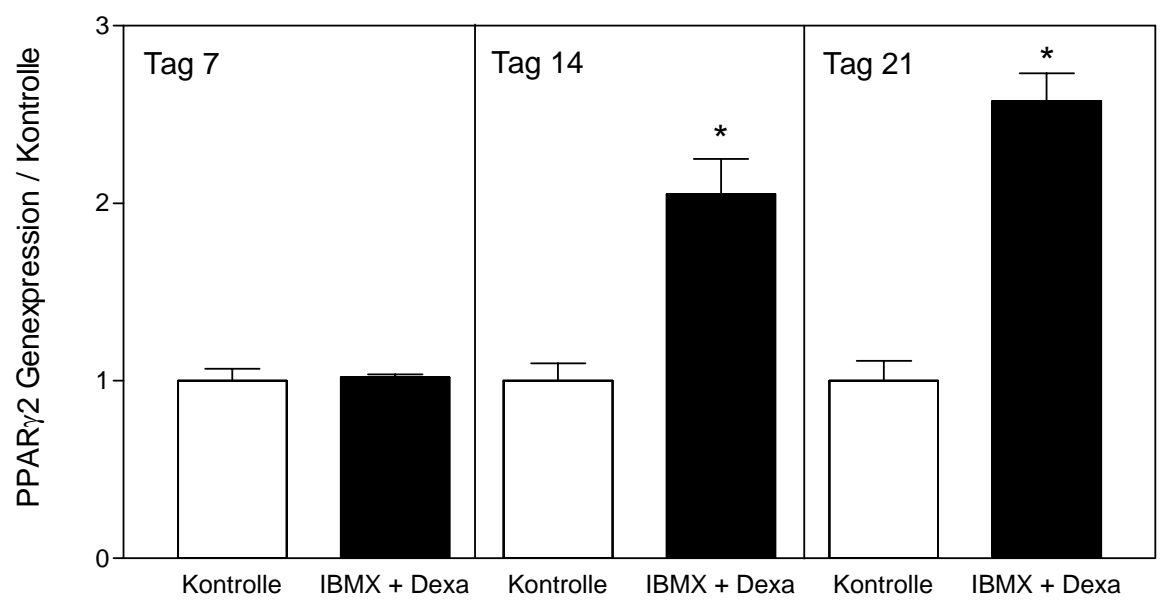

Abb. 16: Induktion der PPAR 2 Genexpression in primären HOB Zellen nach Stimulation mit IBMX + Dexa. Nach 7, 14 und 21 Tagen Stimulationsdauer wurde die mRNA-Expression mittels RT-PCR analysiert. Die Graphik stellt die densitometrische Analyse normalisiert auf die Kontrolle dar. Die Daten repräsentieren das Ergebniss eines Versuches als MW \pm SEM $(n=4)$. Signifikanzen sind gekennzeichnet mit $* p<0,05$ (Mann Withney U Test).

Die stimulierten Zellen zeigten einen signifikanten 2 fachen Anstieg $(p<0,05)$ der PPAR $\gamma 2$ Genexpression nach 14 Tagen. Einen weiteren Anstieg und ein Maximalwert um des 2,5fache wurde nach 21 Tagen $(p<0,05)$ erreicht.

Diese Ergebnisse zeigen eine Induktion der Adipogenese in pHOB Zellen unter IBMX + Dexa Stimulation. 


\section{III.1.2. Untersuchungen zur Induktion der Adipogenese an der immortalisierten Osteoblastenzellinie AHTO}

Die AHTO Zellen sind eine Population differenzierter Osteoblasten, isoliert aus humanen trabekulären Knochen eines 65-jährigen gesunden Patienten, die durch die Genom-Insertion des SV40 Oncogens immortalisiert wurden. Die AHTO Zellen zeigen eine Reihe von Eigenschaften, die typisch für den differenzierten osteoblastären Phänotyp sind. Dies umfaßt die konstitutive mRNA Expression von OC, AP und Kollagen-I (Lomri et al, 1999). Da diese bereits charakterisierte Zellinie einen differenzierten osteoblastären Phänotyp repräsentiert und aufgrund ihrer humanen Herkunft, erscheint sie als ein gut geeignetes Model zur Untersuchung der humanen Osteoblastenzellbiologie. Im folgenden Teil stellten wir die Frage, ob eine Induktion der Adipogenese, wie sie bereits bei pHOB Zellen nachgewiesen wurde, in den AHTO Zellen möglich ist.

\section{III.1.2.1. Histologische und zytochemische Analyse}

An den fixierten AHTO Zellen wurde die Doppelfärbung zum Nachweis der AP-Aktivität, als Osteoblastendifferenzierungsmarker, sowie von Lipidvakuolen (Oil Red O), als Adipozytendifferenzierungsmarker, durchgeführt.

Für die AHTO Zellen wurde eine Populationsverdoppelungszeit von 22 Stunden beschrieben (Lomri et al. 1999). Diese immortalisierten Zellen können aufgrund der fehlenden Kontaktinhibition weiter wachsen, da es bei einer zu hohen Zelldichte zum Absterben der Zellen kommt. Bei einer Aussaatdichte von 1,3 x $10^{4}$ Zellen/ $\mathrm{cm}^{2}$ erreichen die AHTO Zellen in 2 Tagen $100 \%$ Konfluenz. Die Stimulationszeit der AHTO Zellen betrug 14 Tage nach Erreichen der Konfluenz (Tag 2), da es im weiteren Verlauf der Kultur aus den vorgenannten Grunde zu einem Absterben der Zellen kam.

Unter Basalbedingungen wurden kleine Lipidvakuolen und AP-positive Zellen nachgewiesen (Abb.17, I, III). Nach 7 Tagen Stimulation mit Adipogenesemedium stieg der Zahl der Lipidvakuolen und gleichzeitig die AP-Enzymaktivität (Abb.17, II). Ab diesem Zeitpunkt kam es zu einer starken Verringerung der Anheftung der Zellen, dies minderte die Qualität der zytochemischen Analyse am Tag 14 (Abb. 17, III, IV).

Zum Ende des Versuches kam zu einem deutlichen Verlust der Zellen unter Basalbedingungen gegenüber den stimulierten. Dieser Verlust nahm durch die Fixierung noch weiter zu (Abb. 17, III). 

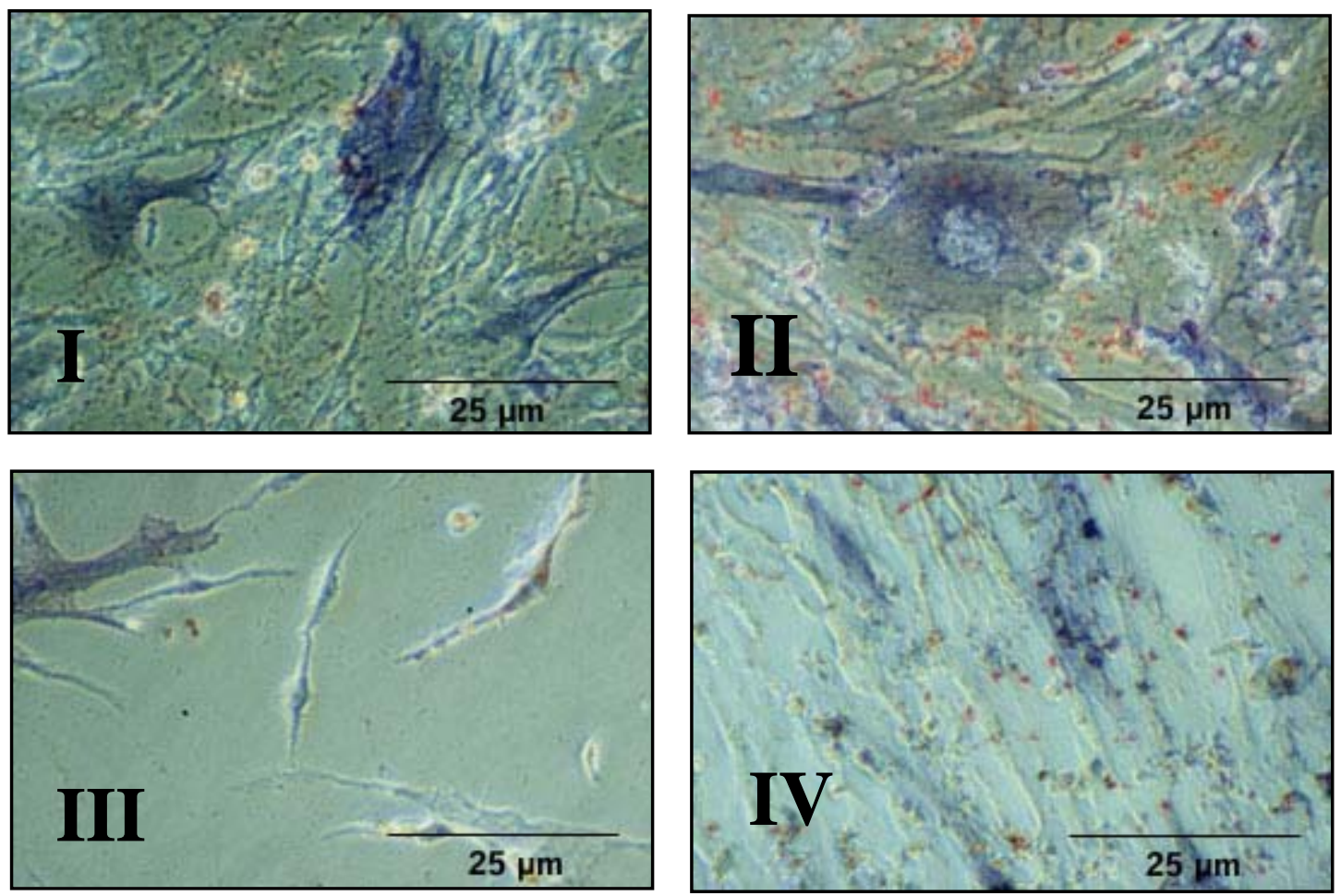

Abb 17: Induktion der Adipogenese in der immortalisierten AHTO Zellinie unter Stimulation mit IBMX + Dexa. Die Doppelfärbung zum Nachweis der AP-Aktivität (blaue Farbe) und Lipidvakuolen (Oil Red $\mathrm{O}$, rote Farbe) wurde nach 7 und 14 Tagen Stimulationsdauer durchgeführt.

I: Zellen unter Basalbedingungen nach 7 Tagen

II: Zellen unter IBMX + Dexa nach 7 Tagen

III: Zellen unter Basalbedingungen nach 14 Tagen

IV: Zellen unter IBMX + Dexa nach 14 Tagen

\section{III.1.2.2. Wirkung auf die Genexpression}

Um den Differenzierungsprozeß zum Adipozyten genauer zu charakterisieren wurde die Induktion der mRNA Expression von PPAR $\gamma 2$ untersucht. Um parallel Information über die osteoblastäre Differenzierung zu erhalten, untersuchten wir die Genexpression von CBFA1 und AP.

Unter Einfluß von Adipogenesemedium zeigte sich eine Induktion der AP Genexpression mit einem maximalen Effekt nach 14 Tagen $(\mathrm{p}<0,05)$ (Abb. 18, oben). Die Untersuchung der CBFA1-mRNA Expression ergab einen signifikanten Anstieg $(\mathrm{p}<0,05)$ sowohl nach 7 als auch nach 14 Tagen Stimulation (Abb. 18, unten). 


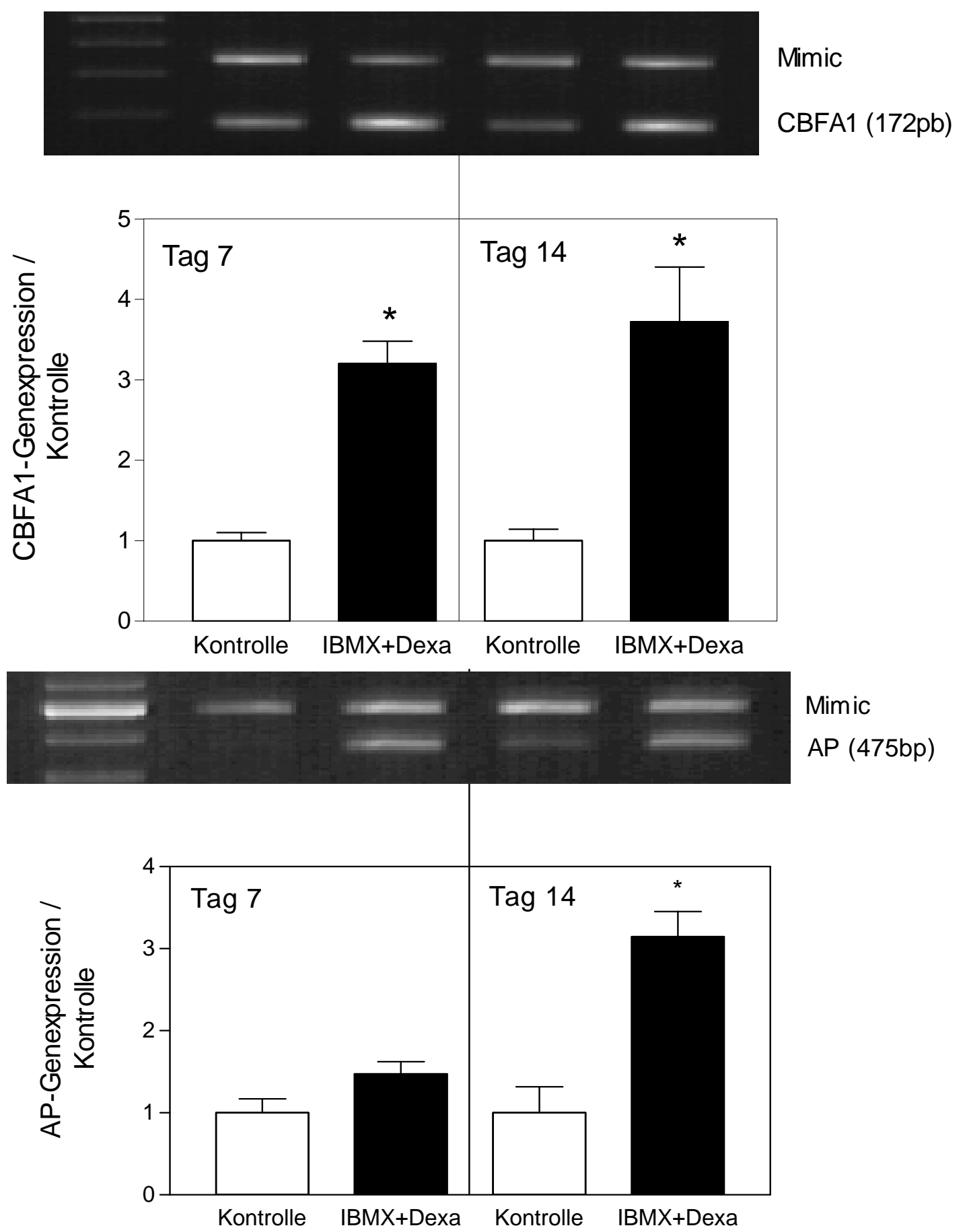

Abb. 18: Analyse der AP- und CBFA1-mRNA-Expression in AHTO Zellen nach Stimulation mit IBMX + Dexa. Nach 7 und 14 Tagen Stimulationsdauer wurde die mRNA-Expression mittels semiquantitativer RT-PCR analysiert. Die Graphik stellt die densitometrische Analyse der Banden (oben) normalisiert auf die Kontrolle dar. Die Daten repräsentieren das Ergebniss eines Zellversuches als MW \pm SEM ( $n=4)$. Signifikanzen sind gekennzeichnet mit * $\mathrm{p}<0,05$ (Mann Whitney Test). 
Die Untersuchung der mRNA-Synthese von PPAR $\gamma 2$ zeigte nur nach 14 Tagen Stimulation einen leichten Anstieg um den Faktor 1,8, der aber statistisch nicht signifikant war (Abb. 19).

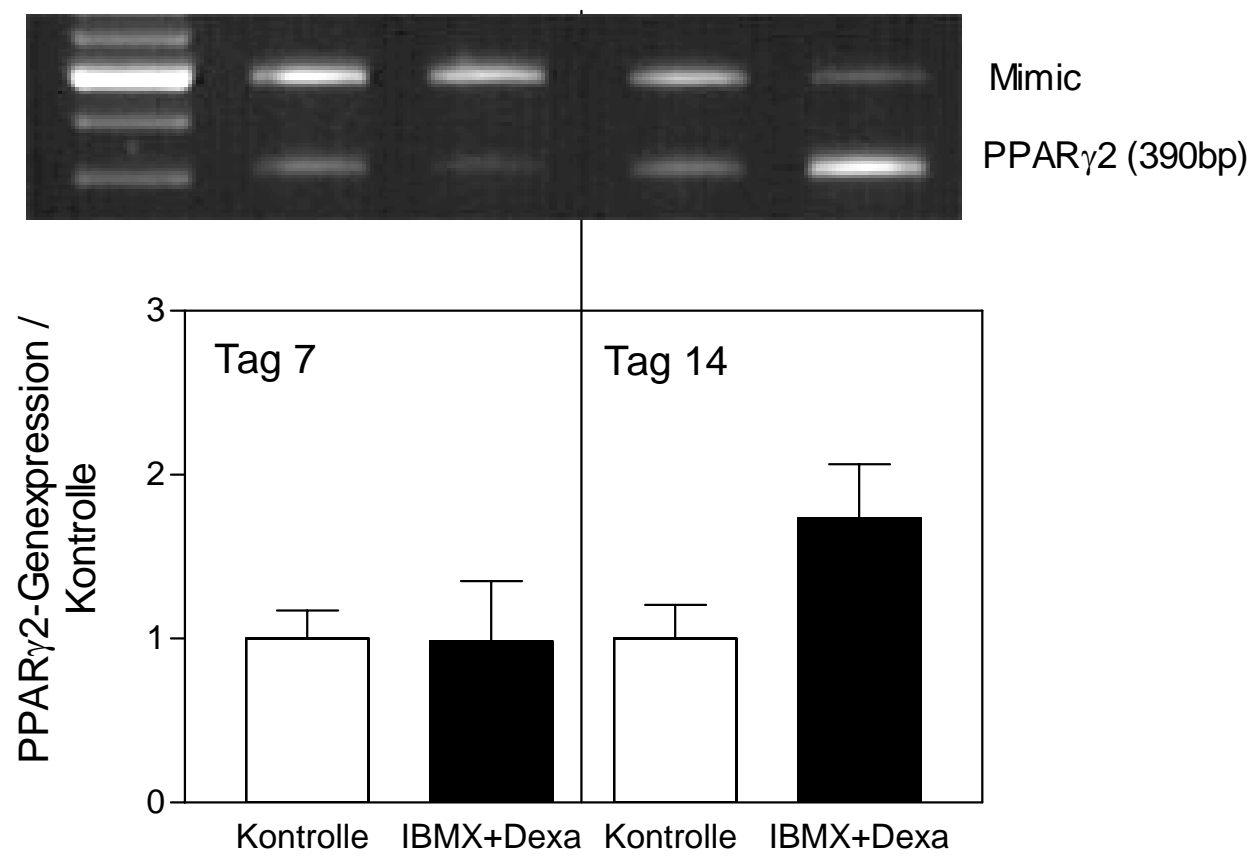

Abb. 19: Analyse der PPAR 2 2-mRNA-Expression in AHTO Zellen nach Stimulation mit IBMX + Dexa. Nach 7 und 14 Tagen Stimulationsdauer wurde die mRNA-Expression mittels semiquantitative RT-PCR analysiert. Die Graphik stellt die densitometrische Analyse der Banden (oben) normalisiert auf die Kontrolle dar. Die Daten repräsentieren das Ergebniss als MW \pm SEM ( $n=4)$. Signifikanzen sind gekennzeichnet mit * $<<0,05$ (Mann Whitney U Test).

Diese Ergebnisse zeigen eine deutliche Induktion der Expression von AP und CBFA1 als Zeichen eines Osteoblastendifferenzierungsprozeßes in den AHTO Zellen. Eine Induktion der Adipogenese auf der mRNA Ebene konnte unter Stimulation mit IBMX + Dexa nicht nachgewiesen werden. 


\section{III.2. Untersuchung zur Expression adipozytärer und osteoblastärer Marker in pHOB Zellen unter Stimulation mit BMP-2}

Um die dosisabhängigen Auswirkungen von BMP-2 auf die Expression von Adipozyten- bzw Osteoblastendifferenzierungsmarker zu untersuchen, wurden die pHOB Zellen für 2 und 7 Tage mit verschiedenen BMP-2-Konzentrationen (50, 100 und $200 \mathrm{ng} / \mathrm{ml}$ ) stimuliert. Die Stimulation der Kulturen erfolgte am Tag 10 der 1.Passage in serumfreiem Medium (DMEM/ 0,1\% BSA). Mittels RT-PCR Analyse wurde sowohl die mRNA-Expression von LPL und PPAR $\gamma 2$ als Adipozytendifferenzierungsmarker als auch AP als Osteoblastendifferenzierungs-marker nachgewiesen. Neben der mRNA-Expressionsanalyse wurde an fixierten Zellen die AP-Aktivität und Lipidvakuolen mittels der Red Oil O-Färbung nachgewiesen.

Die mRNA von PPAR $\gamma 2$ war über den gesamten untersuchten Zeitraum unter basalen Bedingungen nachweisbar (Abb. 20). Unter BMP-2 Stimulation nach 2 Tagen erbrachte die Analyse eine Suppression der Expression von PPAR $\gamma 2$, die statistisch signifikant $(p<0,05)$ für 50 und 200 ng/ ml BMP-2. Einen Anstieg um den Faktor 2, der aber statistisch nicht signifikant war, wurde nur nach 7-tägiger Stimulation mit $50 \mathrm{ng} / \mathrm{ml}$ nachgewiesen (Abb. 20).

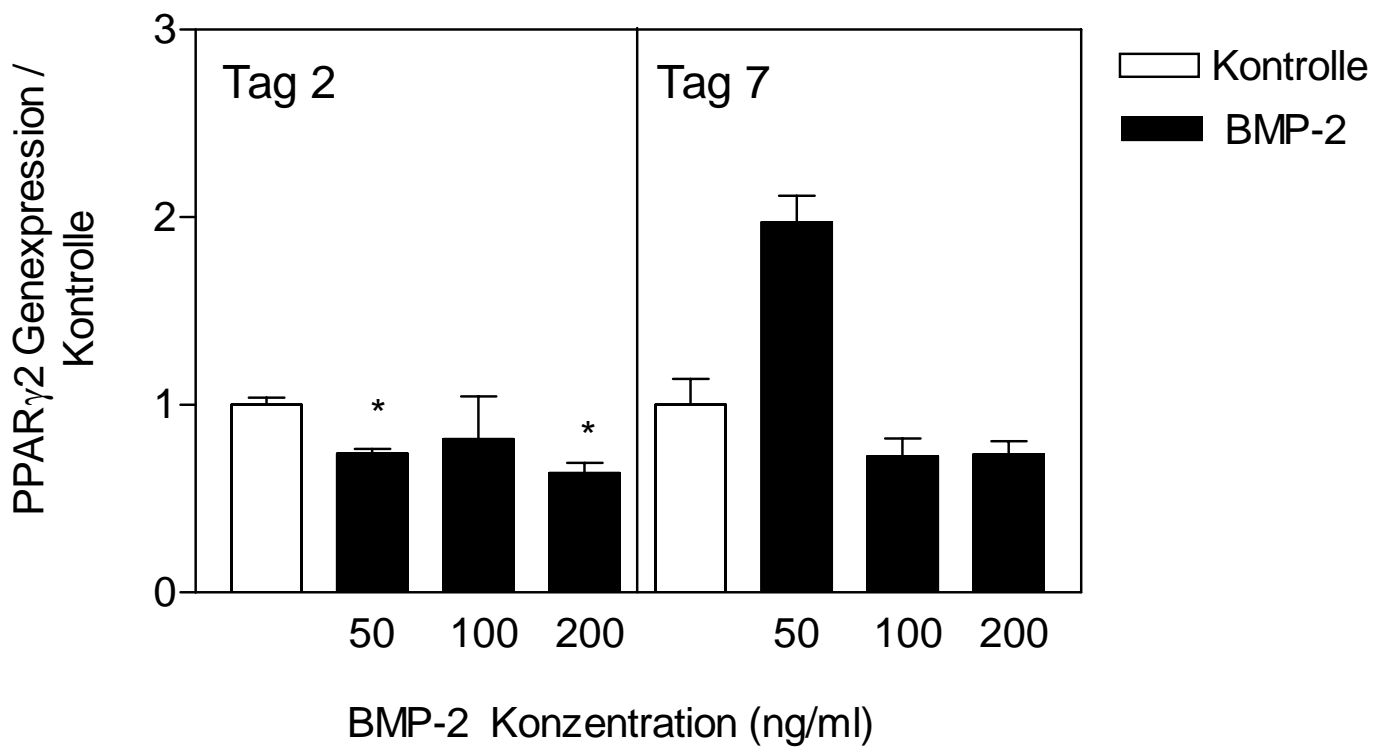

Abb. 20: Analyse der PPAR 2 -mRNA-Expression in pHOB Zellen nach Stimulation mit BMP-2. Nach 2 und 7 Tagen Stimulationsdauer wurde die mRNA-Expression mittels semiquantitative RT-PCR. Die Graphik stellt die densitometrische Analyse der Banden normalisiert auf die Kontrolle dar. Die Daten repräsentieren das Ergebniss von einem Zellversuch als MW \pm SEM $(n=4)$. Signifikanzen sind gekennzeichnet mit * $<<0,05$ (Mann Withney U Test). 
Die Genexpressionsanalyse von LPL ergab sowohl basal (Kontrolle) als auch stimuliert über den gesamten untersuchten Zeitraum einen ähnlichen gleichförmigen Verlauf, ohne signifikante Unterschiede (Abb. 21).

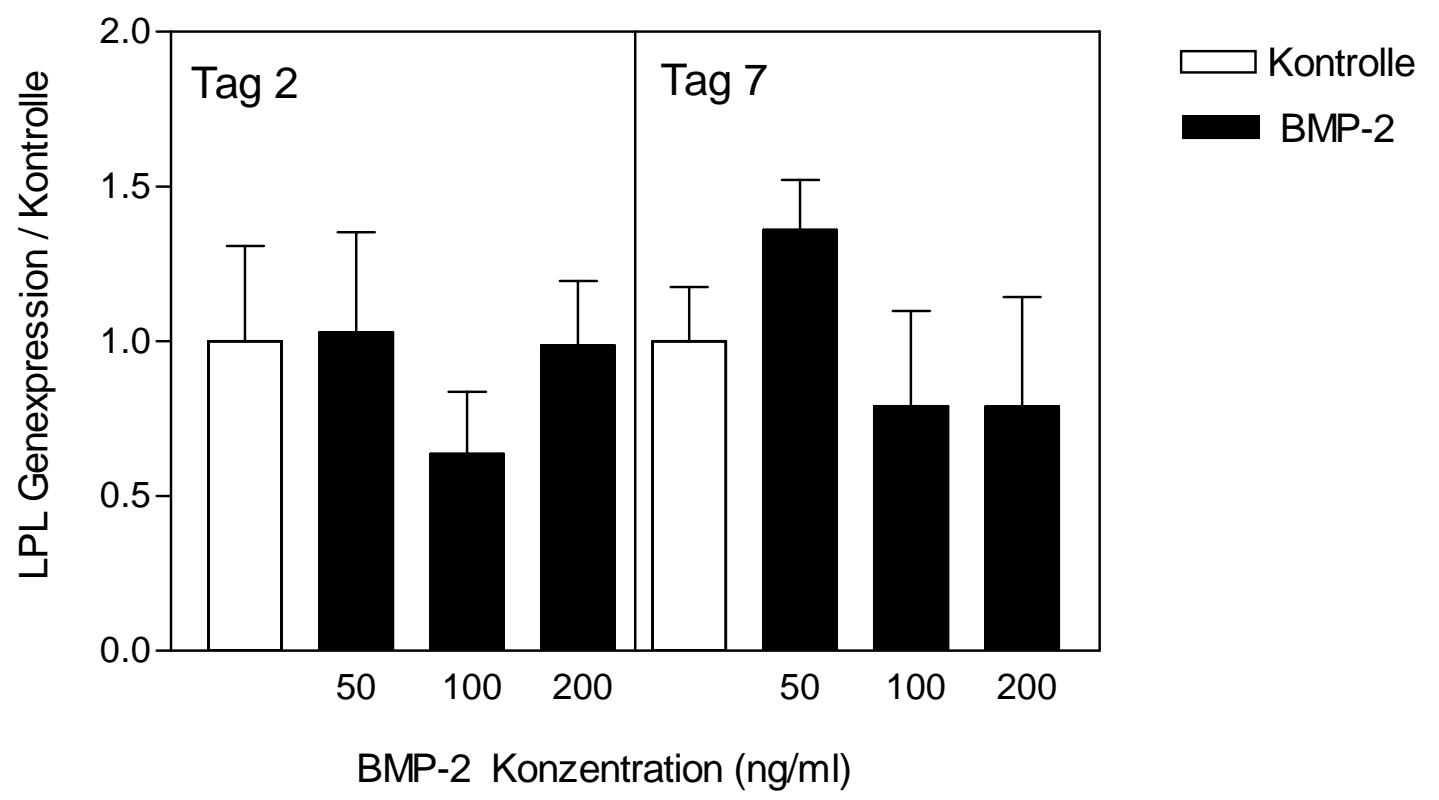

Abb. 21: Analyse der LPL-mRNA-Expression in pHOB Zellen nach Stimulation mit BMP-2. Nach 2 und 7 Tagen Stimulationsdauer wurde die mRNA-Expression mittels semiguantitative RT-PCR. Die Graphik stellt die densitometrische Analyse der Banden normalisiert auf die Kontrolle dar. Die Daten repräsentieren das Ergebniss von einem Zellversuch als MW \pm SEM ( $n=4)$. Signifikanzen sind gekennzeichnet mit*p<0,05 (Mann Withney U Test).

Über den untersuchten Zeitraum konnte weder unter Basalbedingungen noch unter Stimulation auf Gen- oder Proteinebene (RT-PCR, zytochemische Färbung) eine AP-Expression nachgewiesen werden. 


\section{III.3. Untersuchung der Plastizität homogener Subpopulationen von pHOB Zellen}

\section{III.3.1. Magnetische Zellsortierung AP-negativer Zellen}

Kulturen von pHOB Zellen sind bezüglich der AP-Expression heterogen. Um die Differenzierung der Osteoblasten sowie ihre Regulation untersuchen zu können, ist die Isolierung homogener Subpopulationen sinnvoll.

Frühere Untersuchungen (Ponce, 2000, Diplomarbeit) indem die MACS (Magnetische Zellsortierung) Methode zur Isolierung und Weiterkultivierung homogener AP-negativen Subpopulationen etabliert wurde, dienten als Basis für die folgenden Differenzierungsversuche. Die pHOB Zellen (3 Patienten, 1. Passage) wurden vor und nach der Sortierung bis zum Anfang des Differenzierungsversuches unter Standardbedingungen (DMEM/ 10\% FCS) kultiviert.

Die folgenden Abbildungen zeigen die FACS (Durchflusszytometrie) Analyse der pHOB Zellen vor der Sortierung (Abb. 22), unmittelbar nach der Sortierung (Abb. 23) und nach 14 Tagen Rekultivierung (Abb. 24).

Die Abbildung 22 zeigt die FACS Analyse der pHOB Zellen vor der Sortierung (Ausgangspopulation oder ungetrennte Fraktion). Diese Ausgangspopulation enthält $21 \%$ APpositiven Zellen (Abb. 22E-F). Die FACS Analyse unmittelbar nach der Sortierung (Abb. 23) zeigt, daß die AP-negative Fraktion homogen ist ( $<0 \%$ AP-positive Zellen) (Abb. 23E-F).

Die Homogenität der Fraktionen wurde vor dem Beginn des Differenzierungsversuches (III.3) kontrolliert (Abb. 24). Die AP-negativen Zellen blieben nach 14 Tagen annähernd negativ (< $1 \%$ AP-positive Zellen) (Abb. 24E-F). 
FACS Analyse der ungetrennten Fraktion

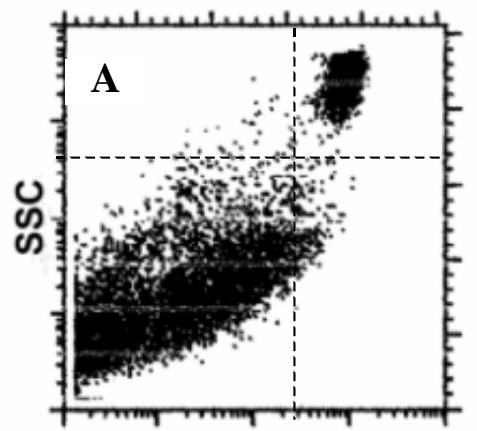

FSC

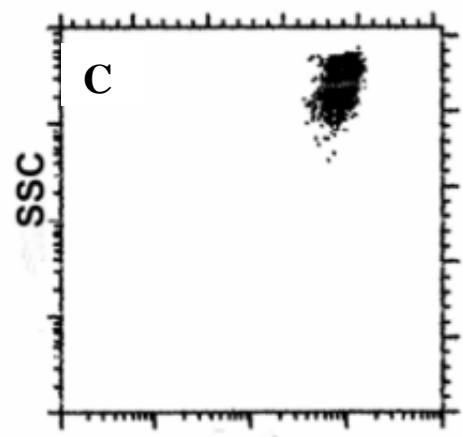

FSC

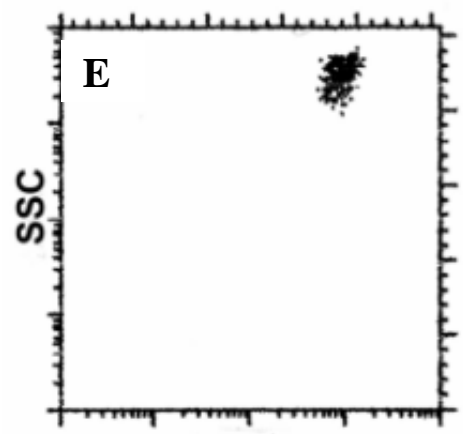

FSC

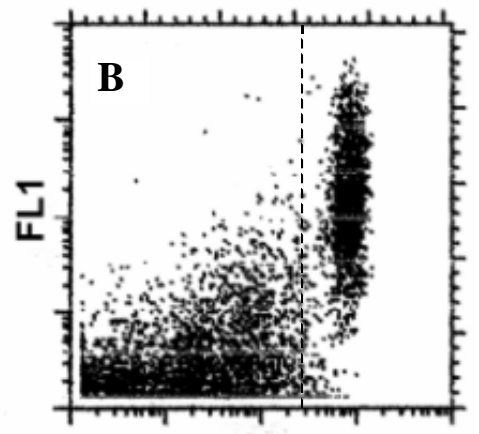

FSC

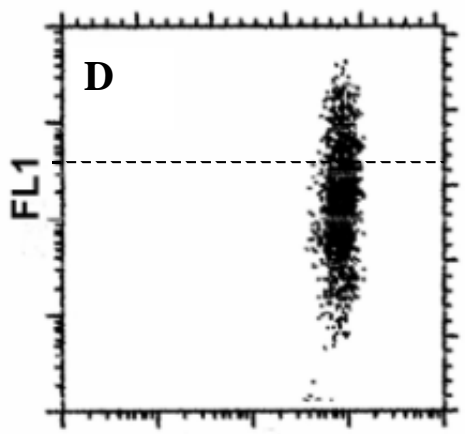

FSC

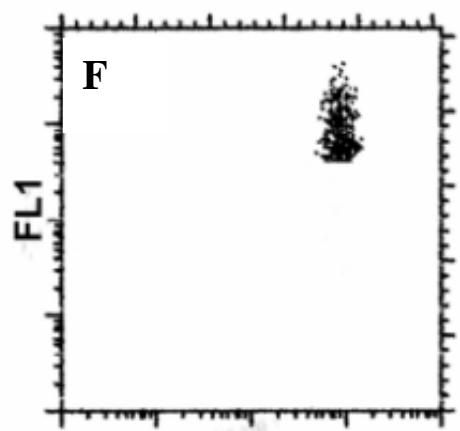

FSC

Abb. 22: FACS Analyse von AP-positiven Zellen der ungetrennten Fraktion (vor der Sortierung).

A, B: Messung von 12.000 Ereignissen (Events). A: Anhand von Zellgröße (FSC) und Granularität (SSC) wurden die intakten Zellen (oben rechts) von den Zelltrümmern abgegrenzt. B: Fluoreszenzanalyse (FL1) der intakten Zellen (rechts) einschließlich Hintergrundfluoreszenz.

C, D: Intakte Zellen, die nach der Aktivierung des (FSC, SSC) Grenzwertes ermittelt wurden. C: von 12.000 Ereignissen wurden 18,4 \% als intakte Zellen nachgewiesen. D: Fluoreszenzanalyse der intakten Zellen. Die positiven Zellen (oben) wurden anhand des FL1 Grenzwertes (Hintergrundfluoreszenz) abgegrenzt.

E, F: Nach der Aktivierung des entsprechenden Grenzwertes wurden 21\% der intakten Zellen als APpositiv nachgewiesen.

FSC: forward scatter, SSC: sideward scatter, FL1: Fluoreszenz 1 


\section{FACS Analyse der AP-negativen Fraktion nach der Sortierung}
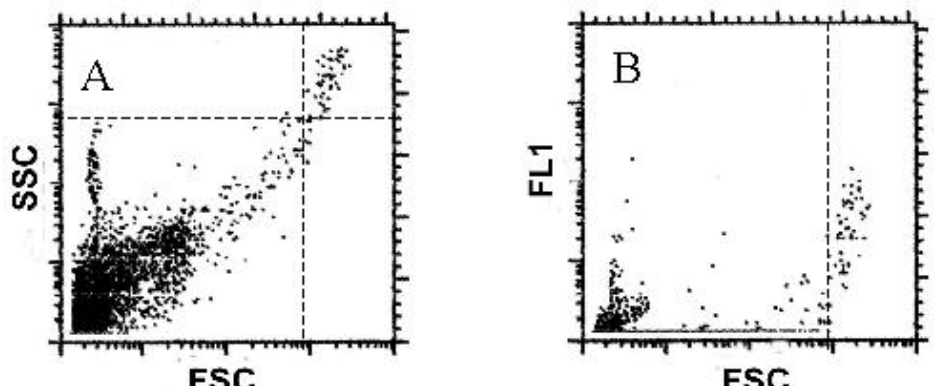

FSC
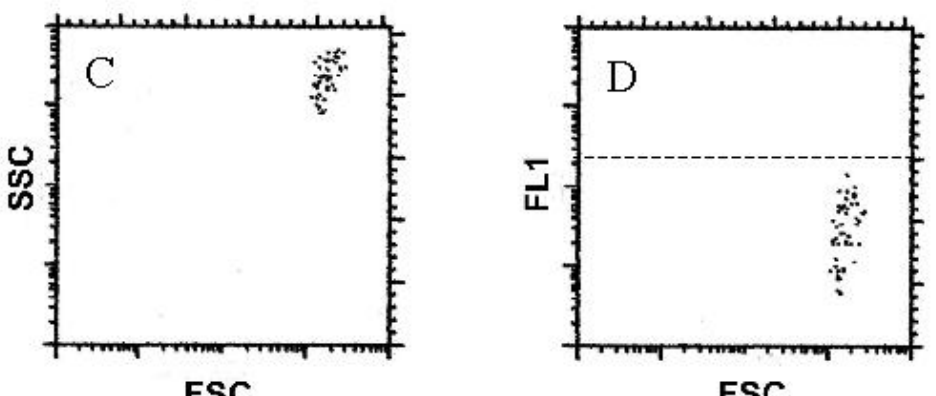

FSC
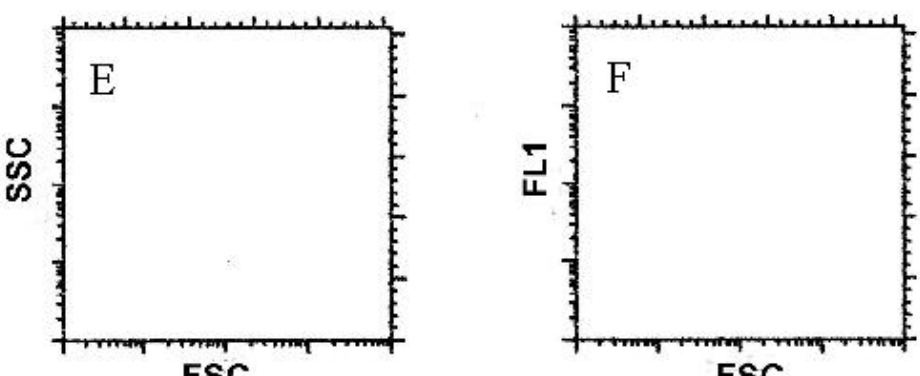

Abb. 23: FACS Analyse von AP-positiven Zellen der negativen Fraktion. Die Daten stellen die Auswertung der negativen Fraktion unmittelbar nach der Sortierung dar.

A, B: Messung von 12.000 Ereignissen (Events). A: Anhand von Zellgröße (FSC) und Granularität (SSC) wurden die intakten Zellen (oben rechts) von den Zelltrümmern abgegrenzt. B: Fluoreszenzanalyse (FL1) der intakten Zellen (rechts) einschließlich Hintergrundfluoreszenz.

C, D: Intakte Zellen, die nach der Aktivierung des (FSC, SSC) Grenzwertes ermittelt wurden C: 12.000 Ereignissen. D: Fluoreszenzanalyse der intakten Zellen. Die positiven Zellen (oben) wurden anhand des FL1 Grenzwertes (Hintegrundfluoreszenz) abgegrenzt.

E, F: Nach der Aktivierung des entsprechenden Grenzwertes wurden 0\% der intakten Zellen als APpositiv nachgewiesen.

FSC: forward scatter, SSC: sideward scatter, FL1: Fluoreszenz 1 


\section{FACS Analyse der AP-negativen Fraktion}

\section{nach 14 Tagen Rekultivierung}
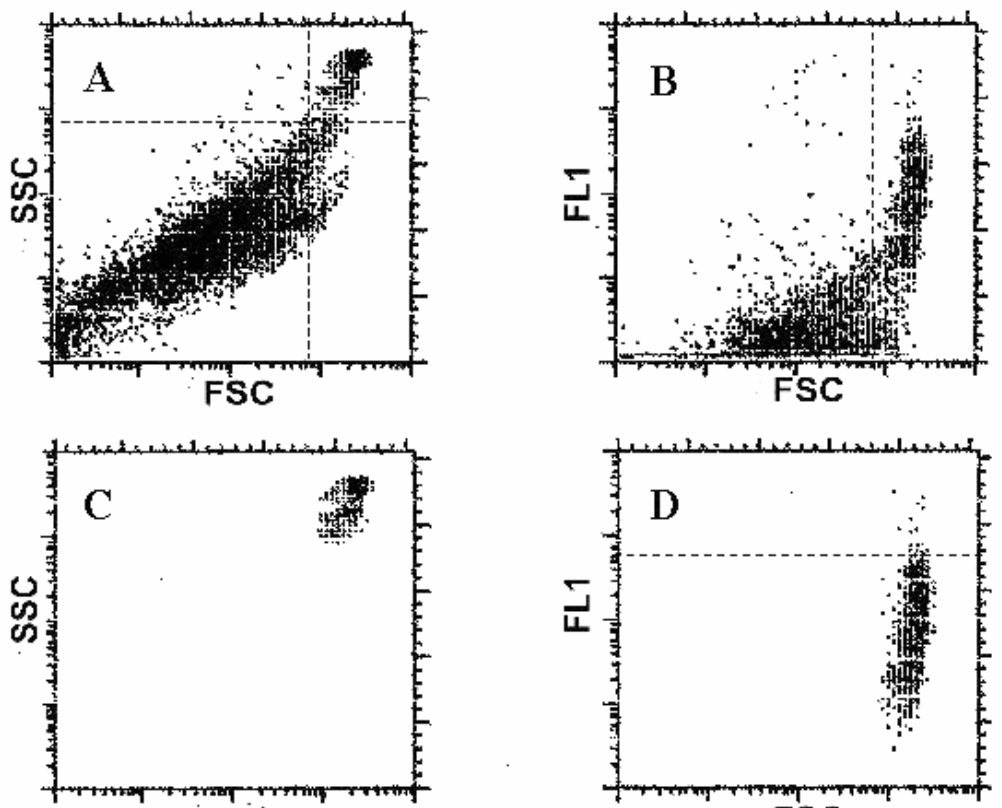

FSC

FSC
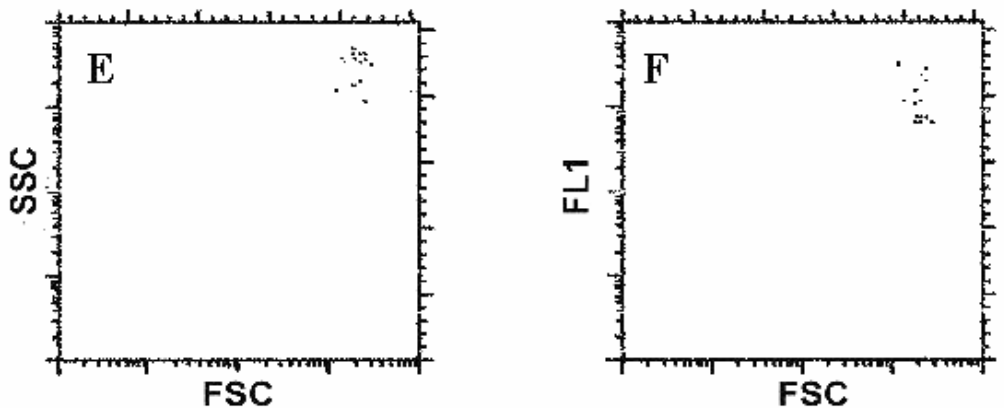

Abb 24: FACS Analyse von AP-positiven Zellen in der negativen Fraktion. Die Daten stellen die Auswertung der negativen Fraktion nach 14 Tagen Rekultivierung unter Standardbedingungen dar.

A, B: Messung von 12.000 Ereignissen (Events). A: Anhand von Zellgröße (FSC) und Granularität (SSC) wurden die intakten Zellen (oben rechts) von den Zelltrümmern abgegrenzt B: Fluoreszenzanalyse (FL1) der intakten Zellen (rechts) einschließlich Hintergrundfluoreszenz.

C, D: Intakte Zellen, die nach der Aktivierung des (FSC, SSC) Grenzwertes ermittelt wurden C: von 12.000 Ereignissen wurden 13,7\% als intakte Zellen nachgewiesen. D: Fluoreszenzanalyse der intakten Zellen. Die positiven Zellen (oben) wurden anhand des FL1 Grenzwertes (Hintegrundfluoreszenz) abgegrenzt.

E, F: Nach der Aktivierung des entsprechenden Grenzwertes wurden 0,96 \% der intakten Zellen als APpositiv nachgewiesen.

FSC: forward scatter, SSC: sideward scatter, FL1: Fluoreszenz 1 


\section{III.3.2. Untersuchung des Differenzierungspotential AP-negativer Zellen}

In folgenden Teil dieser Arbeit sollte das Differenzierungspotential von homogenen Subpopulationen AP-negativer Zellen (pHOB) untersucht werden. Dafür wurden die mittels MACS-Methode isolierten AP-negativen Zellen von 3 Patienten (2. Passage) bei Konfluenz für 2 und 7 Tage mit OF: Betaglycerophosphat $(2 \mathrm{mM})$, Ascorbat $(50 \mu \mathrm{g} / \mathrm{ml}), 1,25(\mathrm{OH})_{2} \mathrm{D}_{3}\left(4 \times 10^{-}\right.$ $\left.{ }^{8} \mathrm{M}\right)$, Dexamethason $\left(10^{-8} \mathrm{M}\right)$ und entweder OF + TGF- $\beta 1(1 \mathrm{ng} / \mathrm{ml})$ oder OF + BMP-2 (50 ng/ ml) stimuliert und bei jedem Zeitpunkt wurden die folgenden Parameter untersucht:

\section{III.3.2.1. Histologische und zytochemische Analyse}

Hier sollte zunächst der Einfluss der Stimulierungsfaktoren auf die Differenzierung der APnegativen Zellen histologisch untersucht werden.

Nach 7-tägiger Stimulation wurden die lebenden Zellen photografiert (Abb 25, Schwarzweiss) und an den fixierten Zellen wurde eine Doppelfärbung zum Nachweis der AP-Enzymaktivität (blaue Farbe), als Osteoblastendifferenzierungsmarker, sowie von Lipidvakuolen (Oil Red O, rote Farbe), als Adipozytendifferenzierungsmarker, durchgeführt (Abb 25, farbig).

Unter Basalbedingungen (Kontrolle) zeigten sich die Zellen schmal und länglich in ihrer Zellform (Abb 25, I). Die entsprechenden fixierten Zellen zeigten unter diesen Bedingungen weder AP-Enzymaktivität noch Lipidvakuolen (keine blaue oder rote Farbe) (Abb 25, I).

Unter Zugabe von Stimulationsfaktoren breiteten sich die Zellen aus, nahmen polygonale und heterogene Formen an (Abb 25, II, III, IV) und zeigten gegenüber nicht induzierten Zellen APEnzymaktivität (Abb 25, II, III, IV). Unter diesen Bedingungen konnten keine Lipidvakuolen beobachtet werden.

Bezüglich der Farbintensität, die mit der AP-Enzymaktivität korreliert, konnte eine starke Variation zwischen einzelnen Zellen nachgewiesen werden. Diese Beobachtung wurde bei unterschiedlichen Patienten bestätigt (Abb. 26). 

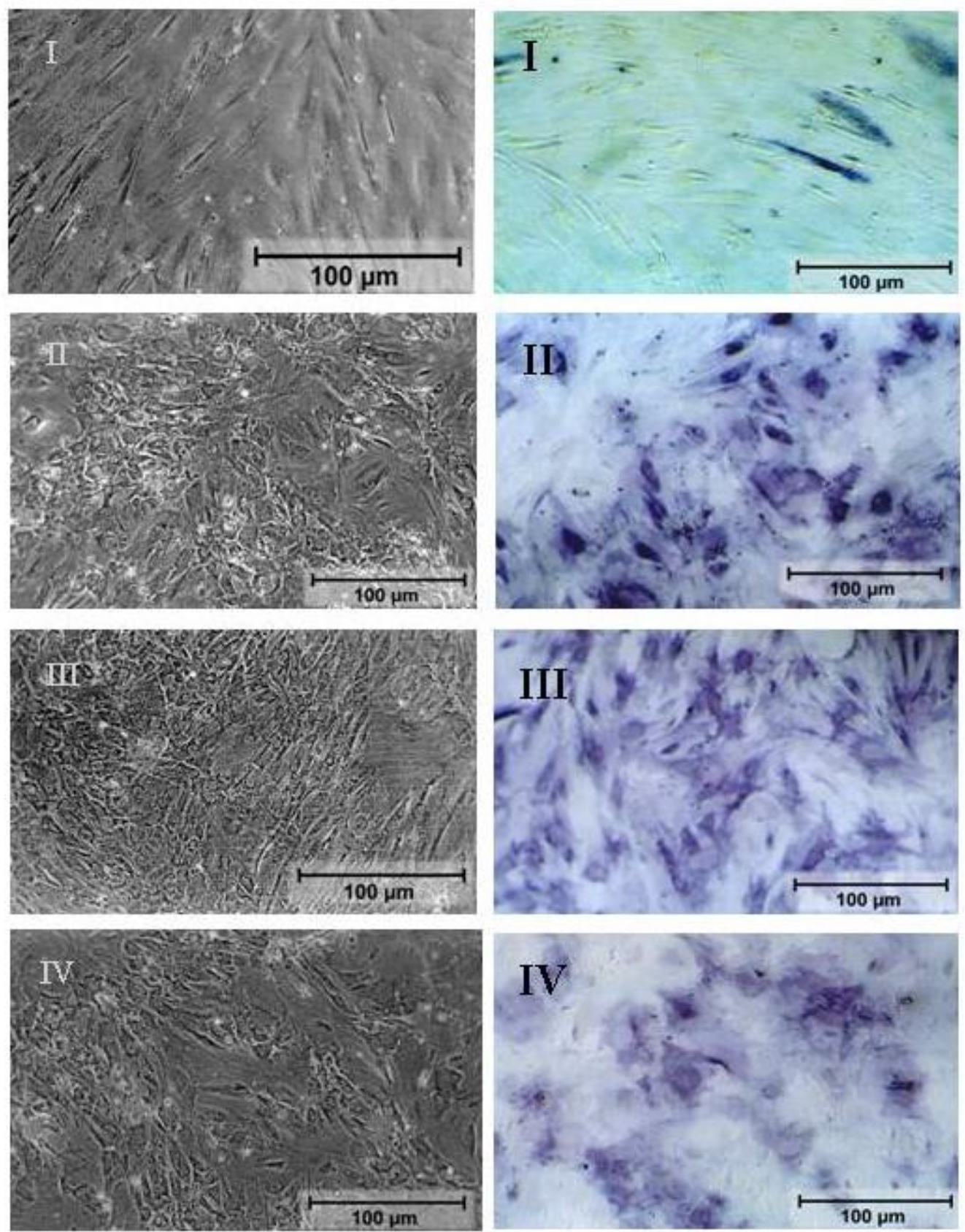

Abb. 25: Vergleich zwischen lebenden (schwarzweiß, links) und fixierten/gefärbten (rechts) pHOB Zellen der AP-negativen Fraktion. Am Ende des 7-tägigen Stimulationsversuches wurden die Zellen lebend photographiert (I, II, III und IV, schwarzweiß) und dann nach der Fixierung die Doppelfärbung für APEnzymaktivität (blaue Farbe) und Lipidvakuolen (Oil Red O, rote Farbe) durchgeführt (I, II, III, IV).

I: Kontrolle (I, I: x100)

II: OF (II, II: x100)

III: OF + TGF- $\beta 1(1 \mathrm{ng} / \mathrm{ml})(\mathrm{III}$, III: x100)

IV: OF + BMP-2 (50 ng/ ml) (IV, IV: x100)

OF: Betaglycerophosphat $(2 \mathrm{mM})$, Ascorbat $(50 \mu \mathrm{g} / \mathrm{ml}), 1,25(\mathrm{OH})_{2} \mathrm{D}_{3}\left(4 \times 10^{-8} \mathrm{M}\right)$, Dexamethason $\left(10^{-8}\right.$

M). Das Inkubationsmedium enthielt DMEM/ $0,1 \%$ BSA. 

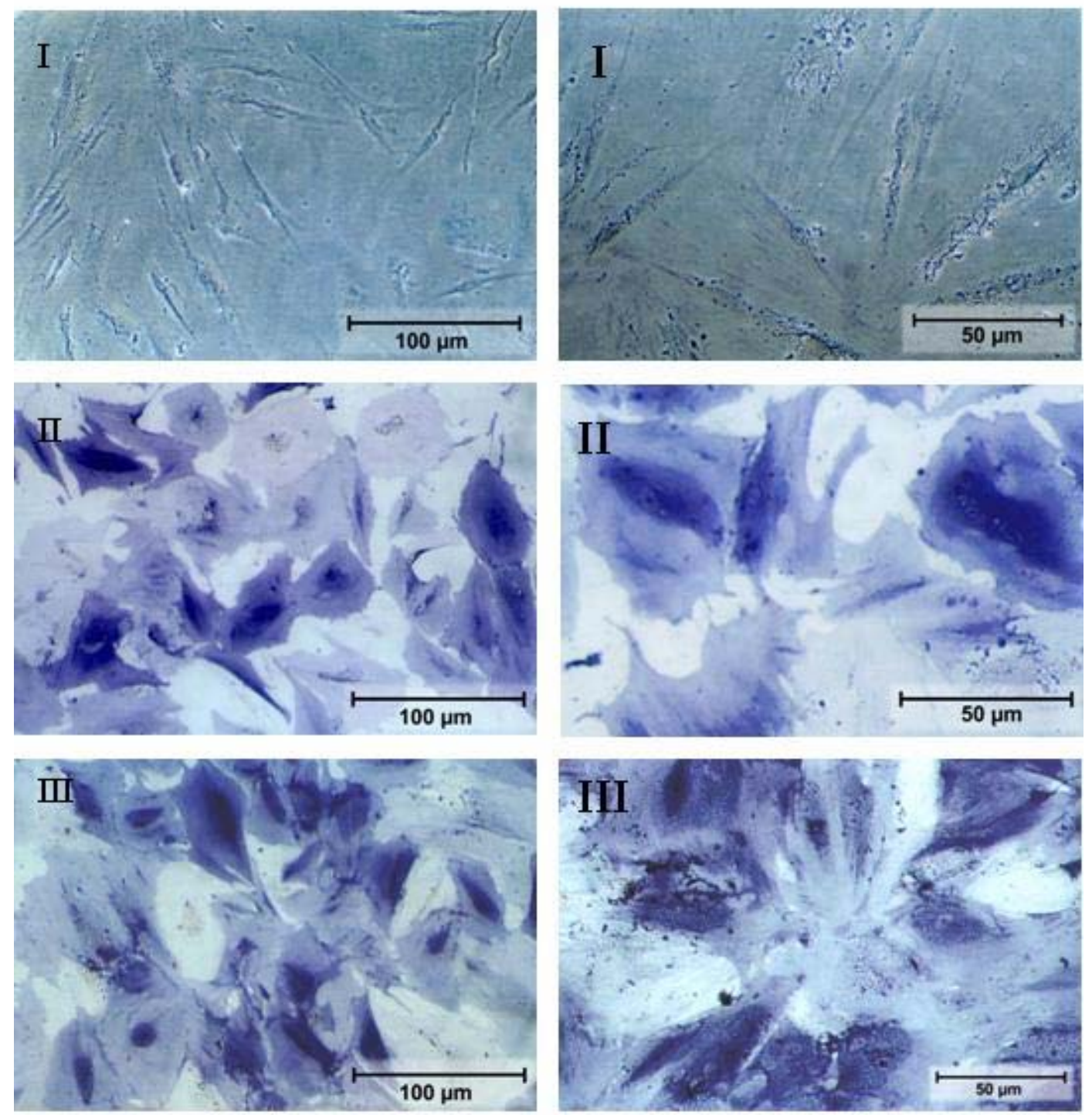

Abb. 26: Histochemische Analyse von pHOB-Zellen der AP-negativen Fraktion nach 7 Tagen Stimulation. Nach der 7-tägigen Stimulation wurde die Doppelfärbung für AP-Enzymaktivität (blau Farbe) und Lipidvakuolen (Oil Red O, rote Farbe) durchgeführt.

I: Kontrolle (I: x100, I: x200)

II : OF + TGF- $\beta 1(1 \mathrm{ng} / \mathrm{ml})(\mathrm{II}: \mathrm{x} 100, \mathbf{I I}: \mathbf{x} 200)$

III: OF + BMP-2 (50 ng/ ml) (III: x100, III: x200)

OF: Betaglycerophosphat $(2 \mathrm{mM})$, Ascorbat $(50 \mu \mathrm{g} / \mathrm{ml}), 1,25(\mathrm{OH})_{2} \mathrm{D}_{3}\left(4 \times 10^{-8} \mathrm{M}\right)$, Dexamethason $\left(10^{-8}\right.$ M). Das Inkubationsmedium enthielt DMEM/ 0,1\% BSA. 


\section{III.3.2.2. Quantifizierung der AP-Enzymaktivität}

Die AP-Aktivität wurde im Zellpellet mit Hilfe eines Assays quantifiziert. Die gesamte gemessene AP-Aktivität (nach 2 und 7 Tagen) im Zellpellet wurde auf die Zellzahl der identischen Probe bezogen und als nmol/min/ $10^{5}$ Zellen dargestellt. An parallelen und identisch behandelten Näpfen wurde, nach der Fixierung der Zellschicht, die AP-Aktivität als zytochemische Färbung (blaue Farbe) nachgewiesen (Abb. 27).

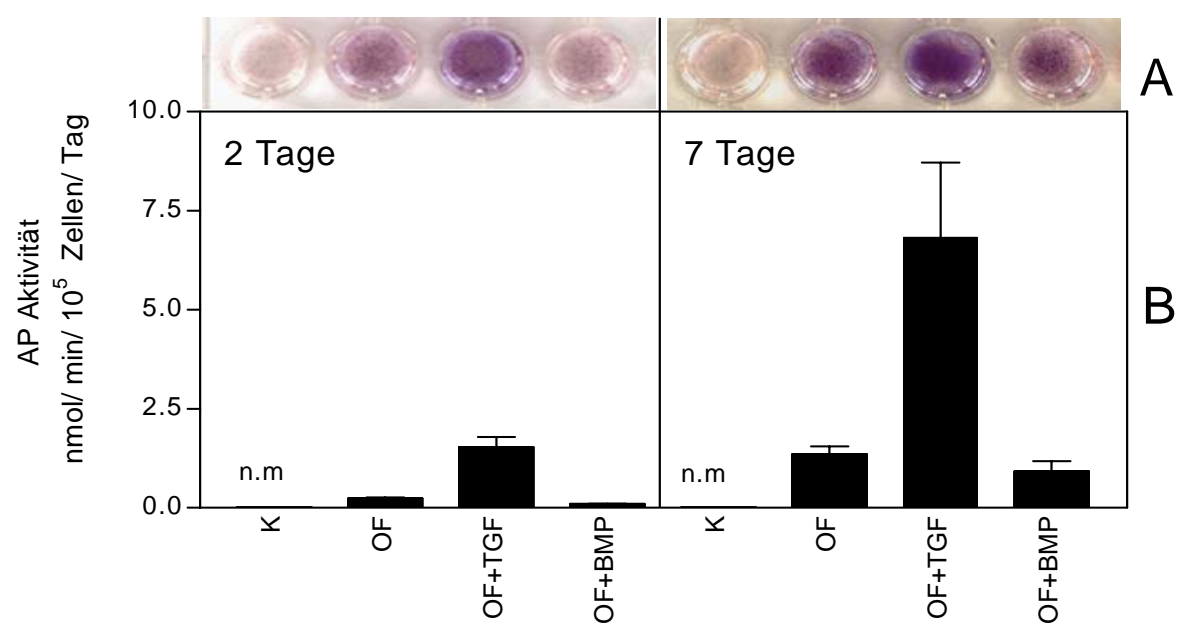

Abb. 27.: AP-Aktivität in den AP-negativen Fraktionen nach 2- und 7-tägiger Stimulation. Die Zellen wurden mit OF und entweder OF + TGF- $\beta 1(1 \mathrm{ng} / \mathrm{ml})$ oder OF + BMP-2 (50 ng/ ml) stimuliert.

Die Daten stellen die im Zellpellet gemessene AP-Aktivität (nmol/ min/ 10 Zellen/ Tag) als MW \pm SEM $(n=4)$ eines repräsentativen Versuches dar $(B$, Säulen Histogramm). Oberhalb des Diagramms ist die entsprechende AP-zytochemische Färbung (A) photographisch dargestellt.

OF: Betaglycerophosphat $(2 \mathrm{mM})$, Ascorbat $(50 \mu \mathrm{g} / \mathrm{ml}), 1,25(\mathrm{OH})_{2} \mathrm{D}_{3}\left(4 \times 10^{-8} \mathrm{M}\right)$, Dexamethason $\left(10^{-8}\right.$ M). Das Inkubationsmedium enthielt DMEM/ 0,1\% BSA.

K: Kontrolle; TGF: TGF $\beta-1$; BMP: BMP-2; n.m: nicht messbar

Generell war eine optische Korrelation der Farbintensität bei der zytochemische Färbung (Abb. 6, A) mit der quantitativen Bestimmung vorhanden (Abb. 27, B).

Unter Basalbedingungen zeigten die AP-negativen Zellen keine AP-Enzymaktivität sowohl in der quantitativen (Abb. 27, B, nicht messbar), als auch in der zytochemischen Messung (Abb. 27, A).

Unter allen Kombinationen von Differenzierungsfaktoren stieg die AP-Enzymaktivität nach 2 Tagen und weiter nach 7 Tagen an. Unter Zugabe von OF + TGF- $\beta 1$ konnte einen maximalen 6fachen Anstieg gegenüber der unter OF induzierten AP-Aktivität ermittelt werden. 


\section{III.3.2.3. Kollagen I Sekretion in den AP-negativen Zellen}

Die Kollagen-I Sekretion wurde durch die im Überstand gemessene carboxyterminale Propeptid (CICP) Konzentration mittels ELISA bestimmt. Das gesamte gemessene CICP wurde auf die Zellzahl der entsprechenden Probe bezogen und die Werte als ng/ $10^{5}$ Zellen/ Tag dargestellt.

Unter Basalbedingungen (Kontrolle) zeigten die AP-negativen Zellen eine deutlich messbar Kollagen-I Sekretion (Abb. 28). Unter allen Kombinationen von Differenzierungsfaktoren stieg die Kollagen-I Sekretion schon nach 2 Tagen. Signifikante Anstiege $(p<0,05)$ gegenüber der Kontrolle wurden aber nach 7 Tagen Stimulation nachgewiesen. Unter Zugabe von OF + TGF$\beta 1$ konnte ein maximaler 3 facher Anstieg ermittelt werden.

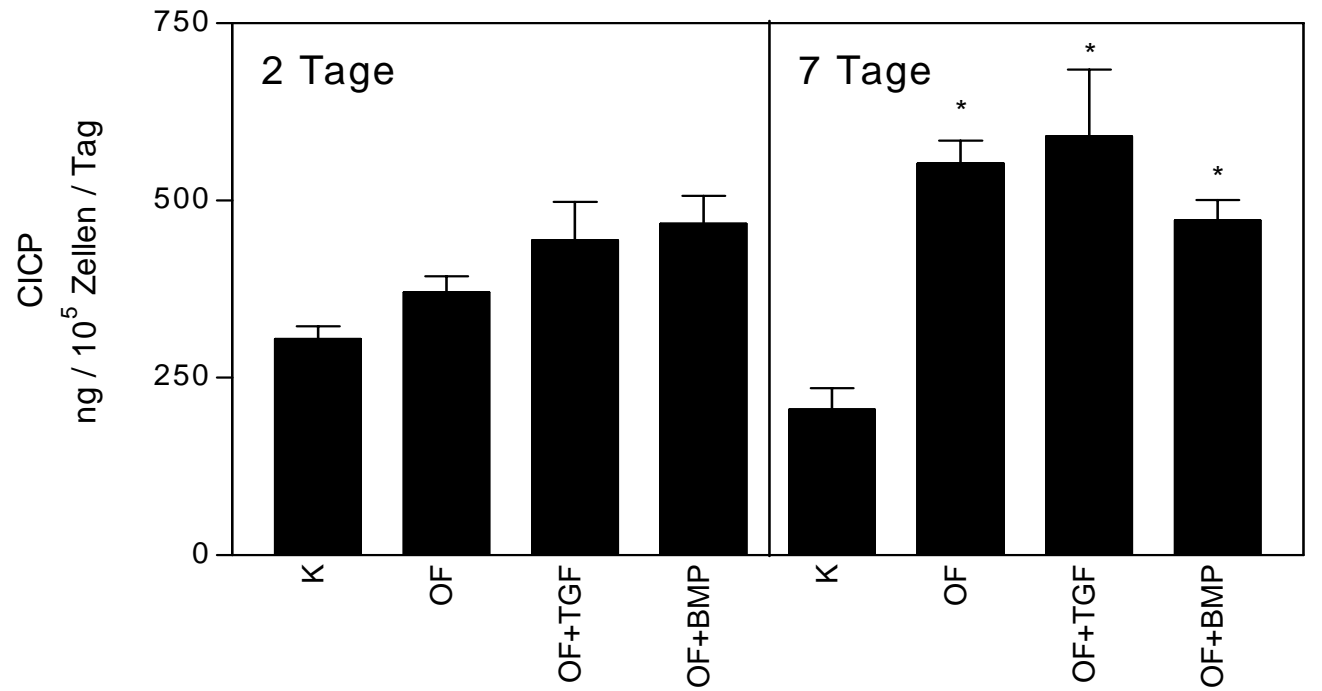

Abb. 28: Kollagen-I Sekretion in den AP-negativen Fraktionen nach 2- und 7-tägiger Stimulation. Die Zellen wurden mit OF und entweder OF + TGF- $\beta 1(1 \mathrm{ng} / \mathrm{ml})$ oder OF + BMP-2 $(50 \mathrm{ng} / \mathrm{ml})$ stimuliert. Die Daten stellen die im Überstand gemessenen CICP (ng/ 105 Zellen/ Tag) nach 2 und 7 Tagen als MW \pm SEM ( $n=4)$ eines repräsentativen Versuches dar. Die Zellzahl wurde zu jedem Zeitpunkt (Tag 2 und 7) bestimmt.

OF: Betaglycerophosphat $(2 \mathrm{mM})$, Ascorbat $(50 \mu \mathrm{g} / \mathrm{ml}), 1,25(\mathrm{OH})_{2} \mathrm{D}_{3}\left(4 \times 10^{-8} \mathrm{M}\right)$, Dexamethason $\left(10^{-8}\right.$ M) Das Inkubationsmedium enthielt DMEM/ 0,1\% BSA und das Kontroll-Inkubationsmedium Ethanol und Citrat Puffer $(<0,01 \%)$. Signifikanzen sind gekennzeichnet mit * $\mathrm{p}<0,05$ (Mann Withney Test). CICP: C-terminale Propeptid; K: Kontrolle; TGF: TGF- $\beta 1$; BMP: BMP-2.

\section{III.3.2.4. Osteokalzinsekretion in den AP-negativen Zellen}

Osteokalzin wurde als sekretorisches Protein im Zellüberstand mittels ELISA quantifiziert. Das gesamte gemessene Osteokalzin wurde auf die Zellzahl der entsprechenden Probe bezogen und die Werte als ng/ $10^{5}$ Zellen/ Tag dargestellt. 
Unter Basalbedingungen (Kontrolle) zeigten die AP-negativen Zellen eine niedrig aber messbar Osteokalzinsekretion (Abb. 29), die sich unter den Einfluss aller Differenzierungsfaktoren bereits nach 2 Tagen und weiter nach 7 Tagen signifikant $(p<0,05)$ steigerte. Der maximale Anstieg um den Faktor 24 wurde unter OF + BMP-2 ermittelt.

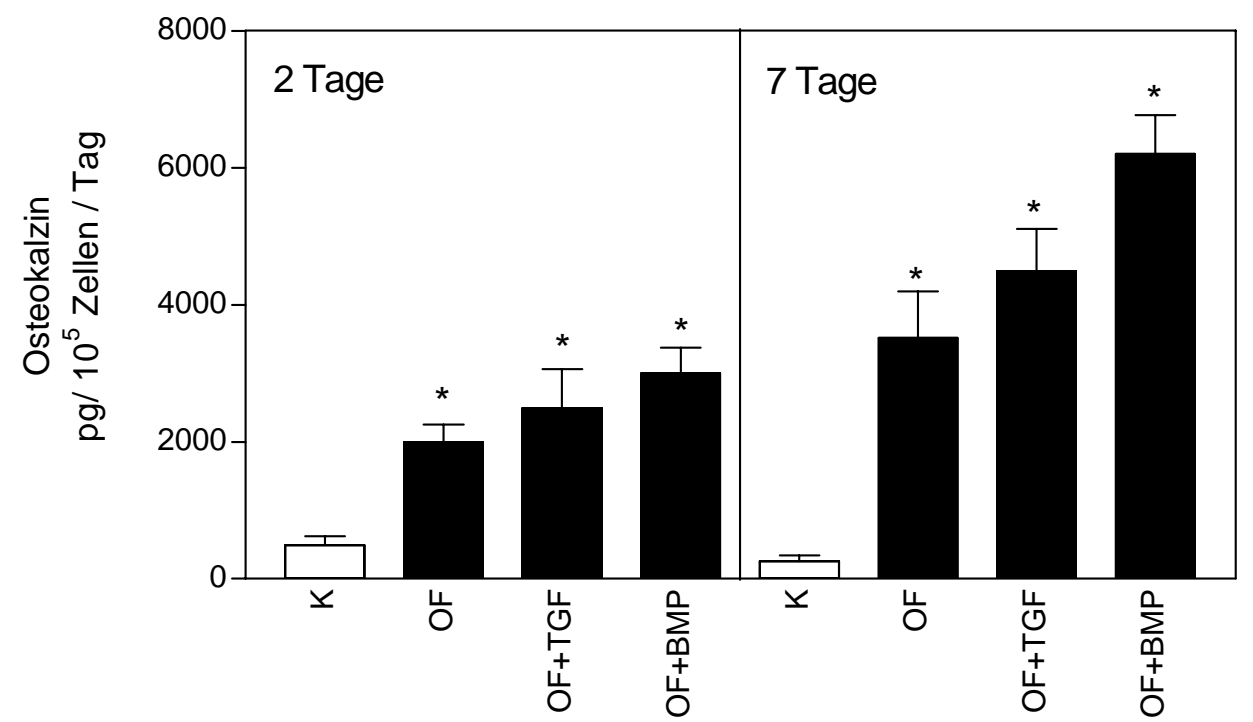

Abb. 29: Osteokalzinsekretion in den AP-negativen Fraktionen nach 2- und 7-tägiger Stimulation. Die Zellen wurden mit OF und entweder OF + TGF- $\beta 1(1 \mathrm{ng} / \mathrm{ml})$ oder OF + BMP-2 (50 ng/ ml) stimuliert. Die Daten stellen die im Überstand gemessenen Osteokalzinsekretion (pg/ 105 Zellen/ Tag) nach 2 und 7 Tagen als MW \pm SEM $(n=8)$ eines repräsentativen Versuches dar. Die Zellzahl wurde zu jedem Zeitpunkt (Tag 2 und 7) bestimmt.

OF: Betaglycerophosphat $(2 \mathrm{mM})$, Ascorbat $(50 \mu \mathrm{g} / \mathrm{ml}), 1,25(\mathrm{OH})_{2} \mathrm{D}_{3}\left(4 \times 10^{-8} \mathrm{M}\right)$, Dexamethason $\left(10^{-8}\right.$ M) Das Inkubationsmedium enthielt DMEM/ 0,1\% BSA und das Kontroll-Inkubationsmedium Ethanol und Citrat Puffer $(<0,01 \%)$. Signifikanzen sind gekennzeichnet mit * $\mathrm{p}<0,05$ (Mann Withney Test).

K: Kontrolle; TGF: TGF- $\beta 1$; BMP: BMP-2

\section{III.3.2.5. Genexpression adipozytärer Marker in den AP-negativen Zellen}

Um parallel Informationen über die adipozytäre Differenzierung der AP-negativen zu erhalten, sollte hier die Genexpression von PPAR 22 und LPL untersucht werden.

Unter Basalbedingungen (Kontrolle) zeigten die AP-negativen Zellen eine deutlich messbare PPAR 2 -mRNA-Expression (Abb. 30A). Nach 2 Tagen wurde diese basale Genexpression um den Faktor 2.2 unter OF induziert. Unter BMP-2 (OF + BMP-2) wurde auch eine 1,2-fache Induktion der PPAR $\gamma 2$-Genexpression ermittelt. In Gegensatz dazu konnte bei der Zugabe von TGF- $\beta 1$ (OF + TGF- $\beta 1$ ) keine Induktion beobachtet werden (Abb. 30A). Nach 7 Tagen zeigte sich unter allen Differenzierungsfaktoren eine Suppression der basalen PPAR $\gamma 2$ mRNA Spiegel. 

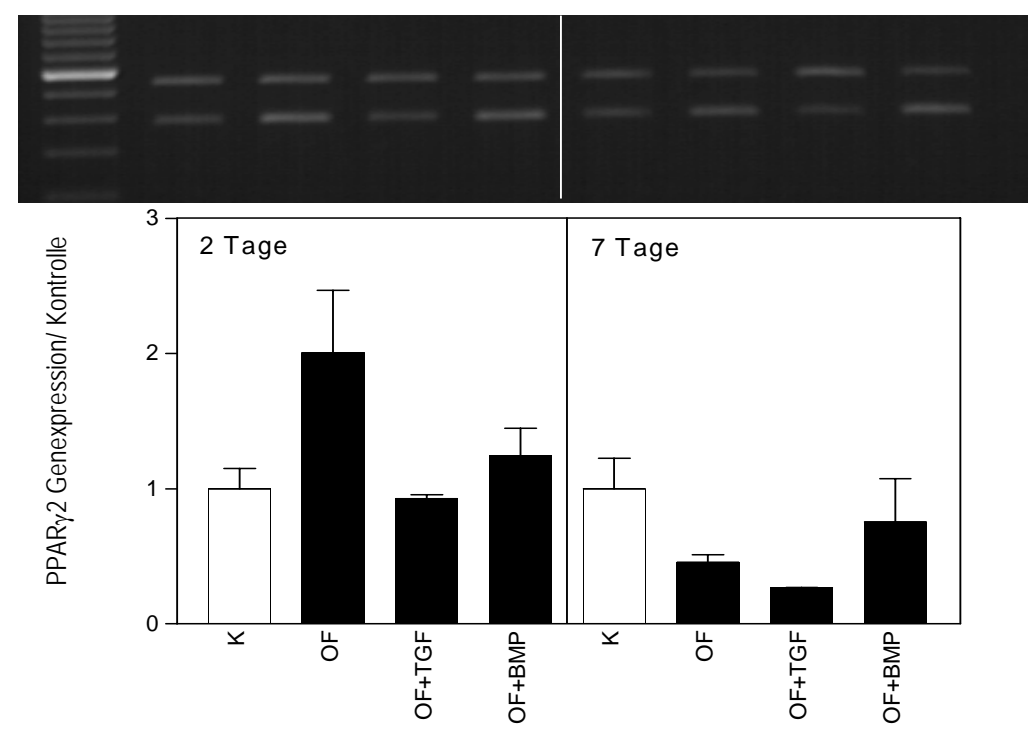

A

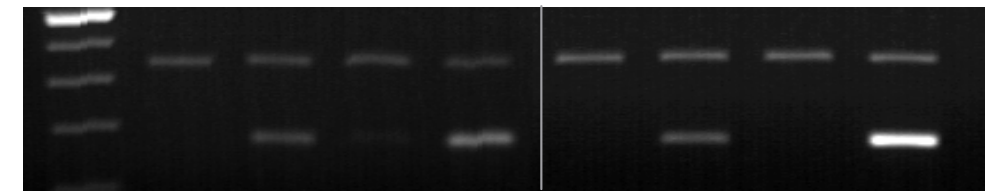

$\mathrm{M}$ im ic

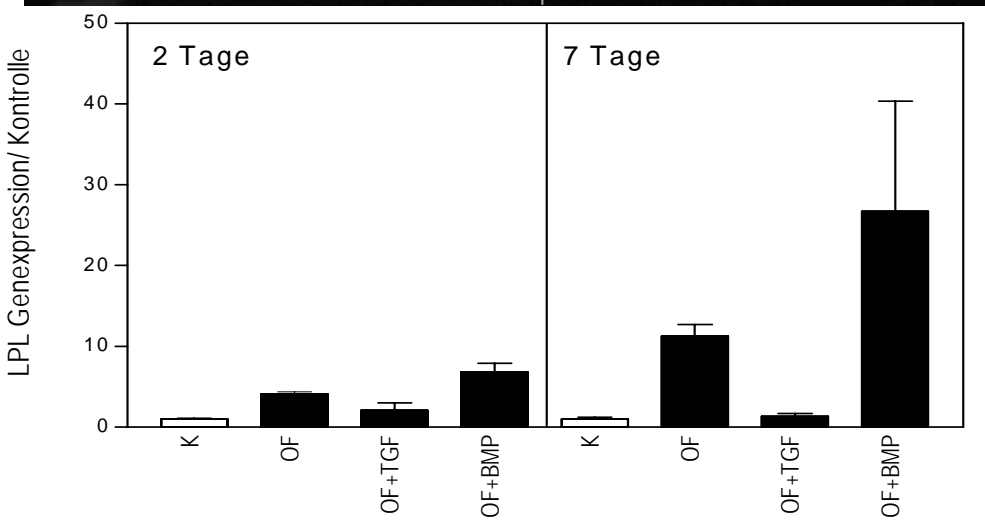

LPL (276 bp)

B

Abb. 30: Analyse der mRNA-Expression von PPAR 2 (A) und LPL (B) mittels semiquantitativen RTPCR in den AP-negativen Fraktionen nach 2- und 7-tägiger Stimulation. Die Zellen wurden mit OF und entweder OF + TGF- $\beta 1$ (1 ng/ ml) oder OF + BMP-2 (50 ng/ ml) stimuliert. Die Graphik stellt die densitometrische Analyse der Banden (oben) normalisiert auf die Kontrolle dar. Die Daten stellen den $\mathrm{MW} \pm \operatorname{SEM}(\mathrm{n}=2)$ eines repräsentativen Versuches dar.

OF: Betaglycerophosphat $(2 \mathrm{mM})$, Ascorbat $(50 \mu \mathrm{g} / \mathrm{ml}), 1,25(\mathrm{OH})_{2} \mathrm{D}_{3}\left(4 \times 10^{-8} \mathrm{M}\right)$, Dexamethason $\left(10^{-8}\right.$ M) Das Inkubationsmedium enthielt DMEM/ 0,1\% BSA und das Kontroll-Inkubationsmedium Ethanol und Citrat Puffer $(<0,01 \%)$.

K: Kontrolle; TGF: TGF- $\beta 1$; BMP: BMP-2

Die AP-negativen Zellen zeigten eine sehr niedrige LPL-mRNA-Expression, die nach 2 Tagen und weiter nach 7 Tagen unter OF bzw. OF + BMP-2 stimuliert wurde (Abb. 30B).

Unter BMP-2 (OF + BMP-2) Stimulation nach 7 Tagen erbrachte die Analyse den maximalen Anstieg um den Faktor 26. Keine Induktion wurde beim Zugabe von TGF- $\beta 1$ (OF + TGF- $\beta 1)$ über den untersuchten Zeitraum beobachtet (Abb. 30B). 


\section{III.4. Untersuchung der Genexpression adipozytärer Marker in den mittels FACS Sorting isolierten AP-Subpopulationen aus pHOB Zellen}

\section{III.4.1. Isolierung von AP Subpopulationen mittels FACS Sorting}

Ein weiteres Ziel dieser Arbeit war es, eine Isolierungsmethode zu etablieren, die eine maximale Anreicherung der AP-positiven Subpopulation gewährleistet, aber auch AP-negative Zellen möglichst rein isoliert, um Unterschiede zwischen den Populationen aufdecken zu können. Mit der FACS Sorting steht eine weitere Methode zur Zelltrennung zur Verfügung, die in dieser Arbeit für den Marker AP verwendet wurde und die der MACS-Methode in einigen Punkten deutlich überlegen ist (Diplomarbeit, Ponce, 2000)

Auf Grund der nachgewiesenen Unterschiede zwischen Kulturen aus Spongiosa verschiedener Skelettabschnitte (Beckenkamm oder proximaler Femur) sollten Primärkulturen verwendet werden, die ausschließlich aus Spongiosa des proximalen Femurs von männlichen Patienten $(\mathrm{N}=6)$ isoliert wurden. Das erste Ziel, war die Isolierung von reinen Populationen aus Osteoblastenkulturen, die ausschließlich unter Standardbedingungen kultiviert wurden. Es fanden sich deutliche quantitative Unterschiede bezüglich der AP-Expression zwischen den Ausgangspopulationen verschiedener Patienten. Der Anteil der AP-positiven Zellen unter Standardbedingungen betrug zwischen 5 und $40 \%$, dies entspricht einem Variationskoeffizienten von $\sim 90 \%$. Um den Anteil der AP-positiven Zellen zu erhöhen, wurden in weiteren Versuchen $(\mathrm{N}=6)$ die $\mathrm{pHOB}$ Kulturen mit Osteoblastendifferenzierungsfaktoren kultiviert um so eine bessere Ausbeute APpositiver Zellen zu erreichen.

Für die Anpassung der FACS Sorting-Methode für den Marker AP wurde zuerst die Sortierungsgrenze so gesetzt, daß eine klare Abgrenzung der AP-positiven Zellen von den AP-negativen möglich wurde. Nach der Sortierung wurde die Reinheit der Fraktionen mittels FACS Analyse kontrolliert, so daß die Sortierungsgrenzen während der Analyse geändert werden konnten. Auf diese Weise konnte die höchste Reinheit der isolierten Fraktionen erreicht werden. In der Abb. 31, A, werden die Sortierungsgrenzen, R1 für die AP-negativen und R2 für die APpositiven Zellen, dargestellt. Die idealen Sortierungsgrenzen wurden so gewählt, daß nur die Zellen, die stark fluoreszieren bzw. eine starke AP Expression aufwiesen, isoliert wurden. Auf diese Weise konnte eine zu 99\% reine AP-positive-Subpopulation gewonnen werden (Abb. 31, B), dies war mit der MACS-Methode nicht möglich. 

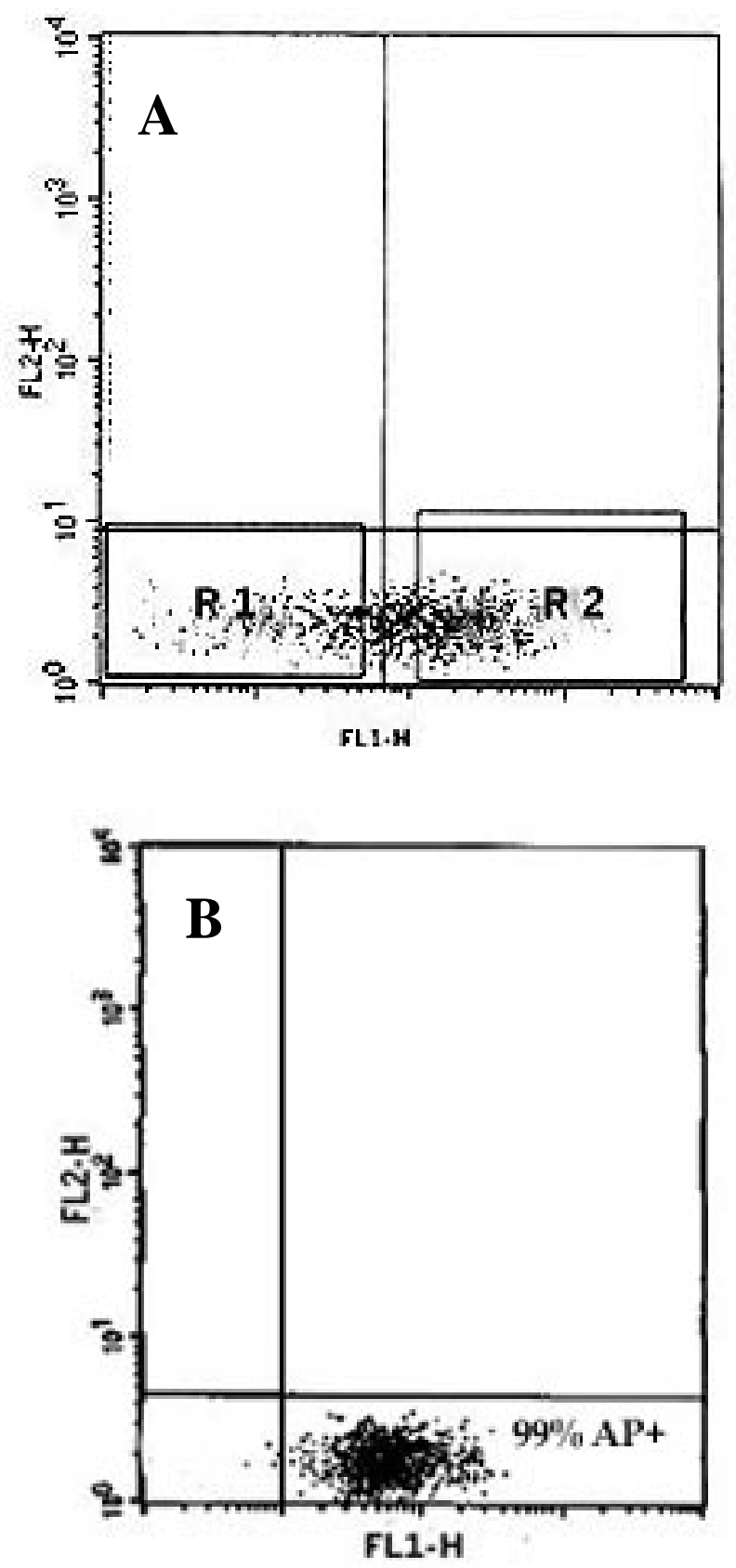

Abb. 31: AP Subpopulationen wurden aus pHOB Zellkulturen wie oben geschrieben mittels FACS Sorting isoliert und nach der Sortierung die Reinheit der Fraktionen mittels FACS Analyse überprüft. Die Ausgansgpopulation wurde mit dem Primärantikörper gegen AP und dem Sekundärantikörper (FITCmarkiert) gefärbt.

A: Die intakten Zellen der Ausgangspopulation wurden als Dot-Plot dargestellt. Die Sortierungsgrenze für die AP Subpopulationen (R1: AP-negative, R2: AP-positive) wurden anhand der Hintergrundfluoreszenz über den FL1-H Kanal (Grünfluoreszenz, X-Achse) bestimmt.

B: FACS Analyse der auf 99\% angereicherten AP-positiven Subpopulation.

Aufgrund dieser sorgfältigen Abgrenzung war die Zellausbeute allerdings so gering (ca. $30 \%$ der Zellen), daß nur die Analyse der isolierten Fraktionen mittels RT-PCR möglich war. 
In der Tab. III.1 werden Ergebnisse aller FACS Sortingsversuche zusammengefaßt. Aufgrund der großen Variation zwischen den Versuchen werden die Ergebnisse einzeln dargestellt. Die Sortierung mit FACS Sorting ermöglichte es, im Gegensatz zur MACS-Methode, aus verschiedenen HOB Kulturen AP-positive Fraktionen mit hoher Reinheit $>90 \%$ zu gewinnen. Der höchste Wert (99\% AP-positive Zellen) wurde aus einer Ausgangspopulation mit 82\% AP-positive Zellen erreicht. Eine schwache Anreicherung, wie z.B bei Fraktionen mit $<67 \%$ AP-positiven Zellen war, trotz optimierter Bedingungen, durch den niedrigen Anteil der AP-positiven Zellen $(<25 \%)$ in der Ausgangspopulationen bedingt.

Durch diese Methode war es auch möglich homogene AP-negative Fraktionen bis zu 100\% APnegativer Zellen, zu gewinnen. Aufgrund des großen Zellverlustes war es aber nicht für jede Kultur möglich die entsprechenden AP-negativen Fraktionen zu gewinnen (siehe Tab. III, 1).

\begin{tabular}{|c|c|c|c|c|c|c|c|c|}
\hline \multirow[b]{3}{*}{ Ausgangspopulation } & \multirow{2}{*}{\multicolumn{2}{|c|}{$\begin{array}{c}\text { Standard- } \\
\text { bedingungen }\end{array}$}} & \multicolumn{6}{|c|}{ OF Stimulation vor der FACS Sorting } \\
\hline & & & \multicolumn{3}{|c|}{7 Tage } & \multicolumn{3}{|c|}{14 Tage } \\
\hline & 5 & 40 & 25 & 20 & 14 & 72 & 85 & 82 \\
\hline$\%$ AP-positive Fraktion & 55 & 90 & 55 & 67 & 50 & 90 & 92 & 99 \\
\hline$\%$ AP-negative Fraktion & 1 & $\mathbf{0}$ & $\mathbf{X}$ & 4 & $\mathrm{X}$ & 0 & 7 & $\mathbf{x}$ \\
\hline
\end{tabular}

Tab. III.1: Die Daten stellen den Anteil (\%) der intakten AP-positiven Zellen in der FACS Analyse dar. $\mathrm{X}$ : nicht messbar 


\section{III.4.2. Basale Genexpression adipozytärer Marker in den AP Subpopulationen}

In vorherigen Versuchen konnte gezeigt werden, daß die AP negativen Subpopulationen, nach 2-3 Wochen Rekultivierung, eine basale Genexpression adipozytärer Marker (PPAR $\gamma 2$, LPL) aufwiesen, die unter dem Einfluß von Osteoblastendifferenzierungsfaktoren anstiegen. Entsprechend dem Differenzierungsablauf der Osteoblasten (siehe Einleitung) kann man davon ausgehen, daß die AP-negativen- und die AP-positiven Zellen unterschiedliche Differenzierungsstufen des Osteoblasten darstellen.

Es wurden AP-positive- und AP-negative-Subpopulationen verglichen, die aus unter Standardbedingungen (HOB Medium, 4 Wochen, 1.Passage) kultivierten pHOB Zellen isoliert wurden. Ziel dieser Untersuchung war die Analyse von Zellen, die spontan den AP-Phänotyp aufwiesen, bezüglich der adipozytären Genexpression mit spontan AP-negativen Osteoblasten derselben Patientenkultur zu vergleichen.

In der Abb. 32 wird die basale Genexpression der AP-Subpopulationen von 2 Patienten verglichen. Über den Säulen steht der Anteil (\%) der AP-positiven Zellen jeder Subpopulation. Unter Standardbedingungen war die Genexpression des Transkriptionsfaktors PPAR $\gamma 2$ als frühen Marker der Adipozytendifferenzierung, in jeder AP-Subpopulation nachweisbar (Abb. 32, unten). Sowohl die AP-negativen als auch die AP-positiven Zellen zeigen eine identische PPAR 2 Genexpression.

Bei der Analyse von LPL stellte sich ein starker Unterschied zwischen den AP-Subpopulationen heraus (Abb. 32, oben). Bei allen AP-negativen Fraktionen (Patient A und B) bei denen die Reinheit $>99 \%$ betrug ( $\sim 0 \%$ AP-positive Zellen) ließ sich eine sehr niedrige basale LPL-Genexpression nachweisen. Im Gegensatz dazu zeigten die AP-positiven Fraktionen eine deutlich höhere LPL Genexpression verglichen mit der AP-negativen Fraktion. Am deutlichsten ist der 25 fache Unterschied in der zu 90\% angereicherten AP-positiven Fraktion (Patient A) (Abb. 32, oben). 


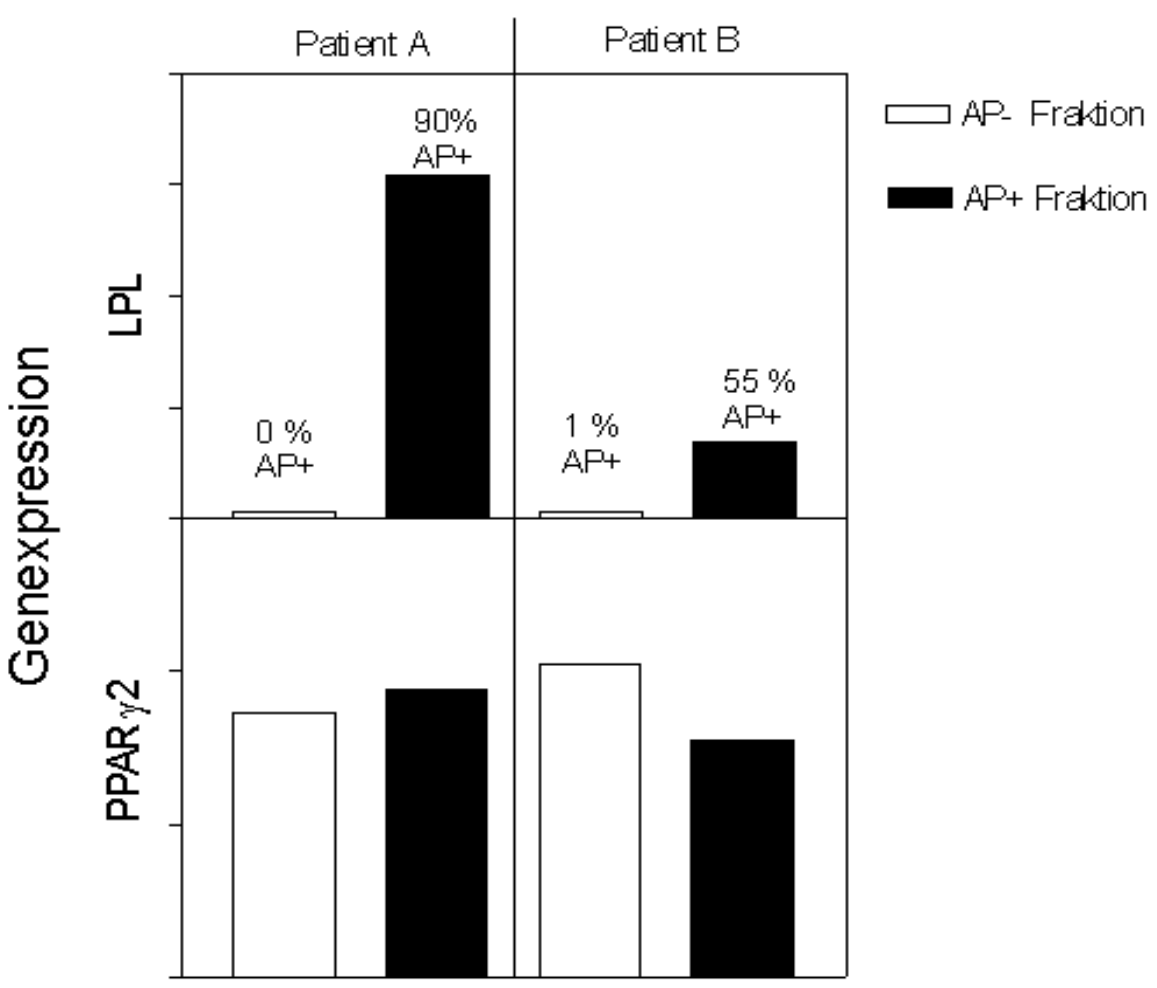

Abb. 32: Basale Genexpression von LPL- und PPAR 2 in den AP-negativen und AP-positiven Fraktionen von 2 Patienten. Die pHOB Zellen in der 1.Passage wurden unter Standardbedingungen kultiviert und nach 4 Wochen mittels FACS Sorting in AP-Negative und AP-Positive getrennt.

Die Daten (auf den Säulen) stellen den Anteil (\%) der intakten AP-positiven Zellen der sortierten Fraktionen in der FACS Analyse dar. Die Genexpression wurde mittels RT-PCR analysiert. Die Daten von den 2 Patienten sind getrennt dargestellt. 


\section{III.5. Langzeitwirkung von TGF $\beta-1$ und BMP-2 auf die Adipogenese und die Osteogenese in pHOB Zellen}

Es konnte nachgewiesen werden, daß die Zugabe von TGF $\beta$-1 oder BMP-2 über einen Zeitraum von 7 Tagen die Osteokalzinsekretion und somit die osteoblastäre Differenzierung förderte. Bezüglich der adipozytären Differenzierung (Genexpression von PPAR $\gamma 2$ und LPL) konnte gezeigt werden, daß BMP-2 eine fördernde, während TGF $\beta-1$ eine hemmende Wirkung hat.

Hier sollte zunächst die unterschiedliche Wirkung dieser Faktoren über einen längeren Zeitraum untersucht werden. Dafür wurden konfluente pHOB Kulturen (1.Passage) für 24 Tage mit entweder OF+TGF- $\beta 1(1 \mathrm{ng} / \mathrm{ml})$ oder OF+BMP-2 (50 ng/ ml) kultiviert. Das OF-Medium bestand aus DMEM/ 0,1\% BSA und enthielt Betaglycerophosphat $(2 \mathrm{mM})$, Ascorbat $(50 \mu \mathrm{g} / \mathrm{ml})$, Dexamethasone $\left(10^{-8} \mathrm{M}\right)$ und $1,25(\mathrm{OH})_{2} \mathrm{D}_{3}\left(10^{-8} \mathrm{M}\right)$. Die Auswirkung dieser Faktoren wurde (zytochemisch) durch den parallelen Nachweis eines Mineralisationsprozesses (Osteogenese) bzw. Lipidvakuolen (Adipogenese) durchgeführt.

Zur Analyse eines Mineralisationsprozess wurde die Alizarinrot Färbung durchgeführt. Die pHOB Zellen zeigten unter Basalbedingungen (Kontrolle) über den Zeitraum von 24 Tage keine Mineralisation sowie keine Veränderung der Zellstruktur (Abb. 33A). Im Vergleich zur Kontrolle wiesen die Zellen, die entweder unter OF + TGF- $\beta 1$ (Abb. 33B) oder OF + BMP-2 (Abb. 33C) kultiviert wurden, eine Mineralisationsprozess auf. Hierbei bildeten die Zellen einen konfluenten Zellrasen in dem die rotgefärbten Mineralisationskerne („nodules“) zwischen den Zellen homogen verteilt waren.

Parallel dazu wurde eine Doppelfärbung zum Nachweis der AP-Enzymaktivität, als Osteoblastendifferenzierungsmarker, sowie von Lipidvakuolen (Oil Red O), als Adipozytendifferenzierungsmarker, durchgeführt. Unter Basalbedingungen über 24 Tage zeigten die pHOB Zellen weder AP-Aktivität noch Lipidvakuolen (Abb. 33D). Unter dem Einfluß von OF + TGF$\beta 1$ waren AP-positive Zellen zu sehen aber keine Lipidvakuolen (Abb. 33E). Im Vergleich dazu, konnten unter Stimulation mit OF + BMP-2 Zellen nachgewiesen werden, die sowohl Lipidvakuolen als auch AP-Aktivität zeigen (Abb. 33F). 

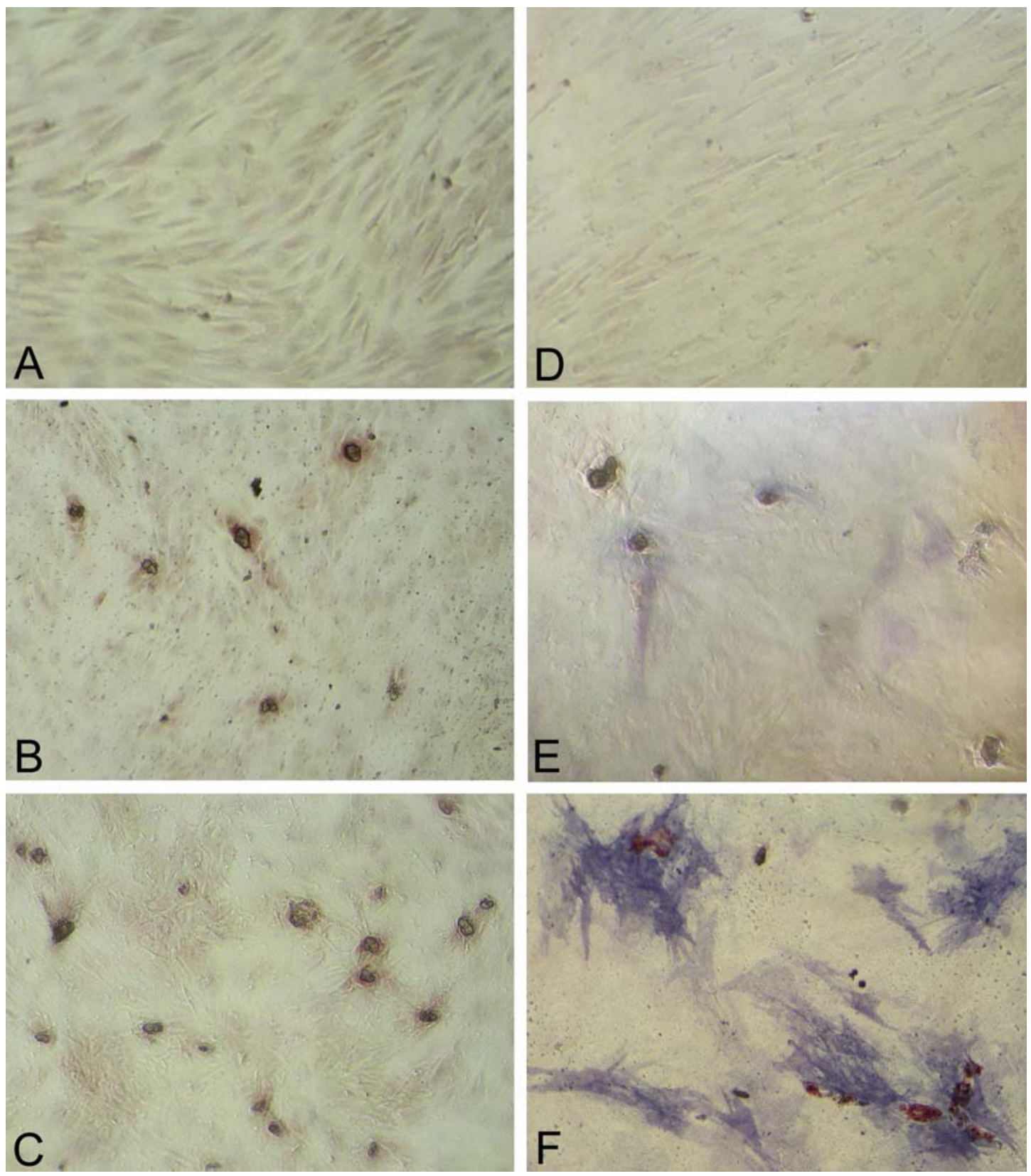

Abb 33: Untersuchung der Langzeitwirkung von TGF $\beta-1$ und BMP-2 auf die Adipogenese und die Osteogenese in pHOB Zellen. Die konfluenten Kulturen wurden entweder mit OF + TGF $\beta-1$ oder OF + BMP-2 über 24 Tage stimuliert.

A-C: Alizarinrot Färbung zum Nachweis eines Mineralisationsprozesses.

D-F: Doppelfärbung zum Nachweis der AP-Aktivität (blaue Farbe) und Lipidvakuolen (Oil Red O, rote Farbe).

A-D: Kontrolle

B-E: OF + TGF $\beta-1$

C-F: OF + BMP-2

OF: Betaglycerophosphat $(2 \mathrm{mM})$, Ascorbat $(50 \mu \mathrm{g} / \mathrm{ml}), 1,25(\mathrm{OH})_{2} \mathrm{D}_{3}\left(4 \times 10^{-8} \mathrm{M}\right)$, Dexamethason $\left(10^{-8}\right.$ M) Das Inkubationsmedium enthielt DMEM/ 0,1\% BSA und das Kontroll-Inkubationsmedium Ethanol und Citrat Puffer $(<0,01 \%)$. 


\section{III.6. Ultrastrukturalle elektronmikroskopische Lokalisation adipozytärer und osteoblastärer Marker auf Einzellzellniveau in pHOB Zellen}

Hier sollte eine Coexpression adipozytärer (PPARy2, LPL) und osteoblastärer (AP, Osteokalzin) Marker auf Einzelzellebene unter Einfluß von BMP-2 erfasst werden. Dafür wurde an den pHOB Zellen, die über 7 Tagen mit OF + BMP-2 (50 ng/ ml) stimuliert waren, einen Doppelnachweis mittels Immunogoldzytochemie durchgeführt.

Um einen zuverlässigen Proteinnachweis zu ermöglichen, wurden die Primärantikörper direkt an Goldpartikeln verschiedener Grosse gekoppelt. In der Abbildung 34A ist eine repräsentative elektronmikroskopische Aufnahme eines Osteoblasten dargestellt. Nach 7 Tagen Stimulation zeigt diese Zelle einen prominenten Kern (n), zahlreiche zytoplasmatische Organellen (Mitochondrien, Vesikeln), sowie charakteristische Pseudopodien.

Die weiteren Abbildungen 34B bis 34F sind vergrößerte Aufnahmen indem die Coexpression adipozytärer ( $8 \mathrm{~nm}$ Golpartikeln, schwarze Pfeile) und osteoblastärer (16 nm Goldpartikeln, offene Pfeile) Markerproteinen gezeigt werden.

Der Transkriptionsfaktor PPAR 2 wurde sowohl in Zellkern als auch in den Zytoplasma von Zellen, die sowohl das AP-Enzym an der Zellmembran (Abb. 34B) als auch Osteokalzin in zytoplasmatischen Vesikeln aufweisen (Abb. 34C-D), lokalisiert. Das Enzym LPL konnte auch zusammen mit entweder AP (Abb. 34E) oder mit Osteokalzin (Abb. 34F) im Zytoplasma der selber Zelle lokalisiert werden. 

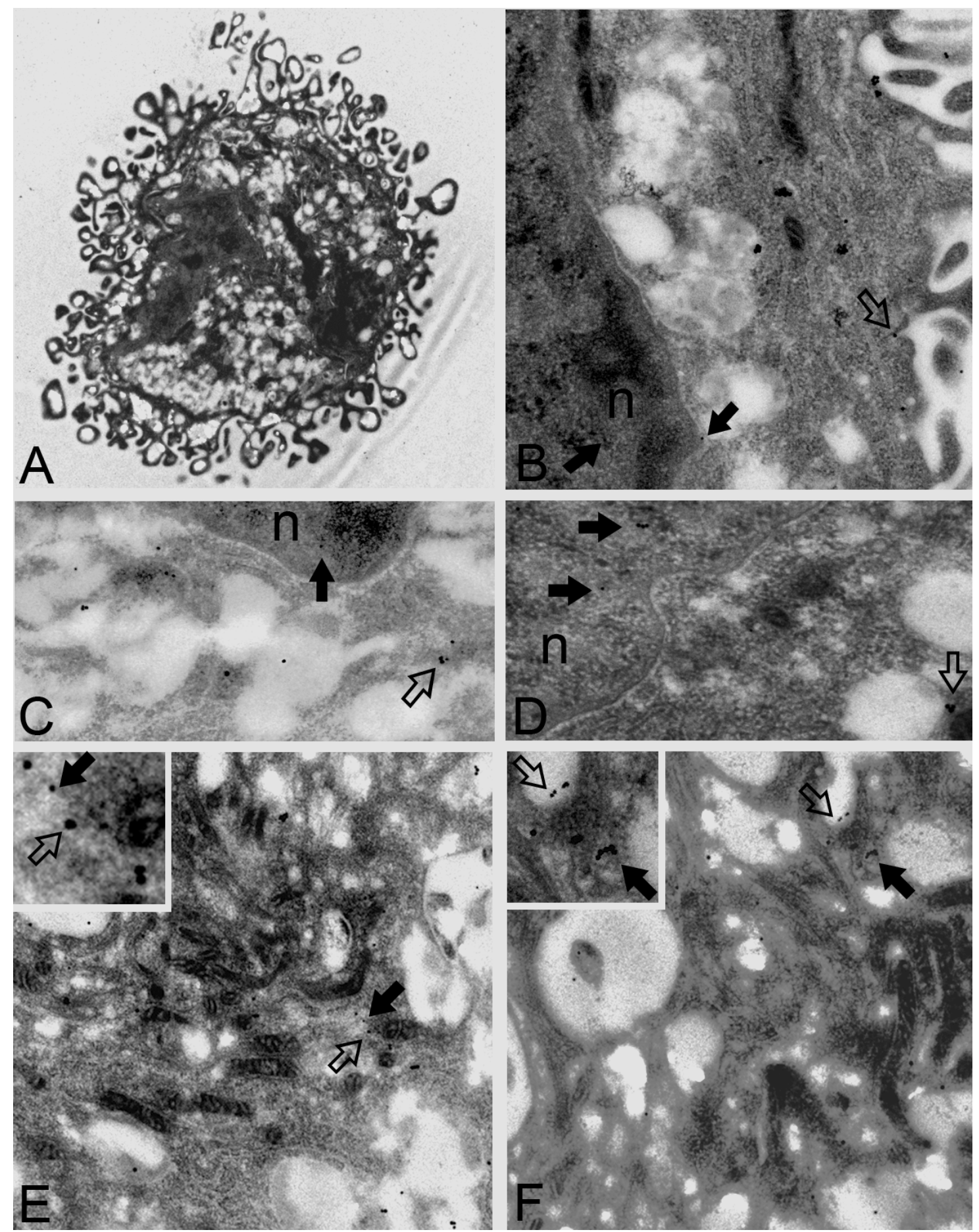

Abb. 34: Coexpression adipozytärer und osteoblastärer Markerproteine in pHOB Zellen nach 7-tägiger Stimulation mit OF + BMP-2 $(50 \mathrm{ng} / \mathrm{ml})$. Die adipozytären Marker, PPAR $\gamma 2$ und LPL $(8 \mathrm{~nm}$ Goldpartikeln, offene Pfeile) und die osteoblastären Marker, AP und Osteokalzin (16 nm, schwarze Pfeile) wurden mittels direkte Immunogoldzytochemie doppelnachgewiesen.

A: Übersichtsaufnahme einer Zelle. n: Zellkern

B: Coexpression von AP und PPAR $\gamma 2$. C-D: Coexpression von Osteokalzin und PPAR $\gamma 2$.

E: Coexpression von AP und LPL. F: Coexpression von Osteokalzin und LPL

E-F Links oben: In der vergrösserten Ausschnitt sind die unterschiedlichen Goldpartikeln deutlich erkennbar.

OF: Betaglycerophosphat (2mM), Ascorbat $(50 \mu \mathrm{g} / \mathrm{ml}), 1,25(\mathrm{OH})_{2} \mathrm{D}_{3}\left(4 \times 10^{-8} \mathrm{M}\right)$, Dexamethason $\left(10^{-8}\right.$ M) Das Inkubationsmedium enthielt DMEM/ 0,1\% BSA. 


\section{Diskussion}

\section{IV.1. Untersuchung zur Induktion der Adipogenese}

\section{IV.1.1. Induktion der Adipogenese in primären humanen Osteoblasten}

In normalen primären humanen Osteoblasten konnte eine Transdifferenzierung zum Adipozyten unter dem Einfluß von einem sogenannten Adipogenesemedium (IBMX + Dexamethason) nachgewiesen werden (Nuttall et al. 1998; Prichett et al. 2000). Diese Beobachtung führte zu der Fragestellung, ob auch in den in dieser Arbeit verwendeten primären humanen Osteoblasten die Adipogenese stimuliert werden kann. Zu diesem Zweck erfolgten die Untersuchungen unter definierten Kulturbedingungen. Üblicherweise wurden die Zellen mit einem Standard HOB Medium, DMEM supplementiert mit 10\% FCS, kultiviert. Unter diesen Bedingungen wuchsen die Zellen für 10 Tage bis zur Konfluenz. Nachfolgend, während der Stimulation mit dem Adipogenesemedium, sollte das DMEM mit einem speziellen FCS ersetzt werden, welches mit Kohle filtriert und mit Hitze inaktiviert wurde (Nuttall et al. 1998). Durch den Einsatz von diesem speziellen FCS sollen eventuelle inhibierende Effekte des normalen FCS ausgeschlossen werden (Oreffo et al. 1997; Park et al. 1999).

In der vorliegenden Untersuchung konnte schon nach 7 Tagen ein stimulatorischer Einfluß auf die Adipogenese durch die Veränderung der Zellform sowie die Entstehung kleiner zytoplasmatischer Lipidvakuolen erkannt werden. Als ein Zeichen der zunehmenden adipozytären Differenzierung stieg im zeitlichen Kulturverlauf nach 14 und 21 Tagen die Anzahl und Größe der Lipidvakuolen. Die hier parallel beobachtete signifikante Induktion der adipozytären Marker PPAR $\gamma 2$ (auf mRNA Ebene) weist die Adipogenese nach (Tontonoz et al. 1994; Gimble et al. 1996; Lecka-Czernik et al. 1999; Nuttall et al. 1998; Prichett et al. 2000).

Neben dem adipogenen Effekt fand sich aber auch eine Stimulation der AP-Aktivität als Zeichen einer osteoblastären Differenzierung. Da die Zellen sehr dicht gewachsen waren, war es nicht möglich durch einen histochemischen Nachweis zu bestätigen, ob beide Phänotypen, also Lipidvakuolen und AP-aktivität, in derselben Zelle vorkommen. Diese unterschiedliche Induzierbarkeit der primären humanen Osteoblasten konnte durch die Heterogenität des Kultursystems erklärt werden, wobei die Zellen eine differenzierungsabhängige Reaktion auf die adipogene Behandlung zeigen.

Welche spezifische funktionelle Bedeutung die verwendete Kombination von IBMX (100 $\mu \mathrm{g} /$ $\mathrm{ml})+$ Dexamethason $(1 \mu \mathrm{M})$ hat, ist jedoch nicht vollständig geklärt. IBMX ist bekannt als ein Hemmer der Phosphodiesterase, die für den Abbau des zyklischem Adenosinmonophosphat (cAMP) verantwortlich ist (Gregoire et al. 1998). Es wird somit angenommen, daß IBMX durch 
die Potenzierung der intrazellullären cAMP-Aktivität zelluläre Vorgänge induziert bzw. verstärkt.

Die Rolle des synthetischen Glukokortikoids Dexamethason ist vielfältig. Es gilt sowohl als adipozytärer (Gregoire et al. 1998) als auch als osteoblastärer Differenzierungsfaktor (Cheng et al. 1994; Rickard et al. 1996; Fromigue et al. 1997; Ahdjoudj et al. 2001; Atmani et al. 2002; Porter et al. 2003; Pei et al. 2003). Diese unterschiedlichen Effekte sind allerdings abhängig von der Dosis und Inkubationszeit sowie von den verwendeten Kulturmodellen.

In dem humanen System ergeben sich Hinweise, die für eine regulatorische bzw. fördernde Wirkung von Dexamethason auf die Osteoblastendifferenzierung sprechen. Bezüglich der adipozytären Differenzierung wurde von Nuttall et al. (1998) festgestellt, daß die Inkubation primärer humaner Osteoblasten mit Dexamethason $(1 \mu \mathrm{M})$ allein (ohne IBMX) nicht ausreichend ist, um die adipozytären Marker zu induzieren. Diese Konzentration wurde auch in Untersuchungen von Pei et al. (2003) in denen dexamethasonabhängige humane Osteoprogenitorzellen identifiziert wurden, angewendet. In der humanen Osteorsarkomzellinie SaOS-2 konnte unter Einfluß von Dexamethason eine Hemmung der Phosphodiesterase mit einem parallelen Anstieg der AP-Aktivität festgestellt werden (Ahlström et al. 2005). Unter Berücksichtigung dieser Ergebnisse wäre die in der hier vorliegenden Arbeit beobachtete Induktion der AP-Aktivität vermutlich auf osteoblastendifferenzierungsfördernde Wirkung von Dexamethason zurückzuführen. Die Tatsache, daß nicht alle Zellen eine AP-Aktivität aufweisen, kann noch einmal durch die unterschiedliche Induzierbarkeit dieser heterogenen primären humanen Osteoblastenpopulation erklärt werden.

Die Ergebnisse zeigen, daß die in dieser Arbeit verwendeten primären humanen Osteoblasten in der Lage sind, unter Einfluß eines Adipogenesemediums eine vollständige Differenzierung zu Adipozyten, gezeigt auf histologischer und mRNA-Ebene, zu durchlaufen.

\section{IV.1.2. Induktion der Adipogenese in der AHTO Zellinie}

Neben den Untersuchungen an primären humanen Osteoblasten verwendeten wir die immortalisierte Zellinie AHTO (Lomri et al. 1999). Es interessiert insbesonderes, inwiefern die Expression adipozytärer Marker bei einer relativ differenzierten Osteoblastenzellinie nachgewiesen bzw. induziert werden kann. Bei der AHTO Zellinie konnte neben der konstitutiven mRNA Expression von Osteokalzin, alkalischer Phosphatase und Kollagen-I auch die Regulation dieser Gene durch Vit. D3 und Dexamethason nachgewiesen werden (Lomri et al. 1999). Diese Eigenschaften, die charakteristisch für den differenzierten osteoblastären Phänotyp sind, zeigen auch, daß die Transformation keinen Einfluß auf die weitere Differenzierung der Zellen hat. Ein weiterer Vorteil, im Gegensatz zu Kulturen primärer humaner 
Osteoblasten ist, daß diese eine relativ homogene Zellpopulation darstellen und wegen ihrer schnellen Proliferationsrate in ausreichender Menge zur Verfügung stehen. Darüberhinaus ist von entscheidender physiologischer Bedeutung, daß diese humane Zellinie aus einem gesunden Patienten isoliert wurde, um die normale Osteoblastenzellbiologie untersuchen zu können. Als Nachteil muss jedoch berücksichtig werden, dass die Immortalisierung die Funktion der Osteoblasten verändern könnte (Avioli 1995).

Inzwischen wurde in weiteren Studien nachgewiesen, daß die AHTO Zellinie ein gut geeignetes Model ist, um die Aktivität bzw. Differenzierung von Osteoblasten zu untersuchen. In ersten funktionellen Untersuchungen wurde von Ulsperger et al. (1999) die Wirkung chemotherapeutischer Substanzen auf die Proliferation und Differenzierung dieser Zellen getestet. Die Autoren stellten in weiteren Untersuchungen, indem die Wirkung von Prostatazellen-sezernierten Faktoren auf die Proliferation verschiedener Osteoblastenzellinien untersucht wurde, fest, daß die Ergebnisse der AHTO Zellen die beste Korrelation mit den primären humanen Osteoblasten aufweisen (Ulsperger et al. 2003).

Über ein eventuelles adipozytäres Differenzierungspotential der AHTO Zellen wurde nicht berichtet. In der vorliegenden Arbeit wurde die Induktion der Adipogenese unter Einfluß von Adipogenesemedium (IBMX + Dexamethason), wie bereits bei den primären humanen Osteoblasten, untersucht. Im Gegenteil zu primären Osteoblasten können die AHTO Zellen nach Erreichen der Konfluenz weiterwachsen, dies führte aber zu übermäßiger Proliferation bedingten Zellverlusten. Deshalb wurde die Kultivierungszeit sowie die Vitalität der Zellen getestet und die Kulturzeit, in Übereinstimmung mit den von Lomri et al. (1999) publizierten Ergebnissen gewählt. In den hier vorliegenden Untersuchungen kam es zum Ende des Versuches zu einem deutlichen Verlust der Zellen nur unter Basalbedingungen. Folglich waren nach der erforderlichen Fixierung nur einzeln liegende Zellen für die zytochemische Analyse am Tag 16 verfügbar. Ein möglicher Grund dafür könnte sein, daß das hier verwendete Kontrollmedium gegenüber dem Stimulationsmedium die Anheftung der Zellen beeinträchtigt. Gleichzeitig würde es bedeuten, daß die Stimulation mit Adipogenesemedium die Vitalität der Zellen positiv beeinflussen kann.

RT-PCR-Analysen ergaben, daß die AHTO Zellen unter Basalbedingungen sowohl osteoblastäre als auch adipozytäre Marker stark exprimieren. Allerdings konnte eine Induktion adipozytärer Marker auf mRNA Ebene nicht nachgewiesen werden. Anders als bei primären humanen Osteoblasten, konnte hier die spontane Bildung (unter Basalbedingungen) von Fettvakuolen nachgewiesen werden, deren Zahl unter Stimulation anstieg. Allerdings konnte dieser Anstieg aus den vorgenannten Gründen nur nach einem Stimulationszeitraum von 7 Tagen nachgewiesen werden. Durch den fehlenden Zusammenhang zwischen der Expression von adipozytären Markergenen (PPAR $\gamma 2$, LPL) und dem Anstieg von Lipidvakuolen, kann hier kein vollständiger Adipogeneseprozeß, wie bei primären humanen Osteoblasten, belegt werden. 
Wahrscheinlich liegt der Regulation der Adipogenese unter diesen Bedingungen in AHTO Zellen ein anderer Mechanismus zu Grunde als bei primären humanen Osteoblasten. Es konnte hier stattdessen gezeigt werden, daß durch diese Behandlung die Expression osteoblastärer Markern in den AHTO Zellen stark induziert werden. Der Anstieg der Genexpression des Transkriptionsfaktors CBFA-1 und alkalische Phosphatase unter Stimulation (IBMX + Dexamethason) ist als Zeichen zunehmender osteoblastäre Differenzierung zu werten.

Durch die hier vorgestellten Ergebnisse erwiesen sich die AHTO Zellen für weitere Untersuchungen als ungeeignet.

\section{IV.2. Effekt von BMP-2 auf die adipozytären Marker in primären humanen Osteoblasten}

BMP-2 spielt sowohl für die postnatale Knochenentwicklung als auch für die osteoblastäre Differenzierung eine entscheidende Rolle (Hogan, 1996). Präklinische in vivo Studien belegen eine fördende Wirkung von BMP-2 sowohl auf die Knochenmasse als auch auf den Frakturheilungsprozeß. Diese positiven Effekte auf die Osteogenese, die an verschiedenen experimentellen in vivo und in vitro Tiermodellen (Raten, Mäuse und Kaninchen) nachgewiesen wurden, konnten jedoch an dem humanen System nicht bestätigt werden (Diefenderfer et al. 2003).

Bezüglich der Wirkung von BMP-2 auf die Adipogenese existieren in vitro Hinweise, die sowohl von einer Hemmung als auch von einer Förderung dieses Prozesses (Gimble \& Nuttall 2004) sprechen. $\mathrm{Zu}$ berücksichtigen ist dabei, daß die überwiegende Mehrheit der Daten aus unterschiedlichen Kultursystemen bzw. Kulturbedingungen erhoben wurden.

Auf Grund der widersprüchlichen Daten wurde in dieser Arbeit zunächst der Effekt von BMP-2 auf die adipozytären und osteoblastären Marker in primären humanen Osteoblasten untersucht. Dazu wurden verschiedene BMP-2-Konzentrationen (50, 100 und $200 \mathrm{ng} / \mathrm{ml}$ ) in serumfreiem Medium (bei konfluenten Kulturen) über einen Zeitraum von 2 und 7 Tagen getestet. Hierbei wurden die Kulturen bezüglich der PPAR $\gamma 2$-, LPL- und AP-mRNA-Expression mittels RTPCR, und die AP-Aktivität sowie Lipidvakuolen mittels Färbung untersucht.

Unter basalen Bedingungen (Kontrolle) lie $\beta$ sich ein mRNA Spiegel von PPAR $\gamma 2$ und LPL nachweisen. Interessanterweise konnte ein Anstieg der Genexpression des adipozytären Transkriptionsfaktors PPAR $\gamma 2$ am Ende des untersuchten Zeitraums (7 Tage) und unter der Dosis von $50 \mathrm{ng} / \mathrm{ml}$ BMP-2 nachgewiesen werden. Bei der Untersuchung der LPLGenexpression fanden sich dagegen keine relevanten Unterschiede im Vergleich zur Kontrolle. Bezüglich der osteoblastären Differenzierung, die hierbei durch die AP- Genexpression und -Aktivität als frühen Differenzierungsmarker bewertet wurde, ließ sich kein Effekt von BMP-2 über den untersuchten Zeitraum nachweisen. 
Von Ji et al. (2000) konnte in der murinen mesenchymalen Zellinie 3T3-F442A nachgewiesen werden, daß BMP-2 sowohl die Differenzierung in Richtung Osteoblasten als auch zu Adipozyten fördern kann. Ihre Daten zeigen nach 11-tägiger Stimulation mit BMP-2 (300 ng/ $\mathrm{ml}$ ) einen Anstieg der mRNA von C/EBP $\beta$ („CCAT enhancer-binding protein $\beta^{“}$ ) und LPL. $\mathrm{C} / \mathrm{EBP} \beta$ ist einer der ersten Trankriptionsfaktoren, der die Adipozytendifferenzierungskaskade initiiert und zur spezifischen Regulation von PPAR $\gamma 2$ führt. Die Autoren vermuten deshalb, daß BMP-2 seine Wirkungen auf PPAR $\gamma 2$ über C/EBP $\beta$ vermittelt. Weiterhin zeigten die 3T3F442A Zellen nach 5-tägiger Stimulation mit BMP-2 einen dosisabhängigen Anstieg der APAktivität. Bei dieser Studie ist zu berücksichtigen, daß die Stimulation mit BMP-2 in Medium mit 10\% Kälberserum erfolgte. Unter Berücksichtigung dieser Ergebnisse und aufgrund unserer Kulturbedingungen, wie z.B. serumfreies Medium, kann spekuliert werden, daß BMP-2 als einzelner Faktor nicht ausreichend ist, um auf die AP-Expression wirken zu können.

Sottile und Seuwen (2000) untersuchten die Effekte von BMP-2 in primären Rattenstromazellen. Die Autoren konnten zunächst bestätigen, daß BMP-2 (500 ng/ ml) ein potenter Induktor der Adipogenese sein kann, aber nur in Kombination mit anderen PPAR $\gamma 2$ Aktivatoren. Auch wenn diese Daten nicht humanen Ursprungs sind, so sind sie dennoch so zu werten, daß die Wirkung von BMP-2 über die Induktion des Transkriptionsfaktors PPAR $\gamma 2$ erfolgt.

Im Vergleich zu den erwähnten Studien, indem BMP-2 hoch dosiert eingesetzt wurde, konnte in der hier vorliegenden Arbeit diese Induktion nur bei der geringsten Dosierung BMP-2 (50 ng/ $\mathrm{ml}$ ) hervorrufen werden. Da diese Induktion aber verzögert, erst nach 7 Tagen, stattfand, lässt sich vermuten, daß der gleichbleibende mRNA Spiegel von LPL, ein Enzym, das von PPAR 22 reguliert wird (Schoonjans et al. 1996), auf den begrenzten Untersuchungsraum zurückzuführen ist. Aufgrund der hier beobachtete Induktion der PPAR $\gamma 2$-Genexpresion lässt sich vermuten, daß BMP-2 auf die adipozytäre Differenzierung primärer humaner Osteoblasten fördernden Einflüsse nehmen kann.

Die fehlende AP-Aktivität, die in dieser Arbeit durch das Ausbleiben der AP-Genexpression bedingt war, suggeriert auch, daß neben BMP-2 andere Differenzierungsfaktoren erforderlich sind, um einen fördernden Effekt auf die osteoblastäre Differenzierung zu vermitteln. 


\section{IV.3. Untersuchung der Plastizität in Subpopulationen primärer humaner Osteoblasten}

Gegenstand zahlreicher Studien der letzten Jahre war die Untersuchung der Regulation der Plastizität zwischen Osteoblasten und Adipozyten (Bennett et al. 1991; Beresford et al. 1992; Grigoriadis et al. 1988; Jilka et al. 1996; Nuttall et al. 1998; Nöth et al. 2001), die insbesonders bei der Abnahme der Knochenmasse im Alter relevant scheint (siehe Einleitung I.6).

Primäre humane Osteoblastenkulturen durchlaufen eine programmierte Differenzierungssequenz bis zur Mineralisation (Siggelkow et al. 1999) entsprechend des primären Rattenosteoblastenmodells (Owen et al. 1990) (Abb. 6). Da diese aber auch eine besondere Plastizität bezüglich der Adipogenese zeigen (Nuttall et al. 1998; Nöth et al. 2001) erscheinen sie als ein interessantes humanes Modell für die Untersuchung der Regulation dieser beiden engverwandten Phänotypen. Hierbei muss berücksichtig werden, daß der Transdifferenzierungsprozeß von Osteoblasten zu Adipozyten, welcher von Nuttall et al. (1998) beschrieben wurde, unter dem Einfluß von Faktoren hervogerrufen wurde, wie z.B. IBMX, die nicht physiologisch vorkommen. Auch die Daten von Nöth et al. 2001 wurden aus primären humanen Osteoblastenkulturen erhoben, welche Zellen in unterschiedlichen Differenzierungsstadien enthalten. Um die Plastizität der Osteoblasten unter dem Einfluß von verschiedenen Faktoren untersuchen zu können, ist die Isolierung homogener Subpopulationen sinnvoll.

In zahlreichen Studien wurde der osteoblastencharakteristische Marker AP eingesetzt, um unterschiedliche Differenzierungsstadien osteoblastärer Zellen zu isolieren (Rickard et al. 1994; Herbertson \& Aubin 1997; Walsh et al. 1995; Gronthos et al. 1999; Stewart et al. 1999). Diese Studien konzentrieren sich auf die Untersuchung des osteoblastären Differenzierungspotentials der AP-negativen und AP-positiven Zellen. Über ein eventuelles adipozytäres Differenzierungspotential dieser AP-Subpopulationen wurde aber nicht berichtet.

In der vorliegenden Arbeit untersuchten wir das adipozytäre Differenzierungspotential APnegativer Zellen, die aus primären humanen Osteoblasten mittels magnetischer Zellsortierung gewonnen wurden (Ponce 2000). Hierbei wurden die AP-negativen Zellen unter dem Einfluß eines Cocktails osteogener Differenzierungsfaktoren (Betaglycerophosphat, Ascorbat, $1,25(\mathrm{OH})_{2} \mathrm{D}_{3}$, Dexamethason), hier OF genannt, welcher in der Lage ist, die osteoblastäre Differenzierung bis zur Mineralisation zu induzieren (Halvorsen et al. 2001; Pittenger et al. 1999) gehalten. Weiterhin interessierte der Einfluß von Zytokinen, wie TGF- $\beta 1$ und BMP-2, welche als autokrine/ parakrine Faktoren eine Rolle in der Knochenentwicklung spielen.

\section{IV.3.1. Expression osteoblastärer Marker in den AP-negativen Zellen}

Hierbei wurde die Hypothese aufgestellt, daß die AP-negativen Zellen eine frühe Differenzierungsstufe, d.h. Osteoprogenitoren oder Präosteoblasten, darstellen wie schon bereits 
in früheren Untersuchungen beschrieben wurde (Stewart et al. 1999; Encina et al. 1999; Gronthos et al. 1999). Aus diesem Grund eignen sie sich für die Untersuchung der osteoblastären Entwicklung. Tatsächlich unterstützen folgende Hinweise diese Hypothese: 1) Die FACS Analyse nach 2 Wochen Rekultivierung (unter Standardbedigungen: DMEM/ 10\% FCS) bestätigte, daß die AP-negativen Zellen stabil negativ bezüglich des AP-Phänotyp waren. 2) Nach 3 Wochen unter diesen Standardbedingungen wiesen die Zellen immer noch keine APAktivität auf. 3) $\mathrm{Zu}$ diesem Zeitpunkt wurde auch eine sehr niedrige Osteokalzinsekretion nachgewiesen. 4) Letzlich zeigte sich das immense Differenzierungspotential dieser APnegativen Zellen durch die Induktion der AP-Aktivität sowie die starke Zunahme der Osteokalzinsekretion, die unter Stimulation mit OF und entweder TGF- $\beta 1$ oder BMP-2, beobachtet wurde.

AP ist ein membranassozierten-Enzym, das von pre- bis sekretorischen Osteoblasten exprimiert wird, während Osteokalzin, ein sezerniertes Protein, als Marker fortgeschrittener sekretorischer Osteoblasten bis Osteozyten gilt. Dies entspricht dem gut charakterisierten in vitro Rattenosteoblastenmodell von Owen et al. (1990) in dem die Entwicklung in 3 Phasen eingeteilt wird: Proliferation, Matrixreifung und Matrixmineralisation. Nach diesem Osteoblastendifferenzierungsmodell wird die AP-Expression mit der Phase der Matrixreifung bzw. die Osteokalzinexpression mit der Mineralisationsphase assoziiert. So findet die maximale AP-Expression vor der maximalen Osteokalzinexpression statt. Diese Sequenz gilt auch für die APund Osteokalzinexpression, die für verschiedene in vivo bzw. in vitro Modelle nachgewiesen wurde (Bruder et al. 1997; Aubin et al. 1995). Somit ist der in dieser Arbeit beobachtete Anstieg der AP- Aktivität und Osteokalzinsekretion unter allen Stimulationsfaktoren als Ausdruck eines differenzierungsinduzierenden Effekts zu werten.

In den hier vorgestellten Ergebnissen der AP-zytochemischen Färbung zeigte sich eindeutig, daß alle AP-negativen Zellen nach 7-tägiger Stimulation eine positive Reaktion aufwiesen. Wenn diese Färbung mikroskopisch betrachtet wurde, war eine Variation der Farbintensität als Ausdruck einer unterschiedlichen AP-Aktivität zwischen einzelnen Zellen zu erkennen. Die unterschiedliche Intensität der AP-Färbung könnte eine Zellzyklus-Heterogenität primärer humaner Osteoblastenkulturen widerspiegeln, da unterschiedliche AP-Aktivitäten zwischen G1/S-Phase-synchronisierten und unsynchronisierten primären humanen Osteoblasten Kulturen nachgewiesen wurden. Bei synchronisierten Kulturen sinkt die AP-Enzymaktivität sowie ihre membrangebundene Expression während der Mitosephase und korreliert deswegen mit einer spezifischen Zellzyklusphase (Fedarko et al. 1990). Synchronisierte primäre humane Osteoblasten in vitro durchlaufen eine lange G1-Phase, die sogar in vivo für Ratten nachgewiesen wurde (Kimmel \& Jee 1980) und auch eine typische Eigenschaft für Bindegewebszellen ist. Es wird spekuliert, daß diese lange Phase, in der die höchste 
Proteinsynthese stattfindet, für die Synthese und Produktion einer komplexen Extrazellulärmatrix notwendig ist (Kimmel \& Jee 1980).

Neben der zytochemischen AP-Färbung wurde in dieser Arbeit die AP-Enzymaktivität im Zellpellet quantitativ bestimmt. Auch wenn diese Messung den Mittelwert aus der gesamten Zellmenge darstellt, ermöglicht uns dies, den Einfluß unterschiedlicher Differenzierungsbedingungen differentiell zu untersuchen. So konnte hier gezeigt werden, daß TGF- $\beta 1$ (1 ng/ ml) einem 6-fachen Anstieg der AP-Aktivität im Vergleich zu der Stimulation mit OF oder OF

+ BMP-2 bewirkte. Die Beobachtung, daß diese stimulatorische Wirkung bereits nach 2-tägiger Exposition und über den gesamten untersuchten Zeitraum stattfand, bestätigt die fördernde Wirkung von TGF- $\beta 1$ in der frühen Phase der osteoblastären Differenzierungsprozesse (Joyce et al. 1990; Bolander 1992; Lee et al. 2000).

Die Kollagen-I-sekretion, die hier in Mediumüberstand indirekt durch das carboxyterminale Propeptid (CICP) gemessen wurde, ist das Hauptsyntheseprodukt der Osteoblasten und bildet die Grundsubstanz der Extrazelullärmatrix. In dieser Arbeit wurde nachgewiesen, daß die APnegativen Zellen Kollagen-I konstitutiv (Kontrollbedingungen: DMEM/ 0,1\% BSA) exprimieren und diese Sekretion unter allen Differenzierungsbedingungen ansteigt.

Diese Ergebnisse zeigen, daß die Kollagen-I-sekretion zu einem frühen Zeitpunkt, also bevor die AP-Expression induziert wird, wie aus der Literatur bekannt ist (Owen et al. 1990; Bellows et al. 1999; Manduca et al. 1993; Gronthos et al. 1999) stattfindet. Zu berücksichtigen ist dabei, daß bei den erwähnten Studien andere Standardbedingungen vorlagen, wie z.B. L-Ascorbat-2Phosphat (Owen et al. 1990; Gronthos et al. 1999), welches die Kollagen-I-expression positiv beeinflussen kann (Kipp et al. 1996).

Bei Rattenkalvarienkulturen findet die maximale Kollagen-I-Sekretion und -Genexpression während der Proliferationsphase statt und wird mit zunehmender Differenzierung herunterreguliert (Owen et al. 1990). Im Gegensatz zu dem Rattenkalvariensystem wurde in der hier vorliegenden Arbeit trotz der gesteigerten Osteokalzinsekretion als Ausdruck der zunehmenden Differenzierung keine Herunterregulation der Kollagen-I-sekretion beobachtet. Aufgrund der zunehmenden Sekretion läßt sich vermuten, daß Kollagen-I, eine differenzierungsfördernde Rolle bei primären humanen Osteoblasten spielt.

\section{IV.3.2. Genexpression adipozytärer Marker in den AP-negativen Zellen}

In der vorliegenden Arbeit konnte in den AP-negativen Zellen eine konstitutive (unter Kontrollbedingugen) Expression adipozytärer Marker, PPAR $\gamma 2$ und LPL, auf mRNA Ebene erkannt werden. Dies führte zu der Fragestellung, ob es zu einer Regulation dieser Marker in 
Verlauf der zuvor nachgewiesenen zunehmenden osteoblastären Differenzierung AP-negativer Zellen kommt.

Die Analyse ist auf die Genexpression von PPAR $\gamma 2$ fokussiert, welcher als für die Adipozytendifferenzierung entscheidender Transkriptionsfaktor gilt, der daraufhin die Genexpression des Enzyms Lipoproteinlipase (LPL) induziert (Tontonoz et al. 1994; Gimble et al. 1996). In der hier vorliegenden Arbeit führte die Inkubation der AP-negativen Zellen mit

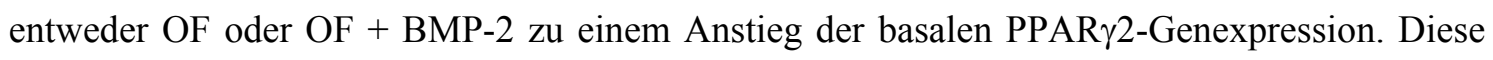
Induktion, die bereits nach 2 Tagen Stimulation stattfand, wurde ebenfalls mit einer entsprechenden über den gesamten untersuchten Zeitraum zunehmender Genexpression von LPL, begleitet.

$\mathrm{Zu}$ berücksichtigen ist dabei, daß die allgemein nachgewiesene Induktion der PPAR $\gamma 2$ nur nach 2 Tagen stattfand, während der Steigerung von LPL bis zum Ende der Kultivierungszeitraum (nach 7 Tagen) erfolgte. Dies deutet auf eine bereits frühe bzw. kurzeitige Regulation bzw. Aktivierung von PPAR $\gamma 2$, welcher durch Bindung an die LPL-Promotor Bindungsregionen eine Hochregulierung der LPL-Genexpression bewirkt. Folglich wäre bei solch einer deutlichen Induktion adipozytärer Marker über 7 Tage mit der Entstehung von Lipidvakuolen in primären humanen Osteoblasten zu rechnen (Nuttall et al. 1998; Prichett et al. 2000). Diese konnte jedoch nicht nachgewiesen werden. Anzumerken ist dabei, daß Lipidvakuolen erst im späteren Stadium der Adipozytendifferenzierung enstehen, während LPL ein Enzym darstellt, das in der frühen Phase gebildet wird.

Da die hier vorgestellten Ergebnisse sich auf die LPL-Genexpression beschränken, kann nicht entschieden werden, ob der Zeitraum von 7 Tagen insuffizient ist, um eine Proteinsynthese zu erreichen, oder ob das verzögerte bzw. fehlende spätere Stadium der Adipozytendifferenzierung durch eine Fehlfunktion des LPL-Enzyms bedingt ist.

Daneben existieren Studien, die einen Anstieg adipozytärer Marker in Verlauf der osteoblastären Differenzierung in primären Mauskalvarienzellen, die mit Ascorbat plus Betaglycerophosphat (10 \% FCS) kultiviert wurden, dokumentieren (Garcia et al. 2002). Diese Autoren untersuchten mittels „microarray“ die Genexpression adipozytärer Marker im Verlauf (21 Tagen) der osteoblastären Differenzierung primärer Mauskalvarienkulturen. Bei dieser Analyse konnte eine zunehmende LPL-Genexpression begleitet von einem konstanten mRNASpiegel des Transkriptionsfaktors PPAR $\gamma$ während der Induktion von AP und Osteokalzin, gezeigt werden. Hierbei muss berücksichtig werden, daß diese Genexpressiondaten den Mittelwert aus möglicherweise heterogenen Kulturen darstellen. Es ist außerdem wesentlich zu berücksichtigen, daß diese Ergebnisse auf die Existenz von Zellen in unterschiedlichen Differenzierungsstadien zurückzuführen sind (Garcia et al. 2002). 
BMP-2 und TGF- $\beta 1$ sind in der Lage die osteoblastäre Differenzierung mesenchymaler Zellen zu fördern (Roelen \& Dijke 2003). Da die Wirkung von BMP-2 und TGF- $\beta 1$ in einer autokrinen/ parakrinen Form erfolgt, wird ihnen eine essentielle Rolle in der lokalen Knochenhomöostase zugeschrieben (Gazit et al. 1998; Hirata et al. 2003). Studien an Knochenmarkzellen von Mäusen suggerieren, daß die biologische Aktivität dieser Zytokine, die sich über die Aktivierung des Transkriptionsfaktors PPAR $\gamma 2$ abspielt, altersabhängig ist (Moerman et al. 2004). Somit lassen die Ergebnisse von Moerman et al. (2004) auf eine lokal regulierende Wirkung von BMP-2 und TGF- $\beta 1$ auf die Osteogenese und Adipogenese im humanen System schliessen.

Ein weiteres Ziel dieser Arbeit war die modulierende Wirkungen von BMP-2 und TGF- $\beta 1$ auf die Adipogenese während der osteoblastären Differenzierung AP-negativer Zellen zu explorieren bzw. zu vergleichen.

Bei der Überlegung der Stimulationsdosis von BMP-2 wurde spekuliert, daß die in dieser Arbeit zuvor getestete Dosis von $50 \mathrm{ng} / \mathrm{ml}$, die eine stimulierende Einfluß auf die PPAR $\gamma 2-$ Genexpression zeigte, in Abwesenheit anderer osteogenen Faktoren ihre Wirkung entfalten würde. Tatsächlich konnte bestätigt werden, daß 50 ng/ ml BMP-2 in Kombination mit OF eine stimulierende Wirkung auf die PPAR $\gamma 2-G e n e x p r e s s i o n$ in den AP-negativen Zellen hat. Zusätzlich ließ sich durch die entsprechende Induktion von LPL, die hierbei maximale Werte erreichte, nachweisen, daß BMP-2 die Wirkung von OF deutlich verstärkt. Unter Berücksichtigung dieser Ergebnisse zeigt sich, daß BMP-2 neben der Induktion der Osteokalzinsekretion auch eine stimulierende Wirkung auf die Adipogenese hat.

Unterstützt werden die hier vorgestellten Ergebnisse durch Experimente von Ahrens et al. (1993). Durch Transfektion einer murinen Zellinie (C3H10T1/2) mit BMP-2-cDNA konnten diese Autoren nachweisen, daß BMP-2 sowohl die Adipogenese als auch die Osteogenese induzieren kann. Auch Date et al. (2004) berichteten in der C3H10T1/2 Zellinie, daß BMP-2 sowohl die osteoblastäre als auch die adipozytäre Differenzierung unter in vivo und in vitro Bedingungen fördert. Bei der mesenchymalen Zellinie (2T3) berichteten Chen et al. (1998) ebenfalls über solch einen Effekt. Die 2T3 Zellen stammen aus transgenen Mäusen, die den BMP-2 Promotor zusammen mit SV-40T Antigen exprimieren. Die Autoren fanden, daß die Zugabe von BMP-2 die Wirkung von osteo- bzw. adipogenen Faktoren verstärkt (Chen et al. 1998).

Auch wenn diese Daten aus murinen mesenchymalen Zellen stammen und nicht humanen Ursprungs sind, erscheinen sie wertvoll unter den Aspekt, daß diese aus undifferenzierten bzw. homogenen Populationen (Zellinien) erhoben wurden. Sie sind dennoch als Hinweis darauf zu werten, daß auch neben der osteoblastendifferenzierungsfördernden Wirkung von BMP-2 noch 
stimulierenden Effekten auf die Expression adipozytärer Marker in einem frühen Stadien zu erwarten sind.

Durch die Stimulation der AP-negativen Zellen mit 1 ng/ ml TGF- $\beta 1$ (OF + TGF- $\beta 1$ ) ließ sich keine Induktion der Genexpression von PPAR $\gamma 2$ und LPL gegenüber der Kontrolle feststellen. Unter diesen Bedingungen konnten auch keine Lipidvakuolen nachgewiesen werden. Hierbei konnte durch die Stimulation mit TGF- $\beta 1$ eine blockierende bzw. tendenziell hemmende Wirkung auf die PPAR $\gamma 2$ Genexpression bis zum Ende des Stimulationsraumes ( 7 Tagen) dokumentiert werden. Diese inhibierende Wirkung, welche jedoch nicht die komplette Suppression von PPAR $\gamma 2$ provozieren kann, erscheint aber suffizient, um selbst die LPLGenexpression sowie die Enstehung von Lipidvakuolen zu unterdrücken.

Von Nuttall et al. (1998) wurde nachgewiesen, daß $100 \mathrm{ng} / \mathrm{ml}$ TGF- $\beta$ die adipogene Wirkung von Dexamethason plus IBMX an primären humanen Osteoblasten inhibieren kann. Bei der Suche nach Faktoren, welche die Osteoblasten/ Adipozyten Differenzierung mesenchymaler Zellen im Knochenmark beeinflussen können, wurde von Ahdjoudj et al. (2002) in vivo Untersuchungen an immobilisierten Ratten mit TGF- $\beta 2$ durchgeführt. Hierbei wurden Ratten, die durch die Immobilisierung einen niedrigen osteoblastenspezifische Genexpression mit einer parallel ansteigendend adipozytenspezifischen Genexpression in Knochenmark aufweisen, verwendet. So konnte durch die Behandlung der Tiere mit TGF- $\beta 2$ nicht nur eine Steigerung osteoblastärer Marker sondern auch eine Abnahme adipozytärer Marker begleitet mit einen verminderten Zahl der Adipozyten in Knochenmark hervorrufen werden (Ahdjoudj et al. 2002). Obwohl diese Studien von den hier vorgestellten Versuchen bezüglich der TGF-Isoform sowie in der Dosis abweichen, deuten sie darauf hin, daß TGF- $\beta$ in verschiedenen Untersuchungsmodellen die Osteoblastendifferenzierung fördert und die Adipozytendifferenzierung hingegen inhibiert.

Dieser aus der Literatur bekannte Effekt von TGF- $\beta$, welcher die osteoblastäre Differenzierung fördert und gleichzeitig auf die Adipogenese inhibierenden Einfluß nehmen kann, konnte hier schon zu einem frühen Zeitpunkt der Differenzierung primärer humaner Osteoblasten, d.h. als die Zellen noch AP-negativ waren, bestätigt werden. Da diese frühe inhibierende Wirkung von TGF- $\beta 1$ auf Ebene der Transkription von PPAR $\gamma 2$, welcher selbst ein essentieller Transkriptionsfaktor der Adipozytendifferenzierung ist, erfolgt, stellt dieses Zytokin eine entscheidende Komponente der molekularen Signalkaskade der Osteoblasten/ Adipozyten Differenzierung im humanen System dar. 


\section{IV.4. Basale Genexpression adipozytärer Marker in den mittels FACS Sorting isolierten AP-Subpopulationen}

Viele Arbeitsgruppen verwendeten die FACS Sorting Methode um unterschiedliche Entwicklungsstadien der Osteoblasten anhand der AP-Expression $\mathrm{zu}$ isolieren und weiterzukultivieren (Rickard et al. 1994; Herbertson \& Aubin 1997; Walsh et al. 1995; Gronthos et al. 1999; Stewart et al. 1999). Aus diesen Studien ist bekannt, daß die mittel FACS Sorting isolierten Subpopulationen sich aufgrund ihrer Reinheit zum Zweck der Genexpressionsanalyse eignen.

In dieser Arbeit sollte daher die FACS Sorting Methode zur Isolierung von AP-Subpopulationen aus primären humanen Osteoblasten etabliert werden, um ihr adipozytäres Differenzierungspotential zu untersuchen. Tatsächlich ermöglichte das FACS Sorting, im Gegensatz zur MACS-Methode, AP-positive und AP-negative Subpopulationen aus den gleichen Patienten/ Kulturen mit hoher Reinheit zu gewinnen. Die Sortierung ging aber mit einem großen Zellverlust einher, so daß die isolierten Zellen nur durch RT-PCR bezüglich der PPAR $\gamma 2$ - und LPL-Genexpression analysiert werden konnten. Diese Analyse erfolgte an isolierten Zellen, die nur mit Standard HOB Medium, DMEM supplementiert mit 10\% FCS gewachsen waren. Auch wenn Einflüsse von FCS nicht ausgeschlossen werden können, kann angenommen werden, daß die nachgewiesenen mRNA-Spiegel die konstitutive Expression von PPAR $\gamma 2$ und LPL darstellt.

Bei dem Vergleich zwischen den AP-negativen und den AP-positiven Subpopulationen konnten keine Unterschiede in der konstitutiven PPAR $\gamma 2$-mRNA-Expression beobachtet werden. Bezüglich der LPL-Genexpression konnten bei den entsprechenden Subpopulationen auffällige Unterschiede dokumentiert werden. Hierbei wiesen die AP-positiven Zellen eine wesentlich höhere konstitutive LPL Genexpression verglichen mit der AP-negativen Fraktion auf.

Bei der Diskussion dieser Ergebnisse wird entsprechend des Differenzierungsablaufs der Osteoblasten (Owen et al. 1990) angenommen, daß die AP-positiven eine weitere Differenzierungsstufe als die AP-negativen Zellen darstellen. Unter diesem Aspekt würde die stärkere LPL-Genexpression in den AP-positiven Zellen darauf hindeuten, daß die Osteoblasten im Laufe der Differenzierung ein zunehmendes adipozytäres Differenzierungspotential entwickeln würden.

Sowohl in dieser Arbeit als auch von Schoonjans et al. (1996) konnte auf Genexpressionsebene nachgewiesen werden, daß die Hochregulierung bzw. die Hemmung von LPL auf die Induktion bzw. die Blockierung von PPAR 22 zurückzuführen ist. In diesem Zusammenhang wäre aufgrund der Hochregulierung von LPL mit einer deutlich ausgeprägten PPAR $\gamma 2-$ Genexpression in den AP-positiven Zellen, zu rechnen. Diese Unterschiede hinsichtlich der PPAR $\gamma 2$-Genexpression konnten hier jedoch nicht beobachtet werden. Allerdings ist 
anzumerken, daß die hier dokumentierte konstitutive PPAR $\gamma 2$-mRNA sowohl von AP-negativen als auch von AP-positiven Zellen ähnlich exprimiert wird, d.h. unabhängig von dem Differenzierungsstatus der Zellen. Diese Beobachtung suggeriert, daß die konstitutive PPAR $\gamma 2-$ Genexpression hoch genug ist, um die LPL-Genexpression, und somit das Adipozytendifferenzierungsprogramm in Osteoblasten die bereits AP-Protein exprimieren, zu induzieren. Da diese adipozytären Marker an relativ reinen AP-positiven Subpopulationen nachgewiesen werden konnten, lässt sich vermuten, daß diese beiden Phänotypen in derselben Zelle vorkommen.

Aus in vitro Studien, welche sich mit der Modulation der Aktivierung des PPAR $\gamma 2-$ Transkriptionsfaktors beschäftigen, ergeben sich Hinweise, daß die Linolsäureoxidationsprodukte, als endogene PPAR $\gamma 2$-Liganden die Adipogenese fördern und gleichzeitig die Osteoblastogenese inhibieren (Lecka-Czernik et al. 2002). Die Autoren schließen daraus, daß diese Oxidationsprodukte für den altersbedingten Knochenverlust verantwortlich sein können. Bemerkenswert ist jedoch, daß bestimmte von diesen Oxidationsprodukte die Adipogenese fördern ohne die Osteoblastogenese zu beeinflussen (Lecka-Czernik et al. 2002).

Auch wenn die hier vorgestellten Ergebnisse sich nur auf die Genexpression beschränken, kann dennoch spekuliert werden, daß die nachgewiesene Induktion der LPL-Genexpression in der Aktivierung des Transkriptionsfaktors PPAR $\gamma 2$ durch endogene Liganden, wie z.B. Linolsäureoxidationsprodukte oder andere Fettsäureoxidationsprodukte, welche nur in APpositiven Zellen vorkommen würden, ihren Ursprung hat.

\section{IV.5. Langzeitwirkung von BMP-2 und TGF- $\beta 1$ auf die Adipogenese und die Osteogenese in primären humanen Osteoblasten}

Für die weitere Beurteilung der zuvor beschriebenen biologischen Effekte von BMP-2 und TGF- $\beta 1$ ist die Untersuchung der endgültigen Phase der Differenzierung von Osteoblasten und Adipozyten von besonderer Bedeutung.

Die günstige Beeinflussung der osteoblastären Differenzierung leitet direkt auf die Frage, ob die starke Induktion der Osteokalzinsekretion die sowohl von BMP-2 als auch von TGF- $\beta 1$ hervorrufen wurde, langfristig einen Mineralisationsprozess auslösen würde. Folglich stellte sich auch die Frage, ob die hier im Verlauf von 7 Tage nachgewiesenen adipozytären Marker, welche auf Genexpressionsebene von BMP-2 gefördert bzw. von TGF- $\beta 1$ gehemmt wurden, auch noch über einen längeren Zeitraum in der Anwesenheit bzw. Abwesenheit von Lipidvakuolen Ausdruck finden würden. 
Aufgrund der durch die Sortierungsmethoden verursachten erheblichen Zellverluste, wurden diese Untersuchungen mit unsortierte Populationen primärer humaner Osteoblasten durchgeführt.

In Rahmen der vorliegenden Arbeit konnte ein Mineralisationsprozess sowohl unter BMP-2 (OF + BMP-2) als auch unter TGF- $\beta 1$ (OF + TGF- $\beta 1)$ innerhalb von 24 Tagen beobachtet werden. Dies deckt sich mit den Ergebnissen zahlreicher Studien, die über eine Mineralisation bei Rattenkalvarienzellen (Owen et al. 1990), bei primären humanen Osteoblasten (Nöth et al. 2002) und bei humanen Knochenmarkstromazellen in einen Zeitraum (Rickard et al. 1996) von 3-4 Wochen berichten. Auch wenn diese Daten aus unterschiedlichen Zellkulturmodellen stammen und unter anderen Kulturbedingungen erhoben wurden, stehen sie im Einklang mit der hier dokumentierten Beobachtung, daß die Induktion der Osteokalzinsekretion konsekutiv in einem Mineralisationsprozess mündet.

Parallel dazu ließen sich in der hier vorliegenden Arbeit zytoplasmatische Lipidvakuolen nur unter Einfluß von OF + BMP-2 innerhalb von 24 Tagen nachzuweisen. Ein solcher adipozytärer Phänotyp konnte hingegen unter Stimulation mit OF + TGF- $\beta 1$ nicht festgestellt werden.

Zusammenfassend lässt sich sagen, daß die stimulatorischen Effekte von BMP-2, welche sich sowohl in der früheren Phase der Adipozytendifferenzierung (Genexpression von PPAR $\gamma 2$ und LPL) als auch in der Matrixsynthesephase (AP-Aktivität und Osteokalzinsekretion) der Osteoblastendifferenzierung äußerten, auch langfristig in der Förderung der späteren Entwicklungsphase von Adipozyten und Osteoblasten durch den Nachweis von Lipidvakuolen bzw. Mineralisationskernen feststellen lassen.

Der supprimierende Effekt von TGF- $\beta 1$ auf die Adipogenese, welche sich erst nur über eine Hemmung der Genexpression von PPAR $\gamma 2$ und LPL nachweisen ließ, konnte hier auch zu einem späteren Zeitpunkt der Adipozytendifferenzierung durch die fehlende Enstehung von Lipidvakuolen bestätigt werden.

\section{IV.6. Ultrastrukturalle elektronenmikroskopische Lokalisation adipozytärer und osteoblastärer Marker auf Einzellzellniveau in primären humanen Osteoblasten}

Entsprechend der hier zuvor vorgestellten Ergebnisse an homogenen AP-Subpopulationen lässt sich eine Coexpression adipozytärer und osteoblastärer Markerproteine auf Einzelzellebene vermuten. In Anbetracht der gesteigerten Genexpression von PPAR $\gamma 2$ und LPL sowie der Nachweis von Lipidvakuolen unter Einfluß von OF + BMP-2 wäre auch mit einer Proteinsynthese dieser Marker zu rechnen.

Durch den Doppelnachweis adipozytärer (PPAR $\gamma 2$, LPL) und osteoblastärer (AP, Osteokalzin) Markerproteine an primären humanen Osteoblasten, die über 7 Tage mit OF + BMP-2 kultiviert 
wurden, sollte festgestellt werden, ob beide Phänotypen in derselben Zelle vorkommen. Hierfür sollte die Methode der Immunogoldzytochemie, welche eine zuverlässige Lokalisation der Markerproteine bei hoher Auflösung in der Transmissionselektronenmikroskopie ermöglicht, genutzt werden (Miosge et al. 1999; Miosge et al. 2003). Die Kopplung der Antikörper an Goldpartikel bestimmter Durchmesser ermöglicht eine exakte Zuordnung des nachzuweisenden Epitops (Markerprotein). Bei dieser Bindung zwischen Goldpartikeln und Antikörpern, welche wahrscheinlich nur durch elektrostatische Anziehungskräfte erfolgt, bleibt die biologische Aktivität der gebundenen Antikörper erhalten (Horisberger 1979).

In dieser Arbeit gelang es für den Nachweis des Transkriptionsfaktors PPAR $\gamma 2$ sowie des LPLEnzyms die entsprechenden Primärantikörper an $8 \mathrm{~nm}$ Goldpartikeln zu koppeln. Im Kontrast dazu konnten die Primärantikörper zur parallelen Beurteilung der Expression des Enzyms alkalische Phosphatase und Osteokalzin an $16 \mathrm{~nm}$ Goldpartikeln gekoppelt werden. Die Anwendung dieser direkten immunzytochemischen Methode verringert der Anzahl der notwendigen Reaktionsschritte. und gleichzeitig werden eventuelle unspezifische Bindungen vermieden, die durch die Verwendung eines Sekundärantikörpers bedingt sind. Dies hat was eine höhere Spezifität des Proteinnachweises zur Folge.

Entsprechend der stimulatorischen Effekte von OF + BMP-2, welche sich sowohl in der APAktivität bzw. Osteokalzinsekretion, als auch in der Veränderung der Zellstruktur äußerten, wäre in der elektronenmikroskopischen Analyse mit Zellformen $\mathrm{zu}$ rechnen, die für sekretorischen aktiven Osteoblasten charakteristisch sind.

Tatsächlich konnten in der hier vorliegenden elektronenmikroskopischen Untersuchung zahlreiche osteoblastenassozierte Zellstrukturen, wie z.B. Mitochondrien, ein prominenter Kern und Pseudopodien, erkannt werden. Aufgrund der beobachteten zahlreichen zytoplasmatischen Vesikeln kann auch festgestellt werden, daß es sich um sekretorisch aktive Osteoblasten handelt.

Die immunogoldzytochemische Methode erlaubte den Nachweis der Coexpression adipozytärer und osteoblastärer Markerproteine sowie ihre genaue Lokalisation in ein und derselben Zelle. So konnte der Transkriptionsfaktor PPAR $\gamma 2$ sowohl im Zellkern als auch im Zytoplasma von Zellen, die sowohl das AP-Enzym an der Zellmembran als auch Osteokalzin in zytoplasmatischen Vesikeln aufweisen, lokalisiert werden. Auch das Enzym LPL konnte zusammen entweder mit AP oder mit Osteokalzin im Zytoplasma derselben Zelle nachgewiesen werden.

In den hier vorgestellten Ergebnissen hat sich bestätigt, daß die unter OF + BMP-2 hervorrufene Induktion der mRNA-Synthese von PPAR $\gamma 2$ und LPL bei primären humanen Osteoblasten von den entsprechenden Proteinsynthese begleitet wurde. Diese Proteinsyntheseinduktion fand ebenfalls in Zellen die osteoblastäre Markerproteine, wie Osteokalzin und AP exprimieren, statt. 
Durch diese Befunde ergeben sich erste Hinweise auf eine gemeinsame bzw. parallele Induktion der Adipogenese und Osteoblastogenese auf Einzelzellebene im primären humanen Osteoblastensystem. 


\section{7. Ausblick}

In den letzten Jahren gewinnt die Altersosteoporose aufgrund der angestiegenen mittleren Lebenserwartung beim Menschen immer mehr an Bedeutung. Bei dieser Form der Osteoporose handelt es sich um einen Knochenverlust, der mit einer Zunahme des Fettgewebes im Knochenmark korreliert. Hierbei wurde anhand zahlreicher Studien postuliert, daß die Beziehung zwischen Osteoblasten und Adipozyten reziprok ist (Ahdjoudj et al. 2004; Gimble \& Nuttall 2004; Nuttall \& Gimble 2004; Akune et al. 2004).

Diese Arbeit konnte aber zeigen, daß beide Differenzierungsprozesse, Osteogenese und Adipogenese, auf Einzelzellebene parallel ablaufen können und das die autokrine/ parakrine Faktoren TGF- $\beta 1$ und BMP-2 eine entscheidende modulierende Rolle dabei spielen (Abb. 34).

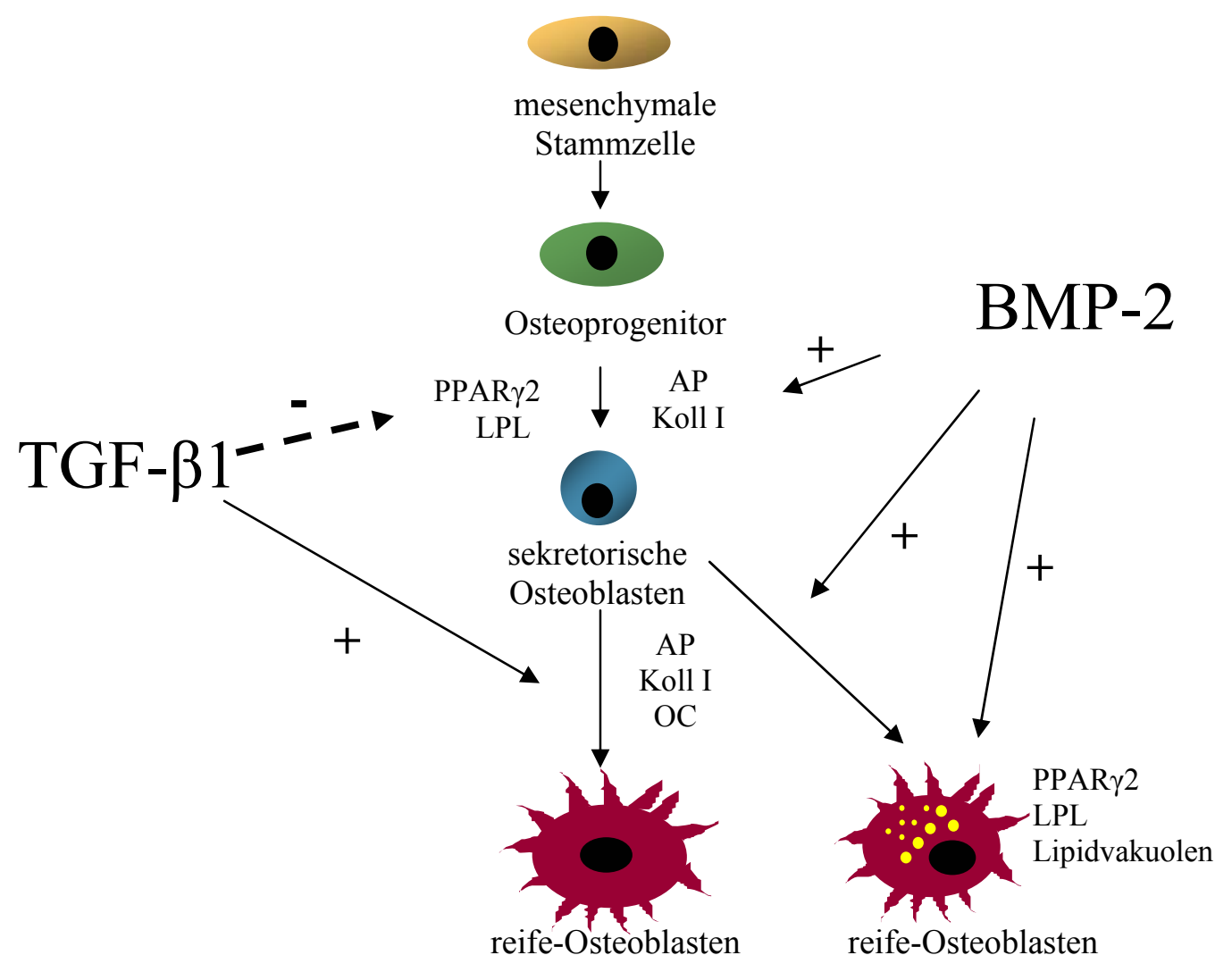

Abb. 35: Modell für den Einfluß von TGF- $\beta 1$ und BMP-2 auf die Osteoblasten/ Adipozyten Differenzierungsmarker in der Entwicklung primärer humaner Osteoblasten.

AP: alkalische Phosphatase; Koll I: Kollagen I; OC: Osteokalzin; PPAR: „peroxisome proliferator activated receptor“, LPL: Lipoproteinlipase;

Die Befunde sollten für die Entschlüsselung der in vitro regulierenden Faktoren, welche in der Differenzierung von Osteoblasten/ Adipozyten involviert sind, beitragen und könnten u.a. für die Entwicklung einer zellbiologischen Therapie der Osteoporose genutzt werden. 
Die funktionelle bzw. physiologische Bedeutung des zunehmenden adipozytären Differenzierungspotentials während der Osteoblastendifferenzierung bleibt ungeklärt. Durch weitere Studien soll geklärt werden, ob die Adipozyten nicht nur eine passive sondern auch eine aktive Rolle als dynamisches Endokrinorgan in der Knochenhomöostase spielen. 


\section{Zusammenfassung}

Mit dem Alter tritt sowohl am langen Knochen als auch an der Wirbelsäule ein Knochenmasseverlust ein. Vom klinischen Standpunkt aus betrachtet, kann dieser Knochenmasseverlust beim Menschen in einem unter dem Namen Altersosteoporose bekannten Krankheitsbild resultieren. Hierbei ist seit Jahren bekannt, daß eine Abnahme des Knochenvolumens im Rahmen der Alterosteoporose mit einer Zunahme des Fettgewebes im Knochenmark einhergeht. Zur Erklärung dieses Phänomens wird die Hypothese aufgestellt, daß die Osteoblasten bzw. Osteoprogenitoren in Adipozyten umdifferenziert bzw. transdifferenziert werden.

Ziel dieser Arbeit war es, die in vitro Regulation der Plastizität bzw. der adipozytären Differenzierungskapazität von Osteoblasten und Osteoblastensubpopulationen zu untersuchen.

Dieser Arbeit liegt ein gut charakterisiertes humanes Differenzierungsmodell primärer Osteoblasten (pHOB) zugrunde, diese sind in der Lage eine programmierte Differenzierungssequenz bis zur Mineralisation zu durchlaufen.

Die osteoblastäre Differenzierung wurde anhand der Expression von Kollagen-I, AP, Osteokalzin sowie von Mineralisationskernen nachgewiesen. Die Untersuchung der adipozytären Differenzierungskapazität erfolgte hier durch den Nachweis der Expression von PPAR $\gamma 2$, LPL sowie von Lipidvakuolen.

In der vorliegenden Arbeit sollte zunächst der Transdifferenzierungsprozeß zum Adipozyten unter einem definierten Adipogenesemedium (IBMX + Dexamethason) in pHOB Zellen und zusätzlich in der immortalisierten humanen Osteoblastenzellinie AHTO überprüft werden. Die Ergebnisse zeigen, daß die pHOB Zellen in der Lage sind, unter Einfluß eines Adipogenesemediums eine vollständige Differenzierung zu Adipozyten, gezeigt durch den histologischen Nachweis von Lipidvakuolen und durch die Induktion der PPAR $\gamma 2-$ Genexpression, zu durchlaufen. Ein solcher Differenzierungsprozess konnte bei den AHTO Zellen nicht bestätigt werden.

BMP-2 und TGF- $\beta 1$ sind Zytokine, denen in einer autokrinen/ parakrinen Form eine essentielle Rolle in der lokalen Knochenhomöostase zugeschrieben wird. Diese sind auch in der Lage in vitro die osteoblastäre Differenzierung mesenchymaler Zellen zu fördern. Ein weiteres Ziel dieser Arbeit war es, die modulierende Wirkungen von BMP-2 und TGF- $\beta 1$ auf die Adipogenese während der Differenzierung von pHOB Zellen zu untersuchen.

Bezüglich der Wirkung von BMP-2 auf die Adipogenese existieren allerdings bisher widersprüchliche Daten. Daher sollte in dieser Arbeit zunächst ein eventueller Einfluss von verschiedenen BMP-2-Konzentrationen auf die Expression adipozytärer Marker in pHOB 
Zellen untersucht werden. Hierbei wurde ein Anstieg der Genexpression des adipozytären Transkriptionsfaktors PPAR $\gamma 2$ unter der geringsten Dosis $(50 \mathrm{ng} / \mathrm{ml})$ von BMP-2 nachgewiesen.

Ein weiterer Schwerpunkt dieser Arbeit war die Untersuchung der Plastizität homogener Osteoblastensubpopulationen, die aus pHOB Kulturen mittels magnetischer Zellsortierung gewonnen wurden. Hierbei erfolgten diese Versuche an AP-negativen Zellen, da diese eine frühe Differenzierungsstufe der Osteoblasten (Osteoprogenitoren oder Präosteoblasten) darstellen und somit für die Untersuchung der weiteren Differenzierung geeignet sind. Dabei sollte die adipozytäre Differenzierungskapazität während der osteoblastären Entwicklung APnegativer Zellen und die modulierende Wirkung von BMP-2 und TGF- $\beta 1$ näher untersucht werden. Die AP-negativen Zellen waren in der Lage sich im Zeitraum von 7 Tagen sowohl unter Stimulation mit entweder TGF- $\beta 1$ oder BMP-2 zum reifen Osteoblasten zu entwickeln, gezeigt durch die Induktion der AP-Aktivität sowie eine starke Zunahme der Osteokalzinsekretion. Parallel dazu wurde eine Induktion der Genexpression von PPAR $\gamma 2$ und LPL unter Einfluß von BMP-2 nachgewiesen. Die Induktion des adipozytären Phänotyps in den AP-negativen Zellen konnte hingegen unter Stimulation von TGF- $\beta 1$ blockiert werden.

Die Etablierung der FACS Sorting Methode erlaubte in dieser Arbeit die konstitutive Genexpression von PPAR $\gamma 2$ und LPL zwischen AP-positive und AP-negative Subpopulationen der gleichen Patienten/ Kulturen zu vergleichen. Hierbei wiesen die AP-positiven Zellen verglichen mit der AP-negativen Fraktion eine wesentlich höhere konstitutive LPL Genexpression auf. Bezüglich der PPAR $\gamma 2$-mRNA konnte hier dokumentiert werden, daß PPAR $\gamma 2$ sowohl von AP-negativen als auch von AP-positiven Zellen ähnlich exprimiert wird.

Die in den AP-negativen Zellen nachgewiesenen Effekte von BMP-2 und TGF- $\beta 1$ wurden in primären humanen Osteoblasten (unsortierte bzw. heterogene Populationen) durch die Untersuchung der endgültigen Phase der Differenzierung von Osteoblasten und Adipozyten bestätigt. So konnte nachgewiesen werden, daß die starke Induktion der Osteokalzinsekretion die sowohl von BMP-2 als auch von TGF- $\beta 1$ hervorrufen wurde, langfristig (24 Tage) einen Mineralisationsprozess auslöste. Auch die stimulatorischen Effekte von BMP-2 auf die Genexpression von PPAR $\gamma 2$ und LPL äußerten sich langfristig in der Förderung der späteren Entwicklungsphase von Adipozyten durch den Nachweis von Lipidvakuolen. Die supprimierende Wirkung von TGF- $\beta 1$ auf die Genexpression von PPAR $\gamma 2$ und LPL konnte hier auch zu einem späteren Zeitpunkt der Adipozytendifferenzierung bestätigt werden. 
Mittels Immunogoldzytochemie wurde in dieser Arbeit die Coexpression adipozytärer und osteoblastärer Markerproteine in primären humanen Osteoblasten unter Einfluß von BMP-2 nachgewiesen. Die elektronenmikroskopische Untersuchung bestätigte, daß in sekretorisch aktiven Osteoblasten, die Osteokalzin und AP exprimieren, gleichzeitig eine Expression adipozytärer Markerproteine, wie der PPAR $\gamma 2$ und LPL, stattfindet.

Hierbei wurde erstmals eine gemeinsame bzw. parallele Induktion osteoblastärer und adipozytärer Marker unter Einfluß von BMP-2 auf Einzelzellebene im primären humanen Osteoblastensystem beschrieben

In dieser Arbeit ist es gelungen die unterschiedliche Wirkung von BMP-2 und TGF- $\beta 1$ auf beide Differenzierungsprozesse, Adipogenese und Osteoblastogenese, in primären humanen Osteoblasten mit verschiedenen Methoden darzustellen und bis zur Einzelzellebene zu überprüfen. 


\section{Literaturverzeichnis}

Aarden E.M, Burger E.H, Nijweide P.J., 1994: Function of osteocytes in bone. J Cell Biochem. 55: 287299.

Abe E., Yamamoto M., Taguchi Y., Lecka-Czernik B., O’Brian C.A., Economides A.N., Stahl N., Jilka R.L., Manolagas S.C., 2000: Essential requirement of BMPs-2/4 for both osteoblast and osteoclast formation in murine bone marrow cultures from adult mice: antagonism by noggin. $\mathrm{J}$ Bone Miner Res. 15: $663-673$.

Ahdjoudj S., Lasmoles F., Oyajobi B.O., Lomri A., Delannoy P., Marie P.J. 2001: Reciprocal control of osteoblast/chondroblast and osteoblast/adipocyte Differentiation of multipotential clonal human marrow stromal F/STRO-1+ Cells. Journal of Cellular Biochemistry. 81: 23-28.

Ahdjoudj S., Fromigué O., Marie P.J., 2004: Plasticity and regulation of human bone marrow stromal osteoprogenitor cells: potential implication in the treatment of age-related bone loss. Histol Histopathol 19: $151-8$

Ahlström M., Pekkinen M., Huttunen M., Lamberg-Allardt C. 2005: Dexamethasone down-regulates cAMP-phosphodiesterase in human osteosarcoma cells. Biochem Pharmacol. 69: 267-275.

Ahrens M., Ankenbauer T., Schröder D., Hollnagel A., Mayer H., Gross G., 1993: Expression of human bone morphogenetic Proteins-2 or -4 in murine mesenchymal progenitor $\mathrm{C}^{2} \mathrm{H}_{10 \mathrm{~T}} 1 / 2$ cells induces differentiation into distinct mesenchymal cell lineages. DNA Cell Biol. 12:871-880

Akune T.J., Kubota N., Harada Y., Azuma Y., Nakamura K., Kamaguchi H., 2001: Heterozygous PPAR $\gamma$-deficient mice exhibit high bone mass with increased osteoblastic differentiation from bone marrow progenitors. J Bone miner Res. 16: 1003.

Akune T., Ohba S., Kamekura S., Yamaguchi m., Chung U., Kubota N., Terauchi Y., Harada Y., Azuma Y., Nakamura K., Kadowaki T., Kawaguchi H., 2004: PPAR $\gamma$ insufficiency enhances osteogenesis through osteoblast formation from bone marrow progenitors. J Clin Invest. 113. 846-855.

Anderson H.C., Reynolds J.J., 1973: Pyrophosphatase stimulation of initial mineralization in cultured embryonic bones. Fine structure of matrix vesicles and their role in mineralization. Dev Biol. 34: 211227.

Anderson H.C., Sipe J.B, Hessle L., Dhamayamraju R., Atti E., Camacho N.P., Millan J.L., 2004: Impaired calcification around matrix vesicles of growth plate and bone in alkaline phosphatase-deficient mice. Am J Pathol. 164: 841-847.

Ali S.Y, Sajdera S.W., Anderson H.C., 1970: Isolation and characterization of calcifyng matrix vesicles from epiphyseal cartilage. Proc Natl Acad Sci USA. 3: 1513-1520. 
Aubin J.E., Liu F., Malaval L., Gupta A.K., 1995: Osteoblast and chondroblast differentiation. Bone. 17: 77-83.

Auf'm Kolk B., Hauschka P.V., Schwartz E.R., 1985: Characterization of human bone cells in culture. Calcif Tissue Int. 37: 228-235.

Atmani H., Audrain C., Mercier L., Chappard D., Basle M.F., 2002: Phenotypic effects of continuos or discontinuous treatment with dexamethasone and/or calcitriol on osteoblasts differentiated from rat bone marrow stromal cells. J Cell Biochem. 85: 640-650.

Avioli L.V.1995: Comments from the Editor. Calcif Tissue Int. 56, S1

Bellows C.G., Aubin J.E., Heersche J.N.M., 1991: Initiation and progression of mineralization of bone nodules formed in vitro: The role of alkaline phosphatase and organic phosphate. Bone Miner. 14: 27-40.

Bellows C.G., Wang Y-H, Heersche J.N.M., Aubin J.E., 1994: 1,25-dihydroxivitamin D3 stimulates adipocyte differentiation in cultures of fetal rat calvaria cells comparison with the effects of dexamethasone. Endocrinology. 134: 2221-2229.

Bellows C.G., Reimers S.M., Heersche J.N.M., 1999: Expression of mRNAs for type-I collagen, bone sialoprotein, osteocalcin, and osteopontin at different stages of osteoblastic differentiation and their regulation by 1,25-dihydroxyvitamin D3. Cell Tissue Res. 297: 249-259.

Bennett J.H., Joyner C.J., Triffitt J.T., Owen M.E., 1991: Adipocytic cells cultured from marrow have osteogenic potential. J Cell Sci. 99: 131-139

Beresford J.N., Gallagher J.A., Poser J.W.,Russel R.G.G., 1984: Production of osteocalcin by human bone cells in vitro. Effects of 1,25-(OH)2D3, 24,25-(OH)2D3, parathyroid hormone and glucocorticoids. Metab Bone Dis Rel Res. 5: 229-234.

Beresford J.N., 1989: Osteogenic stem cells and the stromal system. Clin Orthop Rel Res. 240: 270-295.

Beresford J.N., Bennett J.H., Devlin C., Leboy P.S., Owen M.E., 1992: Evidence for an inverse relationship between the differentiation of adipocytic and osteogenic cells in rat marrow stromal cell cultures. J Cell Sci. 102: 341-351.

Bianco P, Robey P.G., 2000: Marrow stromal cells. J Clin Invest. 105: 1663-1668.

Bolander M.E., 1992: Regulation of fracture repair by growth factors. Proc Soc Exp Biol Med. 200: 165170 .

Bouillon R, Okamura W.H., Norman A.W. 1995: Structure-function relationships in the Vitamin D endocrine system. Endocr Rev. 16: 200-57.

Bruder S.P., Horowitz M.C., Mosca J.D., Haynesworth S.E., 1997: Monoclonal Antibodies reactive with human osteogenic surface antigens. Bone. 21: 225-235. 
Chan G.K., Duque G., 2002: Age-related bone loss: old bone, new facts. Gerontology. 48: 62-71.

Chang S.F., Reich B., Brunzell J.D., Will H., 1998: Detailed characterization of the binding site of the lipoprotein lipase-specific monoclonal antibody 5D2. J Lipid Res. 39:2350-9.

Chen D., Ji X., Harris M.A., Feng J.Q., Karsenty G., Celeste A.J., Rosen V., Mundy G.R., Harris S.E., 1998: Differential roles for bone morphogenetic protein (BMP) receptor type IB and IA in differentiation and specification of mesenchymal precursor cells to osteoblast and adipocyte lineages. J Cell Biol. 142: 295-305.

Cheng S.L., Yang J.W., Rifas L., Zhang S.F., Avioli L.V., 1994: Differentiation of human bone marrow osteogenic stromal cells in vitro: induction of the osteoblast phenotype by dexamethasone. Endocrinology. 134: 277-86.

Date T., Doiguchi Y., Nobuta M., Shindo H., 2004: Bone morphogenetic protein-2 induces differentiation of multipotent $\mathrm{C} 3 \mathrm{H} 10 \mathrm{~T} 1 / 2$ cells into osteoblasts, chondrocytes, and adipocytes in vivo and in vitro. J Orthop Sci. 9: 503-8.

Devlin R.D., Du Z., Pereira R.C., Kimble R.B., Economides A.N., Jorgetti V., Canalis E., 2003: Skeletal overexpression of noggin results in osteopenia and reduced bone formation. Endocrinology. 144: 19721978.

Diefenderfer D.L., Osyczka A.M., Reilly G.C., Leboy P.S., 2003: BMP responsiveness in human mesenchymal stem cells. Connect Tissue Res. 44: 305-311.

Dickson M.C., Martin J.S., Cousins F.M. et al. 1995: Defective haematopoiesis and vasculogenesis in transforming growth factor- $\beta 1$ knockout mice. Development. 121: 1845-54.

Ducy P., Desbois C., Boyce B.,Pinerot G., Story B,. Dunstan C., Smith E., Bonadio J., Goldstein S., Gundberg C., Bradley A., Karsenty G., 1996: Increased bone formation in osteocalcin-deficient mice. Nature. 382: 448-452.

Ducy P., Zhang R., Geoffroy V., Ridall A.L., Karsenty G., 1997: Osf2/Cbfa1: A transcriptional activator of osteoblast differentiation. Cell. 89: 747-754.

Encina N.R., Billotte W.G., Hofmann M.C.C., 1999: Immunomagnetic isolation of osteoprogenitors frrom human bone marrow stroma. Lab Invest. 79: 449-457.

Fedarko N.S., Bianco P., Vetter U., Gehron Robey P., 1990: Human bone cell enzyme expression and cellular heterogeneity: correlation of alkaline phosphatase enzyme activity with cell cycle. J Cell Physiol. 144: $115-121$.

Ferretti J.L., Cointry G.R., Capozza R.F., Frost H.M., 2003: Bone mass, bone strength, muscle-bone interactions, osteopenias and osteoporoses. Mechan of Ageing and Develop. 124: 269-279.

Franceschi R.T.,.Wilson J.X, Dixon S.J., 1995: Requirement for $\mathrm{Na}^{+}$-dependent ascorbic acid transport in osteoblast function. Am.J.Physiol. 268: 1430-1439. 
Fratzl-Zelman N, Fratzl P., Horandner H., Grabner B, Varga F., Ellinger A., Klaushofer K., 1998. Matrix mineralization in MC3t3-E1 cell cultures initiated by beta-glycerophosphat pulse. Bone. 23: 511-520.

Friedenstein A.J., Chailakhyan R.K., Gerasimov U.V., 1987: Bone marrow osteogenic stem cells: in vitro cultivation and trasnplantation in diffussion chambers. Cell Tissue Kinet. 20, 263-272.

Fromigue O., Marie P.J., Lomri A., 1997: Differential induction of the osteoblast phenotype by 1,25dihydroxivitamin D, dexamethasone and TGFbeta2 in long-term cultures of human bone marrow stromaderived osteoprogenitor cells. Cytokine. 9: 613-623.

Fromigue O., Marie P.J., Lomri A., 1998: Bone morphogenetic protein-2 and transforming growth factor beta 2 interact to modulate human bone marrow stromal cell proliferation and differentiation. $\mathrm{J}$ Cell Biochem. 68: 411-426.

Frost H.M., 1987: The mechanostat: a proposed pathogenetic mechanism of osteoporoses and the bone mass effects of mechanical and nonmechanical agents. Bone Miner. 1: 73-85.

Garcia T., Roma-Roman A., Jackson A., Theilhaber J., Connolly T., Spinella-Jaegle S., Kawai S., Courtois B., Bushnell S., Auberval M., Call K., Baron R., 2002: Behaviour of osteoblast, adipocyte, and myoblast markers in genome-wide expression analysis of mouse calvaria primary osteoblasts in vitro. Bone. 31: 205-211.

Gazit D., Zilberman Y., Ebner R., Kahn A., 1998: Bone loss (osteopenia) in old mice results from diminished activity and availability of TGF- $\beta$. J Cell Biochem. 70: 478-488.

Gerstenfeld L.C., Chipman S.D., Glowacki J., Lian J.B., 1987: Expression of differentiated function by mineralizing cultures of chicken osteoblasts. Dev Biol. 122: 49-60.

Gimble J.M., Morgan C., Kelly K., Wu X., Dandapani V., Wang C.S., Rosen V., 1995: Bone morphogenetic proteins inhibit adipocyte differentiation by bone marrow stromal cells. J Cell Biochem 58: $393-402$

Gimble J.M., Robinson C.E., Wu X., Kelly K.A., Rodriguez B.R., Liewer S.A., Lehmann J.M., Morris D.C., 1996: Peroxisome proliferator activated receptor-gamma activation by thiazolidinediones induces adipogenesis in bone marrow stromal cells. Mol Pharmacol. 50: 1087-1094.

Gimble J.M., Nuttall M.E., 2004: Bone and Fat.: old questions, new insights. Endocrine. 23. 3.

Gori F., Thomas T., Hicok K.C., Spelberg T.C., Riggs B.L., 1999: Differentiation of human marrow stromal precursor cells: bone morphogenetic protein-2 increases OSF2/CBFA1, enhances osteoblast commitment, and inhibits late adipocyte maturation. J Bone Miner Res. 14: 1522-1535.

Gregoire F.M., Smas C.M., Sul H.S., 1998: Understanding adipocyte differentiation. Physiological Reviews 78: 783-809. 
Grigoriadis A.E., Heersche J.N.M., Aubin J.E., 1988: Differentiation f muscle fat cartilage and bone from progenitor cells present in a bone derived clonal cell population: Effects of dexamethasone. J Cell Biol. 106: 2139-2151.

Gronthos S., Zannettino A.C.V, Graves S.E., Ohta S., Hay S.J., Simmons P.J., 1999: Differential cell surface expression of the STRO-1 and alkaline phosphatase antigens on discrete developmental stages in primary cultures of human bone cells. J Bone Miner Res. 14: 47-56.

Gundle R., Beresford. J.N., 1995: The isolation and culture of cells from explants of human trabecular bone. Calcif Tissue Int. 56:8-10.

Halvorsen Y-D.C., Franklin D., Bond A.L., Hitt D.C., Auchter C., Boskey A.L., Paschalis E.P., Wilkison W.O., Gimble J.M., 2001: Extracellular matrix mineralization and osteoblast gene expression by human adipose tissue-derived stromal cells.. Tissue Eng. 7 (6): 729-741.

Harada S., Rodan G.A., 2003: Control of osteoblast function and regulation of bone mass. Review. Nature. 423: 349-355.

Hauschka P.K., Lian J.B., Gallop P.M., 1975: Direct identification of the calcium-binding amino-acid, gamma carboxyglutamate. Proc Natl Acad Sci USA. 72: 3925-3929.

Hauschka P.K, Lian J.V., Cole D.E. Gundberg C.M., 1989: Osteocalcin and matrix Gla protein: vitaminK dependent proteins in bone. Physiol Rev. 69: 990-1047.

Haynesworth S.E., Goschima J., Goldberg V.M., Caplan A.I., 1992: Characterization of cells with osteogenic potential from human marrow. Bone: 13: 81-88.

Heinemann D.E., Siggelkow H., Ponce M.L., Viereck V., Wiese K.G., Peters J.H., 2000: Alkaline phosphatase expression during monocyte differentiation. Overlapping markers as a link between monocytic cells, dendritic cells, osteoclasts and osteoblasts. Immunobiology. 202:68-81.

Hemmerich P., von Mikecz A., Neumann F., Sözeri O., Wolff-Vorbeck G., Zoebelein R., Krawinkel U., 1993: Structural and functional properties of ribosomal protein L7 from humans and rodents. Nucleic Acids Res. 21: 223-31

Herbertson A., Aubin J.E., 1997: Cell sorting enriches osteogenic populations in rat bone marrow stromal cell cultures. Bone. 21: 491-500.

Hirata K., Tsukazaki T., Kadowaki A., et al. 2003: Transplantation of skin fibroblasts expressing BMP-2 promotes bone repair more effectively than those expressing Runx2. Bone. 32: 502-12.

Hogan B.L.M., 1996: Bone morphogenetics proteins: Multifunctional regulators of vertebrate development. Genes \& Dev. 10: 1580-1594.

Horisberger M., 1999: Evaluation of colloidal gold as a cytochemicalmarker for transmission and scanning electron microscopy. Biol Cell. 36: 253-258. 
Houghton A., Oyajobi B.O., Foster G.A., Russell R.G.G., Stringer B.M.J., 1998: Immortalization of human stromal cells by retroviral transduction with a temperature sensitive oncogene: Identification of bipotentiall precursor cells capable of directed differentiation to either an osteoblast or adipocyte phenotype. Bone. 22: 7-16.

Ji X., Chen D., Xu C., Harris S.E., Mundy G.R., Yoneda T., 2000: Patterns of gene expression associated with BMP-2-induced osteoblast and adipocyte differentiation of mesenchymal progenitor cell 3T3F442A. J Bone Miner Metab 18: 132-9.

Jilka R.L., Weinstein R.S., Takahashi K., Parfitt A.M., Manolagas S.C., 1996: Linkage of decreased bone mass with impaired osteoblastogenesis in a murine model of accelerated senescence. J. Clin. Invest. 97: $1732-1740$.

Jorgensen N.R., Henriksen Z., Sorensen O.H., Civitelli R., 2004: Dexamethasone, BMP-2, and 1,25dihydroxyvitamin $\mathrm{D}$ enhance a more differentiated osteoblast phenotype: validation of an in vitro model for human bone marrow-derived primary osteoblasts. Steroids. 69: 219-226.

Joyce M.E., Roberts A.B., Sporn M.B., Bolander M.E., 1990: Transforming growth factor- $\beta$ and the initiation of chondrogenesis and osteogenesis in the rat femur. J Cell Biol. 110: 2195-2207.

Justesen J., Stenderup K., Ebbesen E.N., Mosekilde L., Steiniche T., Kassem M., 2001: Adipocyte tissue volume in bone marrow is increased with aging and in patients with osteoporosis. Biogeron. 2: 165-171.

Kelly K.A. Gimble J.M., 1998: 1,25-Dihydroxy vitamin D3 inhibits adipocyte differentiation and gene expression in murine bone marrow stromal cell clones and primary cultures. Endocrinology. 139: 26222628.

Kersten S., Desvergne B., Wahli W., 2000: Roles of PPARs in health and disease. Nature. 405: 421-424.

Kimmel D.B., Jee W.S.S., 1980: Bone cells kinetics during longitudinal bone growth in the rat. Calcif Tissue Int. 32: 123-133.

Kinoshita A., Saito T., Tomita H., et al., 2000: Domain specific mutations in TGF $\beta 1$ result in camuratiEngelmann disease. Nat Genet. 26: 19-20.

Kipp D.E., Grey C.E., Mc Elvain M.E., Kimmel D.B., Robinson R.G., Luckert B.P., 1996: Long-term low ascorbic acid intake reduces bone mass in guinea pigs. J Nutr. 126: 2044-2049.

Knothe Tate M.L., Adamson J.R., Tami A.E., Bauer T.W., 2004: The osteocyte. Intern J Biochem \& Cell Biol. 36: 1-8.

Lacey D.L., Timms E, Tan H.L., Kelley M.J., Dunstan C.R., Burgess T., Elliott R., Colombero A., Elliott G., Scully S., Hsu H., Sullivan J., Hawkins N., Davy E., Capparelli C., Eli A., Qian Y.X., Kaufman S., Sarosi I., Shalhoub V., Senaldi G., Guo J., Delaney J., Boyle W.J., 1998: Osteoprotegerin ligand is a cytokine that regulates osteoclast differentiation and activation. Cell. 93: 165-76. 
Lecka-Czernik B., Gubrij I., Moerman E.J., Kajkenova O., Lipschitz D.A., Manolagas S.C., Jilka R.L., 1999: Inhibition of Osf2/Cbfa1 expression and terminal osteoblast differentiation by PPAR $\gamma 2$. J Cell Biochem. 74: 357-371.

Lecka-Czernik B., Moerman E.J., Grant D.F., lehmann J.M., Manolagas S.C., Jilka R.L., 2002: Divergent effects of selective peroxisome proliferator-activated receptor-gamma 2 ligands on adipocyte versus osteoblast differentiation. Endocrinology. 143: 2376-2384.

Lee K-S., Kim H-J, Li Q-L., Chi X-Z., Ueta C., Komori T., Wozney J.M., Kim E-G., Choi J-Y., Ryoo HM., Bae S-C., 2000: Runx2 is a common target of transforming growth factor $\beta 1$ and bone morphogenetic protein 2, and cooperation between Runx2 and Smad5 induces osteoblast-specific gene expression in the pluripotent mesenchymal precursor cell line C2C12. Moll Cell Biol. 23: 8783-8792.

Lomri A., Fromigué O., Hott M., Marie P.J., 1999: Genomic insertion of the SV-40 large T oncogene in normal adult trabecular osteoblastic cells induces cell growth without loss of the differentiated phenotype. Calcif Tissue Int. 64: 394-401.

Mahmoodian F., Gosiewska A., Peterkofsky B., 1996: Regulation and properties of bone alkaline phosphatase during Vitamin C deficiency in guinea pigs. Arch Biochem Biophys. 336: 86-96

Major R.H., 1945. Classical description of disease (3 ed). Thomas. 587.

Manduca P., Sanguineti M., Pistone M., Boccignone E., Sanguineti F., Santolini F., Federici A., 1993: Differential Expression of alkaline phophatase in clones of human osteoblast-like cells. J Bone Miner Res. 8: 291-300.

Marie P.J., Lomri A., Sabbagh A., Basle M., 1989a: Culture and behaviour of osteoblastic cells isolated from normal trabecular bone surfaces. In Vitro Cell Biol Dev. 25: 373-380.

Marie P.J., 2001: The molecular genetics of bone formation: implications for therapeutic interventions in bone disorders. A. J Pharmacogenomics. 11: 75-87.

Martin R.B., Chow B.D., Lucas P.A., 1990: Bone marrow fat content in relation to bone remodeling and serum chemistry in intact and ovariectomized dogs. Calcif Tissue Int. 46: 189-194.

McGuigan F.E., Armbrecht G., Smith R., Felsenberg D, rRid D.M., Ralston S.H., 2001: Prediction of osteoporotic fractures by bone densitometry and COL1A1 genotyping: a prospective, population based study in men and women. Osteoporos Int. 12: 91-6.

Meunier, P., Aaron J., Edouard C.,. Vignon G., 1971: Osteoporosis and the replacement of cell populations of the marrow by adipose tissue. A quantitative study of 84 iliac bone biopsies. Clin Orthop. $80: 147-54$.

Miao D., Scutt A., 2002: Histochemical localization of alkaline phosphatase activity in decalcified bone and cartilage. J Histochem Cytochem. 50: 333-340.

Miller S.C., 1987: The bone lining cells: A distinct phenotype?. Calcif Tissue Int. 41: 1-5. 
Miller S.C., Bowman B.M., Smith J.M., Jee W.S.S., 1980: Characterization of endosteal bone-lining cells from fatty marrow bone sites in adult beagles. Anat Rec. 198: 163-173.

Minaire P., Edouard C., Arlot., Meunier P.J., 1984: Marrow changes in paraplegic patients. Calcif Tissue Int. 36: 338-340.

Miosge N., Sasaki T., Timpl R., 1999: Angiogenesis inhibitor endostatin is a distinct component of elastic fibers in vessel walls. Faseb J. 13:1743-50.

Miosge N., Simniok T., Sprysch P., Herken R., 2003: The collagen type XVIII endostatin domain is colocalized with perlecan in basement membranes in vivo. J Histochem Cytochem. 51:285-96.

Moerman E.J., Teng K., Lipschitz D.A., Lecka-Czernik B.,. 2004: Aging activates adipogenic and suppresses osteogenic programs in mesenchymal marrow stroma/stem cells: the role of PPAR $\gamma 2$ transcription factor and TGF- $\beta$ /BMP signaling pathways. Aging Cell. 3:379-89.

Moss D.W., 1992: Perspectives in alkaline phosphatase research. Clin Chem. 38: 2486-2492.

Mundlos S., 1994: Expression patterns of matrix genes during human skeletal development. Prog Histochem Cytochem. 28, 1-47.

Nakashima K., Zhou X., Kunkel G., Zhang Z., Deng J.M., Behringer R.R., de Crombrugghe B., 2002: The novel zinc finger-containing transcription factor osterix is required for osteoblast differentiation and bone formation. Cell. 108: 17-29.

Nijweide P.J., Mulder R.J.P., 1985: Identification of osteocytes in osteoblast-like cells cultures using a monoclonal antibody specifically directed againsr osteocytes. Histochemistry. 84: 342-347.

Nöth U., Osyczka A.M., Tuli R., Hickok N.J., Damielson K.G., Tuan R.S., 2002: Multilineage mesenchymal differentiation potential of human trabecular bone-derived cells. J Orthop Res. 20: 10601069.

Ntambi JM, Young-Cheul K., 2000: Adipocyte differentiation and gene expression. J Nutr. 130:31223126.

Nuttall M.E., Gimble J.M., 2000: Is there a therapeutic opportunity to either prevent or treat osteopenic disorders by inhibiting marrow adipogenesis?. Bone. 27: 177-184.

Nuttall M.E., Gimble J.M., 2004: Controlling the balance between osteoblastogenesis and adipogenesis and the consequent therapeutic implications. Curr Opin in Pharmacol. 4: 290-294.

Ogawa S., Urano t., hosoi T., Miyao M., Hoshino S., Fujita M., Shiraki M., Orimo H., Ouchi Y., Inoue S., 1999: Association of bone mineral densitiy with a polymorphism of the peroxisome proliferator-activated receptor $\gamma$ gene: PPAR $\gamma$ expression in osteoblasts.

Oreffo R.O.C., Virdi A.S., Triffitt J.T., 1997: Modulation of osteogenesis and adipogenesis by human serum in human bone marrow cultures. Eur J Cell Biol. 74: 251-261. 
Owen M., 1985: Lineage of osteogenic cells and their relationship to the stromal system. In WA Peck (Eds.): "Bone and Mineral Research Annual". Amsterdam: Experta Medica 3, 1-25.

Owen T.A., Aronow M., Shalhoub V., Barone L.M., Wilming L., Tassinari M.S., Kennedy M.B., Pockwinse S., Lian J.B., Stein G.S., 1990: Progressive development of the rat osteoblast phenotype in vitro: reciprocal relationships in expression of genes associated with osteoblast proliferation and differentiation during formation of the bone extracellular matrix. J Cell Physiol. 143: 420-430.

Park S.R., Oreffo R.O.C., Triffitt J.T., 1999: Interconversion potential of cloned human marrow adipocytes in vitro. Bone. 24: 549-554.

Parfitt A.M., 1994: Osteonal and hemi-osteonal remodeling: The spatial and temporal framework for signal traffic in adult human bone. J Cell Biochem. 55: 273-286.

Pei W., Yoshimine Y, Heersche JNM., 2003: Identification of dexamethasone-dependent osteoprogenitors in cell populations derived from adult human female bone. Calcif Tissue Int 72: 124-34.

Pei L., Tontonoz P., 2004: Fat`s loss is bone`s gain. J Clin Invest. 6: 805-806.

Peterson J., Fujimoto W.Y., Brunzell J.D., 1992: Human lipoprotein lipase: relationship of activity, heparin affinity, and conformation as studied with monoclonal antibodies. J Lipid Res. 33:1165-70.

Pittenger M.F., Mackay A.M., Beck S.C. Jaiswal R.K., Douglas R., Mosca J.D., Moorman M.A., Simonetti D.W., Craig S., Marshak D.R., 1999: Multilineage potential of adult human mesenchymal stem cells. Science. 284: 143-147.

Ponce ML: Anreicherung AP-positiver und AP-negativer Zellen aus primären humanen Osteoblastenkulturen mittels magnetischer Zellsortierung, Charakterisierung und Untersuchung des Differenzierungspotentials. Biologische Diplomarbeit Göttingen. 2000.

Porter R.M., Huckle W.R., Goldstein A.S., 2003: Effect of dexamethasone withdrawal on osteoblastic differentiation of bone marrow stromal cells. J Cell Biochem. 90: 13-22.

Prichett W.P., Patton A.J., Field J.A., Brun K.A., Emery J.G., Tan K.B., Rieman D.J., McClung H.A., Nadeau D.P., Mooney J.L., Suva L.J., Gowen M., Nuttall M.E.., 2000: Identification and cloning of a human urea transporter HUT11, which is downregulated during adipogenesis of explant cultures of human bone. J Cell Biochem. 76: 639-50.

Quarles D.L., Yohay D.A., Lever L.W., Caton R., Wenstrup R.J., 1992: Distinct proliferative and differentiated stages of murine MC3T3-E1 cells in culture: an in vitro model of osteoblast development. J Bone Miner Res. 7, 683-692.

Rickard D.J., Sullivan T.A., Shenker B.J., Leboy P.S., Kazhdan I., 1994: Induction of rapid osteoblast differentiation in rat bone marrow stromal cell cultures by dexamethasone and BMP-2. Dev Biol. 161: 218-228. 
Rickard D.J., Kassem M., Hefferan T.E., Sarkar G., Spelsberg T.C., Riggs L.B., 1996: Isolation and characterization of osteoblast precursor cells from human bone marrow. J Bone Miner Res. 11: 312-324.

Roberts A.B., Flanders K.C., Kondaiah P., Thompson N.L., Obberghen-Schilling E, Wakefield L., Rossi P., de Crombrugghe B., Heine U., Sporn M.B., 1988. Transforming growth factor beta: biochemistry and roles in embryogenesis, tissue repair and remodeling, and carcinogenesis. Recent Prog Horm Res. 44: 157-197.

Robey P.G., 1995: Collagenase-treated trabecular bone fragments: a reproducible source of cells in the osteoblastic lineage. Calcif Tissue Int. 56 (S1): 11-2.

Robison R., 1923: The possible significance of hexose phosphoric esters in ossification. Biochem J. 17: 286-293.

Roelen B.A., Dijke P., 2003: Controlling mesenchymal stem cell differentiation by TGF $\beta$ family members. J Orthop Sci. 8: 740-8.

Rosen E.D., Spiegelman B.M., 2001: PPAR $\gamma$ : a nuclear regulator of metabolism, differentiation, and cell growth. Minireview. J Biol Chem. 276. 41: 37731-37734.

Rzonca S.O., Suva L.J., Gaddy D., Montague D.C., Lecka-Czernik B., 2004: Bone is a target for the antidiabetic compound rosiglitazone. Endocrinology. 145: 401-6.

Saiki R.K., Scharf S., Faloona F., Mullis K.B., Horn G.T., Erlich H.A., Arnheim N., 1985: Enzymatic amplification of beta-globulin genomis sequences and restriction site analysis for diagnostic of sckle cell anemia. Science. 230: 150-1354-

Schoonjans, K., Peinado-Onsurbe, J., Lefebvre, A.M., Heyman R., Briggs M., Deeb S., Staels B., Auwerx J., 1996: PPAR $\alpha$ and PPAR $\gamma$ activators direct a distinct tissue-specific transcriptional response via PPRE in the lipoprotein lipase gene. EMBO J. 15: 5336-5348.

Siggelkow H., Hilmes D., Rebenstorff K., Kurre W., Huefner M. 1998: Analysis of human primary bone cells by fluorescence activated cell scanning: methodological problems and preliminary results. Clin Chimica Acta. 272:111-125.

Siggelkow H., Rebenstorff K., Kurre W., Niedhart C., Engel I., Schulz H., Atkinson M.J., Hüfner M., 1999: Development of the osteoblast phenotype in primary human osteoblasts in culture: comparison with rat calvarial cells in osteoblast differentiation. J Cell Biochem. 75: 22-35.

Siggelkow H., Schmidt E., Hennies B., Hüfner M., 2004: Evidence of downregulation of matrix extracellular phosphoglycoprotein during terminal differentiation in human osteoblasts. Bone 35. 2: 5706.

Simonet W.S., Lacey D.L., Dunstan C.R., Kelley M., Chang M.S., Luthy R., Nguyen H.Q., Wooden S., Bennett L., Boone T., Shimamoto G., DeRose M., Elliott R., Colombero A., Tan H.L., Trail G., Sullivan J., Davy E., Bucay N., Renshaw G.L., Hughes T.M., Hill D., Pattison W., Campbell P., Boyle W.J., et al., 
1997: Osteoprotegerin: a novel secreted protein involved involved in the regulation of bone density. Cell. 89: 309-19.

Song L., Tuan R.S., 2004: Transdifferentiation potential of human mesenchymal stem cells derived from bone marrow. FASEB.

Sottile V., Seuwen K., 2000: Bone morpogenetic protein-2 stimulates adipogenic differentiation of mesenchymal precursor cells in synergy with BRL 49653 (rosiglitazone). FEBS Lett. 475: 201-204.

Spiegelman B.M., Flier J.S., 1996: Adipogenesis and Obesity: Rounding out the big picture. Cell. 87: 377-389.

Spinella-Jaegle S., Roman-Roman S., Faucheu C., Dunn F.W., Kawai S., Gallea S., Stiot V., Blanchet A.M., Courtois B., Baron R., Rawadi G., 2001: Opposite effects of bone morphogenetic protein-2 and transforming growth factor-betal on osteoblast differentiation. Bone. 29: 323-330.

Stewart K., Walsh S., Screen J., Jefferiss C.M., Chainey J., Jordan G.R., Beresford J.N., 1999: Further characterization of cells expressing STRO-1 in cultures of human bone marrow stromal cells. J Bone Miner Res. 14: 1345-1356.

Sugiyama T., Kawai S., 2001: Carboxylation of osteocalcin may be realted to bone quality: a possible mechanism of bone fracture prevention by vitamin K. J Bone Miner Metab. 19: 146-9.

Talmage R.V., 1970: Morphological and physiological considerations in a new concept of calcium transport. Am J Anat. 129: 467-476.

Thomas T., Gori F., Khosla S., Jensen M.D., Burguera B., Riggs L., 1999: Leptin acts on human marrow stromal cells to enhance differentiation to osteoblasts and to onhibit differentiation to adipocytes. Endocrinology. 140. 1630-1638.

Tohmé J.F., Seibel M.J., Silverberg, Robins S.P., Bilezikian J.P., 1991: Biochemical markers of bone metabolism. Z Rheumatol. 50: 133-141.

Tontonoz P., Hu E., Spiegelman B.M., 1994: Stimulation of adipogenesis in fibroblasts by PPAR $\gamma 2$, a lipid-activated transcription factor. Cell. 79: 1147-1156.

Tornvig L., Mosekilde L.I., Justesen J., Falk E., Kassem M., 2001: Troglitazone treatment increases bone marrow adipose tissue volume but does not affect trabecular bone volume in mice. Calcif Tissue Int. 69: 46-50.

Ulsperger E., Hamilton G., Raderer M., Baumgartner G., Hejna M., Hoffman O., Mallinger R., 1999: Resveratrol pretreatment desensitizes AHTO-7 human osteoblasts to growth stimulation in response to carcinoma cell supernatants. Int J Oncology. 15: 955-959.

Ulsperger E., Hamilton G., Olszewski U., Baumgartner G., Engel A., Mallinger R., 2003: Effects of 1 $\alpha$, 25-dihydroxi-vitamin D3 pretreatment and MAP kinase inhibitor PD 98059 on response of osteoblasts to prostate-derived osteoblastic factors. Oncology Rep. 10: 1529-1534. 
Urist M.R., 1965: Bone formation by autoinduction. Science. 150:893-899.

Vidal-Puig A.J., Considine R.V, Jimenez-Liñan M., Werman A., pories W.J., Caro J.F., Flier J.S., 1997: peroxisome proliferator-activated receptor gene expression in human tissues. 99: 2416-2422.

Walsh C.A., Birch M.A., Fraser W.D., Lawton R., Dorgan J., Walsh S., Sansom D., Beresford J.N., Gallagher J.A., 1995: Expression and secretion of parathyroid hormone-related protein by human nonederived cells in vitro: Effects of glucocorticoids. J Bone Miner Res. 10: 17-25.

Wang G.J., Sweet D.E., Reger S.I., Thompson R.C., 1977: Fat-cell changes as a mechanisms of avascular necrosis of the femoral head in cortisone-treated rabbits. J Bone Joint Surg Am. 59: 729-735.

Weinstein R.S., 2001: Glucocorticoid-induced osteoporosis. Rev Endocr metab Disord. 2: 65-73.

Wennberg C., Hessle L., Lundberg P., Mauro S., Narisawa S., Lerner U.H, Millán J.L., 2000: Functional characterization of osteoblasts and osteoclasts from alkaline phophatase knockout mice. J Bone Miner Res. 15: 1879-1888.

Young M.F., 2003: Bone matrix proteins: their function, regulation, and relationship to osteoporosis. Osteoporos Int. 14 (Suppl 3): 35-42.

Zanello L.P., Norman A.W., 2003: Multiple molecular mechanisms of 1,25 $(\mathrm{OH})_{2}$ Vitamin $\mathrm{D}_{3}$ rapid modulations. Bone. 33: 71-9. 


\section{Danksagung}

Herrn Prof. Dr. M. Hüfner danke ich für die Überlassung dieses sehr interessanten Themas, für die Arbeitsmöglichkeiten sowie für seine Fachgespräche und Anregungen während der Durchführung dieser Arbeit. Außerdem möchte ich mich für die Möglichkeit Kongresse zu besuchen, bedanken.

Frau PD Dr. H. Siggelkow gilt mein besonderer Dank für die hervorragende Betreuung dieser Arbeit, für die Diskussionsbereitschaft sowie für ihre motivierende Anerkennung.

Herrn Prof. Dr. R. Hardeland danke ich für die Übernahme des Erstreferates und sein Interesse am Fortgang dieser Arbeit.

Herrn Prof. Dr. F.W. Schürmann danke ich für die Übernahme des Korreferates.

Allen Kollegen aus der Arbeitsgruppe von Prof. Dr. M. Hüfner/ PD Dr. H. Siggelkow, Iris Engel, Hiltrud Schulz, Bettina Hennies, Chris Klaus, Michael Schenk, Simone Tauber, Volker Viereck, Anne Kluever, Eva Schmidt und Julia Urbach möchte ich für die nette Atmosphäre und die praktische Unterstützung bei meinen Experimenten bedanken. Mein besonderer Dank gilt Bettina Hennies und Hiltrud Schulz, die mir beim Erlernen der Methoden geholfen haben.

Bei Frau Boguslawa Sadowski (Arbeitsgruppe Prof. Dr. G. Wulf) möchte ich mich besonders für die Durchführung der FACS Sorting Methode bedanken.

Herrn Prof. Dr. R. Herken aus der Abteilung Histologie im Zentrum Anatomie möchte ich für die Möglichkeit an seinem Institut arbeiten zu dürfen bedanken. Mein besonderer Dank gilt Herrn Prof. Dr. N. Miosge für die hervorragende Betreuung sowie für die freundschaftliche Zusammenarbeit bei der Durchführung der Immunogoldzytochemischen Analyse.

Danken möchte ich mich auch bei den Mitarbeitern der Abteilung Histologie im Zentrum Anatomie Frau C. Zelent, Herrn R. Dungan Frau E. Heyder, Frau C. Maelicke, Herrn B. Manshausen und Frau Sonja Schwoch für die freundliche Hilfsbereitschaft und Unterstützung beim Erlernen der Immunogoldzytochemische Methode.

Mein besonderer Dank gilt Herrn Rodney Dungan für die stets motivierende Hilfsbereitschaft bei der Anfertigung mikroskopischer bzw. elektronenmikroskopischer Aufnahmen.

Herrn Dr. K-H. Frosch und Herrn Diplom-Biologe F. Kauer möchte ich für die Bereitstellung des Knochenmaterials auch danken. Meinen besonderen herzlichen Dank gilt Herrn DiplomBiologe F. Kauer für die stets motivierende Hilfe sowie für das Korrekturlesen dieser Arbeit. 
Bei der FAZIT-Stiftung der Frankfurter Allgemeinen Zeitung möchte ich mich für die Vergabe eines Promotions-Stipendiums bedanken.

Bei der Deutschen Gesellschaft für Endokrinologie möchte ich mich für die Verleihung des von Recklinghausen Preises 2005 bedanken.

Frau Dr. Dagmar Heinemann danke ich ganz besonders für die unermüdliche Hilfe während der Anfertigung dieser Arbeit.

Frau Elke Heyder, Frau Friederike Kloth und Frau Cyrilla Maelicke gilt auch ein herzliches Dank für das Korrekturlesen dieser Arbeit.

Meine Freunde, Marcela und Peter, für die liebevolle Unterstützung und Ausleihung der Computer danke ich auch.

Anke Freytag (meine Yogalehrerin) und Mythile Gajendran (meine Tanzlehrerin) gilt auch ein herzliches Dankeschön für die spirituelle Unterstützung, die sehr viel zum Schreiben dieser Arbeit beigetragen hat.

Ich möchte mich ganz herzlich bei meiner Familie und meinen Freunden für die immense moralische Unterstützung (in der Ferne und in der Nähe) ohne die ich niemals soweit gekommen wäre. 
Name: María Laura Ponce

Geburtsdatum: 12/ 12/ 1968

Geburtsort: Buenos Aires, Argentinien

Nationalität: Italienerin / Argentinierin

$1975-1981 \quad$ Ganztagsgrundschule, Buenos Aires, Argentinien

$1982-1986 \quad$ Gymnasium, Buenos Aires, Argentinien

Abschluß als Absolventin einer höheren Handelschule

$1987-1988 \quad$ Einführungskurs: Fachbereich Biologie. Universität von Buenos Aires.

1988-1995 Biologiestudium an der Fakultät für Mathematik und

Naturwissenschaften. Universität von Buenos Aires.

Erlangung des Licenciatsgrades in Biologie.

Seit 1996

Aufenthalt in Deutschland

1996

Deutsch-Intensivkurs des Europa-Kollegs (Kassel). Stufe I Deutsch-Intensivkurs des Jugendsozialwerkes (Kassel). Stufe II, Mittelstufe I

WS 1997

Vorbereitungskurs für die Deutsche Sprachprüfung für den Hochschulzugang ausländischer Studienbewerber (DSH). Gesamthochschule Kassel

September 1997 DSH Prüfung an der Georg August Universität zu Göttingen

$1998-2000$

Anfertigung der Diplomarbeit (als Voraussetzung für eine spätere Zulassung zum Promotionsverfahren an der der Georg-AugustUniversität zu Göttingen)

Januar 2001

Erlangung des Hochschulgrades einer Diplombiologin an der GeorgAugust-Universität zu Göttingen (Anerkennung des erworbenen Licenciatsgrades in Biologie) 
Seit 2001

Experimentelle Arbeiten zur vorliegenden Dissertation in der Arbeitsgruppe von Prof. Dr. M. Hüfner an der Abteilung Abt. Gastroenterologie/Endokrinologie (Schwerpunkt Endokrinologie), Zentrum Innere Medizin der Georg-August-Universität zu Göttingen. Betreuung: Prof. Dr. R. Hardeland Leiterin: Frau PD Dr. H. Siggelkow

Stipendien und Preise

Promotions-Stipendium gewährt von der FAZIT-Stiftung der Frankfurter Allgemeinen Zeitung.

Von Recklinghausen Preis 2005 für die Arbeit „Primary Human Osteoblasts express increasing Adipogenic Markers when cultured under Osteogenic conditions", verleiht von der Deutschen Gesellschaft für Endokrinologie. 